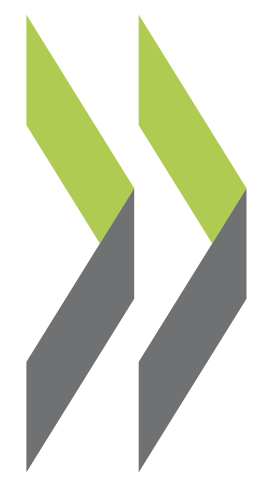

Documents SIGMA No. 41

\title{
Système de contrôle et de recours en matière de marchés publics dans I'Union européenne
} OCDE 


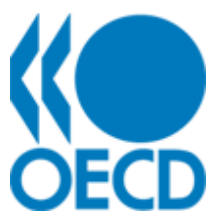
Initiative conjointe de l'OCDE et l'UE, principalement financée par l'UE

\section{SIGMA}

Soutien à l'amélioration des institutions publiques et des systèmes de gestion

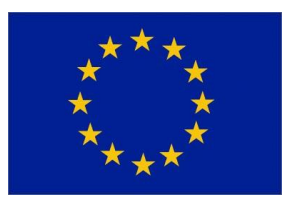

\section{SYSTÈME DE CONTRÔLE ET DE RECOURS EN MATIÈRE DE MARCHÉS PUBLICS DANS L'UNION EUROPÉENNE}

DOCUMENT Sigma N $\mathbf{N}^{\circ}$ 41, 2007

Ce rapport est produit avec le soutien financier de l'Union européenne. Les idées exprimées ici ne reflètent pas nécessairement le point de vue officiel de l'Union européenne, des pays Membres de l'OCDE ou des pays bénéficiaires participant au Programme SIGMA. 


\section{LE PROGRAMME SIGMA}

Le Programme Sigma - Soutien à l'amélioration des institutions publique et des systèmes de gestion est une initiative conjointe de l'Organisation de coopération et de développement économiques (OCDE) et de l'Union européenne principalement financée par l'UE.

Travaillant en partenariat avec les pays bénéficiaires, Sigma soutient les institutions publiques en :

- $\quad$ en évaluant les progrès de la réforme et en définissant des priorités par rapport aux références que constituent les bonnes pratiques européennes et la législation existante de l'UE (l'acquis communautaire)

- $\quad$ en assistant les décideurs et les administrations dans la mise en place de l'organisation et des procédures d'adaptation aux normes et bonnes pratiques européennes

- $\quad$ en aidant les donateurs intra et extra-européens à concevoir des projets, à instaurer les conditions préalables à leur réalisation et en les assistant dans leur mise en œuvre.

En 2007, le programme Sigma fonctionne en partenariat avec les pays suivants :

- $\quad$ Nouveaux États-membres de l'UE - Bulgarie et Roumanie

- $\quad$ Pays-candidats à l'UE - Croatie, ancienne république yougoslave de Macédoine et Turquie

- Pays balkaniques occidentaux - Albanie, Bosnie-Herzégovine (fédération de BosnieHerzégovine et République serbe de Bosnie), Monténégro, Serbie et Kosovo (gouverné depuis juin 1999 par la mission provisoire d'administration de l'ONU (UNMIK) au Kosovo)

- $\quad$ L'Ukraine (activités financées par la Suède et le Royaume-Uni).

Le programme Sigma soutient les initiatives de réforme des pays-partenaires dans les domaines suivants :

- $\quad$ Structures juridiques et administratives, fonction publique et justice ; systèmes publics d'intégrité

- Contrôle financier interne de l'État, audit externe, système antifraude et gestion des fonds de l'UE

- Gestion de la dépense publique, du budget et du trésor public

- $\quad$ Marchés publics

- $\quad$ Politique et coordination

- Amélioration de la réglementation.

Pour plus d'informations sur le programme Sigma, consultez notre site Internet :

http://www.sigmaweb.org

(C) OCDE 2007

Ceci est une traduction à partir du titre original : Public Procurement Review and Remedies Systems in the European Union [GOV/SIGMA(2007)5].

Toute demande d'autorisation de reproduction ou de traduction à usage commercial ou noncommercial devra être envoyée à rights@ oecd.org. 


\section{AVANT-PROPOS}

Un soumissionnaire évincé qui croit que la procédure de marché public conduite est constitutive d'une violation des lois correspondantes doit avoir accès à un contrôle et à un recours. Les procédures de contrôle des marchés publics sont destinées à offrir une voie de recours efficace aux soumissionnaires lésés. Cette étude vise à améliorer la compréhension et la connaissance de la façon dont les États-membres de l'UE ${ }^{\mathbf{1}}$ organisent l'instruction des plaintes et les voies de recours. Il comprend un débat sur les motifs du choix de divers modèles. Il est à souhaiter que ce document incite les actuels et futurs pays-candidats, les autres pays-partenaires de Sigma et les États-membres de l'UE à entreprendre, si nécessaire, des actions pour améliorer la qualité des systèmes de contrôle et de recours. Un accent particulier sera porté, au plan juridique et institutionnel, sur la disponibilité des voies de recours dans le cadre de l'application de la directive 89/665/CEE sur les procédures de recours en matière de passation des marchés publics et de la directive 92/13/CEE sur les procédures de passation des marchés des entités opérant dans le secteur de l'eau, de l'énergie, des transports et des télécommunications. Cette étude jettera en outre la lumière sur la culture du contrôle et des recours et sur le fonctionnement de ces systèmes dans la pratique.

En 2000, Sigma a publié une étude sur les Procédures de contrôle des marchés publics (étude Sigma $\mathrm{n}^{\circ} 30$ ), qui a reçu un bon accueil et a été fortement appréciée par les pays-candidats pour la mise en place des organismes et des procédures de réclamation, contrôle et recours conformément aux règlements correspondants de la Communauté. L'étude a, semble-t-il, été également employé comme documentation de référence et directives pour un cercle élargi de gouvernements, y compris les nouveaux États-membres, dans leur travail de mise en place de mécanismes conformes de contrôle. Cependant, sur la base du dialogue actuel avec les pays-partenaires de Sigma, il semble que contrôles et recours demeurent toujours une préoccupation majeure pour la plupart des pays. Ils ont manifesté leur intérêt d'en apprendre plus sur le mode d'organisation des systèmes de contrôle et sur le fonctionnement de certains mécanismes de contrôle dans les autres pays. Ainsi, ces dernières années, l'un des objectifs prioritaires de coopération de Sigma avec les pays-partenaires a été de fournir l'assistance d'experts, de faire conduire des examens par des homologues et d'organiser des conférences et séminaires sur ce sujet.

La situation a considérablement changé depuis la publication en 2000 de l'étude Sigma ${ }^{\circ} 30$ Procédures de contrôle des marchés publics. Les changements les plus importants sont les suivants :

- La sphère des pays directement ou indirectement intéressés par les procédures de recours en matière de marchés publics dans l'UE s'est élargie et compte aujourd'hui presque 40 pays (Étatsmembres de l'UE, pays de l'EEE (l'AELE), pays-candidats à l'UE et pays balkaniques occidentaux).

- Plusieurs nouveaux arrêts de la Cour européenne de justice dans des affaires de marchés publics, en particulier l'affaire Alcatel $^{2}$, ont eu un important retentissement sur la procédure de contrôle dans les États-membres.

- Les pays s'efforcent non seulement d'instaurer des procédures de contrôle conformes au droit communautaire (ce qui avait souvent été la priorité principale auparavant) mais surtout s'intéressent maintenant, à la lumière de leurs expériences, à accélérer le contrôle et à renforcer son efficacité dans la pratique par le développement de structures et de procédures administratives plus appropriées. Les États-membres sont libres de choisir l'organisme et les procédures de contrôle tant que les droits et les mesures de rectification sont mis en application selon les directives communautaires. Cette évolution a donné naissance à une grande variété de mécanismes de contrôle dans les États-membres, de l'utilisation du système judiciaire à tous les

En raison de leur adhésion imminente à l'Union européenne le 1er janvier 2007, la Bulgarie et la Roumanie ont été assimilées à des États-membres de l'UE dans cette étude.

2 Selon ces arrêts (C-81/98 et C-212/02), une période de délai suspensif raisonnable entre l'attribution du contrat et sa conclusion est indispensable pour permettre de contester efficacement l'attribution dans une procédure de contrôle. 
stades de la procédure d'attribution du contrat au recours à des modèles d'arbitrage et de tribunaux, qu'ils aient ou non la compétence juridictionnelle. Il y a différentes explications et justifications pour le choix d'un modèle spécifique, mais son développement et les expériences tirées de son utilisation constituent une source d'information précieuse pour les pays-partenaires de Sigma dans leur travail d'amélioration des procédures de contrôle.

- $\quad$ Avec les développements récents des marchés publics de l'UE, de nombreux acteurs comme les juges, les arbitres, les avocats, les décideurs politiques et les autres intervenants chargés de l'instruction des plaintes ont un besoin croissant de formation et d'information.

En conséquence, la mise à jour de l'étude Sigma ${ }^{\circ} 30$, forte d'un élargissement des objectifs, devrait s'avérer utile en fournissant aux pays des informations pour leur travail de réforme et d'amélioration des procédures de révision et de recours en matière de marchés publics. Cette étude procède à une analyse comparative des systèmes de contrôle et de recours des États-membres, mais n'essaie pas d'évaluer leurs avantages/inconvénients respectifs ou de préconiser des dispositions institutionnelles particulières. 


\section{TABLE DES MATIÈRES}

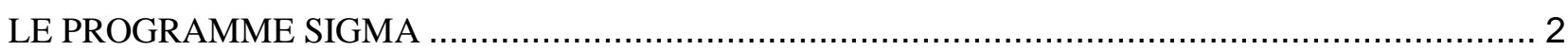

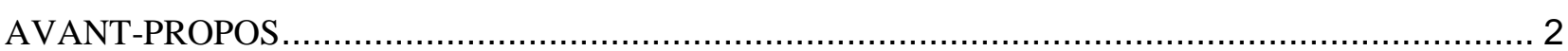

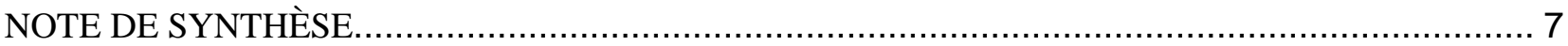

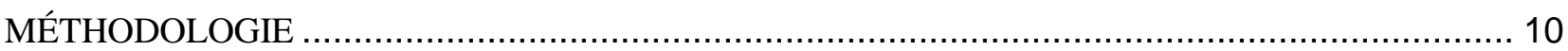

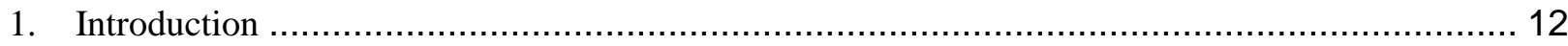

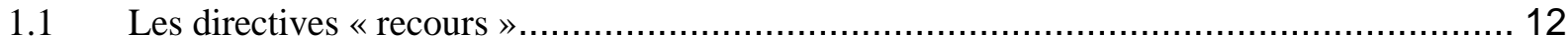

1.2 Traité CE et jurisprudence de la Cour européenne de justice......................................... 13

1.3 Autres pratiques nationales .............................................................................. 14

2. Cadre institutionnel Comment les États-membres ont organisé leurs systèmes de contrôle et de

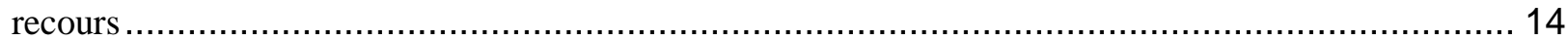

$2.1 \quad$ Plaintes aux autorités adjudicatrices ................................................................ 14

2.2 Classification des systèmes de contrôle en systèmes uniques ou doubles.......................... 15

2.3 Tribunaux de droit commun et organes de contrôle spécialisés ...................................... 16

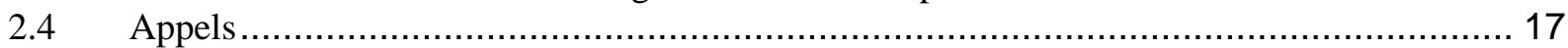

$2.5 \quad$ Organes de contrôle de dernier ressort ................................................................... 18

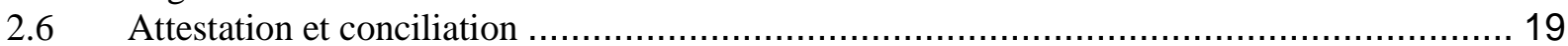

$2.7 \quad$ Médiateur et organismes consultatifs ..................................................................... 19

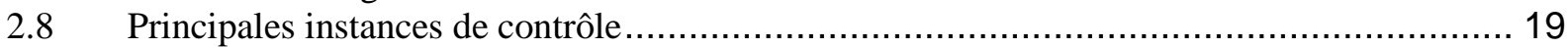

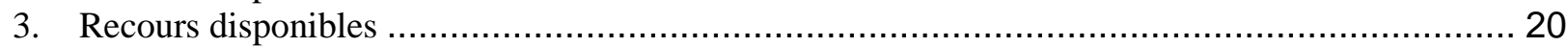

3.1 Annulation des décisions relatives aux marchés publics ........................................... 20

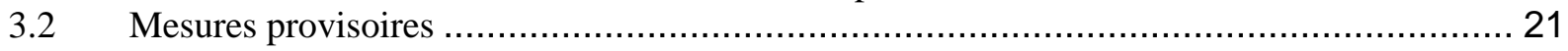

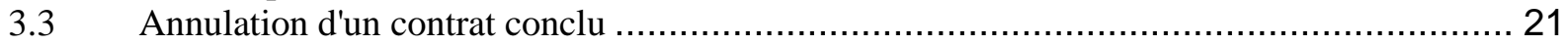

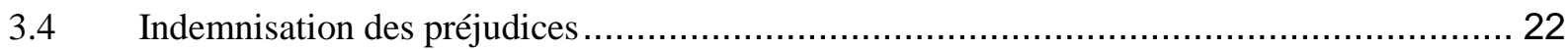

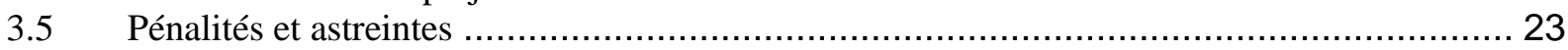

4. Cadre légal des systèmes de contrôle des États-membres ................................................ 23

4.1 Champ d'application des systèmes de contrôle et de recours ....................................... 23

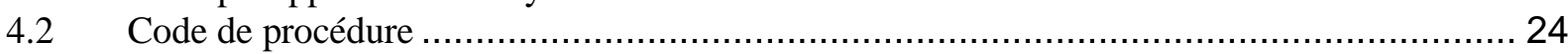

5. Le contexte et la culture du contrôle des actes administratifs en matière de marchés publics......... 29

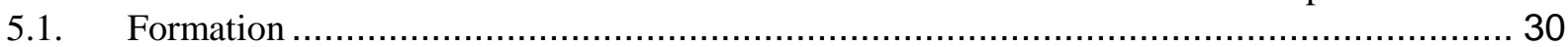

5.2 Attitudes et crédibilité liées aux procédures de contrôle des actes administratifs ................. 31

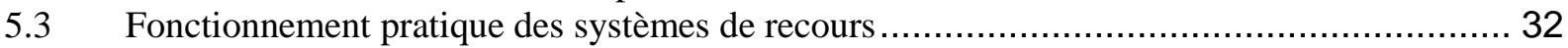

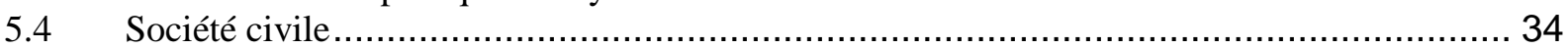

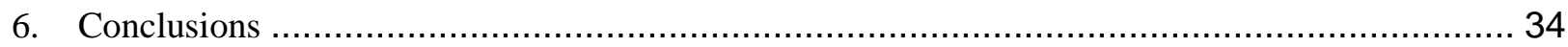

ANNEXE : RAPPORTS NATIONAUX INDIVIDUELS SUR LES SYSTÈMES DE CONTRÔLE ET DE RECOURS EN MATIÈRE DE MARCHÉS PUBLICS DANS LES ÉTATS-MEMBRES................. 36

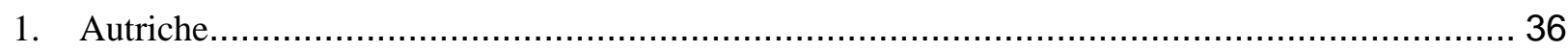

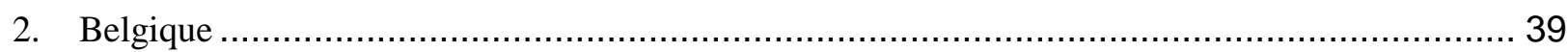

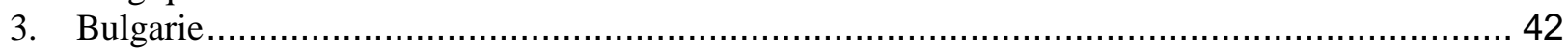

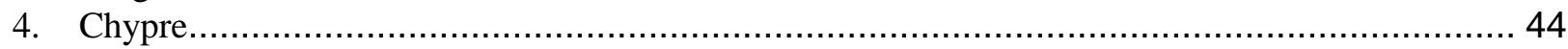

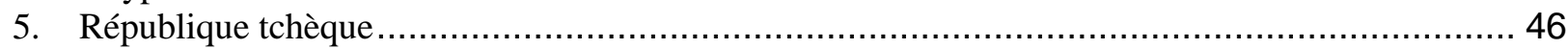

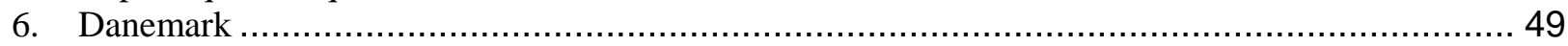

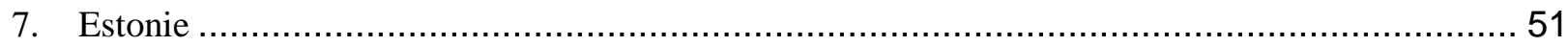

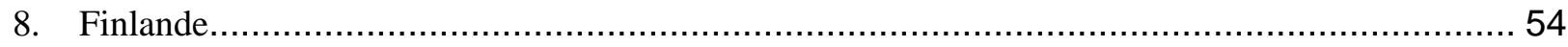

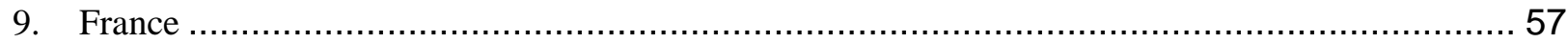

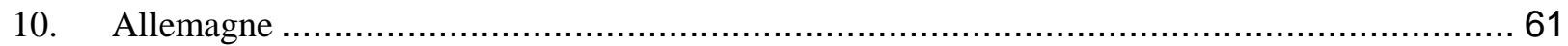

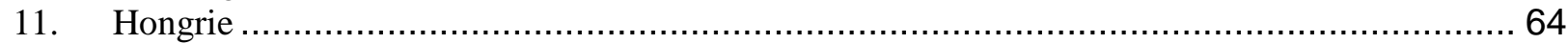

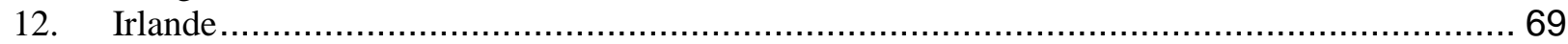

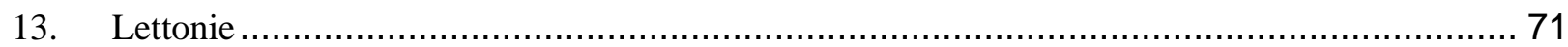

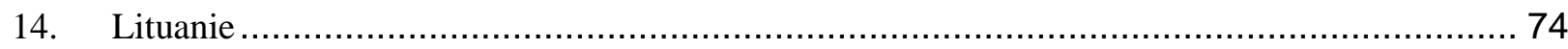




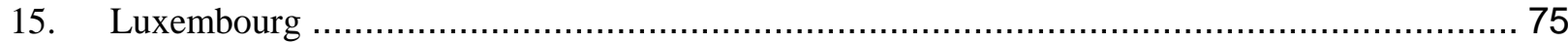

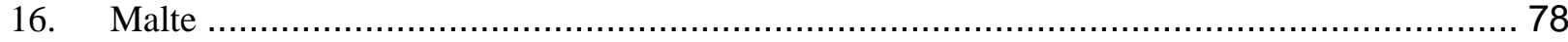

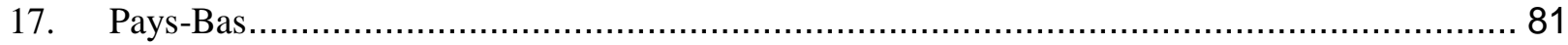

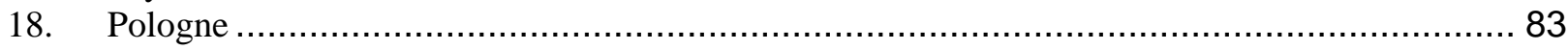

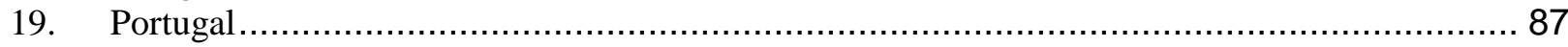

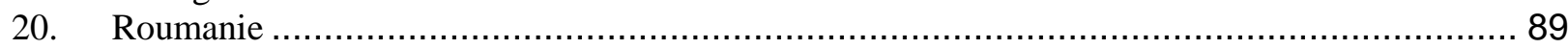

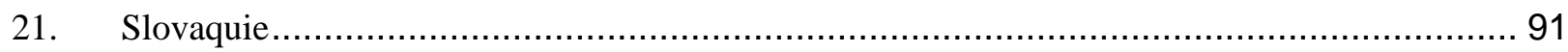

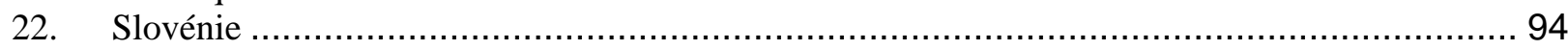

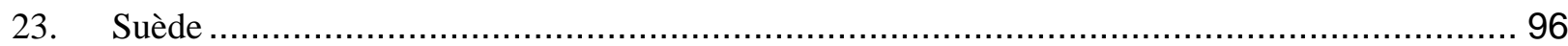

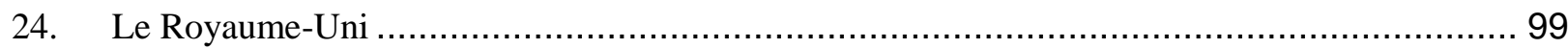




\section{NOTE DE SYNTHÈSE}

Les systèmes de contrôle et de recours en matière de marchés publics des États-membres de l'UE doivent être institués et développés sur le fondement des directives 89/665/CEE et 92/13/CEE sur les procédures de recours en matière de passation des marchés publics, du traité $\mathrm{CE}$ et de la jurisprudence de la Cour européenne de justice. En particulier, ces systèmes doivent offrir aux soumissionnaires lésés des voies de contrôle et de recours rapides, efficaces, transparentes et non-discriminatoires. Il y a un certain nombre d'obligations supplémentaires, mais elles ne régissent pas précisément le système de contrôle et de recours et laissent une marge de manœuvre considérable aux États-membres pour choisir leurs options.

Il existe un socle commun mais également de grandes différences entre les systèmes de contrôle et de recours en dans les 24 États-membres ${ }^{3}$ présentés dans cette étude. Ces similitudes et différences concernent le cadre institutionnel, les recours disponibles et le système légal qui réglemente la procédure et son champ d'application ainsi que la culture du contrôle.

En ce qui concerne le cadre institutionnel, c'est-à-dire le mode d'organisation des systèmes de contrôle, le socle commun de la plupart des États-membres, c'est qu'ils permettent aux candidats lésés de déposer une plainte directement auprès de l'entité adjudicatrice qui a commis l'infraction présumée au droit des marchés publics dans le cadre de la première phase directe ou indirecte de contrôle. Cependant, cette possibilité n'est pas considérée comme la première phase de la procédure de contrôle requise par les directives communautaires concernées. Il existe par conséquent des différences qui portent sur la question de savoir si cette plainte est une première phase obligatoire du contrôle, si les soumissionnaires utilisent réellement cette possibilité dans la pratique et sur certains détails procéduraux comme les délais. Tous les États-membres possèdent une procédure de contrôle juridictionnel et quasi-juridictionnel en première instance des décisions relatives aux marchés publics.

Certains pays disposant d'un double ordre juridictionnel et d'autres d'un seul ordre juridictionnel, ils ont été classés en fonction de ce critère. Les pays dotés d'un seul ordre juridictionnel n'ont qu'une voie de contrôle (du premier au troisième ressort), tandis que ceux qui possèdent un double ordre juridictionnel se caractérisent par deux voies séparées de contrôle. Fréquemment, la conclusion du contrat est le facteur qui sépare les deux voies dans les pays à double ordre juridictionnel. Cependant, ils peuvent également être séparés par la nature publique ou privée de l'entité adjudicatrice «défenderesse ». Les États-membres utilisent à la fois les tribunaux de droit commun et les tribunaux administratifs ainsi que des organes de contrôle spécialisés dans les marchés publics comme institutions de contrôle. À quelques exceptions près, les décisions d'un organe de contrôle spécialisé saisi en première instance peuvent faire l'objet d'un appel auprès d'un tribunal de droit commun ou d'un tribunal administratif. Rares sont les pays qui ont des sections ou des chambres dédiées aux marchés publics dans ces tribunaux de droit commun ou tribunaux administratifs. Dans quelques États-membres, le second ressort est le dernier degré de juridiction, tandis que d'autres possèdent trois degrés de contrôle juridictionnel.

Tous les organes de contrôle de dernier ressort semblent remplir les exigences d'un tribunal tel que défini dans l'arrêt Dorsch et Salzmann de la Cour européenne de justice. ${ }^{4}$ De nombreux États-membres ont mis en place des organes alternatifs de règlement des litiges comme des commissions d'arbitrage et ont même donné au médiateur la possibilité de jouer un rôle.

Enfin, de nombreux États-membres ont des organismes consultatifs non-juridictionnels composés de représentants des deux côtés qui instruisent les affaires de marchés publics et ne rendent pas de décisions ayant force exécutoire.

Aux fins de ce rapport, la Bulgarie et la Roumanie ont été assimilées aux États-membres de l'UE bien que leur adhésion remonte au 1er janvier 2007.

4 Selon cet arrêt, pour qu'un organe soit qualifié de tribunal, il doit tirer sa légitimité de la loi, être permanent, avoir une procédure entre parties et ses décisions doivent être prises selon les règles de droit et avoir force de loi. Un tribunal est indépendant du pouvoir exécutif et de l'administration ou de n'importe quelle autre instance du gouvernement et ses décisions ont force de loi. 
Les États-membres présentent également des points communs et des différences quant aux recours disponibles. Ces recours comprennent l'annulation des décisions illégales relatives aux marchés publics, les mesures provisoires, l'indemnisation des préjudices et, dans certains États-membres, des astreintes. En premier lieu, les États-membres permettent aux organes de contrôle d'annuler les décisions illégales en matière de marchés publics avant la conclusion du contrat. La conclusion du contrat est le point crucial de la procédure de passation du marché et, à cette issue, de nombreux États-membres permettent seulement l'indemnisation des préjudices. Pour permettre l'annulation de la décision d'attribution du marché et conformément à l'arrêt Alcatel ${ }^{5}$ de la Cour européenne de justice, de multiples juridictions ont introduit un délai suspensif de 7 à 30 jours entre la décision d'attribution du marché et la conclusion du contrat. Cependant, l'efficacité de ce délai suspensif diffère entre les juridictions puisqu'il y a des différences sur la question de savoir si l'introduction d'une action suspend la procédure d'adjudication, si la conclusion d'un contrat au cours du délai suspensif frappe le contrat de nullité et sur les délais impartis aux juges pour statuer. Généralement, un contrat conclu ne peut être annulé, le cas échéant, que s'il répond à des conditions strictement définies.

En deuxième lieu, il est possible de prendre des mesures provisoires mais, dans les faits, leur application dépend de différences nationales. Dans un nombre limité d'États-membres, l'introduction d'une action a un effet suspensif systématique, interrompant la procédure de passation des marchés. Dans la plupart des pays, les soumissionnaires doivent adresser une requête spécifique à l'organe de contrôle pour qu'il prenne des mesures provisoires, par exemple l'arrêt de la procédure. L'organe de contrôle peut alors appliquer des mesures provisoires dans l'attente d'une conclusion définitive et en tenant compte de leurs conséquences probables pour tous les intérêts en présence susceptibles d'être lésés, y compris l'intérêt public, et se prononcer contre de telles mesures lorsque leurs conséquences négatives l'emportent sur leurs avantages. En principe, tous les recours permettent d'accorder au requérant des mesures provisoires et il existe un socle commun concernant leurs conditions d'application. Il y a en outre un socle commun relatif à la disponibilité et généralement aussi aux conditions d'indemnisation des préjudices qui sont généralement envisagés après la conclusion du contrat. Les astreintes permettent de faire exécuter les décisions de justice ou constituent des voies de recours dans les marchés publics d'eau, d'énergie, de transports et de télécommunications dans certains États-membres.

Il y a également des similitudes et des différences dans le système légal des systèmes de contrôle des États-membres. Le système légal concerne en premier lieu le champ d'application du système. Dans la plupart des États-membres, les systèmes s'appliquent également aux contrats d'un montant supérieur et d'un montant inférieur aux seuils des directives 2004/17/CE et 2004/18/CE sur les marchés publics. Dans un petit nombre d'États-membres, les systèmes de contrôle et de recours ne s'appliquent qu'aux contrats d'un montant inférieur aux seuils précités, tandis que dans d'autres pays, il y a différents recours, organes de contrôle et contraintes procédurales pour les contrats d'un montant inférieur à ces seuils. De même, dans de nombreux États-membres, les systèmes de contrôle et de recours s'appliquent également à toutes les autorités et entités adjudicatrices, alors que dans certains pays, il y a différents systèmes réglementaires et organes de contrôle selon que le marché a été attribué par une entité publique ou par un opérateur de services d'utilité publique ou que l'entité adjudicatrice est publique ou privée. En deuxième lieu, le système légal se rapporte au code de procédure civile pour le contrôle recouvrant les questions suivantes : qui peut introduire une action, dans quels délais, à quel coût, comment impliquer des experts si le respect de la confidentialité s'impose et comment les requérants sont avertis de l'issue de leur action.

Enfin, il y a des similitudes et beaucoup de différences en ce qui concerne la culture du contrôle des actes administratifs dans les États-membres, notion qui englobe la formation, les attitudes, la crédibilité et l'utilisation du système dans la pratique. Possibilités de formation pour les juges et membres des commissions de contrôle, avocats, responsables des marchés publics; le contexte technologique et économique des marchés publics; le mode de fonctionnement des procédures diffère considérablement dans la pratique. De nombreux États-membres possèdent un large éventail de possibilités de formation, de l'enseignement et de la recherche en université appropriées aux marchés publics et autres institutions 
d'enseignement supérieur, conférences, revues juridiques et autres, séminaires organisés par des prestataires privés, tandis que d'autres ont un choix très limité. Les soumissionnaires utilisent activement les systèmes de contrôle pour corriger les erreurs et pour favoriser leurs propres intérêts. Cependant, dans de nombreuses juridictions, les soumissionnaires sont découragés par le coût élevé des procédures ou par l'appréhension du prochain contrat, alors que dans certains pays, les autorités adjudicatrices considèrent que les soumissionnaires abusent du système afin de faire obstruction aux procédures de passation des marchés ou d'évincer leurs concurrents du marché. L'attitude de la plupart des juges est décrite comme impartiale et équilibrée. Les systèmes nationaux diffèrent considérablement en ce qui concerne le succès des plaintes et des actions en première instance. En deuxième et en troisième instances, les soumissionnaires ont généralement moins facilement gain de cause. Dans certains pays, quelques organisations non gouvernementales s'impliquent généralement dans le système de contrôle en donnant des conseils aux soumissionnaires et parfois en finançant leurs actions. Dans un petit nombre d'Étatsmembres, ces O.N.G peuvent même introduire des actions. 


\section{MÉTHODOLOGIE}

Dans chaque État-membre de l'UE, l'étude s'est concentrée sur quatre domaines principaux : cadre législatif, cadre institutionnel, culture du contrôle des actes administratifs et fonctionnement du système de contrôle et de recours dans la pratique. Même si un effort a été fait pour étudier et débattre de ces questions de façon distincte, cela n'a pas été toujours possible. Les cadres législatifs et institutionnels, par exemple, ont inévitablement un impact sur le contrôle des actes administratifs, la culture du contrôle et sur le fonctionnement du système.

L'étude a été effectuée par l'équipe responsable du projet Sigma et a été revue par une équipe d'homologues. Les données nécessaires ont été rassemblées au moyen d'un questionnaire détaillé qui a été envoyé aux contacts dans les 25 États-membres ainsi qu'en Bulgarie et en Roumanie. L'étude reflète la situation des États-membres au premier semestre 2006. Tous les contacts au sein des administrations publiques des États-membres ont eu l'opportunité de commenter et d'approuver les projets de rapports nationaux dès que l'équipe responsable du projet Sigma les avait achevés.

La responsabilité principale de l'équipe du projet Sigma a consisté à mener toutes les activités liées à la planification, à l'organisation et à la gestion de l'étude jusqu'à l'achèvement réussi du rapport et de la publication de l'étude Sigma. Les membres de l'équipe responsable du projet étaient Martin Trybus, Peder Blomberg et Piotr Nils Gorecki.

Une équipe de pairs a été formée en vue de formuler des observations sur la méthodologie ainsi que sur le projet et les rapports finaux de l'étude. L'équipe était composée de Joël Arnould (France), de David d'Hooghe (Belgique), de Jens Fejö (Danemark) et de Tomaž Vesel (Slovénie).

Un réseau de contacts au sein des administrations publiques des États-membres a été créé et a reçu la tâche de fournir à l'équipe responsable du projet Sigma la documentation et les informations requises sur la façon dont le système de contrôle est organisé et perçu en y incluant des statistiques de plainte lorsqu'il y en avait. Les contacts ont été recommandés ou sélectionnés parmi les membres du Réseau européen de marchés publics (PPN), qui est un réseau de coopération de fonctionnaires experts des marchés publics de tous les États-membres de l'UE, tous les pays en voie d'adhésion, membres de l'EEE, de la Suisse, des pays-candidats à l'UE et des autres pays européens.

L'équipe du projet Sigma a élaboré un questionnaire détaillé qui a été envoyé au réseau des contacts pour être renseigné et étayé de statistiques sur les recours, lorsqu'elles étaient disponibles. Dans toute la mesure du possible, l'équipe du projet Sigma et l'équipe d'homologues ont analysé les textes légaux de référence directement mentionnés dans les questionnaires, dans leur version originale ou dans les traductions disponibles. 24 questionnaires ont été retournés à l'équipe du projet Sigma entre mars et août 2006 par l'Autriche, la Belgique, la Bulgarie, Chypre, la République tchèque, le Danemark, l'Estonie, la Finlande, la France, l'Allemagne, la Hongrie, l'Irlande, la Lettonie, la Lituanie, le Luxembourg, Malte, les Pays-Bas, la Pologne, le Portugal, la Roumanie, la Slovaquie, la Slovénie, la Suède et le Royaume-Uni

Il est nécessaire de clarifier un certain nombre de points en ce qui concerne les limites de cette approche méthodologique. En premier lieu, trois États-membres n'ayant pas retourné le questionnaire, l'étude ne constitue pas un aperçu complet des systèmes de contrôle et de recours de tous les États-membres. Cependant, 24 retours sur 27 témoignent d'une réaction favorable qui devrait constituer une base suffisante pour effectuer une synthèse significative.

De nombreux systèmes nationaux de contrôle et de recours offrent une couverture plus large que ne l'exigent les directives communautaires concernées et incluent aussi, à des degrés variés, des contrats hors du champ d'application des directives communautaires. L'étude fournit des informations utiles sur le champ d'application de cette couverture élargie mais, en raison des limitations de la méthodologie, il n'a pas été possible de débattre systématiquement de cette question dans l'étude.

L'étude ne fait aucune distinction sur le fondement de la nature des contrats (contrats publics ou délégations de services publics) qui peut influer sur les conclusions tirées dans la section vue d'ensemble comparative de l'étude. C'est surtout pertinent en ce qui concerne les États-membres où les responsabilités 
des recours dans le domaine des délégations de services publics sont gérées de manière différente des marchés publics.

L'étude manque donc d'informations systématiques sur le mode d'organisation des recours et référencées en fonction de la nature du contrat dans les États-membres. 


\section{Introduction}

La mise en place de systèmes de contrôle et de recours en matière de marchés publics a pour objectif de favoriser l'application pratique de l'abondante législation relative aux marchés publics. Ces systèmes donnent «du mordant» à cette législation : la possibilité d'exercer des contrôles et des recours sert de moyen de dissuasion à violer la loi et encourage ainsi la conformité. D'ailleurs, les violations de la loi et les erreurs véritables peuvent être corrigées. Par conséquent, un système public fonctionnel de contrôle et de recours en matière de marchés publics peut finalement contribuer à l'accomplissement visé par les règles fondamentales comme la non-discrimination, l'égalité de traitement, la transparence et le rapport qualitéprix. Les systèmes de contrôle et de recours en matière de marchés publics dans les États-membres de l'UE doivent être conformes aux exigences du droit de la Communauté européenne : le traité CE, la directive 89/665/CEE sur les procédures de recours en matière de passation des marchés publics de fourniture et de travaux et la directive 92/13/CEE sur les procédures de passation de marchés des entités opérant dans le secteur de l'eau, de l'énergie, des transports et des télécoms. Les deux directives sont en cours de refonte. ${ }^{6}$ En dehors du champ d'application des directives « recours", ces systèmes de contrôle et de recours cherchent en outre à se conformer à la jurisprudence correspondante de la Cour européenne de justice, à l'article 47 de la Charte des droits fondamentaux de l'Union européenne concernant « le droit à un recours efficace et à l'accès à un tribunal impartial » et à l'article 6 de la Convention européenne de sauvegarde des droits de l'homme et des libertés fondamentales instituant «le droit à un procès équitable » ainsi qu'aux bonnes pratiques nationales.

\section{$1.1 \quad$ Les directives « recours »}

La directive 89/665/CEE sur les procédures de recours en matière de passation des marchés publics de fourniture et de travaux et la directive 92/13/CEE sur les procédures de passation de marchés des entités opérant dans le secteur de l'eau, de l'énergie, des transports et des télécoms règlent certaines exigences minimales concernant les systèmes de contrôle et de recours en matière de marchés publics dans les Étatsmembres. Ces exigences minimales concernent les contrats qui entrent dans le champ d'application de la directive 2004/18/CE relative à la coordination des procédures de passation des marchés publics de travaux, de fournitures et de services et de la directive 2004/17/CE portant coordination des procédures de passation des marchés dans les secteurs de l'eau, de l'énergie, des transports et des services postaux. Ces exigences impliquent des principes, des statuts, des recours, des organes de contrôle et des limitations. Néanmoins, les systèmes de contrôle et de recours peuvent également couvrir les contrats en dehors du champ d'application des directives sur les marchés publics comme les contrats d'un montant inférieur aux seuils d'application et les délégations de services publics.

En règle générale, les États-membres de l'UE doivent veiller à ce que les décisions prises par les entités adjudicatrices soient efficacement contrôlées et aussi rapidement que possible, si elles sont susceptibles de constituer une violation du droit communautaire régissant les marchés publics ou de la réglementation nationale qui en est la transposition. La notion «d'efficacité » des systèmes de contrôle et de recours a été clarifiée par la jurisprudence de la CJUE (voir par exemple affaire C-92/00, paragraphe 67 et affaire C390/98 Banks contre Coal Authority et Secretary of State for Trade and Industry [2001] ECR I-6117, paragraphe 121; affaire C-453/99 Courage et Crehan [2001] ECR I-6297, paragraph 29). Plus concrètement, il s'avère que le système doit comporter des organes actifs de contrôle, une réglementation du statut de ces organes de contrôle, les coûts, les règles de dépôt d'une plainte, le champ d'application, la possibilité d'annuler les décisions relatives aux marchés publics, notamment l'attribution du contrat, les indemnités et les mesures provisoires. L'efficacité comprend en outre les questions de l'accès et de la

6 Proposition de directive de la Commission modifiant les directives du Conseil 89/665/CEE et 92/13/CEE en ce qui concerne l'amélioration de l'efficacité des procédures de recours en matière de passation des marchés publics \[COM (2006) 195 final/2] du 4 mai 2006 :

voir \{4http://ec.europa.eu/internal_market/publicprocurement/remedies/remedies_en.htm. 
satisfaction des soumissionnaires au système (fréquence des actions, appels de décisions en première instance, etc.), et probablement la transparence et même la simplicité générales du système.

D'ailleurs, la notion concomitante de «rapidité » exige d'engager des actions et de prendre des décisions rapides. Outre leur efficacité et leur rapidité, les recours ne doivent faire aucune discrimination du fait de la distinction opérée par les directives entre les règles nationales transposant le droit communautaire et les autres règles nationales. Les procédures de contrôle visées dans les deux directives « recours » confèrent les pouvoirs suivants : prendre des mesures provisoires par voie de référé ou annuler les décisions illégales et indemniser les personnes lésées par une infraction. Les États-membres peuvent décider d'utiliser des organes de contrôle non-juridictionnel mais ils doivent s'assurer que leurs décisions peuvent faire l'objet d'un contrôle juridictionnel. Ce contrôle juridictionnel doit être exercé devant les tribunaux ou devant un organe de contrôle qui est nécessairement indépendant à la fois de l'organe de contrôle initial et de

l'autorité adjudicatrice et cet organe doit adopter des règles identiques à celles d'un tribunal.

Les directives « recours » ne réglementent pas globalement les systèmes de contrôle et de recours des États-membres en matière de marchés publics. Par exemple, elles n'imposent pas d'exercer le recours devant un tribunal de droit commun, un tribunal spécial ou un tribunal administratif et n'imposent pas le cadre législatif dans lequel doit s'intégrer le système de contrôle et de recours. De plus, les directives « recours » contiennent également certaines « options » qui laissent de ce fait une marge de manœuvre aux États-membres pour les voies de recours. Par exemple, la directive sur les services d'utilité publique laisse aux États-membres le choix entre donner le pouvoir à des organes de contrôle d'annuler les décisions relatives aux marchés publics et ou d'imposer des pénalités. Par conséquent, il y a place pour des variations considérables dans les systèmes de contrôle et de recours des 24 pays de cette étude.

Cependant, pour être plus précis en ce qui concerne l'interprétation des directives, selon l'article 2(1) de la directive 92/13/CEE, les États-membres ont le pouvoir de 1) prendre des mesures provisoires et 2) d'annuler les décisions ou 3) prendre d'autres mesures que celles indiquées en 1) et 2), notamment émettre un ordre de paiement d'une somme déterminée. Cet ordre de paiement n'est donc que l'une des mesures susceptibles d'être prises.

\subsection{Traité CE et jurisprudence de la Cour européenne de justice}

Le principe fondamental directement dérivé du Traité CE auquel les systèmes de contrôle et de recours des États-membres de l'UE doivent se conformer est celui de la non-discrimination en raison de la nationalité (article 12 du traité CE). Tandis que les directives de marchés publics de la CEE prévoient spécifiquement certains aspects de ce principe, le principe général plus large s'applique à tous les cas qui ne sont pas spécifiés dans ces instruments juridiques. Les autres principes concernés du Traité CE sont la transparence et la proportionnalité. Très souvent, l'application pratique de ces principes a été clarifiée par des arrêts de la Cour européenne de justice.

S'il n'y a dans le droit communautaire aucune doctrine à proprement parler fondée sur des précédents juridiques qui obligerait la Cour européenne de justice à suivre sa jurisprudence, celle de la CJUE revêt en revanche une importance considérable. La CJUE suit ses propres précédents dans presque toutes les affaires et cite très souvent ses propres arrêts. En outre, l'autorité de la cour à titre d'interprète final du droit communautaire lui permet de clarifier la loi et, même, s'il y a lieu, de combler les lacunes inévitables laissées par le législateur. Certains des arrêts sur les marchés publics de la CJUE éclairent le droit communautaire à la lumière des objectifs indiqués. Ainsi, les arrêts importants de la CJUE sur le contrôle des actes administratifs et les recours doivent être ajoutés au cadre juridique dans lequel s'exercent les systèmes de contrôle et de recours dans les États-membres. En outre, il convient noter que la plupart des arrêts de la CJUE concernent les aspects généraux des recours qui ne sont pas spécifiquement couverts par les directives 89/665/CEE et 92/13/CEE.

Le droit à un procès équitable visé à l'article 6 de la Convention européenne des droits de l'homme exerce un effet considérable sur les systèmes de contrôle et de recours en matière de marchés publics. 
Comme mentionné ci-dessus, les directives « recours » 89/665/CEE et 92/13/CEE ne réglementent pas globalement les systèmes de contrôle et de recours en matière de marchés publics des États-membres. La jurisprudence de la CJUE ne couvre pas davantage l'ensemble des questions qui se posent dans ce contexte. Certaines pratiques de contrôle, qui ont évolué dans de nombreux pays, ne sont pas spécifiquement traitées dans les directives »recours ». Cependant, la frontière entre ces «pratiques nationales » et les principes généraux d'efficacité et de rapidité des contrôles imposés par les directives « recours » et la jurisprudence de la CJUE n'est pas toujours claire. Néanmoins, certaines dispositions comme la justification des décisions prises à la suite de plaintes, l'audition des parties concernées et la confirmation de la réception des plaintes peuvent être considérées comme des bonnes pratiques sans relever spécifiquement et explicitement du droit communautaire sauf à titre général.

\section{Cadre institutionnel Comment les États-membres ont organisé leurs systèmes de contrôle et de recours}

L'étude ne fait aucune distinction fondamentale sur la nature des contrats (marché public ou délégation de services publics) susceptibles d'avoir un impact sur les conclusions tirées dans la présente section. C'est en particulier approprié en ce qui concerne les États-membres où la responsabilité des recours en matière de délégation de services publics est gérée d'une manière différente que pour les marchés publics.

Cette section couvre les diverses institutions (tribunaux, organes de contrôle quasi-juridictionnel et autres organes de contrôle) chargées du contrôle et des recours en matière de marchés publics dans les Étatsmembres de l'UE. Il existe un important socle commun entre ces institutions de contrôle des marchés publics qui présentent aussi des différences considérables. Pour en savoir plus sur les instances en place dans les différents États-membres, reportez-vous aux rapports nationaux fournis dans l'Annexe.

\subsection{Plaintes aux autorités adjudicatrices}

En premier lieu, il est nécessaire d'établir une distinction entre une plainte administrative préalable par laquelle un soumissionnaire s'adresse directement à l'autorité adjudicatrice pour résoudre un conflit et la notification préalable de l'intention d'exercer un recours en vertu de l'article 1 (3) des directives « recours ». La notification préalable est facultative dans les directives « recours » et vise simplement à informer l'autorité adjudicatrice que le soumissionnaire va exercer un recours devant l'organe de contrôle de première instance.

L'étude a révélé que le point commun des systèmes de contrôle et de recours en matière de marchés publics des États-membres est la possibilité de porter plainte directement auprès de l'autorité ou entité adjudicatrice qui attribue le contrat ou auprès d'institutions supérieures pour la violation présumée du droit des marchés publics. Cependant, l'utilisation de cette option diffère beaucoup dans la pratique si c'est une condition préalable du contrôle juridictionnel ou non ainsi qu'en termes précis de réglementation. La plainte préalable à l'entité adjudicatrice elle-même est la première étape obligatoire du contrôle des actes administratifs dans certains pays comme Chypre et l'Allemagne. Au Portugal, une plainte préalable n'est pas requise mais constitue néanmoins la manière la plus fréquente de régler les conflits relatifs aux marchés publics et la plupart des plaintes s'arrêtent là. En Lettonie, cette même plainte n'est la condition préalable du contrôle juridictionnel qu'en cas d'irrégularité des documents contractuels. La plainte adressée à l'autorité adjudicatrice présente des avantages clairs, particulièrement si une erreur véritable et évidente plutôt qu'une violation délibérée du droit des marchés publics est la raison du conflit ou si l'affaire comporte des interprétations « délicate » de la loi. C'est la raison pour laquelle quelques États-membres comme la Finlande et la Hongrie exigent des soumissionnaires désireux de soumettre leur affaire à un contrôle quasi-juridictionnel ou juridictionnel qu'ils envoient une copie de leur plainte ou de leur requête à l'autorité adjudicatrice concernée. De plus, l'entité adjudicatrice a de ce fait l'occasion de corriger une erreur véritable (si ce peut être fait sans léser quiconque). Le soumissionnaire peut éviter la confrontation avec l'autorité adjudicatrice qu'implique un contrôle quasi-juridictionnel ou juridictionnel. D'ailleurs, c'est peut-être la manière la plus rapide de corriger la violation. En conclusion, les coûts inhérents aux procédures de contrôle peuvent être évités. De surcroît, la longue procédure de plainte peut prolonger la procédure générale de contrôle que si elle ne constitue que le prélude à un contrôle quasi-juridictionnel ou 
juridictionnel. Dans une telle situation, un temps précieux peut être perdu en attendant qu'une entité adjudicatrice statue sur une plainte. Dans le cadre d'une plainte directe à l'entité adjudicatrice comme condition préalable au contrôle quasi-juridictionnel ou juridictionnel, l'exigence de rapidité visée dans les directives « recours » doit être prise en considération, particulièrement en réglementant les délais dans lesquels les entités doivent statuer sur cette plainte. Dans de nombreux États-membres, les autorités adjudicatrices doivent statuer sur les plaintes en quelques jours. Cependant, si une notification préalable véritable a été adressée en parallèle, il n'y a aucune obligation d'attendre la décision des autorités adjudicatrices

En Irlande, cette nécessité pour les plaintes et le contrôle juridictionnel est réduite par la pratique de mises au point au cours desquelles les entités adjudicatrices expliquent et débattent des forces et des faiblesses des différentes offres avec le soumissionnaire concerné. Ces mises au point ne sont pas exigées mais sont encouragées parce qu'elles favorisent le dialogue constructif et transparent entre les entités adjudicatrices et les soumissionnaires.

\subsection{Classification des systèmes de contrôle en systèmes uniques ou doubles}

Les cadres institutionnels des 24 États-membres de cette étude se divisent en deux grands groupes : ceux qui possèdent un système unique ou double qui peuvent être à leur tour subdivisés en deux sous-groupes. Ces sous-groupes seront expliqués plus loin ci-dessous.

Très souvent, mais pas toujours, ce sont les États-membres dont le droit civil et le droit public sont clairement séparés qui ont un double système de contrôle des marchés publics. La plupart des Étatsmembres (voir Tableau 1) ont un double système de contrôle. Dans les pays dotés d'un double système, certains recours (pour l'indemnisation des préjudices) ne peuvent se faire que devant les tribunaux de droit commun ou civils. D'ailleurs, ce recours n'est habituellement disponible qu'après la conclusion du contrat. Par conséquent, la conclusion du contrat est souvent un événement crucial qui détermine la compétence des deux organes de contrôle dont chacun possède au maximum trois instances. Les recours autres que les préjudices-intérêts, notamment la suspension et l'annulation des décisions relatives aux marchés publics, sont instruits par des instances de contrôle différentes. Ce peut être le tribunal administratif comme en Suède. Autrement, des organes de contrôle spécialisés dans les marchés publics instruisent les affaires en première instance et il est possible de faire appel de leurs décisions auprès d'un tribunal administratif supérieur comme en Autriche, à Chypre et en République tchèque. En France et au Luxembourg, la claire séparation du droit public et du droit civil est particulièrement importante. En France, les autorités adjudicatrices et les opérateurs publics de services d'utilité publique peuvent présenter un recours devant les tribunaux administratifs, tandis qu'au Luxembourg cela s'applique seulement aux autorités adjudicatrices. En France, les tribunaux de droit commun instruisent les affaires relatives aux marchés des opérateurs privés de services d'utilité publique tandis qu'au Luxembourg, cela concerne les marchés de tous les opérateurs.

D'autres États-membres n'ont qu'une voie unique de contrôle des marchés publics pour toutes les actions (voir Tableau 1). Ce sont notamment, la Bulgarie, l'Irlande, la Lettonie et le Royaume-Uni. Le Danemark est un cas particulier, puisque les demandes de préjudices-intérêts peuvent être instruites à la fois par les tribunaux de droit commun et par un organe de contrôle spécialisé dans les marchés publics. Le type d'organe de contrôle et le nombre d'instances varient considérablement dans ce genre de système. Comme le double système de contrôle, le système unique peut être divisé en deux sous-groupes selon que la première instance est un organe de contrôle spécialisé dans les marchés publics ou un tribunal plus généraliste. Dans certains États-membres, ce sont les tribunaux civils tandis que dans d'autres, ce sont les tribunaux administratifs. L'autre différence substantielle concerne le niveau de première instance de l'organe de contrôle. Au Portugal, par exemple, les organes de contrôle de première instance constituent le premier degré des juridictions administratives (régionales), tandis que dans l'autre pays comme l'Irlande ou le Royaume-Uni, la high court est le tribunal de première instance Le niveau de la première instance peut influer sur les coûts, la rapidité de la procédure et la proximité avec les parties. Les procédures auprès de tribunaux de haut niveau peuvent être coûteuses, longues et détachées de la région du marché public concerné. Cela peut décourager les soumissionnaires d'intenter des actions. En revanche, les procédures auprès de tribunaux de première instance de niveau inférieur peuvent être moins onéreuses, plus rapides et 
plus proches de la région du marché public concerné. Ces instances peuvent néanmoins manquer d'expérience et d'expertise.

Table 1. Résumé des systèmes de contrôle dans les États-membres

\begin{tabular}{|l|l|l|}
\hline \multicolumn{1}{|c|}{ Système/tribunal } & \multicolumn{1}{|c|}{ Tribunaux de droit commun } & \multicolumn{1}{c|}{ Organe de contrôle spécialisé } \\
\hline Système unique & $\begin{array}{l}\text { Irlande, Lituanie, Pays Bas, Portugal, } \\
\text { Royaume-Uni }\end{array}$ & $\begin{array}{l}\text { Bulgarie, Lettonie, Malte, Roumanie, } \\
\text { Slovaquie }\end{array}$ \\
\hline Système double & Belgique, France, Suède & $\begin{array}{l}\text { Autriche, Chypre, République tchèque, } \\
\text { Danemark, Estonie, Finlande, Allemagne, } \\
\text { Hongrie, Luxembourg, Pologne, } \\
\text { Roumanie, Slovénie }\end{array}$ \\
\hline
\end{tabular}

\subsection{Tribunaux de droit commun et organes de contrôle spécialisés}

Qu'ils aient un système unique ou double, la plupart des États-membres ont mis en place des organes de contrôle spécialisés dans les marchés publics pour gérer les procédures de contrôle :

- $\quad$ Autriche : Bureaux fédéraux des marchés publics et institutions régionales

- $\quad$ Bulgarie : Commission de protection de la concurrence

- $\quad$ Chypre : Autorité de recours des soumissionnaires

- $\quad$ République tchèque : Bureau de protection de la concurrence

- $\quad$ Danemark : Comité des plaintes sur les marchés publics

- $\quad$ Estonie : Commission des marchés publics

- $\quad$ Allemagne : 17 chambres de marchés publics

- Hongrie : Conseil des marchés publics avec une branche spécialisée, le comité d'arbitrage

- $\quad$ Lettonie : Bureau de contrôle des marchés publics

- $\quad$ Malte : Comité d'appels du département des contrats

- $\quad$ Pologne : Bureau des marchés publics (gérant la chambre des arbitres)

- $\quad$ Roumanie : Conseil national de résolution des conflits juridiques

- $\quad$ Slovaquie : Bureau des marchés publics

- $\quad$ Slovénie : Commission nationale de contrôle des procédures d'adjudication des marchés publics

Ces organes de contrôle se composent normalement de groupes d'experts des marchés publics présidés par un avocat spécialisé comme en Autriche, en Bulgarie ou en Allemagne. Les membres de cette chambre arbitrale sont souvent nommés selon une procédure comparable à celle des juges. D'ailleurs, ils doivent remplir les mêmes conditions, telles qu'être un citoyen de l'État-membre en question, parler ses langues nationales et ne pas avoir eu de condamnations pénales. En outre, ils ne peuvent exercer d'autre profession rémunérée sauf dans l'enseignement supérieur ni bénéficier sous aucune forme de ressources provenant d'entreprises privées. Cependant, ces chambres arbitrales peuvent comprendre des experts des marchés publics qui ont une expérience de l'économie, des transports, de la construction ou des connaissances en ingénierie ainsi que des intervenants qui ne sont pas juristes.

L'étude révèle que les décisions des organes de contrôle spécialisés dans les marchés publics ont force exécutoire et peuvent faire l'objet d'un appel auprès des tribunaux de droit commun ou des tribunaux administratifs, mais il y a des exceptions. Dans quelques États-membres, tels que Malte, la Pologne ou la Slovaquie, les organes de contrôle spécialisés dans les marchés publics sont une partie indépendante d'un bureau des marchés publics qui traite également d'autres questions relatives aux marchés publics comme les projets de loi, la publication des appels d'offres ou l'élaboration des politiques. Un appel des décisions des commissions de ces bureaux à leur président respectif peut être une étape distincte de la procédure de contrôle. C'est le cas la République tchèque et de la Pologne. La procédure légale est souvent fixée par la 
loi ou le code des marchés publics plutôt que dans les codes généraux de procédure civile ou administrative. L'avantage des organes de contrôle spécialisés dans les marchés publics, c'est que l'expertise des marchés publics peut être concentrée et que leurs implications juridiques, technologiques, économiques et pratiques sont gérées par des experts de ces domaines. De nombreux États-membres n'ont aucun organe de contrôle spécialisé dans les marchés publics, mais se fondent sur les tribunaux administratifs ou civils (voir le Tableau 2). En Belgique, en France, en Irlande, en Lituanie, aux Pays-Bas, au Portugal, en Suède et au Royaume-Uni, le contrôle des décisions relatives aux marchés publics sont la tâche exclusive des tribunaux réguliers. Au Portugal, les tribunaux administratifs instruisent les conflits relatifs aux marchés publics ; en Irlande, en Lituanie, aux Pays-Bas, en Suède et au Royaume-Uni, ce sont les tribunaux civils ; et en France et au Luxembourg, ce sont les tribunaux administratifs et civils. La Cour du marché en Finlande est spécialisée dans les marchés publics mais aussi dans d'autres domaines économiques.

Dans la plupart des États-membres dotés de mécanismes spécialisés de contrôle des marchés publics, les tribunaux administratifs et civils ont toujours un rôle important à jouer, puisque les décisions de ces organes de contrôle spécialisés dans les marchés publics peuvent faire l'objet d'un appel auprès de la Cour administrative suprême ou même de la Cour suprême. En Slovaquie, les appels sont possibles auprès de deux instances des tribunaux de droit commun, en l'Allemagne et au Danemark auprès des hautes cours des États et en Hongrie et en Pologne auprès des tribunaux de droit commun de première instance. Dans de nombreux États-membres, l'indemnisation des préjudices ne relève pas des organes de contrôle spécialisés dans les marchés publics, mais des tribunaux de droit commun.

Tableau 2 Procédure de contrôle de première instance avant et après la conclusion du contrat

\begin{tabular}{|c|c|c|c|}
\hline & Organe de contrôle spécialisé & Tribunal de droit commun & Tribunal administratif \\
\hline $\begin{array}{l}\text { Avant la conclusion } \\
\text { du contrat }\end{array}$ & $\begin{array}{l}\text { Autriche, Bulgarie, Chypre, } \\
\text { République tchèque, Danemark, } \\
\text { Estonie, Finlande, Allemagne, } \\
\text { Hongrie, Lettonie, Malte, } \\
\text { Pologne, Roumanie, Slovaquie, } \\
\text { Slovénie }\end{array}$ & $\begin{array}{l}\text { Belgique (eau, énergie, } \\
\text { transports, télécoms), } \\
\text { Danemark, France } \\
\text { (opérateurs privés eau, } \\
\text { énergie, transports, } \\
\text { télécoms), Irlande, Lituanie, } \\
\text { Luxembourg (eau, énergie, } \\
\text { transports, télécoms), Pays- } \\
\text { Bas, Royaume-Uni }\end{array}$ & $\begin{array}{l}\text { Belgique (public), } \\
\text { Estonie, France (public), } \\
\text { Luxembourg (public), } \\
\text { Portugal, Suède }\end{array}$ \\
\hline $\begin{array}{l}\text { Après la conclusion } \\
\text { du contrat } \\
\text { (indemnisation des } \\
\text { préjudices) }\end{array}$ & Danemark & $\begin{array}{l}\text { Belgique (eau, énergie, } \\
\text { transports, télécoms), } \\
\text { Chypre, République tchèque, } \\
\text { Danemark, Estonie, } \\
\text { Finlande, France (opérateurs } \\
\text { privés eau, énergie, } \\
\text { transports, télécoms), } \\
\text { Allemagne, Hongrie, } \\
\text { Irlande, Lettonie, Lituanie, } \\
\text { Luxembourg (eau, énergie, } \\
\text { transports, télécoms), Malte, } \\
\text { Pays Bas, Pologne, } \\
\text { Slovaquie, Slovénie, Suède, } \\
\text { Royaume-Uni }\end{array}$ & $\begin{array}{l}\text { Belgique (public), } \\
\text { France (public), } \\
\text { Luxembourg (public), } \\
\text { Portugal, Roumanie }\end{array}$ \\
\hline
\end{tabular}

\subsection{Appels}

La plupart des États-membres permettent un appel contre un jugement de première instance ; en d'autres termes, ils permettent à une deuxième instance d'annuler ou de changer la décision des organes de contrôle de première instance, comme évoqué ci-dessus sous le dernier titre. La Belgique, Malte et la Slovénie sont les seuls pays à ne pas permettre un appel des décisions prononcées avant la conclusion du contrat. 
Les deuxièmes instances diffèrent notamment selon que l'État-membre a un système de contrôle unique ou double. Dans de nombreux États-membres où les préjudices post-contractuels doivent être demandés devant les tribunaux civils, les soumissionnaires peuvent saisir la cour d'appel s'ils ne sont pas satisfaits de l'issue de la procédure de contrôle.

Les cours d'appel sont aussi le deuxième ressort dans les États-membres doté d'un système de contrôle unique comme les cours suprêmes ou les cours d'appel. À Chypre, en Irlande et au Danemark, les cours suprêmes sont le second et dernier ressort. En Autriche, en Bulgarie, en République tchèque, en Finlande et au Portugal, les soumissionnaires font directement appel à la cour administrative suprême et en Autriche également à la Cour constitutionnelle, tandis qu'en France et en Suède, il y a des cours d'appel administratives de deuxième ressort avant la Cour suprême administrative de troisième ressort.

Les pays dotés d'un organe de contrôle de première instance spécialisé dans les marchés publics ont normalement une cour d'appel de deuxième instance. Contrairement à cette norme, en République tchèque et en Pologne, les présidents du bureau de protection de la concurrence et du bureau des marchés publics agissent respectivement comme une deuxième instance distincte de contrôle des décisions prises en première instance par leurs propres comités d'appel.

En Roumanie et en Allemagne, les organes de contrôle spécialisés dans les marchés publics sont responsables des contrôles de première instance. Cependant, les soumissionnaires peuvent aussi faire appel en deuxième instance auprès d'un tribunal de droit commun. En Roumanie, la Cour d'appel a une chambre spéciale pour les marchés publics et, en Allemagne, les hautes cours des Länder ont des chambres spécialisées dans les marchés publics qui instruisent ces appels.

\subsection{Organes de contrôle de dernier ressort}

Les systèmes de contrôle en matière de marchés publics de tous les pays de cette étude ont des points communs, notamment en ce qui concerne les organes de contrôle de dernier ressort. Le plus haut degré de juridiction ou la dernière instance de contrôle des marchés publics, tant précontractuels que postcontractuels, est un tribunal administratif ou un tribunal de droit commun À quelques exceptions près, comme à Malte et en Slovénie, les organes de contrôle spécialisés sont la dernière instance pour les conflits avant la conclusion du contrat, tandis que les conflits post-contractuels sont soumis aux tribunaux de droit commun. Le rôle de ces tribunaux est fixé par la constitution et les lois du Parlement et ces derniers répondent aux impératifs d'une juridiction comme l'établit l'arrêt Dorsch et Salzmann de la Cour européenne de justice. Ils se fondent sur la loi ou ont été institués par une loi, sont permanents, leurs décisions ont force de loi, leur procédure est une procédure entre parties et ils statuent à partir des règles de droit. Tous ces tribunaux sont indépendants du pouvoir exécutif, de l'administration ou de toute entité gouvernementale et leurs décisions sont de nature juridictionnelle. Leurs juges doivent être des avocats expérimentés et reconnus. Ce sont normalement des juges au sommet de la hiérarchie judiciaire. Ils sont nommés selon une procédure générale. Le droit national des États-membres exige que les juges soient indépendants et ils peuvent être démis de leurs fonctions que dans des cas particuliers et dans des conditions strictement définies, le cas échéant. Les présidents de tous les tribunaux sont nommés par le gouvernement, le parlement ou un comité spécifique de nomination ou sont élus par les cours elles-mêmes. Il faut cependant préciser que les divers organes de contrôle de première et de deuxième instance des Étatsmembres décrits sous les deux derniers titres ci-dessus remplissent les conditions d'une juridiction.

Les différences concernent le nombre d'instances dont disposent les soumissionnaires. Pour le contrôle des décisions précontractuelles, les soumissionnaires disposent d'une instance en Belgique, à Malte, et en Slovénie, tandis que leurs homologues en Lituanie, aux Pays-Bas, en Slovaquie et au Royaume-Uni peuvent saisir trois instances. Tous les autres États-membres ont deux instances de contrôle des décisions précontractuelles de marchés publics. L'utilisation réelle dans la pratique des possibilités d'appel jusqu'aux organes de dernier ressort sera abordée ci-dessous dans le cadre de la culture du contrôle des actes administratifs. 
Tableau 3. Instances de contrôle des décisions précontractuelles en matière de marchés publics

\begin{tabular}{|l|l|l|l|}
\hline \multicolumn{1}{|c|}{ Instance } & \multicolumn{1}{|c|}{ Organe de contrôle spécialisé } & Tribunal administratif & \multicolumn{1}{c|}{ Tribunal de droit commun } \\
\hline 1e instance & $\begin{array}{l}\text { Autriche, Bulgarie, Chypre, } \\
\text { République tchèque, Danemark, } \\
\text { Estonie, Finlande, Allemagne, } \\
\text { Hongrie, Lettonie, Malte, Pologne, } \\
\text { Roumanie, Slovaquie, Slovénie }\end{array}$ & $\begin{array}{l}\text { Belgique, Estonie, } \\
\text { France (public), } \\
\text { Luxembourg (public), } \\
\text { Suède }\end{array}$ & $\begin{array}{l}\text { Danemark, France (opérateurs } \\
\text { privés de services d'utilité } \\
\text { publique), Irlande, Lituanie, } \\
\text { Luxembourg (services d'utilité } \\
\text { publique), Pays-Bas, Royaume- } \\
\text { Uni }\end{array}$ \\
\hline 2e instance & & $\begin{array}{l}\text { Autriche, Bulgarie, } \\
\text { République Tchèque, } \\
\text { Estonie, Finlande, France } \\
\text { (public), Lettonie, } \\
\text { Luxembourg (public), } \\
\text { Portugal, Suède }\end{array}$ & $\begin{array}{l}\text { Chypre, Danemark, France } \\
\text { (opérateurs privés des services } \\
\text { d'utilité publique), Allemagne, } \\
\text { Hongrie, Irlande, Lituanie, } \\
\text { Luxembourg (opérateurs de } \\
\text { services d'utilité publique), Pays- } \\
\text { Bas, Pologne, Roumanie, } \\
\text { Slovaquie, Royaume-Uni }\end{array}$ \\
\hline 3e instance & \multicolumn{2}{|c|}{$\begin{array}{l}\text { Estonie, France (opérateurs privés } \\
\text { eau, énergie, transports, } \\
\text { télécoms), Hongrie, Lituanie, } \\
\text { Pays-Bas, Slovaquie, Royaume- } \\
\text { Uni }\end{array}$} \\
\hline
\end{tabular}

\subsection{Attestation et conciliation}

Conformément à la directive CE 92/13/CEE, les mécanismes d'attestation et de conciliation sont disponibles pour le secteur des services d'utilité publique dans les États-membres. Cependant, l'étude indique que ces mécanismes sont rarement utilisés dans la pratique. Il s'avère que l'abolition de ces instruments est à l'étude dans le cadre de la révision actuelle des directives « recours ».

\subsection{Médiateur et organismes consultatifs}

Dans certains États-membres, par exemple les Pays-Bas, le médiateur national peut jouer un rôle dans les conflits relatifs aux marchés publics. Cette institution indépendante a accès à toutes les entités gouvernementales et peut résoudre les conflits entre les soumissionnaires et les autorités adjudicatrices, évitant de ce fait une procédure coûteuse et longue.

En Allemagne, les soumissionnaires peuvent contester les décisions d'attribution de marchés publics devant des Comités de contrôle des marchés publics. Ces comités peuvent être mis en place au niveau des Länder et de la fédération et ont le pouvoir d'ordonner aux autorités adjudicatrices, sur requête ou ex officio, d'annuler une décision illégale ou de prendre une mesure légale. Ces comités n'ont pas le pouvoir de suspendre une procédure de passation de marché. La procédure de contrôle devant un tel comité n'est pas une condition préalable à la présentation d'un recours devant les chambres des marchés publics. De même, l'Autorité de la concurrence danoise et la Commission des soumissions du Luxembourg sont les organismes consultatifs et leurs décisions n'ont pas force exécutoire pour les autorités adjudicatrices et peuvent être contestées dans une procédure de contrôle juridictionnel. Les possibilités de règlement amiable offrent une alternative moins conflictuelle, plus constructive, moins coûteuse et longue qu'une action classique.

\subsection{Principales instances de contrôle}

Concernant les principales instances de contrôle des marchés publics, il y a d'énormes différences entre les États-membres dans la mise en place institutionnelle des systèmes de contrôle et de recours et tout classement en grands groupes devient donc plus difficile. La notion «d'instance principale » décrit l'institution de contrôle ou le type d'organe de contrôle où se règlent dans la pratique la plupart des litiges 
relatifs aux marchés publics. Il peut s'agir des autorités adjudicatrices et des entités elles-mêmes, de leur administration de tutelle (Portugal), de comités indépendants de contrôle des marchés publics (Danemark, Estonie, Allemagne, Hongrie, Lettonie et Pologne), de l'Autorité de la concurrence (République tchèque), des tribunaux administratifs de premier et deuxième ressort (France et Suède), de tribunaux de droit commun de premier et deuxième ressort (Lituanie et Pays-Bas) ou hautes cours (Irlande et Royaume-Uni).

\section{Recours disponibles}

L'étude ne fait aucune distinction fondamentale sur la nature des contrats (marché public ou délégation de services publics) susceptibles d'avoir un impact sur les conclusions tirées dans la présente section. C'est en particulier approprié en ce qui concerne les États-membres où la responsabilité des recours en matière de délégation de services publics est gérée d'une manière différente que pour les marchés publics.

L'autre question importante concerne les mesures que les organes de contrôle et les tribunaux peuvent réellement prendre en faveur du soumissionnaire lésé si sa plainte est justifiée. Les mesures susceptibles d'être prises par les organes de contrôle dans la plupart des juridictions comprennent (i) l'annulation de toute décision individuelle concernant les marchés publics, y compris la décision d'attribution, (ii) les mesures provisoires, (iii) l'annulation du contrat conclu (dans certaines juridictions) et (iv) l'indemnisation des préjudices. Les astreintes dans les marchés de services d'utilité publique ne sont pas disponibles dans tous les États-membres.

\subsection{Annulation des décisions relatives aux marchés publics}

L'annulation d'une décision individuelle relative aux marchés publics prises au cours d'une procédure de passation de marchés précontractuelle est un recours possible dans tous les États-membres. Les décisions individuelles d'attribution à annuler peuvent concerner une documentation contractuelle non-conforme à la loi, des spécifications ou des documents de soumission discriminatoires, une décision illégale de sélection ou de présélection et même la décision d'attribution du contrat elle-même. D'ailleurs, les organes de contrôle peuvent, par exemple, ordonner la suppression ou la modification de spécifications et d'autres documents du cahier des charges ou le recommencement de la procédure de passation de marchés toute entière ou à un moment spécifique. Ce genre de recours est disponible dans tous les États-membres. La requête de protection légale contre des décisions avant la conclusion du contrat est recevable et, dans certains États-membres, elle est aussi recevable après la conclusion du contrat, bien qu'elle soit moins efficace dans la pratique. Il faut normalement que la décision dont le candidat demande l'annulation constitue une violation de la loi/du code des marchés publics ou d'autres réglementations. Les diverses violations sont la discrimination des soumissionnaires, le non-respect de l'égalité du traitement, le manque de transparence ou la présence de critères d'attribution discriminatoires. La charge de la preuve incombe normalement au requérant, mais, dans certaines juridictions, les soumissionnaires se plaignent seulement d'une violation et l'autorité ou l'entité adjudicatrice doit montrer qu'aucune violation n'a vraiment été commise ou l'organe de contrôle doit apporter la preuve (système inquisitorial pour recueillir la preuve).

Dans les pays dotés d'un organe de contrôle spécialisé dans les marchés publics, c'est normalement ce dernier qui peut annuler ou suspendre les différentes décisions relatives aux marchés publics, mais, par exemple, les tribunaux de droit commun du Danemark peuvent également le faire. Dans les pays non dotés d'un organe de contrôle spécialisé, ce recours est normalement possible en premier instance. L'annulation d'une décision relative aux marchés publics peut imposer la nécessité de recommencer tout ou partie de la procédure. Dans certaines juridictions, un contrat conclu malgré la décision prise par un organe de contrôle sur l'attribution du marché ou toute autre décision prise au cours de la procédure frappe le contrat de nullité et peut déboucher sur l'indemnisation des préjudices. C'est le cas en Bulgarie, en Estonie, en Pologne et en Roumanie.

Le fondement juridique de ce recours est souvent la loi ou le code des marchés publics. Cependant, dans certains États-membres, le fondement se trouve dans le code civil, le code de procédure civile et la jurisprudence (Pays-Bas), en particulier quand l'État membre ne possède pas d'organe de contrôle spécialisé dans les marchés publics. 
Dans la plupart des États-membres, déposer une plainte ou former un recours contre une décision relative aux marchés publics ne suspend pas systématiquement la poursuite de la procédure de passation de marchés. Seuls les systèmes de contrôle de quelques États-membres comme l'Estonie, l'Allemagne, la Pologne, la Roumanie et la Slovénie prévoient un délai suspensif systématique dès le début de la procédure de contrôle. La disponibilité des mesures provisoires est la condition préalable de l'efficacité des systèmes de contrôle et de recours car, sans cette suspension, la procédure de passation de marchés peut continuer jusqu'à la conclusion du contrat, sans sanctionner l'illégalité des actions ou décisions. Comme décrit ci-dessus sous le titre précédent, les contrats conclus ne peuvent être annulés que dans des cas très limités et strictement définis, le cas échéant. Les demandes post-contractuelles d'indemnisation sont ainsi souvent le seul recours restant à la disposition des candidats évincés. Il est intéressant de noter qu'en Estonie la nouvelle loi de 2006 sur les marchés publics supprime la suspension systématique de la procédure de passation des marchés. Par conséquent, dans la plupart des États-membres, un soumissionnaire qui considère que la poursuite de la procédure d'attribution du marché est susceptible de léser ses intérêts doit saisir l'organe de contrôle d'une demande de mesures provisoires, par exemple d'arrêt de la procédure d'attribution. L'organe de contrôle peut alors adopter des mesures provisoires en l'attente d'une conclusion définitive en prenant en considération les conséquences probables des mesures provisoires pour l'ensemble des intérêts en présence, notamment l'intérêt public, et ne pas faire usage de ses pouvoirs s'il estime que les conséquences négatives pourraient l'emporter sur les conséquences positives. En principe, tous les recours peuvent donner lieu à des mesures provisoires. Dans toutes juridictions, les conditions requises pour un «référé » ou une «injonction»sont : l'intérêt fondé du plaignant et une violation présumée ou probable de la loi. Des conditions supplémentaires peuvent s'appliquer dans différents États-membres.

Le délai suspensif est habituellement d'environ dix jours entre la décision d'attribution du marché et la conclusion du contrat, décrites ci-dessus sous le titre précédent. S'il n'y a pas de délai suspensif systématique ou si les juges ou une formation collégiale ne peuvent pas ordonner facilement et rapidement la suspension de la procédure de passation de marchés, le délai suspensif et les délais pour rendre une décision doivent être synchronisés pour assurer l'efficacité du contrôle. Par exemple, si le délai suspensif est de dix jours mais que le juge dispose de 20 jours pour statuer sur l'action menée au cours de la période de délai suspensif, c'est peut-être trop tard pour se prononcer parce que le contrat peut être légalement conclu d'ici là.

En l'Allemagne et en Slovénie, comme évoqué ci-dessus, les plaintes ont un effet suspensif systématique. Par conséquent, la situation est le contraire de celle de la plupart des autres États-membres, car, en Allemagne, l'autorité ou l'entité adjudicatrice peut demander à l'organe de contrôle l'autorisation de conclure le marché pendant la procédure de recours. La Chambre peut accorder cette autorisation, après qu'une période de deux semaines se soit écoulée depuis l'annonce de la décision, si elle envisage, après avoir pris en considération tous les intérêts susceptibles d'être lésés, notamment l'intérêt public, que les conséquences négatives de la suspension l'emporte sur les conséquences positives. En Slovénie, la Commission nationale de contrôle peut permettre la poursuite de la procédure de passation de marchés à l'exception de la conclusion du contrat.

\subsection{Annulation d'un contrat conclu}

L'annulation d'un contrat déjà conclu ou la déclaration de nullité du contrat par une tierce partie est un recours disponible dans quelques États-membres qui s'applique au moins si le contrat est signé au cours de la période de délai suspensif. La possibilité d'annuler le contrat conclu est un recours crucial puisque, dans les juridictions privées de cette possibilité, la demande d'indemnisation des préjudices est le seul recours disponible après cet événement. C'est en partie en raison de ce fait que de nombreux États-membres ont suivi la Cour européenne de justice dans l'arrêt Alcatel et ont introduit un délai suspensif d'environ dix jours entre la décision d'attribution du marché et la conclusion du contrat (voir le Tableau 4 ci-dessous). Ce délai suspensif permet aux soumissionnaires d'entreprendre une procédure en vue de l'annulation de la décision d'attribution du marché. Avant l'introduction de ce délai, l'attribution du marché et la conclusion du contrat constituaient un seul et même acte ou au moins étaient simultanées et rendaient impossible la 
contestation de la décision d'attribution du marché et limitaient donc les recours disponibles pour l'indemnisation des préjudices. Pour motiver l'annulation d'un contrat signé, il faut que l'autorité adjudicatrice ait signé le contrat au cours du délai suspensif bien que ce ne semble pas être le cas dans tous les États-membres. Dans tous les cas autres que la conclusion du contrat au cours du délai suspensif, il est difficile d'obtenir l'annulation d'un contrat signé, voire impossible. Par exemple, à Chypre, en République tchèque et en Lettonie, une telle annulation ne peut être obtenue que devant un tribunal, tandis que l'annulation d'autres décisions relatives aux marchés publics est possible auprès d'organes de contrôle spécialisés. En vertu du droit administratif français, seul le préfet peut solliciter l'annulation d'un contrat conclu. Les parties à un contrat peuvent demander au tribunal compétent de prononcer la nullité du contrat. Les tiers ne peuvent pas agir ainsi, mais s'ils obtiennent l'annulation d'un acte concernant la passation du contrat, ils peuvent demander à la cour d'ordonner à l'entité adjudicatrice d'annuler le contrat signé sur le fondement de l'acte annulé. En Lituanie, l'annulation n'est possible que si les clauses du contrat sont illégales. En Autriche, l'annulation est théoriquement possible mais elle ne s'est jamais produite dans les faits, tandis qu'en Belgique, une annulation peut prendre de quatre à cinq ans. Aux Pays-Bas, le contrat conclu ne peut être annulé par les tribunaux que s'il occasionne des troubles à l'ordre public (ordre public) En Suède et au Royaume-Uni, l'annulation n'est possible qu'en cas de fraude ou d'illégalité. En Irlande, il est théoriquement possible qu'un tribunal prononce la nullité d'un contrat public s'il a été attribué en violation des lois irlandaises transposant les directives sur les marchés publics. Cependant, dans la pratique, cela ne s'est jamais produit.

Tableau 4. Délai suspensif entre la décision d'attribution du marché et la conclusion du contrat (en jours)

\begin{tabular}{|llll|}
\hline Autriche & 7 ou 14 & Lituanie & 10 \\
Bulgarie & 10 & Luxembourg & 15 \\
République tchèque & 15 & Malte & 10 \\
Danemark & $7-10$ & Pays-Bas & 15 \\
Estonie & 14 & Pologne & 7 \\
Finlande & 21 ou 28 & Portugal & 10 \\
France & 10 & Roumanie & 15 \\
Allemagne & 14 & Slovaquie & 14 \\
Hongrie & 8 & Slovénie & 20 \\
Irlande & 14 & Suède & 10 \\
Italie & 30 & & \\
\hline
\end{tabular}

\subsection{Indemnisation des préjudices}

Le soumissionnaire peut souvent avoir subi des préjudices en raison de la violation de la réglementation des marchés publics par l'autorité ou l'entité adjudicatrice qu'il n'a été découverte qu'après la signature du contrat, à une étape où aucun recours destiné à l'annulation ou à la suspension de la décision d'attribution du marché, voire à l'annulation du contrat n'est possible. Dans ces cas, la perte ne peut être réparée qu'en attribuant une indemnisation des préjudices subis. Cette indemnisation est accessible dans la plupart des États-membres.

Les conditions d'attribution d'une indemnisation des préjudices sont communes à la plupart des juridictions et sont les suivantes : perte (pécuniaire ou autre) subie par le requérant, violation de la loi commise par l'autorité ou l'entité adjudicatrice, causalité (de cause à effet signifiant que la perte doit être provoquée par la violation de la loi). Des conditions supplémentaires s'appliquent à différentes juridictions. Par exemple, au Danemark, en Finlande, en France, en Allemagne et Suède, le requérant doit prouver qu'il aurait eu une réelle possibilité de remporter le marché si la procédure avait été légalement conduite. Le fondement de l'indemnisation des préjudices est le droit civil général (code civil, code de procédure civile, droit des obligations, jurisprudence) ou, dans le cas de la France et de la Roumanie, dans le droit administratif. La loi/le code des marchés publics en est la source en Finlande et en Hongrie. La loi relative aux marchés publics en est la source au Danemark où le Comité des plaintes sur les marchés publics statue sur les affaires, tandis que les tribunaux de droit commun attribuent les indemnités sur le fondement du droit des obligations. Autrement, ce sont normalement les tribunaux civils, et dans certaines juridictions 
comme la France et la Roumanie, les tribunaux administratifs qui ont le pouvoir d'indemniser les préjudices subis d'attribuer et non les organes de contrôle non spécialisés dans les marchés publics. Dans la plupart des États-membres, il n'est pas nécessaire que la décision contestée soit annulée avant de faire une demande indemnitaire.

En ce qui concerne le calcul des préjudices, les frais de soumission (damnum emergens) peuvent être remboursés dans tous les États-membres. Les différences s'appliquent aux bénéfices perdus (cessans de lucrum). Au moins au Danemark, en Finlande, en Allemagne, en Hongrie, en Lettonie, en Lituanie, aux Pays-Bas, au Portugal, en Suède et au Royaume-Uni, les pertes de bénéfices peuvent être indemnisées et, en France, si le requérant avait une possibilité sérieuse de remporter le marché (plus qu'une simple chance). Comme mentionné ci-dessus, le soumissionnaire doit habituellement démontrer qu'il aurait eu une vraie possibilité de remporter le marché qui a été attribué par la décision illégale. Si les plaignants ne remplissent pas cette condition, ils ont simplement droit au remboursement des coûts de soumission. En Lettonie, les indemnités dépassent très rarement les coûts de soumission et, dans la plupart des Étatsmembres, il est très difficile de fournir la preuve exigée pour obtenir l'indemnisation des pertes de bénéfices. En conséquence, les demandes d'indemnisation sont relativement peu nombreuses dans la plupart des pays, de même que les jugements en faveur des demandeurs.

\subsection{Pénalités et astreintes}

Selon le paragraphe de l'article 2. 1c) de la directive 92/13/CEE, afin de forcer les autorités et entités adjudicatrices à se conformer à leurs jugements, les tribunaux et les autres organes de contrôle peuvent imposer des astreintes interdisant à l'autorité ou entité adjudicatrice de poursuivre la procédure d'adjudication jusqu'à la rectification de la violation. Cette possibilité est donnée à Chypre, au Danemark et au Luxembourg ; en France, elle est accordée pour les services d'utilité publique. En outre, en République tchèque, en Hongrie, aux Pays-Bas, en Pologne et en Slovénie, le paiement de pénalités et de redevances peut être imposé aux autorités adjudicatrices et à leurs services. Ces paiements ne sont pas des recours disponibles pour les soumissionnaires lésés mais font partie des systèmes de contrôle des marchés publics dans ces États-membres.

\section{Cadre légal des systèmes de contrôle des États-membres}

Le cadre législatif des systèmes de contrôle est un autre point de référence de cette étude. La notion de «cadre législatif » est un vaste concept qui recouvre le fondement légal de l'institution des organes de contrôle, le système et le code de procédure. Le code de procédure réglemente notamment les questions relatives à la recevabilité des acteurs (statut légal), à la rapidité d'introduction de l'action (délais), aux effets de l'action sur la procédure de passation de marchés (effet et délai suspensifs) et aux coûts de ces procédures. La conformité aux exigences générales et spécifiques des directives « recours » 89/665/CEE et 92/13/CEE et du droit communautaire en général est une question importante dans ce contexte puisqu'elle doit fournir un socle commun à tous les systèmes nationaux. Cela pose la question de savoir si et dans quelle mesure les systèmes de contrôle et de recours s'étendent aux contrats hors du champ d'application des directives sur les marchés publics et si le même système s'applique aux pouvoirs publics et aux services d'utilité publique.

\subsection{Champ d'application des systèmes de contrôle et de recours}

Tant qu'il n'est fait référence qu'aux dispositions des directives « recours », la loi nationale sur les marchés publics en général et les systèmes de contrôle et de recours en particulier peuvent s'appliquer conjointement à tous les contrats attribués par les autorités adjudicatrices et les services d'utilité publique des entités publiques et privées Autrement, il ne peut s'appliquer qu'au-dessus des seuils des directives sur les marchés publics de la CEE ou seulement aux contrats attribués par les pouvoirs publics, avec un système distinct pour les services d'utilité publique. Enfin, les systèmes de contrôle et de recours de certains États-membres ont été aussi étendus aux contrats en dehors du champ d'application des directives sur les marchés publics de la CEE, par exemple aux délégations de services. 


\subsubsection{Marchés dont la valeur est supérieure ou inférieure aux seuils des directives sur les marchés publics de la CEE}

Il y a essentiellement trois réponses différentes à la question de savoir si les systèmes de contrôle et de recours s'appliquent également aux contrats dont la valeur est supérieure ou inférieure aux seuils des directives sur les marchés publics de la CEE. En premier lieu, dans la plupart des États-membres, les systèmes de contrôle et de recours s'appliquent également aux contrats dont la valeur est supérieure ou inférieure aux seuils. Ce groupe de pays comprend Chypre, l'Estonie, la France, la Hongrie, la Lituanie, les Pays Bas, le Portugal, la Roumanie, la Slovénie et la Suède. En second lieu, dans un petit groupe d'Étatsmembres, ces systèmes de contrôle et de recours s'appliquent seulement aux contrats dont la valeur est supérieure aux seuils. Ce groupe de pays comprend l'Allemagne, l'Irlande et le Royaume-Uni. En troisième lieu, dans un nombre restreint d'États-membres, il y a des différences substantielles des systèmes de contrôle et de recours pour les contrats dont la valeur est inférieure aux seuils. Par exemple, en République tchèque, il faut remplir d'autres conditions pour accéder à certains recours ; au Danemark, dans certaines situations, les recours ont un fondement légal différent; en Finlande, il y a un circuit entièrement différent pour le contrôle juridictionnel.

\subsubsection{Différences d'organisation-autorités adjudicatrices et opérateurs de services d'utilité publique}

Il existe des différences entre les systèmes de contrôle et de recours dans les États-membres si le marché est attribué par une autorité adjudicatrice ou un opérateur de services d'utilité publique. D'ailleurs, il peut y avoir différentes règles applicables aux opérateurs publics et privés de services d'utilité publique. Cependant, dans de nombreux États-membres comme la Bulgarie, l'Estonie, la Lituanie et les Pays-Bas, le système de contrôle et de recours s'applique également aux autorités et entités adjudicatrices. En France, il y a différents fondements juridiques et différents organes de contrôle selon que le marché est attribué par une entité publique ou privée de droit français ; au Luxembourg, les différences se fondent sur la nature privée ou publique de l'entité adjudicatrice. En Lettonie, les contrôles et recours auprès du Bureau de contrôle des marchés publics ne sont pas possibles pour les contrats inférieurs aux seuils fixés pour les services d'utilité publique. En Pologne, il n'y a de même aucun contrôle possible pour les contrats inférieurs aux seuils fixés pour les services d'utilité publique.

\subsection{Code de procédure}

Le code de procédure réglemente les actions introduites auprès des tribunaux et organes de contrôle. Il couvre des questions comme le statut légal, c'est-à-dire le droit d'introduire une action, les délais impartis pour introduire la procédure, les frais et coûts, la publication des jugements et les appels. Le code de procédure détermine des questions cruciales comme l'accès à la procédure (statut légal) et la rapidité (délais). La réglementation du code de procédure de l'organe de contrôle dépend de son caractère institutionnel. En général, la procédure des tribunaux civils est régie par (i) le code de procédure civile national, tandis que la procédure des tribunaux administratifs est régie par (ii) le code de justice administrative et la procédure des organes de contrôle spécialisés dans les marchés publics est régie par (iii) une loi ou un code des marchés publics spécifique. Dans de nombreux États-membres, il y a souvent une combinaison de diverses sources de droit.

- $\quad$ En Bulgarie, en République tchèque, en Estonie, en Lettonie, au Portugal et en Roumanie, la procédure légale correspondante est régie par la loi ou la réglementation combinée avec le code de justice administrative régissant les recours auprès des tribunaux administratifs.

- $\quad$ En Allemagne, en Lituanie, aux Pays-Bas, en Pologne et au Royaume-Uni, la loi ou la réglementation relative aux marchés publics et le code de procédure civile régissent la procédure concernée.

- $\quad$ En France, en Hongrie, au Luxembourg et en Suède, ces procédures sont à la fois régies par le code de justice administrative et le code de procédure civile.

- $\quad$ Enfin, la Slovénie a un code spécial de procédure pour le contrôle des marchés publics qui régit les procédures de contrôles à toutes les instances. 


\subsubsection{Statut légal}

Normalement, il n'est pas permis à un simple citoyen de perturber les procédures de marchés publics en les contestant par la formation d'un recours. Le locus standi ou statut légal des acteurs habilités à introduire une action est réglementé. Ces règles peuvent être complexes et différer selon le type de recours formé, l'organe de contrôle saisi et l'étape de la procédure de passation de marchés à laquelle l'action est introduite, notamment si la saisine est précontractuelle ou post-contractuelle. Référence peut être faite à l'article 1(3) des directives «recours » qui établit les conditions de recevabilité du requérant selon son statut légal.

Dans la plupart des États-membres, les soumissionnaires désireux de contester la procédure d'adjudication en introduisant une action doivent indiquer qu'ils ont un intérêt particulier dans le contrat en question. Autrement, il ne leur est pas permis d'introduire une action. C'est normalement aux soumissionnaires d'apporter la preuve de cet intérêt dans la procédure, mais, dans certains cas, des opérateurs économiques non-soumissionnaires peuvent avoir le statut légal (voir par exemple l'affaire Grossmann C-230/02). En Estonie, par exemple, seuls les soumissionnaires peuvent introduire une action relative à l'attribution du marché. Le soumissionnaire doit normalement avoir présenté une offre pour contester l'attribution du contrat. En Bulgarie, à Chypre, en Allemagne, en Hongrie, en Irlande, en Lettonie et en Pologne, les candidats à la procédure de contrôle juridictionnel doivent montrer qu'ils ont un intérêt dans l'adjudication, tandis qu'aux Pays-Bas, ce doit être «un intérêt bien fondé » et en Roumanie « un intérêt légitime ». En Suède, tout fournisseur ou prestataire de services qui a un intérêt dans l'attribution du marché, peut entamer une action même s'il n'a pas présenté d'offre. En Allemagne, si le requérant n'a pas vraiment présenté d'offre, il doit montrer que la conduite de l'autorité adjudicatrice l'a empêché de le faire. Au Luxembourg, toute personne qui a participé à une adjudication en respectant la procédure légale et s'estime lésée par une illégalité peut introduire une action. Enfin, en Slovénie, le demandeur doit montrer qu'il a un intérêt véritable dans ce marché et donner des preuves de la perte qu'il est supposé avoir subie.

En France, le statut légal dépend du type de procédures. Dans les référés précontractuels, seuls les candidats et les soumissionnaires réels ou ceux qui ont été illégalement empêchés de faire une offre en raison du manquement de l'autorité adjudicatrice à son obligation de publicité, ont le statut légal requis. Cependant, pour les demandes ordinaires d'annulation, d'autres parties peuvent avoir ce statut comme les conseillers municipaux ou même les contribuables de la commune.

En outre, dans un certain nombre d'États-membres, des tierces parties qui ne sont ni des soumissionnaires réels ou probables ni des entités adjudicatrices ont le statut légal pour introduire une action. Par exemple, le Bureau slovaque des marchés publics peut introduire une action à sa discrétion et le fait très fréquemment. Au Danemark, les plaintes au Comité des plaintes relatives aux marchés publics peuvent être présentées par écrit par toute personne ayant un intérêt légal à cet égard et par l'Autorité de la concurrence danoise, le ministre du logement et de l'urbanisme, les syndicats professionnels et les autorités publiques auxquels le ministre de l'économie a donné accès à la procédure devant le Comité. L'accès de ces organismes et autorités publiques à ces procédures a été introduit pour permettre le contrôle des décisions d'attribution des marchés publics lorsqu'aucun soumissionnaire individuel ne souhaite déposer plainte. Une action devant la Cour du marché en Finlande peut être introduite par la partie concernée, le ministère du commerce et de l'industrie et le ministère des finances pour les contrats de travaux ou d'autres marchés et par l'autorité publique qui a accordé l'aide de l'État pour les contrats de travaux concernés. Le principal avantage d'accorder ce statut à plusieurs acteurs, c'est qu'il résout le problème rencontré par de nombreux soumissionnaires qui ont peur qu'une plainte ou une action ne compromette compromettre leurs chances d'obtenir le contrat suivant.

\subsubsection{Délais}

Dans certains États-membres, les procédures de contrôle des marchés publics ne peuvent être introduites à aucun moment donné. Dans d'autres États-membres, il n'y a aucun délai ou ils sont interprétés de façon si souple que toute décision prise au cours de la procédure d'adjudication peut être contestée après l'annonce de l'attribution du marché. Les requérants doivent normalement doivent introduire une action dans certains délais à partir du moment où ils ont connaissance de la violation présumée la loi/code des marchés publics. Pour les recours autres que l'indemnisation des préjudices, ces délais servent à équilibrer les intérêts 
privés des soumissionnaires et l'intérêt public à l'égard de l'assurance de légalité nécessaire pour signer un contrat. Les plaintes directes à l'autorité ou à l'entité adjudicatrice doivent être adressées dans des délais très courts, dans les dix jours par exemple. Dans de nombreux d'États-membres, il y a un délai général de 10 à 15 jours pour saisir l'organe de contrôle approprié. Conformément aux règles générales du droit civil et compte tenu que ce type de recours n'affecte pas la validité et la conclusion du contrat, les délais pour la demande d'indemnisation des préjudices sont souvent très généreux, par exemple un an en Suède, cinq ans aux Pays-Bas et 30 ans au Luxembourg.

Les délais dans lesquels les tribunaux et les organes de contrôle doivent rendre un jugement ou une décision sont une question connexe. Dans de nombreux États-membres, les délais pour que les entités et autorités adjudicatrices traitent une plainte contre une de leurs décisions relatives à l'attribution d'un marché public sont très serrés. Ce sont par exemple 15 jours en Slovénie, dix jours en Pologne, cinq jours en Lituanie et seulement deux jours ouvrables en Lettonie.

Les organes de contrôle spécialisés dans les marchés publics doivent normalement prendre des décisions plutôt rapidement : par exemple, le Bureau estonien des marchés publics dans les 10 jours, ses homologues bulgares dans les 15 jours et l'Autorité de contrôle chypriote dans les 30 jours. Le Conseil hongrois des marchés publics décide dans les 15 jours s'il n'y a aucune audience et dans les 30 jours si une audience est nécessaire. En Pologne, les commissions de contrôle du Bureau des marchés publics ont 15 jours et le Président a un mois pour prendre une décision ; la complexité de l'affaire peut permettre une prolongation de ces délais. Le Bureau tchèque de protection de la concurrence statue dans les 30 jours et, pour les affaires complexes, dans les 60 jours ; le Conseil national roumain pour la résolution des litiges statue dans les 10 jours et, pour les affaires complexes, dans les 20 jours ; les chambres allemandes des marchés publics statuent normalement sur tous les cas dans un délai de cinq semaines.

Les tribunaux ont normalement besoin de beaucoup plus de temps pour rendre un jugement. Par exemple, la Cour suprême chypriote nécessite 75 jours, les tribunaux régionaux polonais deux ou trois mois, les trois ressorts du tribunal administratif letton deux ans, la Cour du marché finlandaise 6,2 mois en moyenne mais, pour les affaires complexes, environ un an. Les tribunaux civils et administratifs suédois sont particulièrement rapides, puisqu'ils statuent dans un délai d'environ trois à quatre semaines. De même, la haute cour irlandaise statue généralement en quelques semaines.

Il est à noter que, dans certain pays comme la Finlande, la Suède et le Royaume-Uni, il n'y a aucun délai obligatoire pour que les organes compétents statuent, que le recours soit précontractuel ou post-contractuel (demande d'indemnisation des préjudices).

\subsubsection{Effet des réclamations ou des actions}

Les systèmes de contrôle des marchés publics mentionnés dans cette étude peuvent se diviser en deux grands groupes selon que l'action introduite auprès d'un organe de contrôle des marchés publics a un effet suspensif systématique ou non. En Estonie, en Allemagne, en Pologne, en Roumanie et en Slovénie, l'introduction d'une action exerce un effet suspensif systématique sur l'attribution du marché. Dans d'autres États-membres, le soumissionnaire doit saisir le juge des référés comme expliqué ci-dessus dans le chapitre 3,2 .

\subsubsection{Délai suspensif}

Comme décrit ci-dessus, de nombreux États-membres ont introduit un délai suspensif entre la décision d'attribution du contrat et la conclusion réelle du contrat, à l'issue duquel le soumissionnaire ne peut plus que demander l'indemnisation des préjudices. Au cours de ce délai suspensif de 8 à 28 jours dans les Étatsmembres, les soumissionnaires ont la possibilité de contester la décision d'attribution du contrat par une procédure de contrôle. Pour que ce délai suspensif soit efficace, il faut que l'introduction d'une action exerce un effet suspensif (voir ci-dessus, le chapitre 4.2.3.) et que la conclusion d'un contrat au cours du délai suspensif frappe le contrat de nullité et que les délais dans lesquels les juges doivent rendre leur jugement soient fixés. Si, par exemple, le délai suspensif est de 10 jours, que l'introduction d'un recours n'a aucun effet suspensif, que le contrat n'est pas frappé de nullité en étant conclu au cours du délai suspensif 
et que les jugements sont normalement rendus dans les 20 jours (voir ci-dessus, le chapitre 4.2.2.), le délai suspensif n'est alors pas efficace.

\subsubsection{Communication des jugements}

Les soumissionnaires plaignants ou requérants, mais aussi les autorités et entités adjudicatrices doivent être avisés du résultat de la procédure de contrôle. La manière la plus fréquente d'aviser les parties qui forment un recours contre une décision d'attribution de marchés publics auprès d'un organe de contrôle spécialisé ou auprès du tribunal est par courrier régulier dans les États-membres. D'ailleurs, de nombreux organes de contrôle publient leurs décisions et jugements sur leurs propres sites Internet. En outre, il est habituel de publier les jugements/arrêts les plus importants, notamment ceux des instances les plus élevées dans des recueils annuels, journaux, bulletins officiels et dans la presse juridique. Cette pratique peut s'appliquer à tous les jugements concernés ou seulement à une sélection des arrêts les plus importants. En ce qui concerne les tribunaux de première instance en Lituanie, les parties doivent demander une copie de la décision, qui est soumise au paiement d'un droit spécial. Cependant, les parties aux procédures de recours contre une décision relative aux marchés publics apprennent les jugements et décisions par la poste et par des sites Internet et les décisions les plus importantes et d'intérêt plus général sont souvent publiées dans les bulletins officiels ou dans la presse juridique.

\subsubsection{Coûts, frais et dépôts}

Dans de nombreux États-membres, les soumissionnaires qui introduisent une action doivent payer des droits de procédure, effectuer des dépôts et acquitter les honoraires des experts et des avocats. Les règles sur les frais inhérents à la procédure de contrôle varient considérablement dans les États-membres. En outre, ils peuvent varier selon l'organe de contrôle, le recours en question, selon que la valeur du contrat est supérieure ou inférieure aux seuils des directives sur les marchés publics de la CEE et selon que le recours concerne des fournitures, des services ou des travaux. Le seul trait commun à la plupart des Étatsmembres, c'est que la plainte auprès de l'autorité ou de l'entité adjudicatrice elle-même est gratuite. Dans de nombreux États-membres, les organes de contrôle et les tribunaux concernés ne perçoivent aucun frais de justice. Les soumissionnaires courent seulement le risque de devoir payer des coûts supplémentaires pour les honoraires des avocats ou des experts. Dans certains États-membres, il y a des «frais fixes » pour toutes les procédures indépendamment du type ou de la valeur du contrat, à savoir au Danemark (500€ au Comité des plaintes sur les marchés publics), en Finlande (204€) et en Lituanie (30€). En Slovénie, les frais fixes se montent à $420 €$ pour les contrats de fourniture et de prestation de services et à $840 €$ pour les contrats de travaux inférieurs aux seuils des directives sur les marchés publics de la CEE. Ces montants sont doublés pour les contrats d'une valeur supérieure aux seuils. Il y a également différents frais en Hongrie pour les contrats d'une valeur inférieure et supérieure aux seuils des directives. Cependant, dans d'autres États-membres, il faut effectuer un dépôt représentant un certain pourcentage de la valeur du contrat, par exemple $3 \%$ en Estonie, $5 \%$ dans les hautes cours d'Allemagne, $1 \%$ en République tchèque ou $1 \%$ pour une injonction en Bulgarie. Enfin, dans de nombreux États-membres, les frais dépendent généralement de la valeur de contrat, par exemple à Chypre et au Royaume-Uni. Le Bureau polonais des marchés publics requiert des frais d'enregistrement qui dépendent de la valeur du contrat et notamment si sa valeur est supérieure ou inférieure aux seuils des directives sur les marchés publics de la CEE et s'il s'agit d'un contrat de prestation de services, de fourniture ou de travaux. En ce qui concerne les frais de justice et les autres coûts (avocat, voyage, experts, etc.), de nombreux États-membres ont pour règle de mettre tout ou partie des dépens à la charge de la partie perdante y compris ceux supportés par la partie gagnante.

\subsubsection{Formulaire-type pour les marchés publics}

Les organes de contrôle doivent disposer d'un minimum d'informations telles que le nom et l'adresse du demandeur, l'objet du conflit et de l'adjudication, les raisons factuelles et juridiques et les preuves. Par conséquent, les lois/codes des marchés publics de nombreux États-membres stipulent qu'un minimum d'informations obligatoires doit être fourni pour les plaintes et recours. D'ailleurs, il y a des arguments en faveur des formulaires-types obligatoires ou facultatifs pour les plaintes et recours. Il n'y a qu'un petit 
nombre d'informations disponibles sur un formulaire-type obligatoire ou facultatif utilisé dans les procédures de contrôle des marchés publics. Cependant, ces formulaires-types obligatoires ne sont pas exigés dans un grand nombre d'États-membres. Aux Pays-Bas et au Royaume-Uni, il n'y a aucun formulaire-type pour les recours en matière de marchés publics, mais des formulaires généraux pour tous les litiges qui sont également utilisés pour les marchés publics. Aux Pays-Bas, un formulaire-type pour aviser l'autorité adjudicatrice qu'un recours est formé contre elle est également en service, bien qu'il s'agisse d'un formulaire général plutôt que d'un document spécifiquement conçu pour les marchés publics. À Chypre, il existe un formulaire-type pour les recours en matière de marchés publics.

\subsubsection{Le problème de la confidentialité - aperçu}

S'il y a un besoin d'ouverture et de transparence en ce qui concerne les recours auprès des tribunaux et auprès d'autres organes de contrôle des marchés publics, il doit néanmoins permettre d'équilibrer les exigences de confidentialité liées aux secrets d'État, aux secrets industriels ou aux personnes. Par conséquent, de nombreux États-membres intègrent ce besoin de confidentialité dans leur système de recours. Le principe général d'ouverture et de transparence de la procédure de contrôle des actes administratifs n'autorise que des exceptions clairement prescrites et strictement limitées. Dans le champ d'application de ces exceptions, le code de procédure peut permettre des procédures à huis clos (hors de la présence du public), la restriction de l'accès aux documents, ou imposer une obligation de confidentialité aux participants à la procédure. Les questions de la confidentialité peuvent avoir des implications plus larges. Par exemple, si un système de contrôle ne prévoit pas le maintien de la confidentialité, un soumissionnaire peut décider de ne pas introduire d'action afin de ne pas révéler ses secrets industriels.

Le Bureau fédéral autrichien des marchés publics peut prendre toute mesure adéquate pour protéger la confidentialité et les intérêts des parties engagées dans une procédure de passation de marchés, y compris limiter ou prohiber l'accès aux dossiers et aux documents concernés et débattre de l'affaire à huis clos. En Belgique il n'y a aucune possibilité de prendre en considération la nécessité de protéger les informations confidentielles des entreprises, mais selon l'avis d'un auditeur du Conseil d'État, le besoin de protection des informations confidentielles des entreprises peut être pris en compte. En pareil cas, les preuves ne peuvent être présentées qu'au Conseil d'État et pas aux concurrents. Le personnel et les experts externes du Bureau tchèque de protection de la concurrence sont obligés de maintenir la confidentialité sur toutes les questions évoquées au cours de la procédure. Cette obligation ne s'applique pas si ces personnes sont invitées à témoigner devant un tribunal ou des autorités habilitées à enquêter ou à leur fournir des preuves par écrit en vertu du code pénal. Si le Bureau a connaissance d'un fait relevant du secret commercial, il doit adopter toute mesure à même d'éviter une violation. L'exercice du droit du soumissionnaire à consulter la documentation contractuelle est soumis à l'obtention par le Bureau de l'accord de tous les soumissionnaires impliqués. Il y a également des possibilités de procédures à huis clos en Slovénie, mais pas en Estonie et en Pologne. En France, elles sont possibles dans des circonstances exceptionnelles, si elles sont nécessaires pour préserver l'ordre public, le respect de la vie privée ou les secrets protégés par loi (par exemple les contrats avec l'armée). Cependant, les procédures à huis clos sont une possibilité très récemment données aux tribunaux administratifs qui ne s'applique pas facilement dans la pratique. En Finlande, le tribunal peut décider que l'audition ait lieu hors de la présence du public, si nécessaire, dès qu'un document confidentiel est présenté ou dès que certaines informations soumises à un devoir de discrétion sont révélées au cours de l'audience. Les chambres allemandes des marchés publics doivent refuser l'accès aux dossiers de l'affaire afin de protéger les secrets commerciaux ou industriels. Par principe, les auditions du Conseil hongrois des marchés publics se tiennent en séance publique, mais le Conseil peut décider de les mener à huis clos si c'est nécessaire pour des raisons d'État ou pour la protection des secrets commerciaux ou industriels. À quelques exceptions près dues aux secrets industriels et commerciaux, l'accès aux dossiers des marchés publics est entièrement garanti à toutes les parties concernées par la procédure.

Selon le code Lituanien des marchés publics, toutes les informations sont confidentielles si le soumissionnaire ou l'autorité adjudicatrice les considère ainsi et ne peuvent être communiquées à un tiers sans leur consentement, sauf exceptions concernant notamment les activités criminelles. Les recours à huis clos sont possibles pour protéger, si nécessaire, la confidentialité aux Pays-Bas. La cour peut également interdire aux parties de donner des informations sur la procédure pendant et après la procédure. En 
Slovaquie, la supervision est une procédure qui n'est pas ouverte de public et les fonctionnaires ont une obligation de discrétion à l'égard des informations communiquées au cours de la procédure. Cependant, le jugement final est accessible au public, bien que les données susceptibles d'identifier les acteurs soient supprimées. Ces principes s'appliquent aussi aux réclamations. En Slovénie, la procédure tient également compte des besoins de confidentialité des secrets industriels et commerciaux, par exemple par des audiences à huis clos. Cependant, le principe de transparence est primordial et le code de procédure est soumis à la loi sur l'accès public à l'information. Au Royaume-Uni, un requérant peut avoir accès au dossier des marchés publics en vertu de la procédure normale de communication applicable aux actions en justice en Angleterre et au Pays de Galles. Cependant, une demande de confidentialité peut être faite au tribunal afin que les informations ne soient pas révélées en dehors du cadre de la procédure. La décision est prise par le juge. Sinon, le requérant peut demander des informations en vertu du Freedom of Information Act de 2000 (loi sur la liberté de l'information). L'autorité adjudicatrice peut cependant refuser l'accès au dossier en vertu de cette loi si le dossier du marché public a été reçu avec des instructions spécifiques destinées à préserver la nature confidentielle de ces informations qui précisaient que la divulgation des informations concernées constituerait une violation de la confidentialité dont le soumissionnaire concerné pourrait se prévaloir ou que la communication du dossier de marché public serait préjudiciable à l'intérêt commercial d'une autre personne.

\subsubsection{Rôle des experts dans le procédures de contrôle}

Dans tous les États-membres, les juges sont généralement des avocats y compris ceux des organes de contrôle spécialisés dans les marchés publics. Néanmoins, il y a dans certains cas un besoin d'expertise spécialisée qui n'est pas de nature juridique pour les recours liés aux marchés publics. Cette expertise comprend les finances, l'ingénierie, la gestion et la technologie. L'adaptation à cette nécessité consiste à intégrer ces experts dans les chambres des tribunaux ou dans les commissions à titre de juges nonprofessionnels. L'audition d'experts indépendants à titre de preuve est aussi une autre possibilité au cours de la procédure. Cependant, requérir l'avis d'experts nécessite plus de temps et d'argent.

En Allemagne, des experts techniques et autres sont impliqués dans la procédure de contrôle en qualité de membres des chambres des marchés publics. En particulier, un des trois membres de la chambre est toujours un membre honoraire associé doté de plusieurs années d'expérience des marchés publics. Selon le code des marchés publics autrichien, les intervenants de la chambre de recours du Bureau fédéral des marchés publics sont des experts des marchés publics et sont nommés par des soumissionnaires et des entités adjudicatrices.

Ces experts peuvent être notamment entendus dans les organes de contrôle autrichiens, estoniens, français et hongrois. Dans les tribunaux belges c'est toujours le juge qui nomme les experts. Les coûts sont avancés par la partie intéressée mais sont finalement payés par la partie perdante. C'est également le principe pour les honoraires des experts dans les procédures de recours devant la Commission bulgare de protection de la concurrence, devant les tribunaux néerlandais, devant les organes de contrôle roumains et devant les tribunaux du Royaume-Uni. Dans les procédures devant le Bureau tchèque de protection de la concurrence, la participation des experts (avocats ou interprètes) peut être décidée par la Section Achat en coopération avec la Section Économique, si cela s'avère nécessaire. Les coûts experts sont financés par un budget spécial du Bureau. C'est également le cas pour les procédures devant le Comité danois des plaintes relatives aux marchés publics, la Commission d'appel du département maltais des contrats et le Bureau slovaque des marchés publics.

\section{Le contexte et la culture du contrôle des actes administratifs en matière de marchés publics}

La notion de « contexte et de culture du contrôle des actes administratifs en matière de marchés publics » des États-membres comprend diverses questions concernant le fonctionnement pratique du système.

En premier lieu, cette notion se rapporte au personnel impliqué dans la procédure de contrôle. Les aspects étudiés comprennent le niveau général de connaissance de la loi relative aux marchés publics et du droit communautaire qu'ont les juges et juges non-professionnels et leur connaissance des procédures des marchés publics ainsi que les considérations techniques et financières impliquées. En outre, les attitudes à 
l'égard de l'intérêt public d'une part et les intérêts privés des soumissionnaires de l'autre et leur équilibre sont des aspects importants qui influent sur l'issue des procédures.

En deuxième lieu, cette culture se rapporte aux soumissionnaires qui demandent un contrôle de légalité des décisions relatives aux marchés publics. Les aspects concernés sont la connaissance du contexte juridique, financier et administratif de la procédure de passation des marchés publics. De plus, l'attitude générale à l'égard de la procédure de contrôle des actes administratifs revêt ici de l'importance. Elle peut aller du souci de «ne pas mordre la main qui nourrit » à celui d'adopter un comportement sécuritaire en poursuivant. Cette attitude générale influe sur le nombre de réclamations couronnées de succès.

En troisième lieu, la culture du contrôle des actes administratifs se rapporte aux autorités et entités adjudicatrices qui sont confrontées à ces recours. Les aspects comprennent leur connaissance du fondement juridique des marchés publics et leur attitude à l'égard des soumissionnaires qui déposent une plainte ou introduisent un recours contre des décisions relatives aux marchés publics.

En quatrième lieu, cette notion se rapporte aux avocats qui conseillent et représentent à la fois les soumissionnaires et les autorités ou entités adjudicatrices dans la procédure de contrôle. Les aspects comprennent en particulier leur connaissance du droit communautaire et de la loi relative aux marchés publics.

En cinquième lieu, la notion se rapporte aux responsables politiques des gouvernements et aux parlementaires. Les aspects comprennent les politiques gouvernementales qui font connaître les systèmes de contrôle et de recours ou les procédures qui font l'objet de débats parlementaires.

En sixième lieu, cette notion se rapporte au contrôle des autres acteurs et à l'exercice d'une pression par la société civile. La question est ici de savoir s'il y a des associations ou organismes qui ont un intérêt spécifique pour les systèmes de contrôle et de recours. Cet intérêt peut exercer un effet immédiat sur l'efficacité du système. Par exemple, une association peut payer les frais de justice et autres coûts inhérents aux procédures afin de créer des précédents. Les acteurs possibles sont ici des ONG comme les chambres de commerce, des associations des industries du bâtiment ou des mouvements de lutte contre la corruption.

\subsection{Formation}

La question cruciale posée par la connaissance des juges et des membres des commission qui statuent dans les affaires relatives aux marchés publics, des soumissionnaires formant un recours, des responsables des adjudications des autorités et entités adjudicatrices et des avocats qui les informent et les représentent dans les procédures est de savoir si une formation au droit communautaire, au système de contrôle et de recours ainsi qu'à la technique, à l'économie et aux finances liées aux marchés publics est disponible dans les États-membres En outre, la question de savoir si ces sources de formation et d'information sont utilisées dans la pratique est importante. Les sources appropriées de formation et d'information sont les universités d'économie et de droit, la formation prodiguée par les bureaux de marchés publics, par les différents ministères et écoles nationales d'administration, les cours de formation du secteur privé, de l'UE et d'autres organismes internationaux ainsi que les informations obtenues lors de séminaires et conférences, congrès nationaux de syndicats ou fédérations professionnelles, revues universitaires et juridiques, sites Internet.

Un éventail très large de possibilités de formation pour les juges, avocats, soumissionnaires et responsables des adjudications est offert dans tous les États-membres, bien qu'avec des différences significatives en termes d'ampleur et de mode d'organisation de la formation d'un pays à l'autre. Dans certains Étatsmembres, les études de droit comprennent l'étude du code des marchés publics dans le cadre du droit administratif ou du droit communautaire ; il y a des livres, des sites Internet et des journaux spécialisés dans les marchés publics, des associations nationales dédiées aux marchés publics et des recherches dans ce domaine. En France, en Allemagne et au Royaume-Uni, il existe des programmes de troisième cycle de droit public et des instituts de recherche de sciences économiques et politiques sont spécifiquement consacrés aux marchés publics. Une partie de la formation sur les marchés publics est dispensée par les institutions privées en coopération avec des universités et des institutions publiques et des conférences et séminaires sont organisés par des associations nationales ou régionales de marchés publics.

Dans certains États-membres, il n'y a ni cursus universitaire ni université ni centre privé de formation sur les marchés publics et il n'y a aucun journal ou association nationale. Il y a cependant quelques séminaires 
et conférences sur les marchés publics. Il est intéressant de noter que les avocats luxembourgeois et les autorités adjudicatrices tirent parti des possibilités de formation de la Belgique, de la France et de l'Allemagne.

Dans d'autres États-membres, le bureau central de marchés publics joue un rôle considérable dans la formation aux marchés publics.

Cependant, tous les États-membres ont signalé que la plupart des juges, soumissionnaires, et responsables des adjudications, qui représentent la source principale de compétence dans le domaine, acquièrent leur connaissance des marchés publics par l'expérience « sur le tas », c'est-à-dire par un apprentissage actif.

\subsection{Attitudes et crédibilité liées aux procédures de contrôle des actes administratifs}

L'autre question posée par la culture du contrôle des actes administratifs et des recours dans les Étatsmembres est l'attitude des soumissionnaires, des responsables des adjudications et des juges à l'égard des recours.

Dans de nombreuses juridictions, les soumissionnaires n'envisagent de mener une action qu'en dernier ressort. C'est ce qu'ont dit l'Autriche, la République tchèque, le Danemark, la Finlande, l'Allemagne, le Luxembourg et la Roumanie. Cette même réticence s'applique aussi à certains soumissionnaires en Hongrie, au Portugal et en Slovaquie.

Cependant, d'autres considérations incitent les soumissionnaires à introduire une action ou à s'abstenir de le faire. Par exemple, certains soumissionnaires ne souhaitent entreprendre aucune action parce qu'ils ne veulent pas compromettre leurs chances d'obtenir un prochain contrat.

D'ailleurs, de nombreux États-membres rapportent que, fréquemment, le seul but du soumissionnaire plaignant est de faire obstruction au marché public par son action. En Slovaquie, certains soumissionnaires «n'hésitent pas à entreprendre toutes les procédures possibles pour obtenir l'attribution du contrat, même au prix de la détérioration consécutive des relations avec l'autorité adjudicatrice impliquée. »

En outre, certains soumissionnaires cherchent à obtenir des gains financiers par la procédure en essayant de réaliser un bénéfice à partir d'un contrat qui ne leur a pas été attribué. Selon l'Allemagne, le Portugal et la Slovaquie, ce fait se produit avec un nombre restreint de soumissionnaires.

Les niveaux précis de coût ne sont pas disponibles pour cette étude. Néanmoins, certains soumissionnaires semblent découragés d'introduire une action en raison des frais de justice de la haute cour et des coûts généraux élevés (honoraires d'avocat) ou, dans certains cas, en raison de longue durée de la procédure.

L'attitude des juges et des membres des commissions des organes de contrôle à l'égard des intérêts privés des soumissionnaires formant un recours et de l'intérêt public est généralement décrite comme juste et équilibrée.

L'attitude des autorités adjudicatrices varie considérablement en fonction des États-membres. En Autriche, il y a une certaine réserve à l'égard des procédures de contrôle qui retardent l'exécution du contrat, mais il y a également une acceptation générale puisqu'elles donnent une assurance de la légalité des actes administratifs. La Belgique suppose que les responsables des adjudications sont plutôt opposés à la procédure et, en Pologne, ils ne les «encouragent pas ». D'autres États-membres rapportent une image plus positive : leur attitude est jugée «équitable » en République tchèque, «normalement équitable » en Suède, «neutre » en Estonie et en Lettonie, «équilibrée » en Allemagne et «principalement positive » en France. Les responsables des adjudications irlandais et leurs supérieurs qui reçoivent les plaintes des soumissionnaires plaignants ou formant un contrôle juridictionnel contre des décisions d'attribution de marchés publics ont été décrits comme généralement très sûrs de leurs procédures et disposés à les défendre. Il y a « un sens général de respect et de conscience des droits légaux concernant les plaintes et l'équité des procédures à l'égard des soumissionnaires » au Portugal. En Slovénie, les responsables des adjudications et leurs supérieurs sont conscients que les soumissionnaires peuvent en permanence requérir une protection légale. Généralement, ils ne tiennent pas grief à un plaignant mais sont néanmoins opposés aux recours en matière de marchés publics. Le Royaume-Uni rapporte que les responsables des adjudications doivent agir conformément à la réglementation des marchés publics et équitablement et 
raisonnablement en respectant les principes ordinaires de droit public. Toute plainte doit être traitée conformément à ces règles et principes.

\subsection{Fonctionnement pratique des systèmes de recours}

Le fonctionnement pratique du système de recours est une question cruciale posée par la culture du contrôle des actes administratifs et des recours dans les États-membres. Il comprend la fréquence d'utilisation du système de recours par les soumissionnaires, les appels des jugements de première instance en deuxième ou troisième instance, la réussite et la satisfaction des soumissionnaires à l'issue des procédures et le succès réel des recours dans la pratique. Plusieurs de ces aspects sont difficiles à apprécier. Cependant, le nombre de plaintes, d'actions et d'appels peut être interprété comme un indice de la confiance à l'égard du système de contrôle et de recours. Très rares sont les affaires examinées par les organes de contrôle qui indiquent un manque de confiance ou de crédibilité, des coûts trop élevés, des juges polarisés sur l'intérêt public, ou d'autres défauts du système de contrôle comme le temps accordé et/ou les délais stricts pour introduire un recours, l'auto-restriction des soumissionnaires pour des motifs économiques ou l'absence d'une culture de la contestation. De plus, il peut également indiquer que la plupart des contrats des marchés publics sont conclus légalement et que les procédures de contrôle des actes administratifs ne sont donc simplement pas nécessaires. La multiplication des recours peut indiquer que de nombreux contrats sont illégaux, mais aussi refléter simplement une société très litigieuse ou des intérêts économiques [liés à d'importants investissements (financés par des fonds de l'UE) qui sont lancés dans de nouveaux États-membres après la date de l'adhésion]. $50 \%$ des 24 États-membres qui ont retourné le questionnaire ont également fourni des chiffres sur le fonctionnement pratique du système, à savoir l'Autriche, la République tchèque, l'Estonie, la Finlande, la France, l'Allemagne, la Hongrie, l'Irlande, la Lettonie, la Pologne, la Roumanie, la Slovaquie et la Suède. Ces chiffres ont un intérêt et des précisions variables mais fournissent une synthèse limitée d'un nombre représentatif des États-membres. Pour plus d'informations sur les chiffres du système en usage dans les États-membres, référence peut être faite au rapport d'évaluation d'impact préparé par la Commission au cours de l'année 2002 Ce rapport (sec (2006) 557) est disponible sur Internet à l'adresse :

http://ec.europa.eu/internal_market/publicprocurement/remedies/remedies_en.htm.

En qualité d'organe de contrôle principal au niveau fédéral, le Bureau fédéral autrichien des marchés publics instruit environ 200 demandes par an (un total d'environ 1100 requêtes entre le 1er septembre 2002 et le 31 décembre 2005). Sur les 723 décisions prises au cours de cette période, 52 ont fait l'objet d'un appel à la Cour constitutionnelle fédérale et 30 devant la Cour administrative suprême. Seuls neuf jugements n'ont pas été pleinement confirmés.

Le Bureau tchèque de protection de la concurrence a enregistré 334 recours en 2005, 184 sur requête des soumissionnaires et 152 à l'initiative du Bureau. Il y a eu 228 décisions dont 104 procédures terminées et 64 qui se sont soldées par des pénalités pour les entités adjudicatrices concernées.

281 réclamations ont été faites au Bureau estonien des marchés publics (PPO) en 2005, sur un total de 7569 adjudications. Sur ces dernières, 65 n'ont pas fait l'objet d'une décision, 67 ont répondu aux exigences procédurales, 52 n'ont pas répondu aux exigences procédurales, 66 ont été admises par l'autorité adjudicatrice, 28 ont été retirées et, dans seulement quatre cas, le Bureau a décidé d'annuler la procédure d'attribution. La fréquence des recours contre des décisions relatives aux marchés publics par le Bureau à titre d'organe principal de contrôle est de $4 \%$.

En 2005, environ 500 plaintes ont été déposées contre les décisions relatives aux marchés publics des entités adjudicatrices finlandaises et la Cour du marché a statué sur 206 affaires. Sur ces affaires, $26 \%$ ont été approuvées, $33 \%$ rejetées, $8 \%$ annulées et $33 \%$ ont expiré.

Le nombre d'affaires portées (y compris les litiges liés à l'exécution des contrats) devant les tribunaux administratifs français a augmenté depuis 2001 : en première instance, 4365 affaires en 2001 contre 4627 en 2002, 4743 en 2003 et 5048 en 2004 ; en seconde instance, 499 affaires en 2001, 683 en 2002, 724 en 2003 et 755 en 2004 ; devant le Conseil d'État, dernier ressort, 165 cas en 2001, 128 en 2002, 180 en 2003 et 133 en 2004. Il faut cependant souligner que la plupart de ces affaires concernent l'exécution des contrats qui est régie par le droit français et ne sont pas liées aux procédures d'adjudication. 
Concernant les décisions précontractuelles, le nombre de décisions prises, totalement ou partiellement, en faveur du requérant est sensiblement plus élevé que celui des décisions de rejet des requêtes. En 2004, 2538 décisions favorables ont été prononcées par des tribunaux administratifs en première instance contre 1515 demandes rejetées. Les appels devant les tribunaux administratifs d'appel et le Conseil d'État ont eu un résultat négatif. La raison de la confirmation par la plus haute instance des décisions rendues en première instance est l'attention particulière prêtée par les juges administratifs à l'égard des soumissions et des obligations contractuelles des autorités adjudicatrices. Le nombre de référés précontractuels devant des tribunaux administratifs de première instance a aussi augmenté depuis $2000: 149$ demandes en 2000, 173 en 2001, 265 en 2002, 290 en 2003, 474 en 2004. Cette hausse prouve que les attributions de marchés publics entachées d'irrégularités peuvent être corrigées rapidement et facilement et que l'application du jugement d'Alcatel concernant le délai suspensif a permis de former des recours plus efficaces. En 2004, 139 décisions des tribunaux administratifs ont partiellement ou totalement accédé à la demande des requérants et il y a eu 174 décisions de rejet. D'ailleurs, le chiffre de 139 comprend également des décisions partiellement favorables condamnant l'entité adjudicatrice à ne payer que de très petites sommes.

En 2004, il y a eu 1493 demandes devant les chambres allemandes de marchés publics et 314 réclamations immédiates devant les hautes cours des Länder. La plupart des décisions du Conseil hongrois des marchés publics ne sont pas contestées devant les tribunaux. Il semble qu'en Irlande, la plupart des plaintes soient abandonnées avant qu'elles ne fassent l'objet d'une décision et les autorités adjudicatrices sont généralement préparées à défendre leurs procédures.

Il y a eu plus de 200 plaintes par an au Bureau letton de contrôle des marchés publics au cours des dernières années, dont $70 \%$ se sont révélées infondées. Dans $30 \%$ des affaires, le Bureau interdit la conclusion du contrat s'il identifie que des violations peuvent influer sur la décision d'attribution des marchés publics. Les raisons de l'issue des plaintes comprennent spécialement l'attitude partiale des autorités adjudicatrices à l'égard des soumissionnaires et les spécifications techniques restrictives. Environ 10 à 18 décisions du Bureau font l'objet d'un appel auprès des tribunaux chaque année. Bien que la majorité des affaires ne soient pas résolues, le résultat correspond presque toujours à la décision précédente du Bureau.

Environ 60 à 70 affaires ont été jugées par les organes de contrôle luxembourgeois entre 1997 et 2005. En 2005, les décisions du Bureau polonais des marchés publics ont fait l'objet de 4094 appels dont 308 ont été retirés, 1714 confirmés, 1226 annulés, 440 rejetés et 406 non examinés en raison du défaut de paiement des droits d'enregistrement. En 2005, 506 requêtes ont été faites auprès des tribunaux régionaux polonais. Seulement $12,5 \%$ des jugements ont eu comme conséquence l'annulation des décisions prises par le Bureau

Les tribunaux administratifs sont les principales instances de recours en matière de marchés publics en Suède. 1280 affaires ont fait l'objet d'un recours en 2005 dont la grande majorité auprès des tribunaux administratifs. Très peu d'affaires concernent des soumissionnaires citoyens d'autres États-membres, mais la plupart des entreprises internationales ont une filiale suédoise. Moins de $1 \%$ de tous les contrats de marchés publics a donné lieu à des réclamations. Environ $30 \%$ des jugements ordonnent à l'autorité ou entité adjudicatrice de rectifier (13\%) ou de recommencer (17\%) la procédure. De nombreuses affaires ne donnent pas lieu à un jugement parce que l'autorité ou l'entité adjudicatrice a mis fin à la procédure ou l'a rectifiée ou a déjà signé le contrat. La plupart des recours concernent le processus d'évaluation.

En 2005, le Bureau slovaque des marchés publics a reçu 1089 réclamations dont 83 de l'étranger et 108 concernant des contrats d'une valeur supérieure aux seuils de la CEE (en hausse de $50 \%$ par rapport à 2004). Le Bureau a pris 500 décisions de fond sur des requêtes précontractuelles et neuf décisions postcontractuelles (conformément à la loi de 2006 sur les marchés publics, une réclamation n'est plus recevable après la conclusion du contrat). Sur ces décisions, $44 \%$ étaient en faveur des requérants et $56 \%$ des requêtes ont été rejetées car elles étaient infondées. Pour 578 réclamations déposées, la procédure a été interrompue. 18 décisions du Bureau ont été contestées auprès des tribunaux. La surveillance s'est principalement concentrée sur l'utilisation illégale de la procédure négociée sans notification préalable. Sur 856 attributions de marchés publics, 489 violations diverses de la loi ont été enregistrées. En 2005, des amendes ont été infligées à 21 autorités adjudicatrices et à une entité adjudicatrice. En 2005, les auditions dans la plupart des affaires en cours de jugement avaient débuté en 2004. 30 jugements du tribunal de 
première instance ont été rendus au Bureau et, dans 25 affaires, le recours (accusation) a été rejeté ou la procédure a pris fin. Pour trois décisions sur cinq qui n'étaient pas en sa faveur, le Bureau a fait appel auprès d'un tribunal de deuxième instance. Les décisions de première instance en faveur du Bureau ont fait l'objet de 11 appels auprès d'un tribunal de deuxième instance dont dix ont été en faveur du Bureau.

Alors que tous les États-membres n'ont pas communiqué de données sur le fonctionnement de leur système de contrôle et de recours national et que les données envoyées par certains États-membres sont incomplètes, que les marchés publics, les traditions juridiques et l'envergure des États-membres diffèrent énormément, un certain nombre de remarques générales peuvent néanmoins être faites sur le fonctionnement des procédures en matière de marchés publics et des systèmes de recours dans la pratique.

Seul dans un nombre limité de cas, les soumissionnaires et parfois d'autres acteurs font appel de la décision des organes de contrôle de première instance auprès des tribunaux de deuxième et troisième ressort.

\subsection{Société civile}

La participation de la société civile sous la forme de groupes de pression ou d'ONG dans les recours relatifs aux marchés semble être plutôt limitée dans la plupart des États-membres. De nombreux Étatsmembres disent n'avoir aucune association dédiée aux marchés publics. Les associations dédiées aux marchés publics existent au moins en France, en Allemagne, en Hongrie, en Irlande et aux Pays Bas. D'ailleurs, dans de nombreux États-membres, les chambres de commerce couvrent les marchés publics.

Les sections nationales de Transparency International ont été mentionnées par la Bulgarie, la République tchèque, la Lituanie, la Slovaquie et le Royaume-Uni. Les autres organismes concernés sont les fédérations d'industrie, des associations spécialisées de l'industrie du bâtiment, d'architectes, des syndicats de PME, des associations sectorielles spécifiques, des groupes environnementaux et des groupements de collectivités locales. Bien que l'intérêt principal de ces collectivités locales consiste à influer sur les lois relatives aux marchés publics, elles prodiguent souvent une formation et organisent des conférences. Elles informent également leurs électeurs sur les marchés publics en général et donnent à divers degrés des conseils sur les procédures de recours.

La presse et la télévision couvrent souvent les procédures relatives aux marchés publics en Bulgarie, en République tchèque et en Slovénie et de temps en temps en France et au Royaume-Uni. Les médias danois manifestent un intérêt croissant à cet égard mais les médias finlandais n'y accordent aucune attention particulière.

\section{Conclusions}

La plupart des pays de cette étude semblent avoir un système fonctionnel de contrôle des marchés publics et de recours doté d'organes spécialisés de contrôle des actes administratifs, de tribunaux civils et administratifs ou des deux. La plupart des États-membres donnent la possibilité de faire appel auprès d'une deuxième, voire d'une troisième instance. Non seulement les organes de dernière instance mais toutes les instances de recours remplissent les conditions d'une juridiction comme établies par la Cour européenne de justice. Il $\mathrm{y}$ a des systèmes de contrôle uniques et des systèmes doubles auprès des tribunaux civils et administratifs ; en règle générale, les demandes d'indemnisation sont présentées auprès d'autres tribunaux que les autres requêtes. Les soumissionnaires lésés ont la possibilité ou l'obligation de se plaindre directement à l'entité adjudicatrice avant ou au moment où ils soumettent leur affaire au contrôle juridictionnel ou quasi-juridictionnel.

Le champ d'application des systèmes de contrôle et de recours en matière de marchés publics des Étatsmembres de cette étude couvrent toujours des contrats de valeur supérieure aux seuils des directives sur les marchés publics de la CEE. Dans de nombreux pays, le système s'applique également aux contrats d'une valeur inférieure à ces seuils. Cependant, certains États-membres ont un système de contrôle différent et souvent plus élémentaire ou limité pour ces marchés publics. De nombreux pays ne différencient pas les autorités adjudicatrices et les opérateurs de services d'utilité publique, tandis que d'autres possèdent différents organes de contrôle, règles de procédure et recours pour les marchés de ces derniers. D'ailleurs, la nature publique ou privée d'un opérateur de services d'utilité publique peut impliquer des différences. 
Les systèmes nationaux permettent l'annulation de différentes décisions prises au cours d'une procédure de passation de marchés, y compris la décision d'attribution du contrat. L'annulation d'un contrat signé est seulement possible, le cas échéant, au prix de conditions strictement définies qu'il est difficile de réunir. Par conséquent, afin de permettre à des soumissionnaires de contester l'attribution d'un contrat, en raison de la jurisprudence d'Alcatel, la plupart des États-membres ont introduit un délai suspensif entre le moment de l'attribution du marché et la conclusion du contrat. Les États-membres prennent également des mesures provisoires en attendant la décision finale, et, dans certain pays, l'introduction d'une action exerce un effet suspensif systématique sur la procédure de passation de marchés. Tous les États-membres semblent permettre l'indemnisation des préjudices. Les recours sont disponibles à des conditions à peu près comparables.

Si l'attitude des juges et des autres commissions de contrôle à l'égard des intérêts impliqués dans les procédures est décrite comme juste et équilibrée, l'attitude des soumissionnaires formant un recours varie considérablement d'une juridiction à l'autre. Dans de nombreux pays, les soumissionnaires considèrent les procédures comme le dernier recours pour imposer leurs intérêts légitimes ou une solution équitable et pour remédier à des erreurs. Cependant, dans certaines juridictions, quelques soumissionnaires abusent du système afin de faire obstruction aux procédures des marchés publics ou éliminer des concurrents du marché concerné. Plusieurs systèmes de contrôle essaient d'empêcher cet abus par des délais, des limitations du statut légal, des frais de justice, des dépôts et parfois même par des pénalités pour des requêtes frivoles.

Le droit communautaire exige que les systèmes de contrôle et de recours des États-membres permettent des recours rapides et efficaces. $\mathrm{Si}$, dans la plupart des pays de cette étude, tous les recours, y compris l'indemnisation des préjudices, sont disponibles dans des délais raisonnables, dans certains Étatsmembres, l'indemnisation des préjudices ou l'annulation d'un contrat conclu peut requérir des années. C'est rarement dû aux délais mais plutôt à la charge de travail de l'organe de recours en question et parfois au comportement des parties, par exemple quand elles échangent des mémoires pendant des mois ou même des années. L'efficacité est un problème plus complexe. Elle comprend l'accès des soumissionnaires au système, la satisfaction des soumissionnaires à l'égard du système, la disponibilité des recours appropriés pour les préjudices subis en raison des violations de la loi et, probablement, la transparence et même de la simplicité générale du système. L'efficacité du système de contrôle et de recours est notamment accrue par un large champ d'application, une claire attribution des affaires entre les organes de contrôle et des règles sur le statut, les frais de justice et les dépôts raisonnables (ou non), un accès aux mesures provisoires ou un effet suspensif systématique lors de l'introduction d'une action, des possibilités d'appel des décisions prises en première instance, des juges et des membres des commissions bien informés et équitables, une communication ouverte des décisions, une possibilité d'adapter la procédure à la confidentialité et une participation des experts. Les systèmes de contrôle et de recours en matière de marchés publics de la plupart des pays de cette étude ont mis en place un ou plusieurs de ces éléments. 


\section{ANNEXE : RAPPORTS NATIONAUX INDIVIDUELS SUR LES SYSTÈMES DE CONTRÔLE ET DE RECOURS EN MATIÈRE DE MARCHÉS PUBLICS DANS LES ÉTATS-MEMBRES}

\section{Autriche}

Le système autrichien de contrôle et de recours en matière de marchés publics se fonde sur un double système de contrôle juridictionnel par l'intermédiaire d'un organe de contrôle spécialisé dans les marchés publics dont les décisions peuvent faire l'objet d'un appel auprès de la Cour administrative suprême ou auprès de la Cour constitutionnelle et des tribunaux de droit commun qui instruisent les demandes d'indemnisation des préjudices. Le système s'applique aux pouvoirs publics et aux opérateurs de services d'utilité publique ainsi qu'aux contrats d'une valeur supérieure et inférieure aux seuils de la CEE. Les changements récents les plus importants comprennent l'application de la loi sur les marchés publics (1993), l'introduction de la loi d'uniformisation des marchés publics (2002), l'extension du système spécifique de contrôle des marchés publics aux contrats de valeur inférieure aux seuils de la CEE et la réglementation des délais de forclusion pour le dépôt des plaintes. Une version plus ancienne de la loi concernée peut être trouvée sur www.ris.bka.gv.at.

\subsection{Réclamation auprès de l'autorité adjudicatrice}

La gestion des réclamations et des plaintes contre les décisions relatives aux marchés publics fait partie de l'organisation interne de l'autorité adjudicatrice et n'est donc pas régie par la loi fédérale sur les marchés publics (BVergG). Il n'y a aucune obligation légale d'informer l'autorité adjudicatrice avant d'introduire une action et aucun texte ne réglemente les plaintes aux autorités et entités adjudicatrices en Autriche.

\subsection{Contrôle juridictionnel}

Selon le système fédéral établi dans la constitution fédérale autrichienne, il y a dix organes de contrôle différents pour faire appel des décisions des entités adjudicatrices. Par conséquent, les procédures à suivre sont définies dans neufs lois des différents Länder de la fédération sur les procédures de contrôle des marchés publics au niveau régional ou municipal (Landesvergabekontrollgesetze) d'une part et le BVergG d'autre part. Comme les lois des Länder sont dans une large mesure harmonisées avec le BVergG, la description suivante est axée sur les réglementations au niveau fédéral. Le fait que le système fédéral donne naissance à dix organes de contrôle différents qui appliquent le BVergG est considéré comme le principal inconvénient du système autrichien. Le BVergG prévoit un seul système de contrôle au niveau fédéral qui est confié à un tribunal administratif spécial indépendant et conforme aux exigences des directives «recours » de la CEE et à l'article 6 de la Convention européenne des droits de l'homme (CEDH). Le Bureau fédéral des marchés publics (Bundesvergabeamt- BVA, Praterstraße 31, 1020 Wien, www.bva.gv.at) fait partie du système de contrôle juridictionnel comme l'établit la constitution fédérale et se compose de juges administratifs indépendants (nommés d'abord pour un mandat de trois ans et bénéficiant ensuite d'une possibilité de nomination à vie) et de juges non-professionnels nommés sur un pied d'égalité pendant une certaine période sur proposition des autorités adjudicatrices et des soumissionnaires. Les décisions de ce Bureau sont généralement rendues dans les tribunaux appelés « chambres » qui se composent d'un juge administratif et de deux juges non-professionnels. Ce Bureau a les pouvoirs légaux requis par les directives (annulation des décisions des autorités adjudicatrices, mesures provisoires). Selon le BverG, ce Bureau a les compétences pour assurer la protection juridique des soumissionnaires pendant la phase précontractuelle (c'est-à-dire avant la signature du contrat) de la procédure de passation de marchés et doit statuer dans un délai de six semaines. Après l'attribution du contrat, la compétence de ce Bureau se limite à déclarer la conformité ou la non-conformité de la procédure de passation de marchés avec le BVergG. Cette déclaration constitue une condition essentielle et, par conséquent, le fondement des demandes d'indemnisation de préjudices devant les tribunaux civils. Les décisions de ce Bureau sont publiées sur Internet (voir le http://www.bva.gv.at)_et peuvent être contestées devant la Cour administrative suprême et la Cour constitutionnelle à Vienne (voir le http://www.vwgh.gv.at et http://www.vfgh.gv.at, Judenplatz 11, 1010 Wien). Le BVergG réglemente l'organisation et la structure interne de ce Bureau selon l'article 6 de la CEDH. L'indépendance des juges administratifs (membres permanents-Senatsvorsitzende) est garantie par le droit constitutionnel. Les 
membres permanents sont nommés par le président fédéral de l'Autriche ; le président et le présidentadjoint sont nommés à vie. Il faut posséder certaines qualifications pour être nommé au Bureau (connaissance spécifique des marchés publics et expérience juridique). Le président, le président-adjoint et les membres permanents doivent être des avocats dotés d'au moins cinq ans d'expérience professionnelle en qualité d'avocat ou au moins cinq ans d'expérience professionnelle dans les marchés publics. Le Bureau, la Cour administrative suprême et la Cour constitutionnelle remplissent les conditions de l'arrêt Dorsch et Salzmann. Le Bureau a statué dans 208 affaires sur 285 en 2003, 195 sur 266 en 2004 et 183 sur 257 en 2005. Entre le 1er septembre 2002 et le 31 décembre 2005, le Bureau a traité 1092 des 1126 requêtes. Sur les 723 décisions prises au cours de cette période, 52 ont fait l'objet d'un appel à la Cour constitutionnelle fédérale et 30 devant la Cour administrative suprême. Seuls neuf jugements n'ont pas été pleinement confirmés. Selon le système fédéral établi dans la constitution autrichienne, il y a dix organes de contrôle différents ou tribunaux administratifs (Unabhängige Verwaltungssenate dans sept Länder) ou tribunaux spécialisés dans les recours en matière de marchés publics (dans deux Länder et au niveau fédéral). La liste de ces organes figure sur http://www.bka.gv.at/DesktopDefault.aspx?TabID=5100\&Alias=bka. Les organes de contrôle des actes administratifs ont été institués par la Constitution fédérale (BundesVerfassungsgesetz), une loi (Bundesvergabegesetz) et les constitutions (Landesverfassungen) et les lois (Landesvergabekontrollgesetze) des différentes Länder de l'Autriche.

\subsection{Autre règlement des litiges}

Deux Länder, à savoir Carinthie (Kärnten) et Basse Autriche (Niederösterreich) ont mis en place des organes alternatifs de règlement des différends. Les règles sont établies, respectivement, dans le Kärntner Vergaberechtsschutzgesetz (loi carinthienne de protection des marchés publics http://www.bka.gv.at/2004/4/20/kaernten-vergabe.doc) ethttp://www.bka.gv.at/2004/4/20/kaerntenvergabe.doc le NÖ Vergabe-Nachprüfungsgesetz (loi de Basse Autriche sur les recours en matière de marchés publics http://www.bka.gv.at/2004/4/20/noe-vergabe.pdf).

\subsection{Recours}

Toute décision sur les marchés publics visée dans l'article 2 du $\S 16$ du BVergG et rendue avant la conclusion d'un contrat peut être contestée devant le Bureau des marchés publics (« décision séparément attaquable »). Toute autre décision préalable à la conclusion d'un contrat et non visée dans cet article peut être contestée conjointement à une décision précédente visée et donc attaquable. L'éventail des décisions séparément attaquables couvre toutes les décisions fondamentales qu'une entité adjudicatrice peut prendre avant la conclusion du contrat (avis, documents contractuels, présélection des candidats, élimination d'offres, décision d'attribution, etc.). Le Bureau a le pouvoir d'annuler les décisions des autorités adjudicatrices et de prendre des mesures provisoires pendant la phase précontractuelle. Après l'attribution du contrat, la compétence de ce Bureau se limite à déclarer la conformité ou la non-conformité de la procédure de passation de marchés avec le BVergG. Cette déclaration constitue une condition essentielle et, par conséquent, le fondement des demandes d'indemnisation des préjudices devant les tribunaux civils. Si une autorité adjudicatrice attribue directement un marché en violation évidente de la loi, le Bureau peut annuler le contrat lui-même et c'est la seule circonstance dans laquelle il peut le faire. Les compétences du Bureau sont régies par l'article 312 du BVergG et les procédures par les articles 320à 327 (annulation des décisions), articles 328 à 330 (mesures provisoires) et articles 331-334 (déclaration sur la conformité). L'annulation ou la suspension d'un contrat attribué ne peut être décidée que par les tribunaux civils sur le fondement du droit civil. Jusqu'ici, un tel cas ne s'est jamais produit dans la pratique. Le dépôt d'une plainte n'a en principe aucun effet suspensif. Le plaignant doit demander des mesures provisoires. Seulement dans certains cas (énumérés dans le BVergG), la demande de mesures provisoires a un effet suspensif (ouverture des offres, la passation d'un contrat et le retrait de la procédure). Le Bureau peut prendre toute mesure provisoire demandée par un opérateur économique si c'est approprié et nécessaire pour empêcher la survenue de préjudices en suspens (voir l'article $328 \mathrm{BVergG}$ ). Le tribunal ou tout autre organe de contrôle des actes administratifs peut tenir compte des conséquences probables des mesures provisoires pour tous les intérêts susceptibles d'être lésés, y compris l'intérêt public, et décider de ne pas prendre de telles mesures si les conséquences négatives l'emportent sur les conséquences positives. L'indemnisation des préjudices est régie par l'Allgemeines Bürgerliches Gesetzbuch (ABGB, code civil). Après l'attribution du contrat, la compétence de ce Bureau se limite à déclarer la conformité ou la nonconformité de la procédure de passation de marchés avec le BVergG. Cette déclaration constitue une 
condition essentielle et, par conséquent, le fondement des demandes d'indemnisation de préjudices devant les tribunaux civils. Les préjudices ne se limitent pas aux coûts de soumission et peuvent dans certains cas comprendre l'intérêt du contrat ou les bénéfices. Il n'y a aucune disposition relative aux astreintes. La jurisprudence est limitée mais a une importance considérable, en raison du système qui associe code et jurisprudence.

\subsection{Procédure}

Les questions procédurales sont régies par le BVergG et les lois des Länder mentionnées ci-dessus (Landesvergabekontrollgesetze). Si le BVergG ne fournit pas de réglementation, l'Allgemeines Verwaltungsverfahrensgesetz - AVG (la loi générale de procédure administrative s'applique, voir http://www.ris.bka.gv.at/englische-rv/). Des recours peuvent être formés par des soumissionnaires et des opérateurs économiques à condition qu'ils aient un intérêt à la conclusion du contrat en jeu et que les requérants subissent ou risquent de subir des préjudices en raison de la violation présumée de la loi (sur les marchés publics). Les soumissionnaires doivent se plaindre au Bureau dans les 15 jours. Dans des cas particuliers (procédures en dessous des seuils, procédures d'urgence, etc.), ces délais se réduisent à sept jours. Selon les exigences du BvergG, les juges non-professionnels des chambres de contrôle sont des experts des marchés publics. Des experts spécialisés peuvent être impliqués à la demande du Bureau. Le remboursement des coûts est régi par l'AVG (voir l'article 52 et suivants) selon la loi sur les frais de justice. Pour toute plainte au Bureau, il faut acquitter une somme forfaitaire selon l'annexe XIX BVergG. Les frais minimaux se montent à $200 €$ pour les attributions directes et à $5000 €$ pour les contrats de travaux dont la valeur est supérieure aux seuils de la CEE. Aucun autre droit ne doit être payé à ce Bureau. Il y aura une modification mineure de la réglementation des droits concernant la somme forfaitaire due au titre de la procédure en raison d'un arrêt de la Cour constitutionnelle. Des frais administratifs supplémentaires doivent être payés aux organes de contrôle des Länder. Les soumissionnaires sont libres de choisir leur avocat mais doivent en supporter les coûts eux-mêmes. La partie gagnante a droit au remboursement de la somme forfaitaire. Le Bureau décide de ces coûts. Le Bureau peut prendre toute mesure adéquate pour protéger la confidentialité et les intérêts des parties engagées dans une procédure de passation de marchés, y compris limiter ou prohiber l'accès aux dossiers et aux documents concernés et débattre à huis clos. Les décisions sont communiquées par écrit aux parties par fax ou par e-mail et sont aussi publiées sur Internet (voir le http://www.bva.gv.at). Le Bureau doit statuer sur les annulations en moins de six semaines et, pour les mesures provisoires, dans un délai d'une semaine. La relative rapidité du Bureau à rendre ses décisions eu égard au système judiciaire civil est le principal avantage du système autrichien de contrôle des actes administratifs. Il n'y a aucun formulaire-type obligatoire ou d'autres documents obligatoires pour les procédures de contrôle.

\subsection{Culture du contrôle des actes administratifs}

Il n'y a aucune formation (gouvernementale) officielle sur les marchés publics ou le droit communautaire. Les études universitaires de droit comprennent le code des marchés publics dans le cadre du droit administratif et du droit communautaire. La formation aux marchés publics est en grande partie prodiguée par des institutions privées en coopération avec des universités (Vergaberechtslehrgänge) et des programmes spéciaux de formation professionnelle (accords-cadres, partenariats entre le secteur public et le secteur privé, etc.). L'attitude des juges et des membres des commissions des organes de contrôle à l'égard de l'intérêt public et des intérêts privés des soumissionnaires de l'autre est généralement considérée comme équilibrée, avec une légère tendance en faveur des soumissionnaires. Certains soumissionnaires ne souhaitent pas introduire d'action parce qu'ils ne veulent pas compromettre leurs chances d'obtenir un prochain contrat (particulièrement pour les contrats de faible valeur). Quelques soumissionnaires essaient de faire obstruction aux marchés par des procédures tandis que d'autres sont découragés de le faire en raison des coûts élevés (honoraires d'avocat compris, etc.). La connaissance des fondements juridiques des marchés publics diffère en fonction de l'autorité adjudicatrice concernée. Si les grandes autorités adjudicatrices au niveau fédéral ont les moyens de donner une formation adéquate aux fonctionnaires, il y a des problèmes de qualification du personnel au niveau municipal et local. Généralement, les responsables des adjudications sont opposés aux procédures de contrôle parce qu'elles retardent la passation des marchés concernés. Néanmoins, il y a acceptation générale des procédures de recours qui donnent une assurance de la légalité des actes administratifs. Il y a deux revues juridiques sur les marchés publics : Zeitschrift für Vergaberecht und Beschaffungspraxis (ZVB, voir www.manz.at ) et Recht und Praxis der öffentlichen 
Auftragsvergabe (RPA, voir www.verlagoesterreich.at ). La loi sur les marchés publics fait l'objet de conférences et de séminaires universitaires et professionnels en Autriche. La conférence la plus importante est le Vergabeforum qui est organisée chaque année par un institut privé de formation professionnelle et le Vergaberechtstag, également organisé annuellement par le Bureau des marchés publics ; ce dernier sert principalement de forum aux juges et aux juges administratifs qui instruisent les affaires de marchés publics. Il y a une association nationale consacrée au droit et à la politique des marchés publics appelée Tender Club Austria (voir le www.tenderclub.at). Il n'y a pas de groupe de pression spécifique pour les marchés publics, mais la chambre de commerce (voir www.wko.at) et la Fédération de l'industrie autrichienne (voir www.iv-net.at) militent notamment pour les intérêts généraux des soumissionnaires aux marchés publics. Généralement, les arrêts de la CJUE ont un impact direct sur les procédures de marchés publiques parce que la rédaction du BVergG est en grande partie calquée sur celles des directives communautaires ; en conséquence, l'interprétation des directives de la CJUE constitue aussi bien une interprétation du BVergG. Les arrêts sont aussi mis en application dans le code national des marchés publics (le BVergG et le Landesvergabekontrollgesetze). Dans la pratique, les parties font souvent la référence à leurs jugements respectifs. Un rapport actuel sur la plupart de ces questions est inclus dans le rapport d'activité annuel (Tätigkeitsbericht) du Bureau des marchés publics (voir www.bva.gv.at, en allemand).

\section{Belgique}

Différentes décisions administratives, notamment en matière de marchés publics, peuvent être contestées devant les tribunaux civils et devant le tribunal administratif, c'est-à-dire le Conseil d'État. Une distinction doit être faite entre les possibilités de contrôle national avant et après l'annonce de la décision d'attribution du marché au soumissionnaire choisi (conclusion de contrat). Avant la notification de la décision, un soumissionnaire lésé peut contester la décision devant le Conseil d'État en présentant une demande de suspension en référé ou auprès des tribunaux civils en saisissant le juge des référés. Grâce à ces procédures précontractuelles sommaires, le soumissionnaire a la possibilité d'empêcher la signature du contrat. Après la notification de la décision, un soumissionnaire lésé ne peut contester la décision devant le Conseil d'État qu'en présentant une demande d'annulation (qui peut prendre quatre à cinq ans voire plus) ou devant les tribunaux civils. Ces dernières procédures peuvent également être employées pour indemniser un soumissionnaire indûment rejeté, sous réserve qu'il prouve qu'il a été privé d'une vraie possibilité de remporter le contrat et, dans certains cas, pour suspendre ou frapper de nullité tout contrat attribué irrégulièrement. Le Conseil d'État n'est compétent que pour juger des décisions des autorités administratives. Certaines autorités adjudicatrices n'ont pas la qualification d'autorité administrative. En pareil cas, un soumissionnaire lésé ne peut contester une décision relative aux marchés publics que devant les tribunaux civils. Il n'y a aucune différence entre les contrats auxquels les directives s'appliquent et les contrats auxquels elles ne s'appliquent pas. De même, le système ne diffère pas pour les services d'utilité publique.

\subsection{Plainte à l'autorité adjudicatrice}

En Belgique, les soumissionnaires ne sont pas obligés de se plaindre directement à l'autorité adjudicatrice en préalable à l'introduction d'un recours. Il n'y a aucune règle précise sur le sujet. Un soumissionnaire peut porter plainte directement auprès de l'autorité adjudicatrice. Chaque autorité adjudicatrice peut cependant décider comment traiter ces plaintes. Il n'y a pas de textes spécifiques régissant les plaintes officielles des soumissionnaires.

\subsection{Contrôle juridictionnel}

Les organes de contrôle belges ont été institués sur le fondement des articles 144 à 161 de la Constitution. Le tribunal de dernier ressort examinant les décisions relatives aux marchés publics est la Cour de cassation (Palais de Justice, place Poelaert 1, 1000 Bruxelles ; téléphone +32 50861 11, site Web : http://www.cass.be). Selon l'article 152 de la Constitution belge, les juges sont inamovibles. La Cour de cassation est le dernier ressort d'appel et il y a cinq Cours d'appel (précisions sur http://www.cass.be) et 27 tribunaux de première instance. Il y a un tribunal administratif de dernier ressort examinant des décisions relatives aux marchés publics, le Conseil d'État (Rue de la Science 37, 1040 Bruxelles ; téléphone +32 2 23496 11, site Web : http://www.raadvst-consetat.fgov.be). Selon l'article 70, § 4 des lois coordonnées sur 
le Conseil d'État du 12 janvier 1973, les juges administratifs du Conseil d'État sont également inamovibles. Il n'y a aucun tribunal administratif au-dessus du Conseil d'État. Les présidents et les autres membres des organes de contrôle de dernier ressort ont une expérience juridique qualifiée et doivent passer des examens organisés par le Hoge Raad voor Justitievoor Justitie de Hoge Raad (droit civil) ou par le Conseil d'État (droit administratif). Tous les tribunaux mentionnés remplissent les conditions de l'arrêt Dorsch et Salzmann. Il n'y a aucun organe alternatif de règlement des litiges chargé de contrôler la légalité des décisions relatives aux marchés publics en Belgique. Cependant, concernant les services d'utilité publique, la Belgique a transposé le mécanisme d'attestation (articles 3 à 7 de la directive 92/13/CEE) et le mécanisme de conciliation (articles 9 à 11 de la directive 92/13/CEE) dans les articles 113 à 121 de l'Arrêté royal du 10 janvier 1996.

\section{$2.3 \quad$ Recours}

Toute décision liée aux marchés publics peut être contestée par les soumissionnaires (spécifications, attribution, etc.). Néanmoins seules les décisions qui peuvent être qualifiées d'actes juridiques administratifs exécutoires peuvent être contestées devant le Conseil d'État. Les juges civils et les juges administratifs, à savoir le Conseil d'État, sont responsables de la mise en application des dispositions des directives «recours » de la CEE. L'organisation et le fonctionnement du Conseil d'État sont régis par les lois organiques sur le Conseil d'État coordonnées avec l'Arrêté royal du 12 janvier 1973 (http://raadvstconsetat.fgov.be/En/whatwedo_en.htm) et ses décrets d'application. L'expertise du Conseil d'État est la force majeure du système belge. Le Conseil d'État a le pouvoir d'annuler les décisions de l'administration, y compris des autorités adjudicatrices. En raison de la surcharge de travail du Conseil d'État, les délais en cas de demande d'annulation sont souvent de quatre à cinq ans. Cette lenteur est une faiblesse importante du système belge. Outre faire une requête d'annulation devant le Conseil d'État il est possible de demander la suspension pour nécessité urgente. Afin d'obtenir une suspension, le plaignant doit présenter des motifs graves et des préjudices sérieux qu'il est difficile de réparer. En cas de suspension par nécessité urgente, la nécessité urgente doit également être prouvée. Le Conseil d'État peut également imposer des astreintes. Un soumissionnaire lésé ne peut pas obtenir d'indemnisation des préjudices au Conseil d'État. C'est une autre faiblesse du système belge. Les préjudices ne peuvent être obtenus qu'auprès des tribunaux civils. Les réparations que peuvent ordonner les tribunaux sont citées dans le code judiciaire. Seuls les tribunaux civils peuvent juger des responsabilités délictuelles. L'indemnisation des préjudices financiers ne peut être obtenue qu'auprès des tribunaux de droit commun. Il n'y a aucun système particulier pour l'estimation des préjudices liés aux marchés publics. L'article 1382 et suivants du code civil fixent les principes généraux du droit de la responsabilité et s'appliquent également à l'indemnisation des préjudices dans le domaine des marchés publics. Ce concept juridique est largement développé dans la jurisprudence et la doctrine. Selon l'article 1382 du code civil, des préjudices peuvent être réclamés quand trois exigences sont réunies : existence d'une erreur, existence de préjudices et existence d'un lien de causalité entre l'erreur et l'indemnisation réclamée. En vertu de la loi belge, la demande d'indemnisation des préjudices est indépendante des demandes de suspension ou d'annulation des décisions administratives «précontractuelles » en matière de marchés publics. Cependant, l'annulation d'une décision relative aux marchés publics par le Conseil d'État prouve ipso facto l'erreur de l'autorité adjudicatrice devant les tribunaux. Dans ce cas, le plaignant doit seulement prouver les préjudices et le lien de cause à effet entre l'erreur et le préjudice subi. Le plaignant ne doit pas attendre l'issue de la requête d'annulation auprès du Conseil d'État pour demander l'indemnisation des préjudices aux tribunaux, mais, dans ce cas, le plaignant est obligé de prouver l'erreur de l'autorité adjudicatrice, en plus des préjudices et du lien de cause à effet. Concernant le calcul des préjudices, le plaignant doit évaluer et justifier le montant de l'indemnisation demandée que les juges pondèrent selon le cas. En grande partie, l'indemnisation des préjudices accordés à la suite d'une plainte relative aux marchés publics sont simplement l'indemnisation de la perte d'une chance Cependant, l'article 15 de la loi du 24 décembre 1993 fixe une indemnité forfaitaire de $10 \%$ du montant de l'offre pour les recours introduits par un soumissionnaire qualifié « qui a remis l'offre régulière la plus basse » si ce critère est le fondement obligatoire de l'attribution du marché («aanbesteding »). En outre, il faut noter que puisque les contrats ne peuvent pas être considérés comme des actes unilatéraux, ils ne sont pas soumis à la juridiction du Conseil d'État. Seuls les tribunaux civils peuvent indemniser les préjudices dans ce contexte. Les possibilités de suspendre et/ou d'annuler les contrats conclus font l'objet d'un débat. En outre, les soumissionnaires peuvent saisir les tribunaux par voie de référé (article 584 du code judiciaire) pour demander une interdiction ou une injonction contre l'autorité 
adjudicatrice. De cette façon, le tribunal peut ordonner à l'autorité adjudicatrice d'agir, de ne pas agir ou de ne pas prendre une certaine décision. Ainsi, le tribunal peut prendre des mesures provisoires en attendant la décision du juge sur le fond ou du Conseil d'État pour la demande de suspension. L'obéissance à cette injonction peut être assurée par des astreintes. Récemment, une nouvelle loi relative aux marchés publics a été votée (4 mai 2006) et introduit quelques innovations. En ce qui concerne les recours, un délai suspensif a été instauré. Pendant ce délai, le plaignant ne peut demander la suspension (au Conseil d'État, aux tribunaux de droit commun) de l'attribution du contrat, sans un préjudice sérieux qu'il est difficile de réparer. L'intérêt public peut être pris en compte, bien qu'il n'y ait aucune exigence légale à cet égard. Cependant, la nouvelle loi relative aux marchés publics mentionne explicitement cette possibilité. Si le contrat a été attribué avant l'expiration du délai suspensif, le plaignant peut demander au président du tribunal de première instance d'annuler le contrat. Cette possibilité est un grand avantage du système belge et son innovation la plus importante des dernières années. Une fois que le contrat a été attribué, il ne peut pas être annulé ou suspendu en raison d'une irrégularité de la procédure d'attribution (immunité du contrat). Des astreintes peuvent être imposées par le juge du tribunal (tribunaux de droit commun) et par le juge administratif (le Conseil d'état). Le concept juridique de l'astreinte qui peut être imposée par les tribunaux a été spécifié dans le code judiciaire (article 1385 et suivants). Les conditions requises pour que le Conseil d'État ordonne une astreinte sont visées dans l'Arrêté royal du 2 avril 1991 «déterminant la procédure devant la section d'administration du Conseil d'État en matière d'astreinte ».

\section{$2.4 \quad$ Procédure}

Les textes régissant le code de procédure des organes de contrôle en matière de marchés publics sont le code judiciaire (« code judiciaire ») et les lois organiques sur le Conseil d'État combinés avec l'Arrêté royal du 12 janvier 1973 et ses décrets d'application (traduction : http://www.raadvst-consetat.be/En). Seules les parties ayant un intérêt effectif à conclure le contrat et susceptibles d'être lésées par l'irrégularité présumée ainsi que les autorités adjudicatrices elles-mêmes ont le statut pour former un recours afin de remédier aux irrégularités précontractuelles. Les parties au contrat, soumissionnaires potentiels ou évincés et certaines tierces parties peuvent faire une requête d'annulation de toute décision préliminaire à la conclusion du contrat. Il faut noter qu'il est contesté que des tiers puissent faire une requête d'annulation du contrat au juge (cf. supra, par exemple, la nouvelle loi relative aux marchés publics établit l'immunité du contrat dans certains cas). Les parties au contrat peuvent la plupart du temps demander des préjudices en pareil cas. Une requête d'annulation ou de suspension (par nécessité urgente) doit être introduite devant le Conseil d'état dans les 60 jours après la notification de la décision exécutoire. Pour une demande devant les tribunaux, les conditions générales de prescription s'appliquent. Dans certains cas, le délai suspensif qui prescrit le temps imparti aux soumissionnaires pour introduire un recours est défini par la loi (10 jours prorogeables, cf. également loi relative aux marchés publics). L'introduction d'une action n'a aucun effet suspensif. Il n'y a aucune disposition précise concernant les délais obligatoires pour les décisions relatives aux marchés publics. Les réglementations applicables établissent différents délais, mais aucun d'eux n'est obligatoire (si le juge dépasse le délai, la décision rendue reste valide). En raison des retards procéduraux au Conseil d'État, l'attente d'un arrêt à la suite d'une requête d'annulation est de quatre à cinq ans. Le délai d'attente d'une décision à la suite d'une requête ordinaire de suspension est environ de deux à dix mois. C'est toujours le juge qui décide de l'opportunité de nommer un expert. Les coûts sont avancés par la partie demanderesse, mais la partie perdante les supporte ensuite. Les conditions pour le Conseil d'état sont visées dans l'Arrêté du régent du 21 août 1948, en particulier dans les articles 20 à 25 . Les dispositions qui s'appliquent aux experts désignés par les tribunaux sont établies dans le code judiciaire, notamment dans les articles 962 à 991 . Les coûts liés à la délivrance d'une assignation et à la procédure d'indemnisation (tribunaux), les droits de timbre (Conseil d'État) et les frais d'enquête doivent être payés par les requérants. Il n'y a de pas d'autres frais supplémentaires spécifiques pour les soumissionnaires que ceux du contrôle juridictionnel dans le contexte des affaires relatives aux marchés publics. Si une représentation juridique est nécessaire, chaque partie doit payer ses propres avocats, mais les autres frais de justice sont en principe à la charge de la partie perdante. Néanmoins, dans certaines circonstances les honoraires d'avocat sont également supportés par la partie perdante. Il n'y a aucune possibilité de prendre en considération la nécessité de protéger les informations confidentielles des entreprises, mais un auditeur du Conseil d'État a néanmoins reconnu que le besoin de protection des informations confidentielles des entreprises pouvait être pris en compte. En pareil cas, les preuves peuvent n'être présentées qu'au Conseil d'État et pas aux concurrents. Il n'y a aucun formulaire-type et document obligatoire utilisé pour les recours en matière de 
marchés publics, mais quelques mentions obligatoires et règles formelles doivent être observées pour toute requête. Les décisions des organes de contrôle sont notifiées aux parties par courrier. Les décisions du Conseil d'État sont publiées sur son site Internet officiel (http://www.raadvst-consetat.be). Pour les décisions des tribunaux, il n'y a aucune publication systématique. La jurisprudence est limitée mais a une importance considérable, en raison du système qui associe code et jurisprudence.

\subsection{Culture du contrôle des actes administratifs}

Les juges et les membres des commissions des organes de contrôle des marchés publics et les avocats spécialisés dans les marchés publics représentant les soumissionnaires ou les entités adjudicatrices dans les procédures acquièrent leur connaissance de loi relative aux marchés publics, du droit communautaire et du mode de fonctionnement des marchés publics dans la pratique ainsi que de leurs implications techniques et financières au cours de leurs études universitaires ou de la formation continue, à l'aide de livres et articles sur les marchés publics, par des juristes expérimentés, des cours prodigués par le ministère de la justice ou par des organismes privés et des sites Internet comme http://www.simap.eu.int/, http://www.jepp.be, http://www.binnenland.vlaanderen.be/overheidsopdrachten/index.htm. Cela s'applique également aux soumissionnaires qui reçoivent également des informations par des avocats, des conseillers ou des organismes professionnels. Le Tijdschrift voor Aannemingsrecht (T.Aann.) est un journal traitant spécifiquement la loi relative aux marchés publics. La loi relative aux marchés publics fait l'objet de nombreuses conférences et de séminaires universitaires et professionnels. Le Vlaamse vereniging voor aanbestedingsrecht (http://www.vva-vzw.be)et Esimap, Centre d'études, de services et d'information sur les marchés publics et domaines connexes (www.esimap.be), sont des associations nationales sur la loi et la politique des marchés publics. Parmi les associations issues de la société civile qui exercent une surveillance des marchés, font pression sur les autres acteurs ou participent d'une manière quelconque, on peut citer la Nationale Confederatie van het Bouwbedrijf et la Vlaamse Confederatie Bouw qui organisent des conférences sur les marchés publics et prodiguent informations et conseils. Les responsables des marchés publics, par exemple, peuvent suivre certains des programmes de formation du Vlaamse vereniging vor aanbestedingsrecht.

\section{Bulgarie}

À la suite de la modification de loi relative aux marchés publics qui est entrée en vigueur le 1er juillet 2006, le système de contrôle des marchés publics se compose d'un organe de première instance devant la Commission de protection de la concurrence (CPC) et un second et dernier ressort devant la Cour administrative suprême (CAS). Un large éventail de recours est accessible pour les marchés d'une valeur inférieure et supérieure aux seuils de la CEE. Puisque ces dispositions sont plutôt nouvelles, il y a peu d'expérience pratique jusqu'ici.

\subsection{Plainte à l'autorité ou à l'entité adjudicatrice}

Une plainte à l'autorité ou à l'entité adjudicatrice elle-même n'est pas une étape obligatoire du système de recours. La seule obligation du plaignant est d'envoyer une copie de la plainte à l'autorité ou à l'entité.

\subsection{Contrôle quasi-juridictionnel}

La Commission de protection de la concurrence (CPC) est un organe de contrôle de première instance spécialisé dans les marchés publics qui est indépendant du gouvernement. Chaque décision, action ou manquement à agir de la part des entités adjudicatrices au cours de la procédure d'adjudication publique avant la conclusion du marché public ou de l'accord-cadre peut faire l'objet d'un recours devant la CPC. La CPC n'a aucun pouvoir juridictionnel après la conclusion du contrat. Ses membres n'ont pas un statut comparable à celui des juges. Selon la loi relative à la protection de la concurrence, l'entité se compose de sept personnes élues et approuvées par l'Assemblée nationale pendant une période de cinq ans. Les membres peuvent être réélus pendant encore cinq années. Le président doit être un avocat spécialisé dans les marchés publics depuis au moins dix ans. Tous les membres de la CPC doivent être des citoyens bulgares diplômés de droit ou d'économie, dotés d'une expérience de cinq ans au moins et de grandes qualités morales professionnelles qui n'ont pas eu de condamnations pénales. Ils ne peuvent avoir d'autre profession rémunérée à l'exception d'une activité scientifique ou de conférencier, ni tirer bénéfices d'entreprises sous quelque forme que ce soit. 


\subsection{Contrôle juridictionnel}

La Cour administrative suprême (CAS) est le tribunal administratif de dernier ressort pour les recours en matière de marchés publics. Avant le 1er juillet 2006, les tribunaux civils avaient un pouvoir juridictionnel en matière de marchés publics. Les décisions de la CPC peuvent faire l'objet d'un appel devant un comité de la CAS composé de trois membres. La CAS garantit son indépendance en déterminant la nomination, le mandat, les qualifications des membres, son financement etc. La CAS a été instituée par la Constitution et des lois votée par le parlement et remplit les conditions d'une juridiction conformément à l'arrêt Dorsch et Salzmann. Elle est indépendante du pouvoir exécutif, de l'administration ou de toute autre instance gouvernementale et ses décisions ont force de loi. Ses juges doivent être des avocats expérimentés et reconnus. Ils sont nommés selon une procédure générale. Le président de la CAS est nommé pour sept ans en vertu de la loi relative au système judiciaire sans droit de réélection. Outre leurs fonctions de jugement, les juges exercent des fonctions légales liées à l'application de l'autorité judiciaire qui leur est attribuée par la Constitution et les lois (art. 125a, paragraphe 4 de la loi relative au système judiciaire). Le président a au moins huit ans d'expérience professionnelle.

\subsection{Recours}

Tous les recours disponibles sont stipulés dans la loi relative aux marchés publics. Selon l'article 120, toute décision, action ou manquement à agir de la part des entités adjudicatrices au cours de la procédure d'adjudication publique avant la conclusion du marché public ou de l'accord-cadre peut faire l'objet d'un recours devant la CPC. Il n'y a pas d'effet suspensif systématique pour introduire une action devant la CPC. Cependant, selon l'article 121a, paragraphe 1, sur requête raisonnable du requérant et en cas de vrai risque que l'intérêt public ou les intérêts des parties ne soient lésés et compte tenu des conséquences défavorables du retard de la procédure d'adjudication publique, la CPC peut imposer la suspension de la procédure d'adjudication publique à titre de mesure provisoire. Tout appel d'une décision de la CPC auprès de la SAC doit être fait dans les 15 jours de la communication de la décision aux parties et la procédure ne suspend pas l'exécution. Selon l'article 120a, paragraphes 1 et 2 de la loi relative aux marchés publics, toute personne ayant ou ayant eu intérêt à obtenir un contrat particulier peut présenter une demande de déclaration de nullité d'un contrat public et demander l'indemnisation des préjudices si elle a été lésée en raison des violations de la loi selon les règles du code de procédure civile. Un contrat public est frappé de nullité s'il est conclu sans que les parties n'aient suivi la procédure prescrite. La Bulgarie a un système judiciaire codifié, mais la jurisprudence a une importance limitée en raison des interprétations de la loi données par les jugements des tribunaux. L'impact des arrêts de la Cour européenne de justice sur les marchés publics est limité mais ira croissant en raison de l'adhésion de la Bulgarie à l'UE.

\subsection{Code de procédure}

Le code de procédure est régi parla loi relative aux marchés publics, la loi relative à la SAC et le code de procédure du tribunal administratif. Les preuves écrites, les explications orales et les expertises sont autorisées dans les procédures devant la CPC. Quand des expertises sont présentées au cours des procédures devant la CPC, les honoraires des experts sont réglés d'avance par le partie qui a demandé l'expertise. Quand l'expertise est faite à l'initiative de la CPC, les honoraires des experts sont acquittés par le requérant si sa demande est rejetée ou si la procédure est suspendue, sinon ils sont mis à la charge de l'entité adjudicatrice. Ainsi, la demande peut être faite par toute personne ayant ou ayant eu intérêt à obtenir un contrat particulier dans un délai de dix jours à compter de la notification d'une décision ou d'une action ou si cette personne n'a pas reçu de notification à compter de la date où elle a appris la décision ou de la date à laquelle expire le délai pour cette action particulière. Selon la loi relative aux marchés publics, pour l'imposition de mesures provisoires, le requérant doit verser un dépôt représentant $1 \%$ de la valeur du marché public, mais pas plus de 50000 BGN sur un compte bancaire de la CPC ou donner une garantie bancaire. La CPC fixe le montant maximal du dépôt de garantie à 50000 BGN quand la valeur des marchés publics ne peut pas être déterminée. Si les plaignants décident de se faire représenter (par des avocats), ils doivent régler les honoraires requis mais cette représentation est facultative. La CPC se prononce sur la plainte dans un délai de deux mois à compter du début de la procédure. La décision, accompagnée de la motivation, est prise et annoncée dans les 14 jours. Les décisions des organes de contrôle sont annoncées et publiées sur leur site Internet respectif. La SAC communique ses décisions selon les dispositions de la loi relative à la SAC. 


\subsection{Culture du contrôle des actes administratifs}

Les juges, les membres de la CPC, son administration et les avocats spécialisés dans les marchés publics représentant les soumissionnaires ou les autorités adjudicatrices/entités dans les procédures acquièrent leur connaissance de la loi relative aux marchés publics et du droit communautaire principalement dans le cadre de leurs études universitaires, mais également par des cours organisés par l'UE ou les organismes internationaux ou le PPA ainsi que «sur le tas » par un apprentissage actif. Ils acquièrent leur connaissance du fonctionnement des marchés publics dans la pratique, en plus des considérations techniques et financières impliquées, dans des cours prodigués par l'UE ou les organismes internationaux et apprennent en pratiquant ; certains d'entre eux participent aux cours donnés par le gouvernement et le PPA. L'attitude des juges et des représentants des organes de contrôle des marchés publics à l'égard de l'intérêt public et des intérêts privés des soumissionnaires est considérée équilibrée mais parfois partiale à l'égard de l'intérêt public ou des intérêts des soumissionnaires. Les soumissionnaires qui introduisent une action contre des décisions de marchés publics acquièrent leurs connaissances de l'environnement juridique, financier et administratif et du fonctionnement pratique des marchés dans les cours donnés par le gouvernement et par l'UE ou les organismes internationaux et par leurs organismes professionnels, par exemple les chambres de commerce. Lorsque le système précédent était en place jusqu'en juillet 2006, certains soumissionnaires ne souhaitaient pas introduire d'actions pour ne pas compromettre leurs chances d'obtenir un prochain contrat et certains étaient découragés de soumettre leur affaire à un contrôle juridictionnel en raison de la longue durée des procédures.

Il n'y a aucun journal spécifique dans le domaine des marchés publics. La loi relative aux marchés publics fait l'objet de conférences et séminaires universitaires et professionnels. Il n'y a aucune association nationale sur les marchés publics en Bulgarie, mais d'autres groupes d'intérêt national comme les chambres de commerce, l'association des industries nationales du bâtiment, la confédération des industries bulgares, la chambre industrielle bulgare, l'association internationale des entreprises bulgares, la Chambre de Commerce et d'Industrie bulgare et les ONG comme la section nationale de Transparency International font pression, informent, enseignent et/ou conseillent sur les litiges liées aux marchés publics. La presse et la télévision couvrent les procédures de contrôle des marchés publics si l'intérêt public est en jeu.

\section{Chypre}

Les systèmes de contrôle et de recours en matière de marchés publics à Chypre peuvent se subdiviser en trois éléments : une plainte à l'autorité adjudicatrice, un procédure de contrôle quasi-juridictionnel auprès de l'Autorité de recours des soumissionnaires (ARS) et un contrôle juridictionnel auprès de la Cour suprême de Chypre.

\subsection{Plainte à l'autorité adjudicatrice}

La loi chypriote établit explicitement qu'avant de déposer une demande auprès de l'ARS (décrite cidessous), toute personne intéressée doit, dans un délai de cinq jours à compter de la date où elle a pris connaissance de l'acte ou de la décision, notifier par écrit l'autorité adjudicatrice et envoyer une copie de la notification à l'organe compétent (le Trésor de la République), en ce qui concerne la violation présumée et lui signifier son intention d'introduire une action.. L'autorité adjudicatrice doit examiner l'allégation et prendre une décision motivée moins de cinq jours à compter de la réception de la notification. Si les allégations s'avèrent justifiées, l'autorité prend des mesures appropriées. Si l'ARS ne prend aucune mesure dans les cinq jours, l'autorité est supposée avoir a rejeté l'allégation. Une demande de recours doit être déposée dans les dix jours à compter de la date où la décision vient à la connaissance du demandeur ou à l'expiration de la période de cinq jours ci-dessus mentionnée. La loi ne spécifie pas qui, au sein des autorités adjudicatrices, traite les demandes de recours auprès de l'ARS. Cependant, ce sont dans les faits les responsables de l'adjudication de l'offre concernée qui sont au courant de la question et procèdent à l'examen interne des allégations.

\subsection{Contrôle quasi-juridictionnel}

Organe de contrôle quasi-juridictionnel, l'ARS a été instituée sur décision du Conseil des ministres du 1er décembre 2003 et dotée du pouvoir d'instruire toutes les décisions prises par les autorités adjudicatrices avant la conclusion de tout marché public en cas de violation présumée de la loi. Par conséquent, il y a un 
organe de contrôle spécialisé dans les marchés publics qui est indépendant du gouvernement. Cependant, les membres de cette autorité n'ont pas un statut comparable à celui des juges. L'ARS compte cinq membres dont le président.

\subsection{Contrôle juridictionnel}

En outre, la loi chypriote permet à toute personne lésée par une décision de l'ARC ou par toute décision prise par une autorité adjudicatrice avant ou après la conclusion du contrat de contester cette décision devant la Cour suprême de Chypre. Seule la Cour peut décider l'indemnisation des préjudices. Ces questions sont régies par la Constitution de la République. Toute personne intéressée peut exercer son droit de requête auprès de la Cour suprême de Chypre au lieu de former un recours auprès de l'ARS, à condition de ne pas introduire ces actions conjointement. Les membres de la Cour suprême et de son président sont des juges et leur statut est régi par la Constitution. La Cour suprême remplit les conditions d'un juridiction conformément à l'arrêt Dorsch et Salzmann.

\subsection{Recours}

L'ARS peut annuler une décision illégale prise avant la conclusion du marché public et ordonner la suppression d'une modification discriminatoire des caractéristiques techniques, économiques ou financières dans les documents contractuels ou dans tout autre document relatif à la procédure d'attribution du contrat. De plus, l'ARS peut, lors d'une procédure à la demande du requérant, prendre des mesures provisoires afin d'empêcher qu'il soit porté préjudice aux intérêts concernés, y compris des mesures de suspension ou destinées à assurer la suspension de la procédure de passation d'un marché public ou l'application de toute décision prise par l'autorité adjudicatrice jusqu'à ce qu'une décision finale ne soit prononcée. Dans le cadre des mesures provisoires, l'ARS peut prendre en considération leurs conséquences probables sur les intérêts des parties susceptibles d'être lésées, y compris l'intérêt public et décider de ne pas prendre de telles mesures si les conséquences négatives l'emportent sur les conséquences positives. La Cour suprême peut prendre des décisions comme tout tribunal, y compris décider des mesures provisoires, l'indemnisation des préjudices, l'annulation de l'appel d'offres, l'annulation de la décision d'attribution du contrat, l'annulation du contrat ou des astreintes et des dommages-intérêts. Le contrat conclu ne peut être annulé que par une décision de la Cour.

\subsection{Procédure}

Toute personne ayant ou ayant eu un intérêt à obtenir un marché public particulier et qui a été ou risque d'être lésée par une violation présumée de la loi, par un acte ou une décision prise par une autorité adjudicatrice peut, avant la conclusion de ce marché public, présenter un recours devant l'ARS. Cela n'empêche pas la personne intéressée d'exercer son droit de requête devant la Cour suprême de Chypre au lieu de s'adresser à l'ARS. Il n'y a aucune différence entre les contrats auxquels les directives s'appliquent et les contrats auxquels elles ne s'appliquent pas. La procédureError! Hyperlink reference not valid. auprès de l'ARS est régie par certaines parties des lois relatives à la coordination des procédures pour la passation des marchés publics (partie IV de lois N11 (I)/2006 et N12 (I)/2006). La réglementation 745/2003 concernant l'institution et le fonctionnement de l'ARS, doit également être mentionnée dans ce contexte. Les droits demandés se fondent sur la valeur de l'offre qui a été sélectionnée. Plus spécifiquement, de 1 à 100000 £, les droits se montent à $500 £$, de 100001 à $500000 £$, les droits se montent à 1500 £, de 500001 à 1 million de £, les droits se montent à 2000 £, de 1 million à 5 millions de £, les droits se montent à 3000 £ et à partir de 5 millions et au-delà, les droits se montent à 4000 £. Les coûts pour une demande de mesure provisoire sont de $1000 £$. Si la demande de contrôle des actes administratifs précède la soumission des offres, les droits se montent à 1000 £. L'ARS peut ordonner à tout demandeur dont la requête a été rejetée de supporter les coûts de la procédure et infliger en outre une amende qu'elle peut considérer appropriée en raison des circonstances de l'affaire. Les droits de l'ARS ne sont pas remboursables. L'ARS prend sa décision dans les 30 jours à compter de la communication de la demande. Selon la section 146 de la Constitution, toute personne intéressée peut déposer une requête de contrôle juridictionnel auprès de la Cour suprême de Chypre dans un délai de 75 jours à compter de la date de l'action ou de la publication de la décision ou de la date où la personne a pris connaissance de la décision si elle n'a pas été publiée. Les décisions de l'ARS sont communiquées aux parties et au public par publication sur son site Internet(www.tra.gov.cy) et par écrit aux autorités adjudicatrices, au soumissionnaire et à l'organe compétent (le Trésor de la République). Les arrêts de la Cour suprême sont 
rassemblés dans des recueils qui peuvent être achetés à l'imprimerie nationale. De plus, Leginet Ltd. (www.leginet.com), site accessible sur abonnement, héberge deux grandes bases de données sur la législation et la jurisprudence de la République de Chypre. Cependant, toutes les affaires récentes ne sont disponibles qu'en grec à l'exception des affaires plus anciennes de 1883 à 1989 qui sont disponibles en anglais. En outre, dans deux ans environ, la Cour suprême aura sa propre base de données électroniques qui contiendra notamment ses affaires/arrêts. Une nouvelle loi sur la coordination des procédures de contrôle des actes administratifs est actuellement en préparation.

\subsection{Culture du contrôle des actes administratifs}

Les formulaires-types pour les procédures en matière de marchés publics auprès de l'ARS sont disponibles sur www.tra.gov.cy. La connaissance des fondements juridiques des marchés publics qu'ont les responsables des adjudications est très bonne. La loi relative aux marchés publics fait l'objet de conférences et séminaires universitaires et professionnels. Il y a une formation professionnelle sur le droit et la politique des marchés publics pour les responsables des marchés publics qui se forment sur le tas et par quelques séminaires et conférences appropriés. Les arrêts de la Cour européenne de justice sont utilisés pour trouver des solutions aux questions compliquées.

\section{République tchèque}

Les marchés publics de la République tchèque sont régis par la loi 40/2004 Coll. sur les marchés publics (traduction en anglais sur http://www.compet.cz/English/VZ/Zakony/Rozcesti.htm), mais les nouvelles directives relatives aux marchés publics de la CEE ont déjà été transposées par la loi 137/2006 Coll. (Zákon o veřejných zakázkách) qui est entrée en vigueur le 1er juillet 2006. La loi 139/2006 Coll. régit les délégations de services publics. Le système de contrôle et de recours tchèque se fonde sur un système mixte de contrôle administratif, quasi-juridictionnel et juridictionnel. L'acteur principal est le Bureau de protection de la concurrence (Úřad pro Ochranu Hospodářské Soutěže, Joštova 8, 60156 Brno ; téléphone +420 542161233 ; Fax +420 542 210023, email : posta@compet.cz, site Internet : www.compet.cz) qui a succédé à l'ancien ministère de la concurrence et a reçu le statut d'autorité indépendante du gouvernement par la loi 273/1996 Coll. (traduction en anglais sur http://www.compet.cz/English/LEGI/Zakon273 en.htm). Le contrôle extra-juridictionnel est également disponible dans le secteur des services d'utilité publique car les lois antérieures et actuelles sur les marchés publics ont introduit le mécanisme de conciliation de la directive CE 92/13 ( $\$ 124$ de la loi relative aux marchés publics de 2006). Il n'y a aucun organe spécifique d'arbitrage chargé d'une mission alternative de règlement des litiges dans le domaine des marchés publics.

\subsection{Contrôle des décisions relatives aux marchés publics}

Selon la loi de 2004, il y a quatre étapes pour le contrôle des décisions relatives à une procédure de passation de marché. À la première phase, avant la signature du contrat, tout soumissionnaire est autorisé à adresser une plainte par écrit à l'autorité adjudicatrice dans un délai de 15 jours à compter de la notification de l'exclusion de la procédure. En dessous des seuils de la CEE, pour exercer son droit de réclamation, le soumissionnaire doit prouver qu'il a ou a eu un intérêt effectif à obtenir le contrat et qu'il est susceptible d'être lésé par la violation présumée de la loi de 2004. Dans les deux cas, le dépôt préliminaire d'une plainte à l'entité adjudicatrice est une condition préalable pour introduire une action contre la violation présumée de la loi devant le Bureau de protection de la concurrence. Cette obligation ne s'applique pas si le contrat a déjà été conclu. Dans les 10 jours à compter de la réception de la plainte, l'autorité adjudicatrice informe le plaignant de sa décision motivée. L'autorité adjudicatrice peut confirmer ou rejeter la plainte ou suggérer une solution différente que celle préconisée par le plaignant. Si l'autorité adjudicatrice rejette la plainte ou n'adopte pas les mesures demandées par le plaignant, le contrat ne doit pas être signé pendant 30 jours à compter de la réception de la plainte. Un contrat signé en violation de l'obligation mentionnée ci-dessus est réputé nul. Les dispositions concernant la première phase ont été légèrement modifiées par la loi de 2006 : Dorénavant, tout soumissionnaire est autorisé à adresser une plainte à l'autorité adjudicatrice indépendamment de la valeur prévue du contrat et la période de 60 jours a été ramenée à 45 jours. À la deuxième étape, si les suites données à la plainte ne sont pas favorables au plaignant, les conflits peuvent être portés devant le Bureau de protection de la concurrence. Le Bureau est une autorité indépendante du gouvernement dont le président est nommé pour un mandat de six ans par le 
président de la République tchèque sur proposition du gouvernement. En outre, le président ne peut être membre d'aucun parti politique et ne doit pas nécessairement être un avocat qualifié. Les soumissionnaires peuvent contester tout acte de l'autorité adjudicatrice susceptible de constituer une violation des obligations de transparence et de non-discrimination, telles que les conditions d'attribution, les notices contractuelles/appels d'offres, le type de procédure d'adjudication, la décision d'exclusion d'un candidat et l'attribution du contrat (\$97,3 de la loi de 2004). La requête doit être présentée dans les dix jours à compter de la décision de l'autorité adjudicatrice une fois que la plainte préalable a été notifiée. Dans tous les cas, la requête doit être présentée au plus tard dans un délai de 25 jours à compter de la réclamation préalable à l'autorité adjudicatrice. La loi de 2004 permet également au Bureau d'entamer une procédure à sa propre initiative au plus tard trois ans après la violation de la loi. En 2005, 334 actions ont été introduites, 184 sur requête et 152 à l'initiative du Bureau. Une fois que la procédure a été lancée et que l'autorité adjudicatrice a produit la documentation nécessaire (dossier du marché public), le Bureau a 30 jours (en cas difficiles, 60 jours) pour statuer sur la requête. Selon la loi de 2006, ce délai commence à partir de l'initiation de la procédure devant le Bureau. La requête est instruite par la section des marchés publics du Bureau qui est présidée par un avocat. À la troisième étape, il est possible de faire appel de la décision devant le président du Bureau, qui statue sur proposition du «Comité d'appel », comité consultatif du Bureau qui est composé de fonctionnaires ainsi que d'experts externes. Il n'y a aucune disposition précise dans la loi de 2004 sur cette étape, mais les dispositions générales de la loi 500/2004 Coll. - le code de procédure administrative- s'appliquent. Il n'y a aucun autre appel contre des décisions rendues par le Bureau, mais un recours exceptionnel est possible à une quatrième étape. En particulier, la Cour suprême administrative peut, sur requête (cassation), contrôler la légalité des décisions du Bureau. Le Cour suprême est un tribunal constitutionnel permanent et indépendant ainsi qu'un organe de recours de dernier ressort pour les affaires administratives (Nejvyšší správní soud, Masarykova 31, 65740 Brno ; téléphone +420 542532311 ; Fax +420 542532 361, email : podatelna@ @nssoud.cz, site Internet : http://www.nssoud.cz/en/index.php).

\section{$5.2 \quad$ Recours}

Selon la loi de 2004 et indépendamment de la valeur prévue du contrat, des recours contre les actes des autorités adjudicatrices sont possibles avant ou après la conclusion du contrat auprès du Bureau de protection de la concurrence (mesures provisoires et correctives, suspension de l'exécution du contrat, pénalités) ou des tribunaux civils (indemnisation des préjudices). Avant la fin de la procédure et dans la mesure nécessaire pour maintenir l'objectif de celle-ci, le Bureau a le droit de prendre des mesures provisoires sur demande du requérant ou à sa propre initiative afin d'empêcher d'autres préjudices ou un risque immédiat de préjudice aux intérêts du requérant. En particulier, le Bureau peut, pendant une période précisée dans l'ordre correspondant mais pas après la date de la décision finale, 1) exiger de l'autorité adjudicatrice de ne pas signer le contrat à l'issue de la procédure de soumission; 2) suspendre l'adjudication et 3) suspendre l'exécution d'un contrat déjà conclu. Le Bureau peut tenir compte des conséquences probables des mesures provisoires pour tous les intérêts susceptibles d'être lésés, y compris l'intérêt public, et décider de ne pas accorder de telles mesures s'il estime que les conséquences négatives pourraient l'emporter sur les conséquences positives. Par principe, la présentation d'une requête n'a aucun effet suspensif sur la procédure d'adjudication en cours, mais si le résultat de la première phase (plainte auprès de l'autorité adjudicatrice) n'est pas favorable au plaignant, le contrat ne doit pas être conclu pendant une période de 30 jours (selon la loi de 2006 : 45 jours) à compter de la réception de la plainte. En outre, la loi de 2004 établit que si l'autorité adjudicatrice viole délibérément ses obligations en matière d'adjudication de mauvaise foi, la procédure est réputée invalide dès le tout début. Les appels contre des ordonnances fixant des mesures provisoires n'exercent aucun effet suspensif sur leur application. Par sa décision finale et avant que le contrat ne soit conclu, le Bureau, après avoir confirmé par écrit qu'une violation du droit des marchés publics a réellement été commise, impose une mesure corrective à l'autorité adjudicatrice, c'està-dire l'annulation de la décision d'attribution du contrat si cette violation a influé ou a été réellement susceptible d'influer sur l'évaluation des offres. Après la conclusion du contrat et pour les mêmes raisons que celles mentionnées ci-dessus, le Bureau est habilité à interdire l'exécution d'un contrat conclu et à infliger des pénalités dans une procédure conjointe pour violation d'une obligation visée au $\S 102$ de la loi de 2004 (par exemple : non-conformité aux obligations d'appel d'offres ; conclusion d'un contrat en violation de la loi de 2004 ; abandon injustifié d'une adjudication ; défaut d'enregistrement de la procédure d'adjudication ou d'envoi des informations sur l'attribution du contrat). En 2005, 64 pénalités ont été infligées pour un montant de $2569000 \mathrm{CZK}$. L'annulation d'un contrat signé, cependant, ne peut être 
prononcée que par un tribunal civil sur proposition d'une des parties contractantes. L'indemnisation des préjudices ne peuvent être décidée que par un tribunal de droit commun dans les conditions établies par le code de commerce. Par principe, il doit exister un lien adéquat entre la violation présumée du droit des marchés publics et les préjudices (réels ou potentiels) qui ont lésé les intérêts du requérant. Cependant, l'indemnisation des préjudices n'est pas subordonnée à une décision préalable d'annulation prise par le Bureau de l'acte présumé de l'autorité adjudicatrice. Enfin, il y a des mesures disciplinaires (telles que des amendes périodiques) qui peuvent être prises contre les fonctionnaires de l'autorité adjudicatrice ou des marchés publics par le corps administratif compétent ( 104 de la loi de 2004).

\subsection{Procédure}

Les procédures devant le Bureau de protection de la concurrence sont régies par la loi de 2004 (depuis le 1er juillet 2006, par la loi de 2006) ainsi que par le code de procédure administrative (acte 500/2004 Coll.). L'ouverture de la procédure est subordonnée au virement préalable d'un dépôt sur un compte du Bureau ainsi qu'au paiement de frais administratifs d'un montant de $30000 \mathrm{CZK}$ (environ $1000 €$ ). Le montant du dépôt représente $1 \%$ du marché mais ne doit pas dépasser 1000000 CZK. Si la requête est confirmée, le dépôt est remboursé au requérant (avec des intérêts). En cas de rejet/de désistement, le dépôt est considéré comme un produit du budget de l'État. Les frais administratifs ne sont pas remboursés. Selon la loi de 2006, il n'y a aucune obligation de payer des frais administratifs, mais le montant du dépôt représente maintenant $1 \%$ du prix du marché sans dépasser 2 millions de CZK. L'introduction d'une procédure devant les tribunaux n'exige pas la participation d'un professionnel (c'est-à-dire d'un avocat) mais est soumise au paiement de frais de justice. En cas de demande d'indemnisation des préjudices, les frais de justice s'élèvent à $1 \%$ du montant prévu des dommages.. En cas de procédure devant le tribunal administratif, les frais de justice se montent à $2000 \mathrm{CZK}$. Dans ce dernier cas, le code de justice administrative s'applique. Les frais de justice ainsi que d'autres coûts appropriés peuvent être remboursés par la partie perdante à l'issue du jugement. Lors des procédures devant le Bureau, la participation d'experts (avocats ou interprètes) peut être décidée par la section Achats en coopération avec la section Économique si cela s'avère nécessaire. Les coûts des experts sont payés sur un budget spécial du Bureau. Le personnel du Bureau ainsi que les experts externes doivent maintenir la confidentialité sur toutes les questions traitées au cours de la procédure. Cette obligation ne s'applique pas si ces personnes sont invitées à témoigner devant un tribunal ou devant des autorités d'enquête de l'État ou à fournir des preuves par écrit aux autorités précitées en vertu du Code pénal. Si le Bureau a connaissance d'un fait relevant du secret commercial, il prend toute mesure appropriée afin d'éviter une violation du secret commercial. Le droit du soumissionnaire à consulter la documentation contractuelle est subordonné à l'obtention du consentement de tous les soumissionnaires impliqués. Les décisions du Bureau sont communiquées aux parties impliquées dans la procédure par la poste et sont publiées dans un recueil annuel de décisions du Bureau ainsi que sur son site Internet.

\subsection{Culture du contrôle des actes administratifs}

Les fonctionnaires du Bureau de protection de la concurrence ont étudié le droit des marchés publics dans le cadre de leurs études universitaires ou dans des séminaires organisés par les autorités gouvernementales (comme le ministère du développement régional) ou l'UE (particulièrement dans le contexte des projets de jumelage). L'attitude des fonctionnaires ainsi que des membres de l'ordre judiciaire est considérée juste. La jurisprudence est limitée mais a une importance considérable, en raison du système qui associe code et jurisprudence. Les soumissionnaires peuvent se familiariser avec la politique des marchés publics par des cours fournis par les autorités gouvernementales, le Bureau lui-même, l'UE, des avocats ou des consultants ainsi que par les institutions privées de formation. La plupart des soumissionnaires sont disposés à entreprendre une procédure afin d'obtenir une solution équitable, mais certains d'entre eux souhaitent simplement faire obstruction à la procédure d'adjudication. D'autres semblent peu disposés à accepter une protection juridique, soit parce qu'ils ne veulent pas compromettre leurs chances pour un prochain contrat, soir parce qu'ils estiment les frais trop élevés. D'autres font intentionnellement obstruction aux marchés publics par leur action. Malgré l'absence d'une formation professionnelle spécialisée, les connaissances fondamentales des responsables des adjudications sont considérées adéquates. Généralement, l'instruction des procédures d'adjudication est considérée comme une manière efficace de contrôler la légalité des décisions d'attribution des marchés publics. Il y a une revue spécialisée dans le droit des marchés publics et une association nationale récemment fondée. La société civile joue également un rôle plus actif dans 
l'évolution de la réglementation des marchés publics. Par exemple, les changements récents de la loi sur les marchés publics trouvent leurs origines dans les débats lancés par l'association des industries nationales du bâtiment et la section nationale de Transparency International. Les médias couvrent régulièrement les procédures liées aux marchés publics. L'impact des arrêts de la CJUE est très important et se reflète dans les requêtes présentées par les soumissionnaires. Le système de contrôle et de recours a sensiblement évolué depuis l'adhésion de la République tchèque à l'UE.

\section{Danemark}

Les marchés publics au Danemark sont régis par deux arrêtés du 16 septembre 2004 transposant les nouvelles directives sur les marchés publics de la CEE entrés en vigueur le ler janvier 2005 (voir généralement : http://www.ks.dk/english/procurement/legislation/pro/). En dessous des seuils de la CEE, les marchés publics sont régis par la loi de 2005 sur les procédures d'adjudication des travaux publics ainsi que par une circulaire ministérielle de 2002 sur les fournitures et services. Le système danois de recours se fonde sur le contrôle juridictionnel et extra-juridictionnel. Les acteurs principaux sont le Comité de plainte sur les marchés publics (Klagenævnet for Udbud, Sekretariatet, Kampmannsgade 1,DK-1780 Copenhague V ; téléphone +45 33307621 ; Fax +45 3330 7799, site Web : http://www.klfu.dk), une commission administrative indépendante et l'Autorité de la concurrence (Konkurrencestyrelsen, Nyropsgade 30, DK-1780 Copenhague V ; téléphone +45 72268000 ; Fax +45 3332 6144, email : ks@ks.dk, site Web : http://www.ks.dk/english) placée sous tutelle du ministère de l'économie et du commerce. Les tribunaux de droit commun ont également juridiction sur les litiges relatifs aux marchés publics, mais interviennent rarement dans la pratique.

\subsection{Contrôle extra-juridictionnel}

L'Autorité de la concurrence danoise $(\mathrm{ADC})$ possède un système «de résolution des problèmes » informel. Bien que l'ADC ne soit pas autorisée à prendre des décisions qui ont force exécutoire ou à suspendre/rectifier une procédure d'adjudication, de nombreux soumissionnaires préfèrent s'adresser à elle plutôt qu'au Comité des plaintes sur les marchés publics Le système «informel » semble être avantageux, car il est considéré sur un pied d'égalité avec le système formel (formulation de recommandations dont la plupart sont respectées). Il assure un règlement rapide et moins bureaucratique des conflits (environ deux mois pour un cas), est plus souple (des affaires peuvent être présentées par toute personne/société ou à l'initiative de l'ADC elle-même ; il n'y a aucun besoin de représentation juridique) et c'est gratuit. Par conséquent, l'ADC traite presque 30 affaires de marchés publiques chaque année. L'autorité adjudicatrice peut être sollicitée pour répondre aux allégations et donner accès de concession au dossier du marché public sauf exceptions prévues par le droit administratif général (secrets industriels, etc.). La recommandation est faite au moment par les juristes experts de l'ADC. Si une autorité adjudicatrice manque ou refuse de se conformer conforme à la recommandation faite par l'ADC, cette dernière a le pouvoir de renvoyer l'affaire au Comité des plaintes. L'autorité adjudicatrice peut contester la recommandation devant les tribunaux de droit commun. En plus de ce système, le mécanisme de conciliation établi par la directive CE 92/13 a été mis en application dans la loi danoise mais n'est jamais utilisé dans la pratique. Les soumissionnaires peuvent également adresser une réclamation directement à l'autorité adjudicatrice, mais il n'y a aucune disposition précise pour déterminer quel responsable au sein de l'autorité est autorisé à traiter ces réclamations. La réclamation directe n'est pas une condition préalable pour procéder à un contrôle juridictionnel. Enfin, la résolution des problèmes posés par les marchés transfrontaliers est possible dans le contexte du réseau des marchés publics (PPN, http://www.ks.dk/english/procurement/network).

\subsection{Contrôle juridictionnel}

Indépendamment de la valeur prévue du contrat, les décisions des autorités adjudicatrices liées à une procédure d'adjudication dans le secteur classique et dans celui des services d'utilité publique peuvent être contestées devant les tribunaux de droit commun ou le Comité des plaintes relatives aux marchés publics. Le premier choix s'applique rarement dans la pratique. Le Comité a été institué en 1991 et est actuellement régi par la loi $\mathrm{n}^{\circ} 415$ du 31 mai 2000 et modifications (traduction en anglais de la loi de 2000 sur http://www.ks.dk/english/procurement/legislation/act/), et d'un décret d'application de la loi sur http://www.ks.dk/english/procurement/legislation/415/.). Le Comité n'a aucune juridiction sur les marchés 
comportant l'exploitation d'une zone géographique pour la prospection ou l'extraction du pétrole, du gaz, du charbon ou de tout autre combustible solide (section 3.2 de la loi de 2000) et doit rejeter les plaintes qui lui sont adressées à cet égard (ces plaintes doivent être déposées auprès du tribunal maritime et commercial). Le Comité se compose d'un président, de trois adjoints et d'un certain nombre d'experts de qualification assurée dans les domaines de la construction, des marchés publics, des transports et d'autres activités associées. Tous les membres sont nommés par le ministre des affaires économiques et leur mandat a une durée (renouvelable) de quatre ans. Le président et les adjoints doivent être des membres de l'ordre judiciaire. Le président peut autoriser un adjoint à agir à sa place et définit la manière dont les décisions doivent être publiées. Les décisions du Comité (à l'exception des plaintes systématiquement rejetées en application de la section 3.2 de la loi de 2000) peuvent faire l'objet d'un appel devant les tribunaux de droit commun dans un délai maximal de huit semaines à compter de leur notification aux parties. Si aucun appel n'a été interjeté après ce délai, le soumissionnaire ne peut plus faire appel de la décision. En dernier ressort, les affaires de marchés publics peuvent être instruites par la Cour suprême (Højesteret) ce qui se produit rarement dans la pratique car les décisions du Comité sont généralement respectées. La Cour suprême est un corps permanent, indépendant de l'exécutif (section 64 de la Constitution danoise), dont les décisions prononcées après une procédure contradictoire ont force de loi. Une décision du Comité ne peut pas faire l'objet d'un appel devant un autre tribunal administratif (section 8.1 de la loi de 2000).

\subsection{Recours}

Selon la section 6.1 de la loi de 2000, le Comité des plaintes est habilité à rejeter une plainte ou à en déterminer tout ou partie sur le fond. En particulier, avant la signature du contrat, le Comité peut 1) suspendre la procédure d'adjudication ; 2) annuler une décision illégale ; 3) exiger de l'autorité adjudicatrice qu'elle se conforme aux obligations inhérentes à l'adjudication, c'est-à-dire qu'elle corrige les irrégularités de la procédure, et 4) accorder l'indemnisation des préjudices. L'indemnisation des préjudices est considérée comme une innovation importante du système danois, car, avant la loi de 2000, les soumissionnaires devaient faire cette demande indemnitaire devant les tribunaux de droit commun. Le Comité n'a pas le pouvoir d'annuler un contrat déjà conclu. Cette action doit être intentée devant les tribunaux de droit commun ce qui n'arrive pratiquement jamais. À partir d'octobre 2006, cependant, la législation a été modifiée pour introduire un délai suspensif obligatoire entre la décision d'attribution du contrat et sa conclusion (sous l'influence de l'arrêt « Alcatel »). Les plaintes n'ont pas un effet suspensif systématique, mais le Comité peut ordonner la suspension ad hoc de l'adjudication si cela s'avère nécessaire. Les principes généraux de la loi danoise demeurent applicables. Le Comité peut, cependant, prendre en considération les conséquences probables de la suspension pour tous les intérêts susceptibles d'être lésés, y compris l'intérêt public, et décider de ne rien faire si les conséquences négatives l'emportent sur les conséquences positives. L'octroi d'une indemnisation des préjudices est subordonné à une décision préalable sur le fond de l'affaire, par exemple, une décision confirmant le bien fondé de la plainte contre une violation des règles applicables aux marchés publics. Les demandes d'indemnisation des préjudices sont instruites selon les principes généraux du droit danois. Selon les circonstances de l'affaire, les dommages-intérêts peuvent s'élever aux coûts de soumission (damnum emergens) ou aux bénéfices perdus (lucrum cessans). Le Comité peut exiger que les parties lui fournissent toutes les informations nécessaires pour prendre sa décision. Tout manquement à cet ordre autorise le Comité à infliger des amendes quotidiennes qui peuvent être perçues conformément aux règles relatives à la perception de l'impôt sur le revenu.

\subsection{Procédure}

Les procédures devant le Comité des plaintes sont régies par la loi de 2000 et le décret d'application de 2000. Des plaintes peuvent être déposées par écrit par 1) toute personne ayant un intérêt légal à cet égard ; 2) l'Autorité de la concurrence danoise ; 3) le ministre du logement et de l'urbanisme et 4) les organisations (professionnelles) et les pouvoirs publics auxquels le ministre des affaires économiques donne accès aux procédures devant le Comité (ces entités sont énumérées dans l'annexe du décret d'application). La quatrième catégorie a été introduite pour permettre le contrôle des décisions relatives aux marchés publics si aucun soumissionnaire ne souhaite déposer de plainte. Il n'est pas obligatoire que les soumissionnaires adressent au préalable une plainte officielle à l'autorité adjudicatrice mais il y a une obligation d'informer cette dernière au moment du dépôt de la plainte qu'une procédure légale a été initiée. Il n'y a aucun délai obligatoire pour déposer une plainte auprès du Comité ni aucun formulaire-type. La plainte doit être 
notifiée à la partie défenderesse qui, dans un délai précisé par le Comité, doit remettre un mémoire sur les aspects factuels et juridiques de l'affaire. La Comité ou le président agissant en son nom peut permettre à une tierce partie ou à une autorité publique pour laquelle l'affaire revêt une grande importance d'intervenir pour soutenir le requérant ou le défendeur. Le Comité ou son président a le pouvoir de demander au plaignant, à la partie défenderesse ou à la partie tierce de produire toutes les informations nécessaires sur l'affaire. Le plaignant et tout autre intervenant dans la procédure doivent avoir accès au mémoire mentionné ci-dessus ainsi qu'à d'autres pièces à moins que l'accès aux documents ne soit interdit par loi. Ils doivent avoir la possibilité de répondre. Les parties à la procédure doivent être averties du lieu et de l'heure de l'audience et ont le droit de se faire accompagner par un avocat, un comptable ou un autre expert qui les représente. Les audiences ne sont pas ouvertes au public, à moins que toutes les parties n'en décident autrement. Si l'audience est ouverte au public, l'Autorité de la concurrence danoise est informée en conséquence. Le Comité statue sur les affaires non plaidées oralement sur la base de la délibération écrite, éventuellement lors d'une réunion. Le Comité se compose au moins de deux experts que le président nomme à partir d'une liste officielle. Le décret d'application de 2000 dispose également que «si une décision requiert une connaissance du travail d'attestation, de la certification des personnes, des systèmes ou des produits ou de linspection, au moins un des experts doit avoir des connaissances spécialisées dans le domaine concerné » (section 5.3). Les coûts d'expertise sont couverts par le budget du Comité. Il y a un droit de $4000 \mathrm{DKK}$ (environ $500 €$ ). Les honoraires d'avocat, le cas échéant, sont acquittés par la partie représentée. Il n'y a aucun principe général de succès. Selon la loi de 2000, si tout ou partie de la plainte reçoit confirmation, le Comité peut ordonner à l'autorité adjudicatrice de rembourser les coûts supportés par le plaignant pour introduire la procédure. Il n'y a aucun délai obligatoire pour rendre des décisions. Le Comité statue habituellement dans un délai de cinq à six mois. Les décisions sont notifiées directement aux parties et sont publiées sur le site Internet du Comité (www.klfu.dk, version danoise). Certaines d'entre elles sont publiées dans des revues juridiques.

\subsection{Culture des recours}

Les membres du Comité des plaintes ont étudié le droit des marchés publics dans le cadre de leurs études universitaires ou de séminaires et de conférences organisés par des institutions publiques et privées. La pratique professionnelle est également un facteur important. Il en va de même pour les soumissionnaires qui peuvent en outre se faire aider par leur syndicat professionnel. Par principe, de nombreux soumissionnaires considèrent les procédures légales comme un dernier recours et préfèrent éventuellement adresser une réclamation à l'Autorité de la concurrence (ADC). Bien que le système danois des marchés publics soit structuré de façon décentralisée et les pratiques d'achat soient susceptibles de varier d'une entité à l'autre, les connaissances générales des fonctionnaires chargés des marchés publics sont jugées de manière positive. Les affaires traitées par l'ADC attestent d'un niveau élevé de professionnalisme dans les marchés publics. En outre, l'ADC organise des séminaires professionnels (par exemple, sur les nouvelles directives sur les marchés publics de la CEE) ainsi que d'autres organismes. Il n'y a, cependant, aucune association nationale dédiée aux marchés publics ni publication spécialisée. L'attitude des membres des organes de contrôle à l'égard des marchés publics est considérée équilibrée. La jurisprudence est limitée mais revêt une importance considérable en raison du système qui allie codification et interprétation du droit. Les arrêts de la CJUE ont un fort impact et sont habituellement cités en référence dans les décisions du Comité des plaintes ainsi que dans les recommandations de l'ADC. Enfin, il y a un intérêt croissant pour les affaires de marchés publics parmi les groupes d'intérêt, ONG et médias.

\section{Estonie}

Le système de contrôle et de recours de l'Estonie comprend à la fois un contrôle juridictionnel indépendant et un contrôle dépendant de l'administration. La réforme actuelle va combiner le contrôle indépendant de l'administration et le contrôle juridictionnel. Le système peut être divisé en recours précontractuels et postcontractuels. Il n'y a, cependant, aucune différence entre les procédures de contrôle des marchés publics ou des contrats de services d'utilité publique ou entre les contrats de valeur supérieure ou inférieure aux seuils de la CEE. 


\subsection{Plaintes aux autorités adjudicatrices}

Les autorités adjudicatrices ne traitent pas les plaintes, à moins qu'elles ne leur soient adressées spécifiquement plutôt qu'au Bureau des marchés publics (BMP). Il n'est donc pas obligatoire de porter plainte à l'autorité adjudicatrice et, habituellement, les soumissionnaires adressent leurs réclamations directement au BMP. Il n'y a aucune règle précise dans le domaine des marchés publics qui régisse les réclamations devant l'autorité adjudicatrice. Cependant, selon les procédures de gestion des documents (de l'État, des agences gouvernementales locales et des personnes morales), toutes les lettres doivent recevoir une réponse dans un délai de 30 jours à compter de leur réception.

\subsection{Contrôle non-juridictionnel}

Avant la conclusion du contrat, les soumissionnaires peuvent contester une décision relative aux marchés publics en adressant une réclamation au BMP dans un délai de dix jours ouvrables à compter de la date où ils ont connaissance de la décision concernée. Le BMP a été institué par la loi relative aux marchés publics (LMP) et est un bureau exécutif d'État. Les membres de ce corps n'ont pas un statut comparable à celui des juges. La procédure de contrôle du BMP doit être effectuée dans un délai de dix jours ouvrables. Au cours de cette période, la procédure de passation des marchés est suspendue. L'autorité adjudicatrice a le choix entre des procédures écrites fondées sur les documents présentés ou une séance publique où au moins le représentant du BMP, la personne qui a adressé la réclamation et l'autorité adjudicatrice sont présents. Le BMP peut annuler la décision relative aux marchés publics contestée. Les soumissionnaires peuvent faire appel de la décision du BMP auprès d'un tribunal administratif, comme décrit ci-dessous. Ils peuvent également contester une décision en menant parallèlement une procédure auprès du BMP et auprès du tribunal administratif. La procédure de contrôle du BMP est énoncée dans la LMP (chapitre 9, paragraphes 61-67). Actuellement, le BMP est l'organe de contrôle principal : 281 réclamations lui ont été adressées en 2005 sur un total de 7569 procédures d'adjudication. 65 n'ont pas fait l'objet d'une décision, 67 ont répondu aux exigences procédurales, 52 n'ont pas répondu aux exigences procédurales, 66 ont été admises par l'autorité adjudicatrice, 28 ont été retirées et, enfin, dans quatre affaires, le BMP a décidé d'annuler la procédure d'adjudication. La fréquence des recours contre des décisions relatives aux marchés publics auprès du BMP est de $4 \%$. Cependant, le BMP exerce également des fonctions de surveillance et informe les autorités adjudicatrices. Par conséquent, il y a un conflit d'intérêt potentiel. Néanmoins, la procédure de contrôle du BMP est relativement rapide et bon marché (comme discuté ci-dessous) si bien que ceux qui veulent véritablement contester une décision illégale peuvent le faire sans retarder la procédure d'adjudication. Selon le projet de loi sur les marchés publics de 2006, les plaintes doivent être instruites par la Commission des marchés publics (CMP) nouvellement créée publics et indépendante du BMP de manière à supprimer les conflits d'intérêt entre l'administration et l'organe de contrôle.

\subsection{Contrôle juridictionnel}

Les soumissionnaires peuvent également introduire une action auprès du tribunal administratif contre une décision prise par l'autorité adjudicatrice lors d'une adjudication ou y faire appel d'une décision du BMP. Le tribunal administratif peut prendre des mesures provisoires, y compris la suspension de la procédure d'adjudication. Les soumissionnaires peuvent aussi faire appel du jugement du tribunal administratif à la cour d'appel, tribunal régional estonien. Enfin, les jugements de la cour d'appel peuvent être annulés par la Cour nationale d'Estonie à Tartu. Ces trois instances de contrôle juridictionnel peuvent être saisies en même temps que l'envoi d'une réclamation au BMP. Cependant, selon la nouvelle loi de 2006, une réclamation devra être préalablement adressée à la CMP nouvellement créée pour former un recours auprès des tribunaux. En outre, le tribunal administratif ne sera probablement plus à même de prendre des mesures provisoires telles qu'une suspension des procédures d'adjudication. Le code de procédure du tribunal administratif est régi par le code de la procédure de tribunal administratif. L'organe de contrôle de dernier ressort pour les décisions relatives aux marchés publics est la Cour nationale d'Estonie qui a été instituée par la Constitution et remplit les exigences d'une juridiction visées dans l'arrêt Dorsch et Salzmann. Ses juges doivent être des avocats expérimentés et reconnus. L'indemnisation des préjudices ne peut être demandée qu'auprès de la Cour nationale après la conclusion du contrat sur le fondement de la loi relative à la responsabilité de l'État ou du droit des obligations. Sur le fondement de la LMP, un soumissionnaire peut exiger le remboursement des frais de préparation de sa soumission sous réserve d'être en mesure de prouver que si l'autorité adjudicatrice 
n'avait pas violé la loi, le contrat lui aurait été attribué. Le projet de loi de 2006 stipule nouvellement que l'indemnisation des préjudices ne peut être demandée et obtenue auprès du tribunal administratif que si le soumissionnaire peut prouver que le contrat lui aurait été attribué si l'autorité adjudicatrice n'avait pas violé la loi. La décision contestée doit être déclarée illégale mais cela n'affecte pas la validité du contrat déjà conclu. L'indépendance du système judiciaire estonien (tribunaux départementaux et administratifs, tribunal régional, Cour nationale) se fonde sur la Constitution. Les juges sont nommés à vie et ne peuvent être démis de leurs fonctions que par un jugement de la Cour. Ils doivent avoir accompli un cursus universitaire de droit accrédité, avoir un grand sens éthique ainsi que les capacités et la personnalité nécessaires à un juge. Jusqu'ici la CJUE n'a pas été impliquée dans le système national de contrôle et de recours et aucune affaire de violation n'a fait l'objet d'une procédure de la Commission européenne. Un tribunal d'arbitrage traitant les plaintes auprès du BMP a été supprimée en 2001 et a été remplacée par le contrôle juridictionnel décrit ci-dessus.

\subsection{Recours}

Tous les recours, sauf ceux disponibles après la conclusion du contrat, se fondent sur la LMP et peuvent être formés auprès des tribunaux et du BMP. La procédure d'adjudication peut être suspendue ou annulée et des décisions spécifiques de l'autorité adjudicatrice peuvent être annulées. Le fondement juridique de l'annulation ou de la suspension de la procédure d'adjudication est la LMP. Selon la LMP actuelle, la procédure d'adjudication sera toujours suspendue pendant la durée de la procédure auprès du BMP ou des tribunaux. Le BMP ou le tribunal peut prendre en considération les conséquences probables des mesures provisoires pour tous les intérêts susceptibles d'être lésés, y compris l'intérêt public, et décider de ne pas prendre ces mesures si les conséquences négatives l'emportent sur les conséquences positives. Cependant, ceci est rarement fait. Le projet de loi de 2006 supprime cet effet systématique. Au lieu de cela, l'autorité adjudicatrice n'est pas autorisée à conclure le contrat avant la fin de la procédure auprès de la nouvelle Commission. Si l'autorité adjudicatrice ne suit pas cette règle, le contrat est systématiquement frappé de nullité. Le contrat lui-même ne peut être annulé sur le fondement de la LMP dans aucun autre cas. Cependant, ceci peut être fait sur le fondement du droit des contrats (droit des obligations). Après la conclusion du contrat, aucune mesure provisoire n'est disponible. Il n'y a aucune fondement juridique pour ordonner des astreintes.

\subsection{Procédure}

Le code de procédure permet d'impliquer des experts dans les procédures du BMP et des tribunaux. Les experts donnent habituellement leur avis par écrit et parfois oralement au cours des audiences.. La partie perdante supporte les coûts. Actuellement, un soumissionnaire ou toute personne qui est intéressée de participer à la procédure d'adjudication peut adresser une réclamation. Selon le projet de loi 2006, un soumissionnaire, un candidat ou toute personne intéressée ou a l'opportunité de participer à la procédure d'adjudication peut adresser une réclamation. Les droits à acquitter pour faire une réclamation sont régis par la loi sur les droits réglés à l'État. Actuellement, les droits à acquitter pour adresser une réclamation au BMP se montent à $192 €$ si la décision contestée est une décision d'attribution du contrat et $6 €$ dans tous les autres cas. Dans le cas d'un soumissionnaire qui fait appel devant le tribunal administratif, les droits représentent $3 \%$ de la valeur de l'offre, mais pas moins de $6 €$ et pas plus de $320 €$. Si la personne qui introduit une action n'a pas présenté d'offre, les droits se montent à $6 €$. Dans le projet de loi 2006, les droits à acquitter pour adresser une réclamation au BMP se montent à $639 €$ si la valeur estimée du contrat public est inférieure aux seuils de la CEE et se montent à $1278 €$ si elle est égale ou supérieure aux seuils. Dans le cas d'un soumissionnaire qui fait appel devant le tribunal administratif, les droits représentent $1 \%$ de la valeur de l'offre, mais pas moins de $959 €$ et pas plus de $12782 €$. Si la personne qui introduit une action n'a pas présenté d'offre, les droits sont inférieurs. La représentation juridique n'est pas exigée, bien qu'elle soit favorisée, notamment dans les tribunaux. Les honoraires des avocats varient considérablement. La partie perdante supporte ses propres coûts et rembourse la partie gagnante de tous ses frais : droits et honoraires des avocats et experts. Les réclamations doivent adressées au BMP dans un délai de dix jours et les actions introduites auprès des tribunaux dans un délai de 30 jours à compter de la date à laquelle le requérant a eu connaissance ou doit avoir eu connaissance de la violation de ses droits ou des préjudices causés à ses intérêts, mais pas après la conclusion du contrat de marché public. Les réclamations relatives aux documents de l'adjudication doivent être adressées avant que l'autorité adjudicatrice n'ouvre les offres. Les procédures à huis clos sont impossibles dans le domaine des marchés publics. Tous les jugements du 
BMP et décisions des tribunaux sont envoyés aux parties par la poste et sont publiés sur leurs sites Internet respectifs. Cependant, la cour peut clore une séance si les intérêts d'une partie l'exigent mais seulement dans de rares cas tels que la protection des secrets d'État ou de l'ordre public. Les jugements de la Cour nationale d'Estonie sont également publiés sur son site Internet ainsi que dans le Journal officiel destiné à la publication des lois et des jugements de la Cour nationale. Les soumissionnaires peuvent contester des appels d'offres, les documents de soumission et toutes les décisions prises au cours de la procédure d'adjudication, y compris les décisions de qualification et d'attribution du contrat. Le projet de loi 2006 ajoutera probablement aussi à cette liste toutes les actions effectuées dans le cadre de la procédure d'adjudication par l'autorité adjudicatrice, notamment l'ouverture des offres. Les contrats déjà conclus ne peuvent pas être contestés sur le fondement de la LMP. Cependant, l'indemnisation des préjudices peut être demandée sur le fondement du droit des obligations. Il y a des délais obligatoires dans lesquels le BMP et les tribunaux doivent statuer.. Le BMP respecte généralement les délais à moins qu'il ne faille solliciter l'avis d'un expert. Les tribunaux respectent rarement les délais en raison de la surcharge de travail dont ils sont coutumiers. Il n'y a aucune conséquence juridique à ne pas respecter les délais. Aucun formulaire-type n'est utilisé. La jurisprudence a une importance limitée en raison de l'interprétation du droit faite par les tribunaux.

\subsection{Culture du contrôle des actes administratifs}

Les juges, les membres du BMP et les avocats représentant les soumissionnaires ou les entités adjudicatrices dans les procédures acquièrent principalement leur connaissance de la loi sur les marchés publics et du droit communautaire dans le cadre de leurs études universitaires. En outre, les juges ont l'obligation de poursuivre une formation continue et des cours sont dispensés par le ministère des finances et un certain nombre d'entités privées. L'attitude des juges et des experts du BMP à l'égard de l'intérêt public, d'une part, et des intérêts privés des soumissionnaires, de l'autre, est considérée équitable et équilibrée. Les soumissionnaires qui forment des recours contre des décisions relatives aux marchés publics acquièrent principalement leurs connaissances de l'environnement juridique, financier et administratif ainsi que du mode fonctionnement des marchés publics sur le tas. Le ministère des finances dispense des formations et des avocats sont également consultés. Les soumissionnaires sont très bien informés de leur possibilité de contester une procédure d'adjudication. Certains font intentionnellement obstruction aux marchés publics en introduisant des procédures. Le système national de contrôle et de recours doit rendre l'accès aux procédures plus difficile pour que ceux qui contestent les décisions relatives aux marchés publics mais n'agissent pas de bonne foi et essaient de les instrumentaliser en vue de nuire à leurs concurrents. Les responsables des adjudications s'efforcent d'acquérir une formation permanente et de suivre fréquemment des cours. La nature de ces cours est souvent théorique, de telle sorte qu'ils ont de bonnes connaissances juridiques. L'attitude des responsables des adjudications et de leurs supérieurs qui traitent les plaintes à l'égard des soumissionnaires qui adressent des plaines ou entament des actions est neutre. Il n'existe aucune revue spécialisée dans les marchés publics. De temps en temps, des articles sur la loi relative aux marchés publics sont publiés dans la revue juridique Juridica (www.juridica.ee). La loi relative aux marchés publics ne fait pas souvent l'objet de débats lors des conférences ou des séminaires universitaires et professionnels en Estonie. Il n'y a aucune association nationale sur la loi et la politique de marchés publics. Les groupes d'intérêt national ne s'impliquent pas dans les procédures de contrôle et de recours. La formation professionnelle sur la loi et la politique de marchés publics pour les membres du Bureau des marchés publics est dispensée par le ministère des finances et par quelques entités privées. Bien que pris en considération, les arrêts de la CJUE sont rarement mentionnés.

\section{8. $\quad$ Finlande}

Le système de contrôle et de recours de la Finlande en matière de marchés publics se fonde sur un contrôle juridictionnel indépendant. Le système peut être divisé en recours précontractuels et postcontractuels. Il y a deux voies séparées de contrôle juridictionnel pour les contrats de valeur supérieure et inférieure aux seuils de la CEE.

\subsection{Autorités adjudicatrices}

Il n'est pas obligatoire d'adresser une réclamation à l'autorité ou entité adjudicatrice. Il n'y a aucune règle précise dans le domaine des marchés publics qui régisse les réclamations devant l'autorité 
adjudicatrice. Cependant, il est possible d'essayer de régler les différends de cette façon. La même législation s'applique aux opérateurs publics et privés de services d'utilité publique lorsqu'ils prennent des décisions relatives aux marchés publics. En vertu de la loi relative aux marchés publics (http://www.finlex.fi/en/laki/kaannokset/1992/en19921505.pdf), le requérant doit, avant de présenter une requête à la Cour du marché (voir ci-dessous), informer par écrit l'entité adjudicatrice de cette intention.

\subsection{Contrôle juridictionnel}

Depuis 2002, la Cour du marché à Helsinki est le principal tribunal de contrôle des marchés publics en Finlande. 508 plaintes ont été déposées auprès de la Cour du marché contre des décisions relatives aux marchés publics en 2005 et la Cour a rendu 206 arrêts. 26\% des requêtes ont été accueillies, $33 \%$ ont été rejetés, $8 \%$ ont été écartées et $33 \%$ ont été périmées ou abandonnées. Entre 1994 et 2002, le Conseil de la concurrence avait la juridiction pour rendre des arrêts dans des affaires relatives aux marchés publics. Lors de l'entrée en vigueur de la nouvelle législation, la Cour du marché ne pourra plus statuer sur des affaires de marchés publics inférieurs aux seuils nationaux. En deuxième et dernier ressort, il est possible de faire appel des décisions des tribunaux de première instance auprès de la Cour administrative suprême à Helsinki. Des demandes d'indemnisation des préjudices peuvent être faites aux tribunaux de droit commun de première instance. Ces juridictions sont indépendantes de l'exécutif, de l'administration ou de toute autre entité de l'État et leurs décisions sont de nature juridictionnelle. Tous les tribunaux finlandais exercent le pouvoir judiciaire. Ils sont indépendants et liés seulement par la loi. Aucune partie extérieure ne peut intervenir dans la prise de décision des tribunaux ; cette indépendance est garantie par la Constitution. Le président et les membres de l'organe de contrôle de dernier ressort doivent une grande connaissance et expertise du droit administratif. Les tribunaux ont été institués par la Constitution, la législation spéciale sur les tribunaux de droit commun et la loi sur la Cour du marché (http://www.finlex.fi/en/laki/kaannokset/2001/en20011527.pdf). Tous les juges doivent être des avocats expérimentés et reconnus. Ils sont nommés selon une procédure générale.

\section{$8.3 \quad$ Recours}

La protection juridique est possible contre toutes les décisions relatives aux marchés publics, notamment le choix d'une procédure d'adjudication particulière, les décisions de présélection ou de qualification. Selon le chapitre 9 de la loi sur les marchés publics (LMP), la Cour du marché peut (1) annuler tout ou partie de la décision d'une entité adjudicatrice; (2) interdire à l'entité adjudicatrice de modifier le document concernant le contrat ou de poursuivre d'une autre façon une procédure incorrecte ; (3) exiger de l'entité adjudicatrice qu'elle rectifie la procédure incorrecte ou (4) ordonner à l'entité adjudicatrice d'indemniser un partie qui aurait eu une possibilité réelle de remporter le contrat si la procédure avait été suivie correctement.

La Cour du marché peut, afin de souligner l'importance du respect de l'interdiction visée à la section 9 (1) (2) et de l'obligation visée à la section 9 (1) (3), infliger une amende conditionnelle, conformément à la loi relatives aux amendes conditionnelles (1113/1990). L'introduction d'une action n'a pas un effet suspensif systématique. Après le dépôt d'une plainte, Cour du marché peut, à titre de mesure provisoire, interdire ou suspendre l'exécution d'une décision ou ordonner autrement que la procédure d'attribution du contrat soit suspendue pendant la période où l'affaire est à l'étude. L'interdiction ci-dessus se fonde sur la section 9 (1) (2) et l'obligation visée à la section 9 (1) (3) peut également être imposée à titre de mesure provisoire pendant la période où l'affaire est instruite par la Cour du marché. Si la décision a été prise d'adopter une mesure visée à la sous-section 2, la Cour du marché veille à ce que cette mesure ne cause pas des préjudices supérieurs aux avantages à la partie adverse ou aux droits d'autres parties ou à l'intérêt public. Un juge en chef ou un autre juge de la Cour du marché peut, dans les cas urgents, prendre une mesure provisoire.

Selon la section 8, sous-section 1 PPL, celui qui a occasionné des préjudices à un candidat, soumissionnaire ou entrepreneur par une procédure contraire à la loi sera obligé d'indemniser les préjudices. La sous-section 2 établit que, si une demande d'indemnisation des préjudices représentant les coûts de participation à la procédure de soumission est présentée par le candidat ou le soumissionnaire, il doit seulement prouver la non-conformité de la procédure comme visé à la sous-section 1 et qu'il aurait eu une possibilité réelle de remporter le contrat si la procédure avait été correcte. L'indemnisation des préjudices visée à la sous-section 1 ne se limite pas aux frais de participation à la procédure d'adjudication supportés par le soumissionnaire et peut être accordée pour la perte de contrat. Il n'est pas nécessaire que la 
décision contestée soit annulée avant de réclamer des dommages-intérêts. La Finlande a introduit la procédure de conciliation décrite au chapitre 4 de la directive 92/13/CEE.

La jurisprudence a une importance limitée en raison de l'interprétation de la législation que fournissent les jugements. Les arrêts de la CJUE ont un grand impact sur les procédures de contrôle des marchés publics et sont souvent invoqués dans les procédures comme règles d'interprétation. Pendant les cinq dernières années, la Cour du marché n'a fait aucun renvoi préjudiciel à la CJUE. Pendant les deux dernières années, la Commission européenne a exprimé environ cinq avis motivés contre la Finlande concernant des questions de marchés publics.

\subsection{Procédure}

Les dispositions de la loi sur le code de procédure administrative (http://www.finlex.fi/en/laki/kaannokset/1996/en19960586.pdf) couvrent principalement la procédure d'appel dans les affaires de marchés publics. Selon la section 9 b PPL, le droit d'agir en justice et d'introduire une procédure est donné à la partie concernée, au ministère du commerce et de l'industrie et au ministère des finances pour les contrats de travaux ou les domaines visés à la section 5 (4) et à l'autorité publique qui a accordé à une aide spécifique au contrat l'aide pour le contrat de travaux en question. L'action doit être introduite dans un délai de 14 jours à compter de la date à laquelle le soumissionnaire a été notifié par écrit de la décision en question et a reçu des instructions écrites pour la saisine de la Cour du marché (instructions pour la requête). Le requérant doit payer $204 €$ de droits pour l'audience à la Cour du marché. La LMP contient également une disposition qui oblige les autorités, à savoir les tribunaux administratifs à assurer un examen approprié de l'affaire. Ainsi, les parties sont habituellement en mesure de poursuivre la procédure sans l'assistance d'un avocat ce qui facilite le dépôt d'un appel et de l'accès aux voies de recours. Il y a un principe de succès concernant les coûts. Le principe s'applique rarement, cependant, aux autorités publiques. Selon la loi sur le code de justice administrative section 74, soussection 3, un particulier ne doit pas être tenu responsable des coûts d'une autorité publique à moins que la personne n'ait introduit une action manifestement infondée. Les décisions de la Cour administrative suprême sont envoyées aux parties concernées par courrier traditionnel. Les décisions qui ont par la suite un intérêt pour l'application du droit dans des cas identiques ou semblables ou sont d'intérêt public sont publiées dans le recueil annuel de la Cour administrative suprême. Ce sont principalement les parties concernées qui décident de la participation d'experts techniques et autres à la procédure. Dans ce cas, ce sont les parties elles-mêmes qui supportent les coûts de leur participation. Dans certains cas, la Cour peut faire appel d'office à des experts au cours de la procédure. Si nécessaire, la Cour peut décider de tenir une audience à huis clos lors de la présentation d'un document confidentiel ou lorsque des informations soumises à l'obligation de discrétion sont révélées à l'audience. Les informations commerciales confidentielles sont protégées par la loi sur la transparence des activités gouvernementales. À moins qu'il n'en soit précisé autrement, les documents doivent rester secrets s'ils contiennent des informations sur une entreprise privée ou des secrets professionnels comme le doivent d'autres documents contenant des informations comparables d'une entreprise privée, si l'accès à ces informations risque de causer une perte économique à l'entreprise privée, à condition que ces informations ne concernent pas la sauvegarde de la santé des consommateurs ou la protection de l'environnement ou à la promotion des intérêts de ceux qui souffrent de la poursuite de l'activité et que cela ne concerne pas les devoirs de l'entreprise ou l'exécution de ces devoirs. Il n'y a aucun délai obligatoire imparti aux tribunaux pour statuer ; 2005, la Cour du marché a rendu ses décisions environ 6,2 mois après que l'introduction de l'action.. Le temps peut varier selon la complexité de l'affaire.

\subsection{Culture du contrôle des actes administratifs}

Les juges et les avocats des marchés publics représentant les soumissionnaires ou les entités adjudicatrices dans les procédures de contrôle acquièrent leur connaissance du droit des marchés publics et du droit communautaire au cours de leurs études universitaires, de leur formation professionnelle, de leur formation continue, des cours dispensés par des établissements publics et privés et par l'étude de la jurisprudence ainsi que sur le tas. L'attitude des juges et des membres des organes de contrôle des marchés publics à l'égard de l'intérêt public et des intérêts privés des soumissionnaires est décrite comme juste. Les soumissionnaires exerçant des recours contre des décisions relatives aux marchés publics acquièrent leurs connaissances de l'environnement juridique, financier et administratif et du fonctionnement des marchés 
publics par la pratique, par des avocats, des conseillers et par leurs organismes professionnels. La plupart des soumissionnaires n'envisagent de former un recours qu'en dernier ressort. La connaissance des fondements juridiques des marchés publics qu'ont les responsables des adjudications est « très bonne ». L'attitude des responsables des adjudications et de leurs supérieurs traitant les plaintes à l'égard des soumissionnaires qui leur adressent des plaintes ou entament des actions est décrite comme «très positive ». Il n'y a aucune publication ou revue universitaire consacrée aux marchés publics ainsi qu'au système de contrôle et de recours. Le droit des marchés publics fait fréquemment l'objet de débats lors de séminaires. Il n'y a aucune association nationale sur le droit et la politique de marchés publics et les questions relatives aux marchés publics ne retiennent pas particulièrement l'attention des médias. En général, différentes associations de consommateurs ou groupements d'intérêt économique formulent des observations sur les domaines les concernant ce qui est aussi le cas pour les problèmes de marchés publics. Il n'y a de formation professionnelle spécifique sur le droit et la politique des marchés publics pour les responsables des marchés publics. La force du système, c'est qu'il n'y a presque aucun obstacle qui empêche les soumissionnaires de recourir à la Cour du marché qui a de très bonnes connaissances sur le droit des marchés publics. La longue durée de la procédure est une faiblesse probable qui peut se révéler à l'avenir, car le nombre d'affaires portées devant la Cour du marché devrait augmenter. Le système de contrôle et de recours n'est pas considéré efficace si la durée de la procédure est que celle de la passation des marchés dans le secteur public (habituellement un an).

\section{France}

Le système de contrôle et de recours français s'appuie sur un contrôle juridictionnel indépendant. La division du droit français en droit privé et droit public joue un rôle important. Les contrats attribués par l'État, ses établissements publics, les collectivités territoriales et leurs établissements publics sont assujettis au code de marchés publics (« code des marchés publics »-CMP, décret 2006-975 du 1er août 2006, disponible sur le site Internet : http://www.legifrance.gouv.fr.). Ces contrats relèvent toujours du droit public ( « contrats administratifs»). Les conflits résultant de ces contrats relèvent de la juridiction des tribunaux administratifs. En revanche, les contrats attribués par les établissements publics non assujettis au CMP, les entités de droit privé répondant aux critères « d'établissements régis par le droit public » selon les directives communautaires de coordination des procédures de passation des marchés publics ainsi que certaines entités de nature spécifique (comme la Banque de France) et les opérateurs de services d'utilité publique sont assujettis à l'ordonnance 2005-649 du 6 juin 2005. Deux décrets mettent en application l'ordonnance mentionnée ci-dessus (décret 2005-1742 du 30 décembre 2005 pour les autorités adjudicatrices du secteur classique et décret 2005-1308 du 20 octobre 2005 pour les opérateurs de services d'utilité publique). La nature publique ou privée des contrats est fonction du rattachement de ces établissements au droit public ou au droit privé. Les conflits résultant de ces contrats relèvent de la juridiction administrative ou de la juridiction civile. Dans les deux cas, les soumissionnaires lésés peuvent introduire une procédure précontractuelle en saisissant le juge des référés pour obtenir des mesures provisoires. En principe, aucune plainte préalable ne doit être notifiée à l'autorité adjudicatrice. La procédure générale peut aussi être utilisée pour suspendre la procédure d'adjudication ou pour frapper de nullité un contrat irrégulièrement attribué. La demande d'indemnisation des préjudices peut être faite indépendamment dans les actions mentionnées ci-dessus à l'exception des référés précontractuels et son accueil dépend de la capacité du soumissionnaire évincé à prouver qu'il a été privé d'une vraie possibilité de remporter le contrat.

\subsection{Contrôle extra-juridictionnel}

Tout soumissionnaire peut s'adresser aux entités adjudicatrices pour demander un contrôle administratif de la procédure de passation de marchés. En outre, le Réseau des marchés publics (PPN) peut aider les soumissionnaires lors d'une procédure de marché public dans un État-membre autre que le leur. Si une entreprise est implantée dans un pays PPN et éprouve des difficulté en participant à une procédure de passation de marchés dans un autre État-membre que le sien, le contact national du réseau peut lui apporter son aide avant l'attribution et la signature du contrat. En outre, conformément à la directive CE 92/13/CEE, les mécanismes d'attestation (circulaire du 24 septembre 2001) et de conciliation (circulaire du 20 septembre 2001) sont disponibles dans le secteur des services d'utilité publique. Néanmoins, ces mécanismes sont rarement utilisés dans la pratique. 


\subsection{Contrôle juridictionnel}

Avant la conclusion du contrat, les soumissionnaires peuvent contester toute décision relative à la procédure de passation de marché ainsi que la décision de rejet de l'offre. Ils peuvent également demander une indemnisation des préjudices à l'autorité adjudicatrice qui a abandonné la procédure d'adjudication. Après la conclusion du contrat, les soumissionnaires évincés peuvent requérir l'annulation des actes relatifs à la procédure d'adjudication (par exemple, décision de refus, décision autorisant la signature du contrat). Le soumissionnaire retenu peut contester tout acte de l'autorité adjudicatrice lié à l'exécution, à la modification ou à l'abandon du contrat. Compte tenu de la nature (publique ou privée) du contrat et indépendamment de la valeur estimée du contrat, toutes les décisions ou actes des autorités adjudicatrices mentionnés ci-dessus peuvent être contestés devant les tribunaux administratifs ou les tribunaux de droit commun. Le réseau administratif de justice est régi par le code de justice administrative («code de justice administrative », CJA). Il compte 37 tribunaux administratifs (première instance), huit tribunaux administratifs d'appel (deuxième instance) et le Conseil d'État (dernier ressort, Palais Royal, 75100 Paris 01 SP; téléphone: +33 1402080 00; site Internet : http://www.conseil-etat.fr). Le nombre d'affaires portées devant les tribunaux administratifs a augmenté depuis 2001 (les chiffres comprennent les litiges relatifs à l'exécution du contrat) : en première instance, 4365 affaires en 2001, 4627 en 2002, 4743 en 2003 et 5048 en 2004 ; en deuxième instance, 499 affaires en 2001, 683 en 2002, 724 en 2003 et 755 en 2004 ; devant le Conseil d'État, 165 affaires en 2001, 128 en 2002, 180 en 2003 et 133 en 2004. Le nombre de décisions établies, totalement ou partiellement, en faveur du requérant est sensiblement plus élevé que celui des rejets (concernant les décisions précontractuelles). En 2004, 2538 décisions favorables ont été prononcées par les tribunaux administratifs contre 1515 demandes rejetées. Les appels devant les tribunaux administratifs d'appel et, en dernier ressort, devant le Conseil d'État ont habituellement un résultat négatif. Les juges administratifs prêtent une attention particulière aux obligations des autorités adjudicatrices liées à la procédure de passation des marchés et au contrat ; ainsi les tribunaux administratifs d'appel tendent à confirmer les décisions rendues en première instance. Le réseau (judiciaire) des tribunaux de droit commun est régi par le code de l'organisation judiciaire («Code de l'organisation judiciaire »- COJ). Il comprend 473 tribunaux d'instance (première instance pour les litiges d'une valeur inférieure à $7600 €$ ) et 181 tribunaux de grande instance (première instance pour les litiges d'une valeur supérieure à $7600 €) 35$ cours d'appel (deuxième instance) et la Cour de Cassation (dernier ressort), 5, Quai de l'Horloge, 75055 Paris 01 SP; téléphone: +33144325050 ; site Internet: http://www.courdecassation.fr). Le Conseil d'État et la Cour de Cassation ont été institués par la loi, sont permanents et indépendants du pouvoir exécutif, de l'administration ou de toute entité gouvernementale. La procédure devant ces tribunaux de dernier ressort est contradictoire. Les juges des deux organes de contrôle de dernier ressort sont inamovibles. Les présidents et autres membres sont des magistrats et fonctionnaires issus de l'École Nationale de la Magistrature (juges des tribunaux de droit commun) ou de l' École Nationale d'Administration (juges des tribunaux administratifs). Ils sont nommés par l'exécutif (le président ou gouvernement de la république Française). Les organes de contrôle en dessous des tribunaux de dernier ressort prennent des décisions qui ont force de loi.

Les décisions d'attribution de marchés peuvent également être examinées par les tribunaux correctionnels (juridiction pénale chargée de juger les délits) si elles sont constitutives d'un délit réprimé par le code pénal. En particulier, l'article 432-14 du code punit le « délit de favoritisme » qui consiste à procurer à autrui un avantage injustifié par un acte contraire aux dispositions législatives et réglementaires ayant pour objet de garantir l'accès et l'égalité des candidats dans les marchés publics. Enfin, la Cour des comptes, juridiction financière de l'ordre administratif chargée de contrôler la régularité des comptes publics peut appliquer des sanctions aux fonctionnaires responsables d'irrégularités dans une procédure de passation de marché.

\section{$9.3 \quad$ Recours}

Selon la réglementation nationale transposant les directives «recours» de la CEE, les référés précontractuels peuvent être demandés par les personnes qui ont un intérêt à conclure le contrat et sont susceptibles d'être lésées par l'irrégularité de la procédure d'adjudication portant préjudice à la transparence et à l'égalité commise par l'autorité ou l'entité adjudicatrice. Les soumissionnaires lésés ont dix jours pour former un recours à compter de la date officielle du rejet de leur offre (délai suspensif) mais ils peuvent saisir le juge du demande de référé précontractuel de la date de la publicité jusqu'au dixième jour après le 
rejet officiel de leur offre. La juridiction saisie dépend de la nature (publique ou privée) du contrat. Dans le cas des contrats de droit public, aucune plainte antérieure ne doit être adressée à l'autorité adjudicatrice. Les dispositions concernées sont les suivantes :

Dans le secteur classique (directive CE 89/665/CEE) : article L. 551-1 du code de justice administrative (référé précontractuel devant le tribunal administratif si le contrat relève du droit public); $\S 1^{\circ}$ de l'article 24 de l'ordonnance 2005-649 du 6 juin 2005 (référé précontractuel devant le tribunal judiciaire si le contrat relève du droit privé).

Dans le secteur des services d'utilité publique (directive CE 92/13/CEE) : article L. 551-2 du code de justice administrative (référé précontractuel devant le tribunal administratif si le contrat relève du droit public) ; $\S 1^{\circ}$ de l'article 33 de l'ordonnance 2005-649 du 6 juin 2005 (référé précontractuel devant le tribunal judiciaire si le contrat relève du droit privé).

Cette réglementation prévoit la saisine d'un seul juge, c'est-à-dire le président du tribunal administratif/du tribunal judiciaire compétent ou de son délégué. Les recours auprès des juridictions administratives n'ont pas un effet suspensif. Le juge décide, avant la signature du contrat, si ce dernier a été attribué conformément aux obligations de publicité et de mise en concurrence auxquelles est soumise la passation de contrats administratifs. Si le contrat est signé avant que la décision ait été rendue, le juge est dessaisi de l'affaire. Cette règle est considérée comme la faiblesse principale du système français. Par conséquent, les articles L. 551-1 et 551-2 du code de justice administrative autorisent le président du tribunal administratif à ajourner la signature du contrat à compter de la date de la saisine pendant une période maximale de 20 jours ; cette option est utilisée systématiquement et vise à remédier à la faiblesse du système. Pour statuer, le juge examine une grande variété de motifs (par exemple, motifs sous-jacents à l'exclusion d'un candidat, la légalité de la composition de la commission d'appel d'offres). Le juge n'est cependant pas autorisé à statuer sur les mérites respectifs des soumissionnaires ou sur leur capacité légale à répondre à un appel d'offres. Dans le secteur classique, le juge peut ordonner à l'autorité adjudicatrice de se conformer à ses obligations et de suspendre l'exécution de toute décision qui se rapporte à la passation du contrat. Il peut en outre annuler les décisions qui se rapportent à la passation du contrat et supprimer les clauses ou prescriptions destinées à figurer dans le contrat et qui méconnaissent lesdites obligations. Dans le secteur des services d'utilité publique, le juge peut ordonner à l'entité adjudicatrice de se conformer à ses obligations dans un délai particulier. Il peut, en outre, prononcer une astreinte provisoire courant à l'expiration des délais impartis. Le juge peut toutefois, en considération de l'ensemble des intérêts susceptibles d'être lésés et notamment de l'intérêt public, écarter ces mesures lorsque leurs conséquences négatives pourraient l'emporter sur leurs avantages. Si, à la liquidation de l'astreinte provisoire, le manquement constaté n'a pas été corrigé, le juge peut prononcer une astreinte définitive. L'astreinte, qu'elle soit provisoire ou définitive, est indépendante des dommages et intérêts. L'astreinte provisoire ou définitive est supprimée en tout ou partie s'il est établi que l'inexécution ou le retard dans l'exécution de l'injonction du juge provient, en tout ou partie, d'une cause étrangère Dans les deux secteurs, le juge statue en forme de référé pour ne pas empêcher la poursuite des négociations avant la passation du contrat. La décision doit être prise dans les 20 jours à compter de la saisine. Tout dépassement de ce délai permet à l'entité adjudicatrice de signer le contrat en conséquence de quoi le juge est dessaisi de l'affaire. Les tribunaux administratifs statuent dans les délais (en moyenne 24 jours en 2001, 20 en 2002, 23 en 2003 et 19 en 2004). Les décisions peuvent faire l'objet d'un appel auprès du tribunal de dernier ressort compétent (le Conseil d'État pour les contrats de droit public et la Cour de Cassation pour les contrats de droit privé). Le nombre de référés précontractuels devant les tribunaux administratifs a augmenté depuis $2000: 149$ saisines en 2000, 173 en 2001, 265 en 2002, 290 en 2003 et 474 en 2004. Ces chiffres prouvent que le système français permet de rectifier rapidement et facilement l'attribution irrégulière de contrats. Il semble toutefois que ces recours soient souvent entrepris pour bloquer la procédure d'adjudication des marchés. C'est probablement la raison pour laquelle leur résultat n'est habituellement pas favorable au requérant (en 2004, 139 requêtes accueillies en tout ou partie par les tribunaux administratifs et 174 rejets).

Les parties peuvent aussi entreprendre une procédure de droit commun afin de demander au juge de prononcer la nullité d'un contrat irrégulièrement attribué. En outre les parties contractantes ainsi que les parties tierces qui ont un intérêt au contrat (comme les candidats évincés) sont habilités à demander la suspension ou l'annulation des actes relatifs à l'attribution du contrat (mesures de publicité, décision autorisant la signature du contrat) ou leur exécution. Les requêtes en annulation doivent être déposées dans 
les deux mois de la publication ou de l'avis des actes concernés. Ce délai s'applique seulement devant le juge administratif. Les requêtes en annulation n'ont pas d'effet suspensif (article L. 4 du code de justice administrative). Les décisions doivent être prononcées dans «un délai raisonnable». En cas de dépassement injustifié des délais, les dommages et intérêts peuvent être réclamés. En principe, l'annulation des actes ou des décisions liés au contrat est susceptible de permettre au requérant de demander une indemnisation financière. Devant les tribunaux de droit commun, les tierces parties ne peuvent introduire une action en annulation que s'ils justifient d'un intérêt pour le contrat et d'un motif d'ordre public (ou motivation dérivant de règles de nature obligatoire). Le principal avantage des procédures de droit commun, c'est qu'elles peuvent être utilisées si le référé précontractuel est devenu impossible en raison de la signature du contrat.

En droit français, les demandes de dommages et intérêts en raison de l'irrégularité d'une décision ou d'un acte sont indépendantes des référés précontractuels et peuvent l'être aussi des requêtes en annulation liées au contrat. Selon la nature du contrat et de la juridiction, les dommages et intérêts sont régis par le droit civil (code civil) ou par la jurisprudence administrative. Une plainte officielle antérieure à l'autorité adjudicatrice est nécessaire. L'acte ou la décision contesté doit être, en principe, déclaré avant que des dommages et intérêts ne soient accordés. Les soumissionnaires qui se considèrent rejetés à tort peuvent obtenir une indemnisation sous réserve qu'ils prouvent :

- $\quad$ que l'autorité adjudicatrice a commis une infraction ; et

- $\quad$ qu'ils avaient un vrai chance de remporter le contrat. Les requérants qui ne remplissent pas cette condition ont simplement droit au remboursement des coûts de participation à l'appel d'offres.

Les requérants doivent évaluer et justifier eux-mêmes le montant des dommages et intérêts demandés. Les juges contrôlent cette évaluation ad hoc.

\subsection{Procédure}

Dans les procédures devant les tribunaux administratifs, le code de justice administrative ( code de justice administrative »-CJA) s'applique. Dans les procédures devant les tribunaux de droit commun, le nouveau code de procédure civile («nouveau code de procédure civile», NPC, traduction en anglais sur le site Internet officiel : http://www.legifrance.gouv.fr) et le code de l'organisation judiciaire («code de l'organisation judiciaire »- COJ) s'appliquent. Il n'y a aucun formulaire ou document-type pour les recours en matière de marchés publics. Les requérants doivent, cependant, respecter certaines mentions obligatoires et règles formelles. La participation des experts est possible aux conditions des articles R.6211 à R.621-14 du CJA et des articles 232 284-1 du NCPC. Il n'y a pas de procédure spécifique qui permette de prendre en considération la nécessité de protéger la confidentialité des informations des entreprises comme les procédures à huis clos sauf pour les contrats de l'armée. Il n'y a aucun droit à acquitter. Il n'y a pas de frais supplémentaires liés aux recours en matière de marchés publics. Comme dans toutes les procédures de droit commun, si le ministère d'un avocat est requis, les requérants doivent payer eux-mêmes ses honoraires. Ils doivent également payer les coûts des actes de procédures effectués par les avocats, avoués, huissiers ainsi que les frais de voyage, le cas échéant, des avocats, les honoraires des experts et l'indemnisation des frais des témoins etc. Chaque partie doit payer son propre avocat. La partie perdante, cependant, paye les autres coûts (les « dépenses » comme les honoraires des experts) et les frais de justice. Les décisions des tribunaux ainsi que des organes de dernier ressort sont communiquées par la poste. Les décisions les plus importantes sont publiées en ligne sur (http://www.legifrance.gouv.fr) ou dans bulletins officiels («Recueil Lebon » pour le Conseil d'État, le «Bulletin civil » pour le Cour de Cassation). Toute personne peut en outre demander une copie d'un jugement au greffe du tribunal concerné.

\section{$9.5 \quad$ Culture du recours}

Les juges et les avocats ont pu étudier la réglementation des marchés publics et le droit communautaire dans le cadre de leur cursus universitaire. D'autres doivent recourir à la formation, aux cours et séminaires organisés par les cabinets d'avocats privés, les autorités gouvernementales comme le ministère de la justice ou les institutions internationales comme l'UE. Ces dernières années, il y a eu une spécialisation croissante dans le code des marchés publics (master spécialisé, conférences universitaires). De nombreuses revues juridiques consacrent une rubrique aux marchés publics. Trois revues juridiques traitent exclusivement des marchés publics : la revue mensuelle Contrats publics - Actualité de la Commande et des Contrats Publics 
(CP-ACCP) éditée par les éditions du Moniteur ; le mensuel Contrats et marchés publics édité par les éditions Juris-Classeur ; et la revue bimensuelle Contrats et Marchés publics (BJCP) éditée par les éditons EFE. Les entreprises peuvent s'informer sur le code des marchés publics grâce à la formation et aux conférences ou grâce à l'aide fournie par des organismes professionnels (tels que des chambres de commerce). La formation des fonctionnaires chargés des marchés publics est principalement assurée par l'institut de la gestion publique et du développement économique (IGPDE), qui dépend du ministère des finances ainsi que par l'association pour l'achat dans les services publics (APASP, http://www.apasp.com), qui est l'association nationale la plus importante sur les marchés publics français et de l'UE. L'APASP organise aussi des conférences internationales et édite des guides et des recommandations de bonnes pratiques. La plupart des fonctionnaires chargés des marchés publics sont membres d'associations comme l'APASP. Il y a également nombreux forums sur les marchés publics : le Mouvement des entrepreneurs de France (MEDEF), Fédération nationale des sociétés d'économie mixte, l'Assemblée des chambres françaises de commerce et d'industrie, la Confédération de l'artisanat et des petites entreprises du bâtiment, la Confédération générale des petites et moyennes entreprises, le Conseil national de l'ordre des architectes, la Fédération française du bâtiment, la Fédération nationale des travaux publics, le Syndicat de la presse quotidienne régionale, l'Association des agences-conseils en communication etc. L'avis des organismes mentionnés ci-dessus est sollicité pour l'élaboration de la réglementation des marchés publics. La presse et la télévision couvrent de temps en temps les procédures de contrôle des marchés publics. L'impact des arrêts de la CJUE est considérable. Les fonctionnaires chargés des marchés publics doivent se conformer à ces arrêts et les requérants peuvent les invoquer devant les tribunaux. La jurisprudence française revêt aussi une grande importance en raison de la structure du système judiciaire français qui allie codification et jurisprudence.

\section{Allemagne}

Les marchés publics (Vergaberecht) en Allemagne sont régis par un ensemble de règles structurées à trois niveaux : la quatrième partie de la loi fédérale contre les restrictions de la concurrence, connue sous le nom de GWB (niveau législatif, traduction en anglais sur

http://www.bundeskartellamt.de/wEnglisch/download/pdf/GWB_7_e.pdf) ; la réglementation de marchés publics de 2001 et modifications, connue sous le nom de $\mathbf{V g V}$ (niveau infra-législatif traduction en anglais d'une version antérieure du $\mathrm{VgV}$ dans Klaxon de Lutz, marchés publics en Allemagne, C.H. Beck, Bruylant, Giuffrè Editore, fourmi. N. Sakkoulas, Stämpfi, 2001, Pp. 79 et seq.) ; et trois ensembles de règles liées à l'attribution des contrats de travaux (VOB/A 2006), les fournitures et les services (VOL/A 2006) et les services professionnels (VOF 2006) (niveau infra-réglementaire, traduction en anglais d'une version plus ancienne de VOB/A, de VOL/A et de VOF dans Klaxon de Lutz, marchés publics en Allemagne, C.H. Beck, Bruylant, Giuffrè Editore, fourmi. N. Sakkoulas, Stämpfi, 2001, p. 91 et suivantes). Les règles mentionnées ci-dessus transposent les dispositions concernées des directives relatives aux marchés publics de la CEE et s'appliquent ainsi seulement au-dessus des seuils de la CEE. En dessous des seuils, les marchés publics sont régis par la loi de finances fédérale et municipale ainsi que par quelques dispositions du VOB/A et du VOL/A. La structure compliquée du système allemand est imputable à l'évolution historique des règles intérieures des marchés publics et à la structure fédérale de la République fédérale d'Allemagne. Le système de contrôle et de recours se fonde sur le contrôle juridictionnel et quasijuridictionnel. (voir

http://www.bundeskartellamt.de/wDeutsch/download/pdf/Merkblaetter/Merkblaetter englisch/06Informati onsblatt_E.pdf) Au-dessus des seuils de la CEE et en vertu du GWB (§97 VII), les soumissionnaires ont des droits subjectifs à une procédure d'appel d'offres transparente, concurrentielle et non-discriminatoire. Ces droits peuvent être exercés par une juridiction spéciale, les Chambres des marchés publics (Vergabekammern, VK) et, sur appel (sofortige Beschwerde), par les cours d'appel de droit commun (Oberlandesgerichte, OLG). En dessous des seuils, les soumissionnaires n'ont aucun droit spécifique et ne peuvent réclamer des dommages et intérêts que devant les tribunaux de droit commun. Cependant, la question de savoir si les décisions relatives à des contrats non régis par le GWB peuvent être contestées devant les tribunaux administratifs fait l'objet d'une controverse. Dans certains Länder, les tribunaux administratifs se sont déjà considérés compétents pour statuer sur de tels conflits. 


\subsection{Contrôle extra-juridictionnel}

Dans le secteur des services d'utilité publique, le $\mathrm{VgV}$ transpose l'attestation, la conciliation et les mécanismes correctifs établis par la directive CE 92/13. Il n'y a aucun organe spécial d'arbitrage, mais le GWB permet à des soumissionnaires de contester les décisions relatives aux marchés publics devant les Comités de contrôle des marchés publics (Vergabeprïfstellen). Ces comités peuvent être mis en place au niveau des Länder et de la fédération et ont le pouvoir d'ordonner aux autorités adjudicatrices, sur requête ou ex officio, d'annuler une décision illégale ou de prendre une mesure légale Ces comités n'ont pas le pouvoir de suspendre une procédure de passation de marché. La procédure de contrôle devant ces comités n'est pas une condition préalable à la présentation d'un recours devant les chambres des marchés publics. En revanche, il est obligatoire que les soumissionnaires adressent une réclamation à l'autorité adjudicatrice préalablement à un recours devant les chambres ( $\$ 107$ III GWB). Chaque autorité adjudicatrice décide elle-même du service qui prend en charge ces réclamations.

\subsection{Contrôle juridictionnel}

Avant la conclusion du contrat et si la valeur estimée du contrat atteint ou dépasse les seuils de la CEE, les soumissionnaires peuvent contester toute décision de l'autorité adjudicatrice devant une Chambre des marchés publics. Un contrat déjà attribué ne peut pas être annulé (§ 114 II GWB). Il y a 29 Chambres des marchés publics. La chambre doit statuer dans un délai de cinq semaines à compter de sa saisine. Dans les cas dûment justifiés, ce délai peut être prolongé ; cette possibilité a été utilisée dans presque $27 \%$ des recours en 2005. Si la Chambre ne respecte pas ce délai, la demande est considérée rejetée. Il peut être fait appel de la décision de la Chambre en déposant une plainte immédiate (sofortige Beschwerde) auprès de la chambre des marchés publics de la Cour d'appel régionale compétente (OLG) dans un délai de deux semaines à compter de la communication de la décision aux parties ou à l'échéance du délai (cinq semaines) dans lequel la Chambre doit avoir statué. Il n'y a aucun délai obligatoire pour qu'un OLG rende une décision. Il n'y a donc aucun organe de contrôle de dernier ressort pour les marchés publics : l'OLG de chaque Land est responsable des décisions relatives aux marchés publiques que prennent les autorités adjudicatrices situées dans le Land. En outre, l'OLG de Düsseldorf a la juridiction sur les marchés publics conclus par des autorités adjudicatrices fédérales (tels que les ministères fédéraux). Les OLG sont des tribunaux permanents institués par loi dont les décisions ont force de loi et dont les membres sont indépendants de l'exécutif ou de toute autre entité gouvernementale (article 97 I de la constitution allemande, Grundgesetz). Les juges sont nommés parmi les avocats qualifiés ayant réussi un examen en deux parties. Si une OLG souhaite s'écarter des décisions d'une autre OLG ou de la Cour suprême fédérale (Bundesgerichtshof, BGH), elle est obligée de renvoyer l'affaire à la Cour suprême fédérale qui s prononce à la place de l'OLG. En 2004, il y au 1493 demandes faites devant les chambres et 314 plaintes immédiates avant l'OLG.

\section{$10.3 \quad$ Recours}

Par principe, le droit allemand distingue la protection juridique primaire (assurée par les Chambres de marchés publics) et la protection juridique secondaire (les dommages et intérêts). Si une Chambre de marchés publics décide que les droits du demandeur ont été violés, elle prend toute mesure appropriée pour corriger l'infraction (par exemple, annulation d'une décision de l'autorité adjudicatrice) et empêcher de porter davantage préjudice aux intérêts affectés. Il n'y a aucune disposition concernant des mesures provisoires. Selon le $\S 115 \mathrm{I}$ GWB, après communication par la Chambre de la demande de recours à l'autorité adjudicatrice, cette dernière ne peut signer le contrat avant la décision de la Chambre ou avant que le délai pour déposer une plainte immédiate à l'OLG n'ait expiré (effet suspensif systématique). La demande de recours ne sera pas demande accueillie si elle est évidemment inadmissible ou infondée (II GWB de $\S 110$ II et 115). L'autorité adjudicatrice peut demander l'autorisation de signer le contrat pendant la procédure. La Chambre peut accorder l"autorisation deux semaines après l'annonce de la décision si, tout en tenant compte des intérêts en présence susceptibles d'être lésés, y compris l'intérêt public, elle considère que les conséquences négatives de la suspension l'emportent sur les avantages. Si l'autorisation est accordée, le requérant peut demander un renouvellement de la suspension de la procédure d'adjudication devant l'OLG. Si l'autorisation n'est pas accordée, l'autorité adjudicatrice peut demander à l'OLG de mettre un terme à la suspension de la procédure d'adjudication. Selon le $\S 115$ III GWB, la chambre peut intervenir dans la procédure de passation de marché si les droits du requérant sont susceptibles d'être lésés 
par une autre décision que celle de la conclusion du contrat (par exemple, une décision d'abandon ou d'annulation de l'adjudication). Les dommages et intérêts peuvent être attribués par les tribunaux de droit commun. Il y a plusieurs fondements juridiques pour l'attribution de dommages et intérêts dont les plus importants sont le $\S \mathbf{1 2 6}$ GWB et le $\S \S 311$ II liés à l'article 280 I du code civil allemand (Bürgerliches Gesetzbuch, BGB) concernant la responsabilité précontractuelle (culpa in contrahendo, CIC). Le $\S 126$ GWB s'applique aux contrats dans le champ d'application du GWB, c'est-à-dire aux contrats dont la valeur estimée dépasse les seuils de la CEE. Selon cette disposition, «si l'autorité adjudicatrice viole une disposition destinée à protéger les entreprises et que l'entreprise aurait eu, après estimation des offres et sans cette violation, une vraie possibilité de remporter le contrat, qui, par suite de l'infraction, a été compromise. L'entreprise peut alors demander exiger le remboursement des coûts de préparation de l'offre ou de participation à la procédure d'adjudication. Les autres demandes de dommages et intérêts demeurent inchangées. Les dispositions du code civil relatives au CIC s'appliquent aux marchés publics indépendamment de leur valeur. Par principe, les dommages et intérêts attribués sur le fondement du CIC peuvent couvrir la perte de bénéfices (lucrum cessans) si le requérant prouve qu'il aurait certainement remporté le contrat et si le contrat a réellement été signé, ou les coûts de soumission d'offres (damnum emergens), le contrat n'a pas encore été signé. Dans les deux cas ( $\$ 126$ GWB et CIC), il n'est pas nécessaire que la décision contestée de l'autorité adjudicatrice ait été annulée par un tribunal ou une Chambre des marchés publics. Dans le cas du CIC, cependant, il est possible que l'absence de demande de protection juridique primaire puisse être vue comme une négligence du plaignant selon l'article $\$ 254$ III du code civil. Enfin, il n'y a aucune disposition relative aux astreintes.

\subsection{Procédure}

Les procédures devant les Chambres des marchés publics et les cours d'appel régionales (OLG) sont principalement régis par la quatrième partie de l'acte fédéral contre les restrictions de la concurrence (GWB). D'autres dispositions du GWB ou le code de procédure civile (ZPO) demeurent applicables. Toute partie ayant un intérêt au contrat et affirmant que ses droits en vertu du § 97 VII GWB ont été violés par le non-respect de la réglementation relative à la passation des marchés publics est habilitée à présenter un recours devant une Chambre des marchés publics. Le requérant doit prouver qu'il a subi ou est susceptible de subir une perte en raison de l'infraction contestée aux règles d'attribution. Un requérant qui n'a pas réellement présenté d'offre doit prouver qu'il en été empêché de le faire en raison de la conduite de l'autorité adjudicatrice (par exemple, attribution de fait irrégulière). Les parties sont obligées d'adresser une réclamation officielle à l'autorité adjudicatrice car c'est la condition préalable des recours devant les Chambres de marchés publics ( $\$ 107$ III GWB). Cette obligation s'applique également aux contrats attribués par des opérateurs privés de services d'utilité publique. Il n'y a aucun délai obligatoire pour adresser une réclamation à l'autorité adjudicatrice ou introduire une instance la Chambre. Le GWB déclare simplement que la réclamation et l'introduction de l'instance seront faites sans retard anormal (§ $108 \mathrm{I})$. En outre, l'article 13 de la réglementation des marchés publics $(\mathrm{VgV})$ prévoit un délai suspensif de 14 jours entre la notification des résultats de l'adjudication aux soumissionnaires non retenus et la conclusion officielle du contrat. Un contrat signé en violation de l'obligation mentionnée ci-dessus est frappé de nullité. L'obligation du délai suspensif permet aux soumissionnaires évincés d'adresser une réclamation officielle à l'autorité adjudicatrice et une requête à la Chambre avant la conclusion du contrat. La réclamation et la requête peuvent être faites en même temps (aucune obligation d'attendre la décision de l'autorité adjudicatrice). Si, à l'issue du délai suspensif, aucune requête n'a été déposée, le contrat peut être légalement conclus. Les soumissionnaires lésés ne sont plus autorisés à contester les décisions d'attribution des marchés publics devant les Chambres. Il n'y a aucun formulaire-type pour les affaires relatives aux marchés publics. Le GWB déclare que la demande sera faite par écrit et sera dûment motivée. Les procédures devant les Chambre de marchés publics sont assujetties au paiement de droits dont le montant dépend des charges personnelles et matérielles de la Chambre, en prenant en considération la valeur estimée du contrat. Les droits se montent au minimum à $2500 €(\S 128$ II GWB). Les procédures devant une OLG sont assujetties au paiement de droits dont le montant représente $5 \%$ de la valeur brute du contrat. Dans les procédures devant les Chambres, les honoraires des avocats sont remboursés par la partie perdante si la Chambre considère que le ministère d'un avocat est nécessaire dans l'affaire concernée. Dans les procédures devant une OLG, le ministère d'un avocat est obligatoire et les coûts supportés sont remboursés par la partie perdante. Les chambres et l'OLG peuvent décider si un expert doit être engagé pendant la procédure de contrôle. Les honoraires des experts doivent être payés conformément à la 
décision de la Chambre ou de l'OLG. Des experts techniques et autres experts sont également impliqués dans les procédures à titre de membres des Chambres des marchés publics. En particulier, un des trois membres de la Chambre est un membre honoraire associé avec plusieurs années d'expérience dans le domaine des marchés publics (§105 III GWB). Concernant la confidentialité, les Chambres doivent refuser l'accès aux dossiers de l'affaire afin de protéger des secrets industriels et commerciaux ( $\$ 111$ II GWB). Les Chambres prononcent leur décision dans un délai de cinq semaines à compter du dépôt de la requête. Après communication de la décision aux parties ou si aucune décision n'a été prise dans le délai prescrit, les parties peuvent déposer immédiatement une plainte contre la décision (explicite ou implicite) de la Chambre devant l'OLG compétente. La plainte immédiate exerce un effet suspensif sur la décision de la Chambre. La durée de cet effet est de deux semaines après l'expiration du délai pour déposer une plainte immédiate. Si la Chambre rejette la requête, l'OLG peut, à la demande du plaignant, prolonger l'effet suspensif jusqu'à ce qu'une décision soit prononcée sur la plainte immédiate. Si la Chambre accueille la requête en interdisant l'attribution du contrat, le contrat ne sera pas signé tant que l'OLG n'écarte pas la décision de la chambre selon GWB du $\S \S 121$ ou 123. Les décisions des chambres et de l'OLG sont communiquées aux parties lors d'une procédure où les parties sont présentes à la cour. Certaines décisions sont publiées sur les sites Internet de ces juridictions.

\subsection{Culture du recours}

La loi de marchés publics suivant l'adoption de l'acte 1998 amendant l'acte fédéral contre des restrictions de la concurrence (GWB) a éveillé un intérêt croissant. De nombreuses conférences sont organisées l'université (cours d'été «Vergaberecht» à l'université de Bochum : http://www.ruhr-unibochum.de/fvv/summerschool/frmset.html ; Düsseldorfer Vergaberechtstag : http://www.ruhr-unibochum.de/burgi/vergaberechtstag/frmset.html). Le secteur privé joue également un rôle particulièrement actif dans la formation aux marchés publics. Il y a au moins de trois revues juridiques spécialisées dans les marchés publics. Vergaberecht (VergabeR: Werner Verlag), Neue Zeitschrift für Bau- und Vergaberecht (NZBau: C.H. Beck) and Zeitschrift für deutsches und internationales Bau- und Vergaberecht (ZfBR : Bau Verlag). Il y a également de nombreux magazines périodiques tels que Vergabespezial (http://www.vergabespezial.com) et Vergabenews (édités par le Bundesanzeiger Verlag). Il n'y a aucune association nationale officielle de marchés publics, mais l'institution privée la plus importante est le Forum Vergabe e.V. (Breite Straße 29, 10178 Berlin ; téléphone : +49 (0) 30 2028-1631, fax : + 49 (0) 30 20282631, email : info@forum-vergabe.de, site Web : http://www.forum-vergabe.de). Les acteurs principaux du système de contrôle et de recours étudient le droit des marchés publics dans le cadre des études universitaires. De plus, l'attitude des juges envers les intérêts contradictoires des parties est considérée être équilibrée. Cependant, l'importance de la jurisprudence est limitée en raison des interprétations divergentes de la loi statutaire existante. Les responsables des adjudications ont une connaissance relativement adéquate mais encore améliorable de la réglementation des marchés publics et traitent les réclamations adressées par les soumissionnaires d'une manière équilibrée. Les soumissionnaires peuvent se familiariser avec des pratiques d'achat public par l'expérience professionnelle ou l'aide fournie par les conseillers privés ou les organismes professionnels. Concernant l'attitude des soumissionnaires l'égard des recours, certains d'entre eux ne souhaitent pas entamer de procédures pour ne pas compromettre leurs chances pour le prochain contrat. D'autres n'envisagent d'entamer une procédure qu'en dernier recours ou le font dans l'intention de faire obstruction à la passation du marché. Enfin, un petit nombre cherche à obtenir des gains financier par les procédures. La société civile joue également un rôle plus actif dans la préparation et l'adoption des règles de marchés publics. L'impact des arrêts de la CJUE est considérable. Plus de 170 décisions sur les 700 prononcées en 2005 s'appuyaient sur les arrêts de la CJUE.

\section{Hongrie}

Les marchés publics en Hongrie sont régis par la Loi CXXIX/2003 (dorénavant : loi de 2003 qui est entré en vigueur le 1er mai 2004). La traduction en anglais non officielle de la loi et ses modifications suivantes est disponible sur le site Internet du Conseil de marchés publics (http://www.kozbeszerzes.hu). L'acteur principal est le Conseil de marchés publics (Közbeszerzések Tanácsa, 1024 Budapest, krt de Margit. 85 ; téléphone : 00361336 7748, http://www.kozbeszerzes.hu), service public indépendant et responsable des différents aspects de la politique des marchés publics (projets de loi, fonctionnement du système de recours, publication des notices, enseignement, helpdesk, etc.) qui dispose d'un budget autonome et est 
responsable devant le parlement. Le conseil se compose de 19 membres. Le contrôle des procédures de marchés publics se fonde sur un système mixte de contrôle juridictionnel et de contrôle quasi-judiciaire (partie 7 de la loi de 2003). Ce système ne diffère pas sensiblement de celui de l'ancienne loi relative aux marchés publics de 1995. Un contrôle extrajudiciaire est également disponible. Les dommages et intérêts doivent seulement être demandés devant un tribunal de droit commun. En Hongrie, la justice est administrée dans un système à quatre niveaux par la Cour suprême, les cours d'appel régionales, les tribunaux départementaux (y compris le tribunal municipal de Budapest) et les tribunaux locaux. Dans tous les cas, la protection des soumissionnaires ne dépend pas de la valeur estimée du contrat. Bien les soumissionnaires avisent l'autorité adjudicatrice de leur intention d'entamer une procédure, l'absence de notification n'entraîne pas le rejet d'une requête.

\subsection{Contrôle extra-juridictionnel}

Selon la loi de 2003, deux types de procédures de conciliation sont possibles. La procédure de conciliation spéciale s'applique dans le secteur des services d'utilité publique et met en application les dispositions appropriées de la directive 92/13/EEC (arts. 369 à 371). Ce type de conciliation s'applique seulement au-dessus des seuils de la CEE. En revanche, la procédure de conciliation générale (arts. 352 à 368) s'applique dans les secteurs classiques et des services d'utilité publique indépendamment de la valeur estimée du contrat. Le recours à ce type de conciliation n'est ni obligatoire ni une condition préalable pour un contrôle juridictionnel, mais exige l'accord mutuel des parties impliqués dans la procédure des marchés publics. Les parties participant à la procédure de conciliation peuvent ne pas entamer de recours avant que la fin de la procédure de conciliation. La conciliation générale est confiée aux experts indépendants qui ont une qualification assurée (diplômé en droit et avocat au barreau). Ils s'inscrivent sur une liste à leur propre initiative dans un registre tenu par le Conseil des marchés publics dans des conditions établies par la loi de 2003. Les décisions du conseil concernant l'insertion ou le retrait du registre peuvent être contestées devant les tribunaux. Les demandes de conciliation générale sont présentées au conseil dans les cinq jours à compter du début du délai pour introduire une action et sont notifiées à l'autorité adjudicatrice ainsi qu'aux soumissionnaires concurrents. Par principe, un groupe de trois experts arbitre le conflit. Le requérant et le défendeur nomment chacun un arbitre et le troisième est choisi d'un commun accord. Les parties peuvent d'un commun accord nommer un seul expert pour statuer sur le conflit. Après que le lancement de la procédure de conciliation, l'autorité adjudicatrice peut suspendre la procédure d'adjudication ou retarder la signature du contrat. Le procès verbal des procédures est enregistré. La procédure de conciliation prend fin après la conclusion d'un accord, si aucun accord n'est possible ou si une des parties en décide ainsi. En tous cas, la procédure ne dépasse pas huit jours à compter de la demande de conciliation. Le contrôle juridictionnel demeure possible. Sauf accord différent, les parties doivent supporter les coûts de la procédure de conciliation dans une proportion égale. Les arbitres ont droit à une rémunération ainsi qu'au remboursement d'autres coûts appropriés.

\subsection{Contrôle juridictionnel}

Les soumissionnaires lésés peuvent porter les conflits résultant de la procédure d'adjudication devant le Conseil d'arbitrage des marchés publics, organe de contrôle indépendant opérant à côté du Conseil des marchés publics. Dans le domaine des marchés publics, le Conseil d'arbitrage des marchés publics est la première instance de recours ; une action devant les tribunaux n'est possible qu'après le contrôle du Conseil d'arbitrage des marchés publics. Les soumissionnaires peuvent contester tout acte concernant la procédure d'adjudication avant et après la signature du contrat ; cependant, le conseil d'arbitrage ne peut pas annuler les décisions du l'autorité adjudicatrice après la signature du contrat. Le conseil d'arbitrage est financé par le budget du conseil et est compétent sur l'ensemble du territoire. Les membres du conseil d'arbitrage (« commissaires des marchés publics ») sont des fonctionnaires nommés (et qui peuvent être rappelés) par le Conseil dans des conditions établies par les articles 398 et suivants de la loi de 2003. Le Conseil détermine le nombre de commissaires et nomme le président ainsi que le vice-président du conseil d'arbitrage pour un mandat de cinq ans (renouvelable). Les commissaires agissent d'une façon indépendante et équitable. Ils ne sont assujettis à aucune sorte d'instruction mais seulement à la loi. Les décisions du conseil d'arbitrage sont exécutoires et sont soumises à un système centralisé à deux niveaux de contrôle. La loi de 2003 distingue les décisions rendues au cours des procédures, telles que l'octroi de mesures provisoires, les amendes procédurales, les jonctions d'instance, les questions préjudicielles auprès de la CJUE et les décisions définitives rendues sur le fond du droit. Les premières peuvent faire l'objet 
d'un appel devant la cour municipale de Budapest (Markó utca 27, Budapest 1055), à condition que la loi de 2003 le permette expressément. Il n'y a aucune possibilité de contester la décision de la cour auprès d'un tribunal plus élevé. Les décisions peuvent être contestées comme suit : Toute personne dont le bon ou le légitime droit a été lésé par une décision définitive du conseil d'arbitrage, ainsi que par l'institution ayant lancé la procédure devant le conseil d'arbitrage, est autorisée à demander la protection juridique de la cour municipale de Budapest (art. $346 \S 1$ ). Dans ce cas, la cour peut décider a) de rejeter la demande comme non fondée ; b) ordonner au conseil d'arbitrage de recommencer la procédure ; ou c) modifier la décision rendue par le conseil d'arbitrage, selon le code de procédure civile et les règles spéciales d'accélération de la loi 2003. La décision de cour peut être contestée en deuxième instance devant la Cour d'appel de Budapest (Fővárosi Ítélőtábla, Budapest 1027, Fekete SAS U. 3). Dans les deux instances, les appels sont examinés par les chambres administratives des cours mentionnées ci-dessus. Exceptionnellement, une décision de la Cour d'appel peut être déférée devant la cour suprême au titre d'une voie de recours extraordinaire (en révision) dans des conditions établies par les articles 270 275, 324 et $340 \mathrm{~A}$ du code de procédure civile. La cour suprême assure l'uniformité de la jurisprudence par ses arrêts qui lient les cours inférieures. La Cour d'appel de Budapest est donc la juridiction de dernière instance dans les affaires relatives aux marchés publics. L'indépendance de l'ordre judiciaire est garantie par le chapitre $\mathrm{X}$ de la constitution de 1949, la loi LXVII/1997 sur le statut juridique et la rémunération des juges et par la Loi III/1952 (code de procédure civile). Ces règles prévoient également la nomination et la démission des juges, les qualifications exigées, leur rémunération, le budget de la justice et la forme des jugements. Tout citoyen hongrois, sans casier judiciaire, ayant un diplôme en droit, le droit de vote, ayant réussi un examen en droit de niveau supérieur et acquis une expérience professionnelle démontrée peut devenir juge s'il n'y a aucun motif d'exclusion ou d'incompatibilité.

\subsection{Recours}

Les voies de recours peuvent être divisées en deux catégories : celles exercées devant le conseil d'arbitrage des marchés publics et celles exercées devant les cours. La première catégorie comprend les décisions prises en cours de procédure (mesures provisoires : mesures de l'article 332, amendes procédurales, jonctions d'instances, questions préjudicielles auprès de la CJCE, etc.) et des voies de recours jugées par décision définitive du conseil d'arbitrage (art. 340). Comme les réclamations faites devant le conseil d'arbitrage n'ont pas d'effet suspensif, des mesures provisoires peuvent être ordonnées sur demande ou d'office avant que le contrat ne soit signé à condition qu'il y ait des éléments de preuve suffisants d'une violation (réelle ou potentielle) des obligations relatives à la soumission d'offres. Quoiqu'aucune disposition en relevant ne soit comprise dans la Loi de 2003, le conseil d'arbitrage peut prendre en considération les conséquences probables des mesures requises sur les intérêts et droits susceptibles d'être lésés, y compris l'intérêt public, et décide de ne pas accorder de telles mesures lorsque leurs conséquences négatives sont supérieures à leurs avantages. Le conseil d'arbitrage peut 1) suspendre la procédure d'adjudication ; 2) interdire la conclusion du contrat (mais ne pas déclarer la nullité du contrat lui-même ; seule une cour peut prononcer la nullité d'un contrat signé) et 3) ordonner à l'autorité adjudicatrice d'inviter le requérant à participer à l'adjudication. L'autorité adjudicatrice peut également à son initiative suspendre la procédure d'adjudication après qu'une demande ait été déposée ou repousser la signature d'un contrat jusqu'à ce que le conseil d'arbitrage prenne une décision définitive. Par sa décision définitive, le conseil d'arbitrage peut 1) seulement établir si une violation s'est produite ou pas ; 2) où une violation a été établie, ordonner à l'autorité adjudicatrice de se conformer à ses obligations de soumission d'offres ou de respecter une certaine conduite ; 3) déclarer nul tout acte du l'autorité adjudicatrice concernant la procédure d'adjudication ou l'acte déclarant la procédure close, à condition qu'aucun contrat n'ait été déjà signé (l'autorité adjudicatrice est, cependant, seule responsable pour déclarer la nullité de l'adjudication entière) ; et 4) imposer une sanction pécuniaire en cas d'attributions directes illégales, d'omission de notification du rapport statistique annuel visé à l'article 16 de la Loi 2003, de modification ou d'exécution illégale d'un contrat signé sur la base d'une adjudication (articles 303 à 306). Si le conseil d'arbitrage annule la décision déclarant l'adjudication close, l'autorité adjudicatrice doit prendre une nouvelle décision dans les 30 jours à partir de la date où la décision de le conseil d'arbitrage est devenue exécutoire ou peut déclarer la procédure d'adjudication inachevée (et recommencer une nouvelle procédure ou abandonner son invitation à soumissionner). Si le conseil d'arbitrage établit une violation des obligations relatives à la soumission d'offres, l'autorité adjudicatrice ou le soumissionnaire retenu peut décider du sort du contrat signé dans les 30 jours de l'avis de la décision du conseil d'arbitrage. Par ailleurs, le conseil d'arbitrage est autorisé à 
prononcer des sanctions contre les soumissionnaires (expulsion des adjudications ou des listes de présélection) lorsque ceux-ci s'avèrent responsables de violations récurrentes du droit des marchés publics (art. 341). Généralement, des sanctions pécuniaires peuvent être prononcées contre toute personne (fonctionnaires de l'autorité adjudicatrice ainsi que soumissionnaires) responsable d'une violation de la loi de 2003. Les appels contre une décision définitive du conseil d'arbitrage des marchés publics n'ont pas d'effet suspensif sur l'application de cette décision. La cour municipale de Budapest peut, cependant, suspendre l'application à tout moment sur demande ou d'office. L'octroi de dommages et intérêts peut seulement être poursuivi devant les tribunaux et est sujet à l'établissement antérieur d'une violation du droit des marchés publics par le conseil d'arbitrage ou en cas d'un appel contre la décision sur l'octroi de dommages et intérêts, par le tribunal ou la cour (art. 350). Selon l'article 351, les soumissionnaires lésés peuvent poursuivre le remboursement de leurs coûts de soumission d'offre s'ils montrent que 1) l'autorité adjudicatrice a violé le droit des marchés publics ; 2) ils avaient une véritable chance de remporter le contrat et 3) la violation a compromis leur possibilité de remporter le contrat. Ils peuvent également demander des dommages et intérêts pour perte de bénéfices s'ils fournissent des éléments de preuve suffisants à cet égard, sous réserve des dispositions du code civil de 1959 (art. 339 : « une personne qui cause un dommage illégalement à une autre personne doit réparer un tel dommage. La responsabilité est exclue s'il est montré que l'action était prévisible dans les circonstances données »).

\subsection{Procédure}

Les procédures devant le conseil d'arbitrage des marchés publics concernant le secteur classique et le secteur des services publics sont régies par le chapitre IX de la Loi 2003, ainsi que par la Loi CXL/2004 relative aux règles générales des procédures administratives. Des actions peuvent être lancées 1) par l'autorité adjudicatrice ainsi que tout soumissionnaire, candidat ou tout autre personne intéressée, dont le bon ou le légitime droit a été ou est susceptible d'être lésé par un acte ou une omission en conflit avec la loi de 2003. Dans ce dernier cas, l'autorité adjudicatrice doit être informée de l'intention de lancer une action. Tout manquement à se conformer à cette obligation n'exerce aucun effet sur la recevabilité de la demande ; 2) d'office, c.-à-d., sur demande des personnes ou des institutions suivantes qui se sont rendu compte, dans l'exécution de leurs fonctions, d'une violation de la Loi de 2003 : un membre ou le président du Conseil des marchés publics, la Cour des comptes, le Conseil de contrôle du gouvernement, le Conseil administratif du comté ou de la ville de Budapest, le Trésor public, le commissaire parlementaire pour des droits civiques, le commissaire parlementaire pour des droits des minorités nationales et ethniques, ainsi que le commissaire pour la protection des données, l'entité accordant une subvention pour le marché public, ou l'entité participant en vertu d'une disposition juridique à l'utilisation d'une telle subvention ; et l'entité acquéreuse centrale. Tout acte lié à la procédure d'adjudication peut être contesté (le plus souvent dans la pratique : les conditions du cahier des charges telles que les critères d'éligibilité et d'évaluation ou les caractéristiques techniques, et la décision de désignation du vainqueur ou d'arrêt infructueux de l'adjudication). Les demandes doivent être faites dans les 15 jours de la commission de la violation, et, en cas de décisions déclarant l'adjudication close, dans les huit jours de la notification des résultats. Si la violation devient notoire à une date ultérieure, le délai commencera à cette date et, en tous cas, ne dépassera pas 90 jours à compter de la date où la violation s'est produite réellement. Le défaut de respect des délais mentionnés ci-dessus implique la déchéance des droits d'action. En ce qui concerne la Cour des comptes, le Conseil de contrôle du gouvernement, le Trésor public, l'entité donnant la subvention ou l'entité participant à l'utilisation de la subvention, les actions doivent être introduites dans l'année ou, en cas d'attributions directes illégales, dans un délai de trois ans à compter de la date à laquelle l'infraction s'est produite réellement. Il n'y a aucun formulaire-type pour faire une demande devant le conseil d'arbitrage. Le $\S 1$ de l'article 324 de la Loi 2003 énumère simplement les éléments qui doivent apparaître dans les demandes (nom du requérant et du défendeur, date de la violation alléguée, etc.). Par principe, les auditions sont tenues en séance publique, mais le conseil d'arbitrage peut décider de conduire la procédure sous vidéosurveillance, si cela est nécessaire pour des raisons de secret d'État ou de secret professionnel/d'affaires (art. $336 \S 2$ ). À quelques exceptions fondamentalement dues aux considérations de secret d'affaires, l'accès au dossier de marché public est entièrement garanti à toutes les parties concernées au cours de la procédure (art. 337). Sur demande ou d'office, le conseil d'arbitrage peut demander à un expert de donner une opinion indépendante sur des questions techniques ou juridiques. Les actions devant le conseil d'arbitrage sont sujettes un droit de timbre dont le montant dépend de la valeur des marchés publics et du type de décision contestée (900 000 HUF en cas d'adjudications au-dessus des 
seuils de la CE, à l'exception du recours contre le contenu de l'appel d'offres ; 150000 HUF dans tous les autres cas). Au regard des faits du cas, le conseil d'arbitrage décide quelle partie doit supporter le droit ainsi que d'autres coûts procéduraux. En cas de procédures d'office où aucune violation n'a été établie, tous les coûts sont à la charge de l'État. Les honoraires d'expert sont avancés par le partie ayant demandé l'expertise mais peuvent être par la suite mis à la charge de la partie perdante. Si le conseil d'arbitrage nomme d'office un expert, les honoraires d'expert sont payés par l'État. Le conseil d'arbitrage prend une décision définitive dans les délais suivants : 1) en l'absence d'audience, dans les 15 jours de l'initiation de l'introduction de l'action ; 2) si des audiences ont lieu, dans les 30 jours de l'introduction de l'action. Dans des cas dûment justifiés, ces délais peuvent être prolongés à hauteur de dix jours. La décision définitive est notifiée aux parties aussi bien qu'aux autres personnes/institutions intéressées. Les décisions concluantes sont publiées dans «le bulletin des marchés publics », qui est le support officiel de presse du Conseil de marchés publics (version en ligne sur www.kozbeszerzes.hu). La publication est également possible après que les procédures ont eu lieu ou qu'un appel contre les décisions du conseil d'arbitrage a été interjeté.

Les procédures devant la cour municipale de Budapest sont régies par le chapitre $\mathrm{XX}$ du code de procédure civile (articles 324 à 341), sous réserve des dispositions des articles 347349 de la Loi de 2003. Les appels contre des décisions rendues par le conseil d'arbitrage des marchés publics en cours de procédure peuvent être interjetés dans les huit jours de la date à laquelle de telles décisions ont été rendues. Les appels de ce type doivent être déposés auprès du conseil d'arbitrage lui-même, qui est responsable de les expédier, avec le dossier de l'affaire, à la cour sans tarder (art. $345 § 2$ ). Des appels contre des décisions définitives du conseil d'arbitrage peuvent être interjetés par toute personne dont le bon ou le légitime intérêt a été lésé par la décision, ainsi que par l'institution ayant lancé la procédure devant le conseil d'arbitrage, ceci dans les 15 jours de la notification de la décision définitive (art. 347 § 1). Dans ce cas, les appels seront traité de façon prioritaire, mais il n'y a aucune disposition quant aux délais dans lesquels la cour doit rendre son jugement. Une procédure a lieu dans des conditions établies dans le code de procédure civile (au regard des considérations de secret d'État ou d'affaires ou de respect de la vie privée). Le jugement de la cour municipale de Budapest peut être porté en appel devant la Cour d'appel de Budapest par la partie concernée, les tiers intervenant dans la procédure ou toute personne affectée par une disposition du jugement (art. 233 du code de procédure civile). Le ministère d'avocat est exigé seulement devant la Cour d'appel. L'expertise est disponible dans des conditions semblables à celles qui s'appliquent devant le conseil d'arbitrage des marchés publics. Les arrêts de la Cour sont prononcés publiquement, doivent être notifiés aux parties par écrit dans les 30 jours et sont publiés dans « le bulletin des marchés publics ». Selon la loi XCIII de 1990, le droit de timbre pour toutes les poursuites judiciaires effectuées contre des décisions administratives (telles que la décision du conseil d'arbitrage) est de 16500 HUF. Généralement, les dépens comprennent les dépenses liées aux procédures de droit commun et aux procédures fondées sur la «bonne foi » (en particulier : frais de témoignage, honoraires des experts et des interprètes ; coûts de traduction ; coûts de visites sur place ; coûts exposés pour l'accès aux documents ; frais de représentation juridique ou d'avocat ; frais de voyage et frais postaux). Par principe, il est ordonné à la partie succombante de payer les coûts relatifs à l'introduction de l'action ainsi que d'autres coûts procéduraux.

\subsection{Culture du recours}

Les juges et les fonctionnaires de marchés publics peuvent avoir acquis la connaissance du droit des marchés publics en tant qu'élément de leur cursus universitaire ou par des séminaires organisés par les institutions publiques. Il existe une formation spéciale de 220 heures (par « des membres du Conseil des marchés publics ") reconnue par l'État. On enseigne obligatoirement le droit communautaire général aux étudiants en droit. Le passage du barreau inclut également un examen sur le sujet. Le Conseil de marchés publics offre la possibilité aux fonctionnaires, y compris les commissaires des marchés publics, d'assister à des cours de formation aussi bien qu'à des conférences de second cycle universitaire avec la participation de juges spécialisés dans le domaine du droit des marchés publics. Les fonctionnaires du Conseil de marchés publics suivent régulièrement des séminaires organisés par des organismes internationaux tels que l'institut européen de l'administration publique (EIPA). Des séminaires sont également tenus par le secteur privé (conseillers, organismes de formation). Les soumissionnaires ont pu se familiariser avec les marchés publics par l'expérience professionnelle et peuvent également participer à la formation et aux conférences mentionnées ci-dessus. Ils sont aidés par un service SVP établi par le Conseil de marchés publics. 
L'attitude des juges et des commissaires envers des intérêts divergents est considérée juste et équilibrée. Les fonctionnaires des marchés publics sont considérés comme ayant une connaissance suffisante du droit des marchés publics. Quelques soumissionnaires voient les procédures de contrôle de la légalité comme le dernier recours possible. D'autres font intentionnellement obstruction aux marchés publics par leur action. Dans certains cas, les soumissionnaires ne se tournent pas vers le conseil d'arbitrage des marchés publics mais demandent au délégué de l'organisme professionnel approprié qui est représenté au Conseil des marchés publics qu'une procédure d'office soit effectuée. Il y a de nombreuses publications, y compris « le bulletin des marchés publics », ainsi que d'autres recours publics par des organismes privés (par exemple, «Lettres des marchés publics» publié par la société des marchés publics). Des manuels nombreux sont également publiés. Il y a de diverses associations de marchés publics fonctionnant indépendamment (fondation pour la culture des marchés publics, l'association des consultants officiels en matière de marchés publics) ou au sein d'une organisation mère (telle que le chapitre des marchés publics du Conseil de l'ordre). La jurisprudence est d'importance particulière. $20 \%$ des décisions arbitrales sont contestées à un degré plus élevé. La presse couvre de temps en temps les affaires de marchés publics, particulièrement lorsque des intérêts financiers importants sont en jeu. Les décisions de la CJUE sont également prises en considération par le conseil d'arbitrage et les cours.

\section{Irlande}

Le système des voies de droit et de contrôle de la légalité en matière de marchés publics en Irlande est fondé sur un contrôle judiciaire indépendant. Il y a de deux degrés de juridiction en matière de contrats, ouverts seulement au-dessus des seuils fixés par la CE.

\subsection{Réclamations auprès de l'autorité adjudicatrice}

Il n'est pas obligatoire de faire une réclamation préalable auprès de l'autorité adjudicatrice ou de l'entité. Il n'y a aucune règle précise dans le domaine des marchés publics qui régisse les réclamations devant l'autorité adjudicatrice. Cependant, il est possible d'essayer de régler les différends de cette façon. L'Unité nationale de politique des marchés publics (NPPPU) essaye de maintenir le formalisme des procédures à un minimum en encourageant les autorités à fournir volontairement un exposé constructif aux candidats et aux soumissionnaires infructueux. Les instructions sur la communication des informations aux candidats, qui peuvent être consultées sur le site Web national des marchés publics (www.etenders.gov.ie) sous « guides/instructions générales relatives aux marchés publics», favorisent cette pratique.

\subsection{Voies de recours et contrôle juridictionnel}

S'il n'est pas satisfait de la décision du l'autorité adjudicatrice ou de l'entité, le soumissionnaire peut chercher la révision judiciaire à la Tribunal de grande instance, un tribunal général ou ordinaire, dont les décisions sont d'une nature juridictionnelle. En 2003, le tribunal a mis en place une chambre spéciale pour traiter rapidement des affaires commerciales, y compris des affaires de marchés publics. Cette chambre commerciale emploie les méthodes les plus rapides pour accélérer la procédure et a pour objectif de prendre une décision sur le point de savoir s'il y a des raisons valables pour exercer un contrôle en quelques des semaines, au lieu de nombreux de mois comme cela était le cas dans le passé. Dans de nombreux cas, le réclamant laisse tomber des procédures à la suite de la réponse de l'autorité adjudicatrice. Les autorités adjudicatrices défendent normalement leur conduite des procédures de marchés publics. Le Tribunal de grande instance peut annuler ou modifier un contrat et attribuer des dommages et intérêts en réparation des coûts ou perte ou dommages subis. Toutes les décisions relatives aux marchés publics peuvent être contrôlées et annulées. Sur la base du décret n ${ }^{\circ} 309$ de 1994, même un contrat signé peut être annulé. Il peut être fait droit à ces voies de recours à titre de mesures provisoires en prenant en considération leurs conséquences probables pour tous les intérêts susceptibles d'être lésés, y compris l'intérêt public. Le Tribunal de grande instance peut décider de ne pas prononcer de telles mesures lorsque leurs conséquences négatives seraient supérieures à leurs avantages. L'octroi des dommages et intérêts est fondé sur la jurisprudence. Il n'est pas qu'une décision d'octroi de dommages et intérêts soit prise séparément pour que la cour ordonne leur paiement. Sur les autres sujets, les cours ont un pouvoir de discrétion. Il n'y a aucune disposition relative aux astreintes. Des experts techniques et autres peuvent être impliqués au cas par cas à la discrétion des parties à la procédure. Les coûts sont déterminés par les cours. N'importe quelle partie qui considère que ses droits ont été violés peut intenter une action. Il n'y a aucun 
droit à payer. Les honoraires d'avocats varient considérablement, mais la cour peut ordonner à l'autorité adjudicatrice ou à l'entité de payer les honoraires d'avocat du soumissionnaire si elle succombe. Les soumissionnaires ont normalement trois mois à compter de u moment où ils apprennent l'existence de la violation alléguée pour intenter une action, mais ce délai peut être prolongé à la discrétion de la cour. Il n'y a aucune suspension systématique de la procédure de passation de marchés une fois qu'une action a été intentée devant le Tribunal de grande instance. Cependant, les instructions administratives conseillent à l'autorité adjudicatrice concerner de faire preuve de précaution avant d'exercer des poursuites. Il n'y a aucun délai pour que le Tribunal de grande instance établisse une décision. Le temps écoulé entre l'introduction du recours fondé sur le contrôle de la légalité et sa conclusion définitive est normalement de quelques semaines. Il n'y a aucune disposition particulières aux services publics qui différent des celles applicables aux autorités adjudicatrices. Il n'y a aucun formulaire modèle à utiliser. Les décisions sont publiées par les cours elles-mêmes. Le système de contrôle de la légalité peut traiter des cas des violations claires et manifestes. Elles sont généralement involontaires et, une fois portés à la connaissance de l'autorité adjudicatrice, sont généralement corrigées. Les cas qui montent jusqu'au stade judiciaire sont généralement des infractions techniques qui se rapportent à l'interprétation des règles. L'existence du système est considérée comme un moyen de dissuasion afin que les autorités adjudicatrices ne violent pas les règles et que de ce fait, les soumissionnaires soient confiants. Le système judiciaire, cependant, est considéré cher pour des soumissionnaires. Si le résultat d'une décision du Tribunal de grande instance n'est pas jugé satisfaisant, il peut faire l'objet d'un appel devant la cour suprême à Dublin. L'indépendance de la cour suprême est garantie par le mandat des juristes qualifiés qui y exercent en qualité de juges. Ses décisions sont lues en séance publique et sont publiées. La plupart des conditions posées par les décisions Dorsch et de Salzmann sont remplies, mais il semble que la procédure ne soit pas une procédure contradictoire. Le soumissionnaire peut également demander à la Commission européenne de mener une enquête sur une procédure d'adjudication.

\subsection{Culture du recours}

Les juges et les avocats de droit des marchés publics représentant des soumissionnaires ou des entités adjudicatrices dans le cadre des procédures de contrôle de légalité acquièrent leur connaissance du droit des marchés publics en particulier et du droit communautaire en général au cours de leurs études de droit et de leur formation professionnelle. L'attitude des juges et des membres de jury des organes de contrôle de marchés publics à l'égard de l'intérêt public d'une part et des intérêts privés des soumissionnaires d'autre part, est décrite comme équilibrée. Les soumissionnaires exerçant des recours en vue du contrôle de la légalité des décisions relatives aux marchés publics acquièrent leurs connaissances de l'environnement juridique, financier et administratif qui préside au fonctionnement des marchés publics dans la pratique grâce aux instructions de l'Union nationale pour la politique de marchés publics, dans des forum et réseaux, dans des séminaires et événements semblables organisés par des organisations commerciales professionnelles. A ce stade, la connaissance des responsables des adjudications sur le droit et l'environnement général des marchés publics est décrite comme bonne. Les responsables des adjudications et leurs supérieurs traitant des réclamations des soumissionnaires ou des recours contre les décisions relatives aux marchés publics exercés par eux, ont été décrits comme généralement très sûrs de leurs procédures et disposé à les défendre. Depuis 1992, il n'y a eu aucune publication ou journal universitaire traitant spécifiquement des questions de marchés publics, y compris du contrôle de la légalité des marchés publics et des voies de recours. Le Forum sur l'industrie du bâtiment et le Forum sur des marchés publics en Irlande traitent des questions de marchés publics. L'institut de l'administration publique offre un diplôme conjointement avec un cabinet de consultants en marchés publics du secteur privé. Un cours professionnel de troisième cycle devait être organisé par l'Union nationale pour la politique de marchés publics dès septembre 200. Il y a également des cours de formation courts fournis par des cabinets de consultation et centres de formation du secteur privé. Des cours de marchés publics de deux jours par trimestre font partie du programme de formation du centre de formation central du gouvernement. Les décisions de la CJUE ont un impact sur les procédures de contrôle des marchés publics. Les parties ou les organes de contrôle font référence à ces décisions. 


\section{Lettonie}

La Lettonie a un système de contrôle de la légalité non-juridictionnel et juridictionnel. D'abord, les réclamations sont examinées par le bureau de contrôle des marchés publics (BCMP). Le BCMP est un «établissement public » placé sous la tutelle du ministère des finances qui fonctionne conformément à la loi lettone relative aux marchés publics (LMP). Afin d'examiner les réclamations, le BCMP, qui traite aussi d'autres questions de droit des marchés publics, a établi une commission d'examen des réclamations (CER), se composant au moins de trois membres. Ensuite, en deuxième instance, les parties à la procédure devant le CER peuvent interjeter appel de sa décision auprès du tribunal administratif. Un tel appel n'empêche pas le contrat d'être conclu. En ce qui concerne des contrats attribués par des autorités adjudicatrices publiques, il n'y a aucune différence entre les contrats rentrant dans le champ de l'application des directives communautaires ou non. En ce qui concerne des services publics, seulement des contrats audessus des seuils fixés par de la CE sont examinés par le BCMP ; il n'y a aucun organe de recours spécial concernant des contrats en dessous de ces derniers. Le système letton de révision de marchés publics a été mis en conformité avec les directives «recours » depuis 2002. Avant cela, certains types de décisions des autorités et entités adjudicatrices ne pouvaient pas être contestés, à savoir la décision sur le choix de la méthode de délégation, la décision d'attribution du marché public, les critères de sélection et le refus de toutes les offres. Avant 2002, la CER du BCMP n'était pas opérationnelle. Les réclamations étaient examinées par un département du ministère des finances.

\subsection{Réclamation auprès de l'autorité adjudicatrice}

Une réclamation auprès de l'autorité adjudicatrice elle-même est obligatoire seulement contre les documents de marchés publics illégaux. Une telle réclamation doit être soumise à l'autorité adjudicatrice pas plus tard que six jours ouvrables avant la date-butoir pour la soumission des offres. Si au cours d'une période de deux jours ouvrables après la réception de la réclamation, l'autorité adjudicatrice ne corrige pas la violation indiquée dans la réclamation ou n'a pas fourni une réponse écrite au réclamant, ce dernier peut, jusqu'à à la date-butoir pour la soumission des offres, soumettre une réclamation du BCMP. Les autres réclamations spéciales auprès des autorités adjudicatrices elles-mêmes ne sont pas spécifiquement réglementées.

\subsection{Contrôle non-juridictionnel}

Les réclamations sont examinées par la CER du BCMP. Le BCMP est un établissement public sous tutelle du ministère des finances. La CER constituée par le BCMP n'a pas un statut comparable à celui des juges. Cependant, comme discuté ci-dessous, les décisions du BCMP peuvent être portées en appel devant l'ordre juridictionnel administratif à plus de trois niveaux. Afin d'examiner des réclamations, le BCMP invite des spécialistes ou des experts en marchés publics. Ces spécialistes et experts participent aux réunions de la CER sans droit de vote et n'expriment à la CER qu'une opinion de professionnel indépendant concernant les faits établis au cours de l'examen de la réclamation. Par ailleurs, ils peuvent soumettre une opinion concernant des questions spécifiques relevant de la CER. Les personnes qui ont précédemment fourni des consultations en ce qui concerne le marché public ont mentionné dans la réclamation, ou qui sont intéressé à obtenir le droit d'exécuter le marché, ou qui sont associées au réclamant ou à un soumissionnaire différent ne peuvent pas être des membres de la CER ou des experts participant à ses réunions. Il y a parfois des difficultés à trouver les experts appropriés pour ces procédures. Avant l'examen de la réclamation, tous les membres de la CER et les experts signent une déclaration appropriée. Il y a plus de 200 réclamations par an. Le BCMP permet la conclusion d'un contrat si la réclamation est non fondée ( $\sim 70 \%$ des cas au cours des dernières années) ou interdit sa conclusion s'il a établir des violations qui sont significatives et qui peuvent influencer la décision d'octroi des droits relatifs au marché public ( $\sim 30 \%$ de tous les cas au cours des dernières années). Le résultat des réclamations contre les décisions de marchés publics trouve sa raison spécialement dans une attitude inégale des autorités adjudicatrices par rapport aux soumissionnaires et dans les spécifications techniques trop restrictives. Le temps écoulé entre le dépôt d'une réclamation ou l'introduction d'une action et la décision définitive est normalement d'un mois. Cette relativement courte période est vue comme une force du système letton. 


\subsection{Contrôle juridictionnel}

Les décisions de la CER du BCMP peuvent être portées en appel devant les tribunaux administratifs. Ces tribunaux ne sont pas les tribunaux spéciaux pour les marchés publics mais traitent tous les aspects du droit administratif en général. Un appel contre la décision de la CER ne suspend pas son application. En d'autres termes, si, par exemple, la commission permet la conclusion d'un contrat, la conclusion du contrat n'est pas suspendue en cas d'appel. Mais une cour peut décider que l'autorité adjudicatrice ne peut pas signer un contrat, bien que ceci ne se soit dans la pratique jamais produit. La loi sur le pouvoir judiciaire déclare qu'un pouvoir judiciaire indépendant existe en République de Lettonie, à côté du législatif et de l'exécutif et qu'un juge est indépendant et soumis seulement à la loi. Cette disposition renvoie également à la juridiction administrative de troisième degré (la cour suprême). Les demandes d'emploi au bureau d'un juge de la cour suprême sont ouvertes aux juges qualifiés d'une cour de district (ville) ou d'une cour régionale, ou aux personnes qui ont au moins 15 ans d'ancienneté totale en qualité d'enseignant de droit du supérieur, d'avocat assermenté qualifié ou de procureur. Les tribunaux administratifs remplissent les conditions pour une cour établie dans les décisions Dorsch et Salzmann. Environ 10-18 décisions du BCMP par an sont portées en appel devant les tribunaux. Tandis que la majorité des cas reste toujours irrésolue, le résultat correspond presque toujours à la décision précédente de BCMP. Le temps écoulé entre l'introduction d'une réclamation ou d'une action et la décision définitive est normalement d'un mois. Passer par chacun des trois degrés de juridiction prend habituellement plus de deux ans.

\subsection{Recours}

La CER du BCMP interdit la conclusion d'un contrat si elle a trouvé des violations au droit des marchés publics qui sont significatives et qui peuvent influencer la décision concernant l'octroi des droits liés à l'obtention du marché. En pareil cas, la commission établit une décision concernant les mesures à prendre pour corriger ces violations. Si le contrat a été déjà signé, seule une juridiction peut annuler le contrat et attribuer des dommages et intérêts sur la base de la loi sur le pouvoir judiciaire et la procédure administrative. Ce n'est pas une condition de l'octroi des dommages et intérêts que la décision contestée soit écartée. Des dommages et intérêts peuvent être réclamés également après la conclusion d'un contrat. Très rarement les dommages et intérêts dépassent les coûts de soumission. Le Tribunal (et le BCMP) prennent en considération les conséquences probables des mesures provisoires pour tous les intérêts susceptibles d'être lésés, y compris l'intérêt public, et décident de ne pas prendre de telles mesures lorsque leurs conséquences négatives seraient supérieures à leurs avantages.

\subsection{Procédure}

La loi sur les marchés publics (Chapitres XI et XII) et la loi sur les marchés publics pour les nécessités du service public (Chapitre XV) régissent la procédure devant le BCMP tandis que la loi relative à la procédure administrative (partie $\mathrm{C}$, disponible en anglais) régit la procédure devant les juridictions administratives. Une personne qui est ou était intéressée à se voir attribuer un marché public ou qui réclame le droit à remporter la procédure de passation de marchés et qui selon la procédure spécifique de passation de marchés à laquelle la loi sur les marchés publics et la loi sur les marchés publics pour les nécessités des prestataires de service publics renvoie, prétend que ses droits ont été violés ou qu'il existe une violation possible de tels droits due à une violation possible de législation de l'UE ou de toute autre législation, a le droit de faire une réclamation au sujet des réglementations de sélection de candidat ou de soumissionnaire, des spécifications techniques et d'autres exigences concernant la procédure spécifique de passation de marchés ou au sujet des activités de l'autorité adjudicatrice ou la commission des marchés publics pendant la conduite de la procédure de passation de marchés. Il n'y a aucun droit ou autres coûts à payer devant le BCMP. En vertu de l'article 124 de la loi relative à la procédure administrative, seulement quand une décision de la CER est portée en appel devant la juridiction administrative, un droit de dix LVL doit être payé en vue de l'introduction d'une action devant le tribunal et un droit de cinq LVL doit être payé pour l'introduction d'un appel. Aucun paiement n'est exigé en ce qui concerne le pourvoi en cassation (troisième instance) ou les actions auxiliaires. En outre, les soumissionnaires introduisant une action dans une affaire de marchés publics doivent payer les honoraires des avocats, en particulier quand la représentation juridique devant le tribunal est exigée, ce qui dépend des cas. Il existe un principe de succès : La partie victorieuse obtient remboursement des coûts par la partie perdante. Des réclamations peuvent être introduites jusqu'à la conclusion du marché public. Après conclusion, le requérant peut porter en appel 
les décisions du l'autorité adjudicatrice devant la juridiction administrative dans un délai d'un mois. La CER du BCMP examine une réclamation dans le mois de sa réception. $\mathrm{Si}$, pour des raisons objectives, il n'est pas possible de respecter ce délai, la commission peut le prolonger, informant le réclamant et l'autorité adjudicatrice en même temps. La procédure devant la juridiction administrative à chacun des trois degrés peut prendre plus d'une année. Le BCMP examine les réclamations concernant le secteur des services publics également après que le contrat ait été signé mais pas plus tard que de deux mois après sa conclusion. Après ce délai, le contrat doit être soumis à la juridiction administrative. La loi relative aux marchés publics dispose que la réclamation doit être soumise par écrit. Elle doit comprendre le titre et l'adresse du réclamant, le titre et l'adresse de l'autorité adjudicatrice au sujet duquel la plainte est soumise et décrire les faits justifiant la présentation de la réclamation, indiquant la violation alléguée et la demande du réclamant. Les décisions de la CER sont publiées sur le site Web de BCMP : www.iub.gov.lv. En ce qui concerne la procédure juridictionnelle, si une question a été jugée par une procédure écrite, les parties recevront en temps utile notification de la date où une copie officielle du jugement peut être trouvée au greffe de la cour. Sur demande des participants à la procédure, la copie officielle du jugement peut être envoyée par courrier ou, si ce n'est pas possible, par des autres moyens. Une copie d'un jugement sera envoyée aux parties à la procédure devant la juridiction administrative qui n'ont pas participé aux audiences dans les trois jours du prononcé du jugement.

\subsection{Culture du recours}

Il n'y a aucune institution spéciale pour former les membres de la CER du BCMP ou les juges traitant des affaires de marchés publics, seulement des séminaires du BCMP et l'école d'administration d'État. Cependant, les fonctionnaires du BCMP suivent des séminaires organisés par l'UE sur les marchés publics fréquemment. La connaissance est essentiellement acquise par la pratique. L'attitude des juges et des membres du jury de la CER de BCMP envers l'intérêt public d'une part, et les intérêts privés des soumissionnaires d'autre part, est décrite comme juste et équilibrée. Les soumissionnaires exerçant des recours en vue du contrôle de la légalité des décisions relatives aux marchés publics acquièrent leurs connaissances de l'environnement juridique, financier et administratif qui préside au fonctionnement des marchés publics dans la pratique par des séminaires et des consultations (par écrit et par téléphone) fournis par le BCMP et également par des avocats et des conseillers. Des soumissionnaires sont considérés plutôt actifs. Seulement une minorité est peu disposée à lancer des procédures de contrôle parce qu'elle ne souhaite pas compromettre ses chances d'emporter le prochain contrat. Parfois les procédures sont employées pour empêcher les concurrents de signer des contrats. La connaissance des responsables des adjudications dépend de l'autorité adjudicatrice pour laquelle ils travaillent, par exemple, un grand ministère contre un jardin d'enfants. Comme les marchés publics en Lettonie sont décentralisés, beaucoup d'autorités adjudicatrices (particulièrement les petites) ont seulement une connaissance limitée du sujet. L'attitude des responsables des adjudications et de leurs supérieurs envers les soumissionnaires qui font des réclamations ou introduise des actions devant les juridictions contre les décisions de marchés publics est décrite comme neutre. Il n'y a aucune publication ou journal universitaire traitant spécifiquement des questions de marchés publics. De temps en temps quelques articles concernant des problèmes de marchés publics paraissent dans des magazines. La loi relative aux marchés publics est discutée dans des publications fournies par le BCMP et quelques organismes privés. Il n'y a pas d'association nationale spécifique s'occupant de la loi et la politique de marchés publics ; le BCMP est le seul point focal au niveau national. Quelques organismes, tels que l'association lettone du bâtiment, l'association lettone des gouvernements locaux et régionaux, l'association lettone de marchands d'automobile autorisés, l'association lettone d'assureurs et l'organisme «de liberté verte»sont intéressés à apporter leur participation dans le processus législatif ou par la préparation des documents de marchés publics. La loi relative aux marchés publics est discutée dans les séminaires spéciaux sur les marchés publics organisés par le BCMP, l'école d'administration d'État et quelques organismes privés. Comme les décisions de la CJCE font jurisprudence, elles ont un rôle très important dans l'étude de législation lettone sur les marchés publics. Les organes de contrôle et les parties font la référence à elles. Il n'y a eu aucune procédure fondée sur les articles 234 ou 226 du Traité CE portant sur des marchés publics émanant de Lettonie jusqu'ici. 


\section{Lituanie}

Le système des recours et du contrôle de la légalité des marchés publics de la Lituanie est basé sur un circuit indépendant de trois instances juridictionnelles. Ceci s'applique aux contrats au-dessus et au-dessous des seuils fixés par la CEE. Il y a une réclamation obligatoire à l'autorité adjudicatrice ou à l'entité ellemême comme condition préalable du contrôle juridictionnel. Par ailleurs, il y a une procédure de conciliation en matière de services publics. Le rôle du bureau de marchés publics (BMP) est limité à une décision possible sur la suspension de la procédure de passation de marchés pendant que la réclamation auprès de l'entité adjudicatrice est en instance.

\subsection{Réclamation auprès de l'autorité adjudicatrice}

Il est obligatoire de porter une réclamation devant l'autorité adjudicatrice ou l'entité. Chaque fournisseur ou fournisseur de services qui a un intérêt au contrat et croit que l'autorité adjudicatrice ou l'entité a violé la loi relative aux marchés publics (LMP) peut faire une réclamation. Tous les types de décisions peuvent être contestés, jusqu'à la conclusion du contrat. Selon l'article 121 PPL [...], « lors de la réception de la réclamation écrite du fournisseur, l'autorité adjudicatrice suspendra les procédures de passation de marché jusqu'à ce que les réclamations soient entièrement examinées et une décision est prise. Les procédures de passation de marchés ne sont pas suspendues à la réception de l'autorisation du BMP si, par la suspension de la procédure de passation de marchés, le fournisseur peut subir des pertes beaucoup plus lourdes que celles qui pourraient être subies par le fournisseur qui a déposé la réclamation. » L'autorité adjudicatrice doit prendre une décision sur la réclamation dans les cinq jours de sa réception et informer le réclamant de la décision le jour ouvrable suivant. Il n'y a aucune information pour savoir si ce délai est habituellement respecté. Jusqu'en mars 2003, une réclamation à une «Commission indépendante de conflits » était une condition préalable au contrôle juridictionnel à la place de la réclamation obligatoire actuelle auprès de l'autorité adjudicatrice ou de l'entité.

\subsection{Contrôle juridictionnel}

En cas de décision négative ou partiellement négative du l'autorité adjudicatrice ou de l'entité, ou en l'absence de décision prise dans les délais, le fournisseur ou le fournisseur de services peut intenter des actions auprès des cours régionales (civiles) ordinaires à Vilnius, Kaunas, Klaipèda, Šiauliai ou Panevėžys en première instance, dont les décisions sont elles-mêmes sujettes à appel auprès de la cour de l'appel de Vilnius en deuxième instance. Le troisième et dernier degré de juridiction est la cour suprême de la Lituanie à Vilnius, seule cour de cassation. Toutes les cours ont été établies sur la base de la constitution et des lois et remplissent les conditions prévues par les décisions Dorsch et Salzmann, sauf que la procédure n'est pas contradictoire. Toutes les cours sont indépendantes de l'exécutif, de l'administration ou de n'importe quelle autre partie du gouvernement, et leurs décisions sont d'une nature juridictionnelle. Les juges doivent être des juristes expérimentés et reconnus. Ils sont nommés selon une procédure générale. La constitution, la procédure judiciaire et d'autres lois garantissent l'indépendance des juges ; elles peuvent être écartées seulement dans très des cas particuliers. Les juges de la cour suprême - ainsi que son président, qui est choisi parmi eux - doivent être des juristes fortement qualifiés, et sont nommés (et peuvent être écartés) par le Seimas (Parlement) sur proposition du président de la République de la Lituanie. Le fournisseur ou le fournisseur de services peut déposer une demande de conciliation si le marché public remplit la condition de la directive 2004/17/EC. Chaque candidat ou soumissionnaire qui croit que l'autorité adjudicatrice n'a pas agi conformément aux conditions de la LMP et a violé ou violera ses droits légaux a peut saisir, avant l'adoption de la décision sur l'offre qui l'emportera, la Commission européenne d'une demande de conciliation(comme elle est décrite dans la directive 92/13/CEE. La demande de conciliation peut également être déposée auprès du BMP, qui fera suivre à cette demande la Commission européenne. La réconciliation est une procédure qui s'ajoute au contrôle juridictionnel.

\subsection{Recours}

Les voies de recours comprennent les demandes d'annulation de toutes les décisions de marchés publics, de mesures provisoires et de dommages-intérêts. Un fournisseur ou un fournisseur de services qui a été lésé par une violation de la LMP par l'autorité adjudicatrice ou l'entité peut être se voir attribuer des dommages et intérêts en compensation d'un tort démontré. Ceci normalement couvrira les coûts de soumission mais peut également couvrir les pertes de bénéfices si le requérant peut les prouver. La conclusion du contrat 
peut être annulée dans les cas où les clauses du contrat établissent des conditions illégales. En outre, selon la LMP, le contrat ne peut être signé jusqu'à ce que l'échéance des délais offerts aux fournisseurs pour réclamer.

\subsection{Procédure}

En ce qui concerne les pouvoirs publics et les services publics, la procédure est réglée par le code de procédure civile et partiellement par le chapitre V de la LMP (par exemple, les délais ; version anglaise http://www3.1rs.lt/pls/inter3/dokpaieska.showdoc_1?p_id=273790). Tout soumissionnaire potentiel peut intenter des actions. Les droits sont réglés dans le code de procédure civile. Le droit de timbre est fixé à 30 euros environ. Dans les conflits portant sur des sommes d'argent, les droits sont réglés suivant somme forfaitaire fixée selon la réclamation particulière. La partie perdante rembourse alors la partie victorieuse des droits et des autres coûts de procédure. Les requêtes doivent être déposées auprès de l'autorité adjudicatrice par écrit dans les cinq jours de la date à laquelle le soumissionnaire s'est rendu compte ou devrait s'être rendu compte de la violation de ses droits légaux. Le soumissionnaire doit porter son action devant les juridictions dans les dix jours de la date à laquelle il s'est rendu compte ou devrait s'être rendu compte de la décision de l'autorité adjudicatrice ou de l'entité sur la réclamation. En cas de manque de cette dernière à examiner la réclamation dans le temps établi, les soumissionnaires peuvent porter devant la cour leurs poursuites dans les dix jours de la date à laquelle la réclamation aurait dû être examinée. Selon la LMP, toutes les informations identifiées en tant que telles par le soumissionnaire ou l'autorité adjudicatrice sont considérées confidentielles et ne peuvent pas être portée à la connaissance d'un tiers sans le consentement du soumissionnaire ou de l'autorité adjudicatrice. Il y a quelques exceptions exigeant que l'information confidentielle soit divulguée dans les cas décrits clairement dans les lois, en particulier dans celui des activités délictueuses. Le BMP traite des réclamations formelles et informelles en ce qui concerne des services publics privatisées. Il n'y a pas d'effet suspensif systématique quand une partie intente une action ; la cour décide ceci au cas par cas. La cour doit examiner la demande ou prendre sa décision dans les 60 jours du jour de l'introduction de la procédure ou de l'acceptation de l'appel. La jurisprudence est d'importance limitée mais d'importance considérable en raison d'un système reposant à la fois sur la codification et la jurisprudence. Les décisions de la cour d'appel et de la cour suprême sont publiées dans le bulletin officiel et sur site Web. Cependant, l'accès à cette information est sujet au paiement d'un droit. Excepté les parties au cas, les décisions de tribunaux régionaux sont disponibles sur demande, également sous condition de paiement d'un droit.

\subsection{Culture du recours}

Les juges et les avocats acquièrent leur connaissance de loi de marchés publics dans la pratique. Le BMP édite un bulletin trimestriel sur les marchés publics et avise en continu toutes les parties intéressées des nouvelles concernant les marchés publics sur son site Web officiel. Des séminaires internationaux sont de temps en temps organisés en coopération avec les différents organismes internationaux, par exemple l'OECD/SIGMA, TAIEX etc. Des séminaires locaux sont organisés par le BMP et le secteur privé. Il n'y a pas d'association nationale de marchés publics. Le département national de Transparency International contrôle les procédures de marchés publics. Plus spécifiquement, ce corps traite les questions de corruption.

\section{Luxembourg}

Les marchés publics au Luxembourg sont régis principalement par la loi du 30 juin 2003 (telle qu'amendée), ainsi que par un certain nombre de règlements d'application. Le système de recours et de contrôle de la légalité est basé sur un contrôle juridictionnel indépendant. La loi du 13 mars 1993 (telle qu'amendée) et la loi du 27 juillet 1997 transposent, respectivement, les directives communautaires 89/665/CEE et 92/13/CEE. Un contrôle extrajudiciaire est également disponible. Il y a un site Web officiel sur les marchés publics en français (http://www.marches.public.lu).

\subsection{Contrôle extrajudiciaire}

Les soumissionnaires lésés peuvent protester contre un acte de la procédure d'adjudication directement auprès du fonctionnaire de l'autorité adjudicatrice aussi bien qu'auprès de son supérieur (« recours gracieux »). Ce n'est pas une condition préalable pour former un recours. Les personnes chargées 
légalement de représenter et de lier l'autorité doivent traiter de telles réclamations. L'attestation et les mécanismes de conciliation de la directive 92/13/CEE ont été également transposés en droit interne en ce qui concerne les contrats au-dessus des seuils visés par la directive CE 93/38/CEE. Le médiateur peut également être invité à juger un conflit concernant une procédure d'adjudication (36, rue du Marché-auxHerbes, L-1728 Luxembourg ; Téléphone : +352 262701 01, fax : +352 26270102 , www.ombudsman.lu) dans les conditions établies par la loi du 16 juillet 2003. L'institution la plus importante, cependant, est la Commission des soumissions, au sein du ministère des travaux publics (Commission des Soumissions, Ministère des Travaux Publics, 4 Bd F.D. Roosevelt, L-2450 Luxembourg ; Téléphone : +352 478 3312/478 3315, fax : +352 4627 09, email : commission.soumissions@tp.etat.lu). La commission se compose de neuf membres, dont cinq, y compris le président, représentent les autorités adjudicatrices et quatre les organismes professionnels. Les tâches de la commission comprennent le contrôle de la conformité des adjudications avec les dispositions juridiques, le règlement des conflits portés par des parties à une procédure de passation de marchés publics et des activités consultatives sur demande de l'autorité adjudicatrice ou d'office (en particulier lorsque la conduite d'une procédure négociée est envisagée ou lorsque l'autorité adjudicatrice entends abandonner une adjudication ou se prononcer sur un contrat). L'introduction d'une demande de règlement n'exerce pas un effet suspensif sur la procédure d'adjudication ; les autorités adjudicatrices, cependant, ne se procèdent habituellement pas à la conclusion du contrat jusqu'à ce que la commission ait établi une décision. Les procédures devant la Commission sont régies par la loi du 30 juin 2003 sur les marchés publics. Les autorités adjudicatrices ayant violé la loi relative aux marchés publics peuvent être invités à retirer l'acte allégué. La commission, cependant, est un organisme consultatif et ses décisions («avis») ne lient pas les autorités adjudicatrices et ne sont pas contestables devant les juridictions. Les formulaires-types pour la présentation des demandes sont disponibles en ligne (http://www.marches.public.lu/commissionsoumissions/index.html), mais ils sont rarement utilisés dans la pratique. Il n'y a aucun droit à payer pour les procédures portées devant la commission.

\subsection{Contrôle juridictionnel}

Le contrôle juridictionnel des décisions d'adjudication a lieu dans le cadre des procédures de droit commun et est généralement conforme aux directives « recours » de la CEE. En fonction de la nature juridique de l'autorité adjudicatrice, les conflits résultant des procédures d'adjudication peuvent être apportés devant les juridictions administratives ou ordinaires (civiles). Selon les règles transposant les deux directives « recours », le premier choix s'applique aux autorités adjudicatrices classiques aussi bien qu'aux opérateurs de service public ayant une forme de droit public (loi de 1993). La deuxième option s'applique aux opérateurs de service public ayant une forme de droit privé (loi de 1997). Les développements suivants se rapportent seulement aux procédures devant des tribunaux administratifs selon les règles générales (Loi 1996 sur la justice administrative) et les règles de transposition de la directive 89/665/CEE (loi de 1993). Avant qu'un contrat ait été signé et indépendamment de sa valeur prévue, les soumissionnaires lésés peuvent contester n'importe quelle décision de l'autorité adjudicatrice qui a un caractère définitif (c.-à-d., pas les décisions provisoires avant qu'une décision définitive ait été prise), devant le tribunal administratif (« tribunal administratif», 1 rue du Fort Thüngen, L-1499 Luxembourg ; Téléphone : + 3524210578 55, fax : +352 4210572 78). Dans les procédures de la loi de 1993, il est possible que la décision du président du tribunal ne puisse pas être portée en appel. Dans les procédures normales, la décision du tribunal peut être contestée en deuxième et dernière instance devant la cour administrative d'appel (Cour administrative, 1 rue du Fort Thüngen, L-1499 Luxembourg ; Téléphone : + 3524210578 50, fax : +352 4210578 88après la réforme de 1996, le Conseil d'État n'a plus des fonctions juridictionnelles). La cour administrative d'appel est une juridiction permanente jouissant des garanties d'indépendance et d'impartialité au sens de la constitution de 1868, et rend des décisions légalement obligatoires. Ses juges sont des juristes qualifiés, désignés dans des conditions fixées par la loi 1996 sur la justice administrative.

\subsection{Recours}

Dans le cadre de la loi 1993, le président du tribunal administratif peut adopter des mesures provisoires pour corriger la violation dès que possible ainsi que pour prévenir l'apparition d'autres dommages aux droits en jeu. Le président peut, en particulier, décider de suspendre la procédure d'adjudication jusqu'à ce que l'autorité adjudicatrice se conforme à ses obligations de soumission d'offres, aussi bien qu'annuler des exigences techniques ou financières discriminatoires dans les documents de la soumission, le contrat ou 
n'importe quel autre document concerné. Le président peut prendre en considération les conséquences probables des mesures recherchées pour tous les intérêts d'être susceptibles d'être lésés, y compris l'intérêt public, et décide de ne pas accorder à de telles mesures lorsque leurs conséquences négatives seraient supérieures à leurs avantages. Les mesures provisoires sont exécutoires mais n'ont pas un caractère définitif. Le tribunal, dans les procédures normales, est seulement compétent pour rendre une décision définitive concernant l'annulation d'une attribution de contrat. Quand l'autorité adjudicatrice ne se conforme pas à ses obligations de soumission d'offres, le tribunal est autorisé à appliquer des astreintes pour assurer l'application par l'autorité du jugement. Les dommages et intérêts peuvent être demandés seulement devant les tribunaux civils, à moins que les parties concluent une convention à l'amiable sur l'octroi de dommages et intérêts pour violation du droit des marchés publics. Il est suffisant pour les soumissionnaires lésés de fournir la preuve de la réalité du tort qui leur a été causé. En principe, le montant des dommages et intérêts est évalué par des experts et peut s'étendre aux coûts de soumission aussi bien qu'aux pertes de bénéfices.

\subsection{Procédure}

Dans le cadre de la loi de 1993, les requêtes devant le président du tribunal administratif peuvent être introduites avant la conclusion du contrat par toute personne répondant aux exigences pour participer à une adjudication et se considérant elle-même comme lésée par une violation au droit des marchés publics. Les requêtes n'exercent pas un effet suspensif sur la procédure d'adjudication, mais le requérant peut faire une demande spéciale à cet égard. En plus, les autorités adjudicatrices doivent respecter une période de statu quo de 15 jours entre la notification faite à tous les soumissionnaires de la décision d'attribution et la conclusion formelle du contrat. Cette règle est considérée l'une des évolutions récentes les plus importantes. Dans les procédures normales, les requêtes doivent être introduites dans les trois mois de la notification de la décision de d'attribution par toute personne justifiant un intérêt individuel, direct et actuel. Les procédures dans ce cas sont régies par la loi de 1996 sur la justice administrative (ainsi que les réglementations mettant en application cette loi). En ce qui concerne l'octroi de dommages et intérêts, les procédures sont régies par le code de procédure civile et doivent être lancées dans un délai de 30 ans à compter de la notification de la décision d'attribution (le délai ordinaire pour les cas non contractuels). Dans tous les cas, la participation d'un expert, ainsi que les coûts d'expertise, peut être décidée par les juridictions. Il n'y a aucune disposition concernant les délais dans lesquels les juridictions établiront une décision. En ce qui concerne des procédures de la loi de 1993, des décisions du président du tribunal administratif sont habituellement rendues dans un délai de deux semaines. Il n'y a aucun droit de procédure. Cependant, les parties doivent supporter des coûts de représentation juridique et d'huissier. En principe, les cours décident quelle partie supporte les coûts procéduraux ; les coûts de représentation juridique peuvent partiellement être remboursés sur l'ordre de la juridiction. Il n'y a aucun formulaire modèle pour des requêtes devant les juridictions dans les affaires de marchés publics. Les parties à la procédure devant la juridiction sont mises au courant des décisions par le greffier. Les décisions des cours sont disponibles en ligne (page d'accueil de tribunaux administratifs : http://www.jurad.etat.lu ; aucune référence aux noms des parties) et les plus importants dans le «Pasicrisie», le bulletin officiel de justice administrative.

\subsection{Culture du recours}

Les juges et les avocats ont pu avoir acquis la connaissance dans du droit des marchés publics en tant qu'élément de leurs programmes d'études universitaires. Ils peuvent également suivre des conférences et des cours de formation permanente organisés dans les pays frontières. Il n'y a aucune session de formation spéciale au Luxembourg. Les membres ou la Commission d'adjudication et les tribunaux administratifs sont considérés posséder une large expertise dans ce domaine. Les soumissionnaires peuvent se familiariser avec des marchés publics par leurs organismes professionnels respectifs (chambres de commerce). De tels organismes collaborent habituellement avec des délégués des ministères (travaux publics, intérieur). L'attitude des juges envers des intérêts contradictoires est considérée juste. La compétence des fonctionnaires des marchés publics est suffisante et est renforcée par la formation professionnelle obligatoire organisée par le ministère de la fonction publique et de la réforme administrative. La plupart des soumissionnaires ne recourent à des procédures juridictionnelles qu'en dernier recours. D'autres souhaitent faire obstruction à l'adjudication. Il n'y a aucune publication spécialisée ni aucune association nationale pour les marchés publics. Les conférences et les séminaires sont tenus par 
le ministère des travaux publics (particulièrement en cas de la révision de la loi de marchés publics), ainsi que par des organismes professionnels. L'impact des arrêts de CJUE est très important.

\section{Malte}

Malte a un double système de contrôle juridictionnel, avec la possibilité de réclamer des dommages et intérêts dans les tribunaux civils et toutes les autres procédures de contrôle traitées par des organes de contrôle des marchés publics spécialisés. Il y a une différence entre les contrats en dessous et au-dessus d'un seuil de 20000 LM (environ $47000 €$ ). Toutes les réclamations portant sur des contrats au-dessus de ce chiffre sont entendues par le Comité des appels des marchés publics, alors que le Comité général de contrats entends les requêtes concernant des contrats en dessous du seuil de 20000 LM (les parties IX et $\mathrm{X}$ du règlement de 2005 sur les marchés publics établissent la composition et les règles de fonctionnement du Comité général de contrats). Les règles s'appliquent aux autorités adjudicatrices et aux services publics de la même façon. Ces organes de contrôle ont été établis par les règlements de 2005 (publication légale 177/2005) relatifs aux marchés publics. Avant avril 2002, le Comité général de contrats attribuait des contrats et entendait également les appels. Le changement le plus important récemment a été la séparation des fonctions du Comité général de contrats (responsable d'attribuer des contrats) et du Comité d'appels des marchés publics. À Malte, tous les contrats en dessous du seuil de 20000 LM sont attribués par les différentes autorités adjudicatrices, tandis que tous les contrats au-dessus de ce chiffre sont attribués par le Département des contrats, une institution de l'administration centrale. Par conséquent, le Comité général de contrats agit en tant qu'autorité adjudicatrice pour les contrats au-dessus de $20000 \mathrm{LM}$ et comme organe de recours pour les contrats en dessous de ce chiffre. La transparence et la franchise du procédé, donnant l'accès total aux décisions de non-recommandation etc., sont considérées comme des forces du système maltais de contrôle de la légalité.

\subsection{Autorité adjudicatrice}

Les agents de l'autorité adjudicatrice sont responsables de traiter des réclamations, et il est obligatoire que les soumissionnaires portent formellement leur réclamation directement auprès de l'autorité adjudicatrice afin d'obtenir un contrôle de légalité (clause 83 du règlement 177/2005 : procédure pour la présentation des appels).

\subsection{Contrôle extra-juridictionnel}

La passation envisagée d'un contrat est rendue publique chaque mercredi et vendredi sur le panneau d'affichage et le site Web du département, et les soumissionnaires peuvent également obtenir cette information par fax. Un soumissionnaire lésé peut contester la passation envisagée d'un contrat au conseil des appels des marchés publics dans les dix jours civils suivant la publication de l'attribution au moyen d'une lettre motivée décrivant les raisons derrière la contestation et d'un dépôt de garantie (conseil des appels des marchés publics, département des contrats, Notre Dame Ravelin, Floriana CMR02). Les membres du conseil des appels des marchés publics sont nommés par le premier ministre, et leurs fonctions sont décrites dans la partie XIV des règlements de 2005 relatifs aux marchés publics. Il n'y a aucune condition concernant le président et les membres du conseil des appels des marchés publics qui soient mentionnées dans les règlements de 2005 sur les marchés publics sauf leur nomination par le premier ministre. (Voir ci-joint le règlement 177/2005 partie XIV). Contrairement au Comité général de contrats, qui fait partie du département des contrats, le conseil des appels est un organe de recours séparé et indépendant.

\subsection{Contrôle juridictionnel}

Il y existe un tribunal civil de dernier ressort examinant les décisions relatives aux marchés publics. Ce tribunal ne peut pas annuler la décision du conseil des appels mais peut attribuer des dommages et intérêts aux parties lésées. Les tribunaux de droit commun remplissent les conditions posées par les décisions Dorsch et Salzmann. L'article 84 (19) des règlements de 2005 sur les marchés publics énonce : «Tout soumissionnaire soumettant une réclamation et qui ne sera pas satisfait de la décision définitive prise par le conseil des appels défère le litige à la première chambre du tribunal civil de Malte. Un tel recours cependant n'empêche pas le directeur des contrats ou le chef d'un l'autorité adjudicatrice de mettre en application la décision définitive du conseil des appels ». 


\subsection{Arbitrage}

Il y existe un jury d'arbitrage au centre d'arbitrage de Malte (adresse : Palazzo Laparelli, 33, rue du sud, La Valette ; Téléphone +356 21222557 ; Fax +356 21230672 ; site Web : http://www.mac.com.mt/; Email : malta.arbitration@mac.com.mt) pour régler des questions survenant pendant l'application du contrat, mais pas pendant la procédure d'attribution. Le centre d'arbitrage de Malte a été installé pour favoriser et encourager le développement de l'arbitrage intérieur et de l'arbitrage commercial international. Il est administré par un conseil supérieur désigné par le président de Malte mais est indépendant du gouvernement. Il prévoit également la formation des chambres d'arbitrage entre les Maltais et les nonrésidents de Malte dans les cas d'arbitrage international.

\subsection{Recours}

Les soumissionnaires peuvent contester l'appel à candidatures et les décisions de qualification au cours de la procédure de contrôle auprès du conseil des appels des marchés publics. Le règlement $n^{\circ} 177 / 2005$ et le règlement $n^{\circ} 178 / 2005$ sont les fondements juridiques sur la base desquels le conseil d'appel peut suspendre l'attribution d'un contrat. La recommandation pour la passation du contrat peut être annulée. Après l'attribution du contrat, la première chambre des tribunaux civils peut attribuer des dommages et intérêts aux soumissionnaires lésés qui dépassent les seuls coûts de soumission. Dans le cadre des décisions du tribunal civil, la jurisprudence est d'importance primordiale puisqu'il n'y a aucune législation et tous les principes doivent être fixés par la jurisprudence. La décision du conseil des appels présente un caractère définitif.

\subsection{Procédure}

Il y a deux procédures distinctes : une pour les contrats au-dessus et une autre pour les contrats en-dessous du le seuil de 20000 LM.

Pour les marchés publics au-dessus de 5000 LM et jusqu'à 20000 LM, la procédure est comme suit. Le soumissionnaire lésé doit payer $100 \mathrm{LM}$ pour réclamer. Si l'appel est confirmé, le soumissionnaire lésé est remboursé la quantité déposée. Le soumissionnaire lésé doit objecter dans les trois jours de la notification de la décision d'attribution. Après que l'échéance de la période accordée pour la présentation d'une réclamation, l'autorité adjudicatrice doit fournir la réclamation, le reçu de dépôt de garantie et de tous les documents concernant le marché public en question au directeur des contrats. Le directeur des contrats défère l'affaire au Comité général de contrats, qui examine le problème d'une façon juste et équitable et règle la réclamation en l'accueillant ou en la rejetant. La décision écrite du Comité général de contrats est apposée sur le panneau d'affichage de l'autorité adjudicatrice et des copies s'y rapportant seront expédiées à toutes les parties concernées. Dans sa délibération, le comité aura le pouvoir d'obtenir, de toutes les façons qu'il considère appropriées, n'importe quelle autre information qui n'a pas déjà été fournie par l'autorité adjudicatrice. La décision du Comité général de contrats est définitive et lie l'autorité adjudicatrice et l'opérateur économique intéressé, qui ne n'auront pas de voie de recours (article 20 du règlement 177/2005).

Pour les marchés publics au-dessus du seuil de $20000 \mathrm{LM}$, la procédure est comme suit (règlement 177/05, partie XIII). Tout soumissionnaire qui se sent lésé par la passation envisagée d'un contrat et toute personne ayant ou ayant eu un intérêt à l'attribution d'un contrat de fourniture publique particulier, de délégation de service public ou de travaux publics et qui a été ou risque d'être lésée par une violation alléguée peut, dans les dix jours calendaires de la publication de la décision, introduire une objection auprès du département des contrats ou du l'autorité adjudicatrice impliquée selon les circonstances. Une objection est valide seulement si elle est accompagnée d'un dépôt de garantie équivalent à $1 \%$ de la valeur de soumission prévue et ne peut en aucun cas être inférieur à $200 \mathrm{LM}$ ou supérieur à $25000 \mathrm{LM}$. Le chef d'un l'autorité adjudicatrice informe immédiatement le directeur de l'objection introduite auprès de lui, suspendant de ce fait immédiatement la procédure d'adjudication. Le département des contrats ou l'autorité adjudicatrice impliquée, selon les circonstances, est empêchée de signer le contrat au cours de la période de dix jours civils accordés pour l'introduction des appels. La procédure d'attribution est suspendue si un appel est interjeté. Par conséquent, il y a une suspension systématique de la procédure par le biais du conseil des appels (aucune suspension des contrats par le biais des tribunaux civils). Dans un délai de trois jours ouvrables à compter de l'échéance de la période de dix jours accordée pour l'introduction d'une objection, tout autre soumissionnaire et toute personne ayant ou ayant eu un 
intérêt et se trouvant impliqué dans l'appel d'offres peut intervenir dans la procédure. L'intervention est valide seulement si elle est accompagnée d'un dépôt de garantie équivalent au dépôt de garantie visé par l'alinéa (1). Le soumissionnaire qui avait été indiqué dans la décision d'adjudication du directeur ou de l'autorité adjudicatrice comme celui à qui le contrat devait être attribué est considéré comme un intervenant mais n'a pas besoin de payer un dépôt de garantie. Les noms des soumissionnaires ou des autres personnes ayant ou ayant eu un intérêt à l'obtention d'un marché public particulier et qui interviennent, seront rendus publics le premier jour ouvrable après l'échéance du délai spécifique cidessus. Dans un délai de trois jours ouvrables après la publication de la liste de personnes qui interviennent, le soumissionnaire objectant doit envoyer une lettre motivée d'objection expliquant les raisons de son objection. La lettre d'objection est rendue publique et distribuée à toutes les personnes intervenant. Dans un délai de cinq jours ouvrables à compter de la publication de la lettre d'objection, n'importe quel soumissionnaire intervenant peut envoyer une réponse motivée à celle-ci. La réponse est rendue publique et distribuée à tous les soumissionnaires intervenant et à tous les soumissionnaires qui ont introduit une objection. Dans un délai de dix jours ouvrables à compter de la publication des réponses, le directeur ou le chef du l'autorité adjudicatrice établit un rapport (le rapport d'analyse) analysant la lettre d'objection et des réponses à cette dernière. Ce rapport est distribué aux personnes ayant introduit une objection et ayant intervenu. Après que le processus préparatoire est dûment achevé, le chef de l'autorité adjudicatrice expédie au directeur des contrats toute la documentation concernant l'appel d'offres en question, y compris des dossiers, les offres soumises, les copies des reçus de dépôt de garantie, toute lettre motivée, le rapport d'analyse, etc. Le directeur expédie toute la documentation liée à tous les appels au président du conseil des appels, qui procède alors comme stipulé dans la partie XIII. Le directeur ou le chef du l'autorité adjudicatrice publie une copie de la décision du conseil des appels à son département ou dans les locaux l'autorité adjudicatrice concernée selon les circonstances. Des copies de la décision sont expédiées au soumissionnaire objectant, à toute personne intervenant ou intéressée à la procédure et, par l'intermédiaire du directeur seulement, à l'autorité adjudicatrice concernée quand elle est visée dans l'annexe 2 du règlement 177/2005.

Le conseil d'appels peut utiliser des experts pour aider dans la délibération. Le département des contrats supporte les coûts de leur participation. Les experts des attributaires recommandés, des soumissionnaires lésés et des départements bénéficiaires/entités sont payés par ces derniers. N'importe quelle décision du Comité général de contrats (ou d'un Comité spécial des contrats) et de l'autorité adjudicatrice est rendue publique auprès du département des contrats ou du bureau du l'autorité adjudicatrice avant la passation du contrat. L'objection dûment introduite conformément à l'alinéa (1) est rendu publique pas plus tard que le jour ouvrable suivant son dépôt. Il n'y a aucun formulaire-type ou document obligatoire utilisé pour l'exercice des recours en matière de marchés publics. Les parties sont notifiées par fax. Les décisions sont publiées sur le site Internet du département des contrats (http://www.contracts.gov.mt). La décision définitive prise par le conseil des appels publics est distribuée à tous les parties concernées par fax ou email.

\subsection{Culture du recours}

Les juges et les membres du jury des organes de contrôle des marchés publics, et les avocats de droit des marchés publics représentant les soumissionnaires ou les entités adjudicatrices dans des procédures de contrôle, acquièrent leur connaissance du droit des marchés publics en particulier, du droit communautaire en général, du fonctionnement des marchés publics - ainsi que des considérations techniques et financières associées - par la pratique et par l'étude de la législation. Les juges et les membres du jury agissent d'une façon juste et équilibrée. Les soumissionnaires exerçant des recours en vue du contrôle de la légalité des décisions relatives aux marchés publics acquièrent leurs connaissances de l'environnement juridique, financier et administratif qui préside au fonctionnement des marchés publics dans la pratique par l'intermédiaire des avocats et des conseillers et par leurs organismes professionnels, tels que la chambre de commerce. Quelques soumissionnaires sont découragés de s'engager dans une procédure en raison de son coût élevé (représentation juridique, coûts administratifs, etc.). Généralement, les agents d'adjudication ont une bonne connaissance des procédures et de la législation. Cependant, dans la plupart des cas l'aide du Procureur général est obtenue. L'attitude des responsables des adjudications envers des soumissionnaires introduisant des réclamations ou exerçant un recours en vue d'un contrôle de légalité, est décrite comme tout à fait normale et professionnelle. Ils apportent une assistance du mieux qu'ils peuvent aux 
soumissionnaires lésés. Le directeur des contrats établit une publication annuelle sur les cas entendus par le conseil des appels des marchés publics et le Comité général de contrats. Les conférences et les séminaires organisés par la chambre de commerce et Malta Entreprise traitent des marchés publics. Il n'y a aucune association nationale pour le droit et la politique de marchés publics. La plupart des soumissionnaires emploient la chambre de commerce et d'autres associations nationales pour inciter aux discussions sur des marchés publics. La formation continue des fonctionnaires des marchés publics sur la réglementation applicable a été mise en place récemment. Cependant, aucune formation spécifique sur la loi ou la politique n'a eu lieu jusqu'à présent. L'impact des jugements de la Cour européenne de justice sur des procédures de contrôle de marchés publics est crucial. Néanmoins, la référence faite est ses décisions est rare.

\section{Pays-Bas}

Le système de contrôle de la légalité et de recours des Pays Bas est basé sur un contrôle juridictionnel sur trois degrés de juridictions auprès des tribunaux civils. Le système s'applique aux contrats tombant ou non dans le champ de l'application des directives communautaires et aux autorités adjudicatrices publiques et aux services publics de la même façon. Par ailleurs, l'arbitrage et d'autres mécanismes alternatifs de règlement des différends sont disponibles.

\subsection{Réclamations auprès des autorités adjudicatrices et entités}

Le système néerlandais est fondé sur le contrôle juridictionnel. Si, cependant, un soumissionnaire souhaite seulement faire une réclamation liée au comportement de l'autorité adjudicatrice, il peut introduire une réclamation officielle auprès de l'autorité adjudicatrice ou de l'entité elle-même. Si l'autorité adjudicatrice ne traite pas d'une manière satisfaisante la réclamation officielle, alors le soumissionnaire peut se tourner vers le médiateur national (« médiateur national »).

\subsection{Contrôle juridictionnel}

Un soumissionnaire recherchant une compensation financière (dommages et intérêts), l'exécution du contrat, la suspension de l'adjudication ou l'annulation du contrat, doivent introduire une requête auprès du tribunal civil. La suspension du contrat ou de l'adjudication (mesures provisoires) peuvent être recherchées dans des procédures préliminaires spéciales (ou des procédures provisoires d'injonction) traitant des affaires sur une base provisoire et à court terme (procédure «kortgeding » ou procédure « voorlopige voorzieningen »). En première instance, l'affaire est examinée par le tribunal de première instance (« rechtbank »). La décision du rechtbank peut être portée en appel à la cour de l'appel (« Hof »). La décision de la Hof peut être portée en appel devant la cour suprême («Hoge Raad "). Le système judiciaire néerlandais en général est réglé par une loi, la «Wet op de Rechterlijke Organisatie ». Au sein de la Hoge Raad, il y existe une chambre chargée d'examiner les décisions de marchés publics. Comme le rechtbank et la Hof, elle remplit les conditions établies dans les décisions Dorsch et Salzman pour former un «tribunal». Les dispositions garantissant l'indépendance des juges de chacune des trois instances mentionnées ci-dessus comprennent la nomination à vie, des exigences de qualification (six ans de formation remplis avec succès ou une expérience professionnelle certaine dans la profession juridique), un financement régit par loi (le financement gouvernemental seulement), et des tâches et compétences également régies par loi.

\subsection{Arbitrage}

Il est actuellement encore possible que les parties portent leur conflit devant un jury d'arbitrage ou d'autres conciliateurs ou arbitres. Cependant, une nouvelle législation est discutée au parlement pour interdire l'arbitrage dans les conflits portant sur l'utilisation ou l'application des règles relatives aux marchés publics afin de protéger les droits des soumissionnaires dans le cadre des procédures de passation de marchés. Si cette législation est passée, alors tous les conflits portant sur l'utilisation ou l'application des règles relatives aux marchés publics devront être traités par les tribunaux civils, comme décrit ci-dessus.

\section{$17.4 \quad$ Recours}

Il y existe beaucoup de voies de droit disponibles. Par exemple, il est possible d'obtenir des dommages et intérêts, la suspension de l'adjudication, l'arrêt de l'adjudication, le recommencement de l'adjudication, l'acceptation du soumissionnaire, la suspension ou la résolution du contrat, etc. Il incombe au 
soumissionnaire de définir le droit dont il recherche l'exécution lorsqu'il introduit une action auprès d'une juridiction et d'exposer ses arguments afin qu'elle puisse se prononcer. Toutes les décisions et actions du l'autorité adjudicatrice (ou de l'autorité des marchés publics) peuvent être contestées, même lorsque le contrat a été déjà signé. La base juridique est l'article 162 du « Boek 6, Burgerlijk Wetboek » (code civil) et le «Wetboek van Burgerlijke Rechtsvordering» (code de procédure civile) et la nombreuse jurisprudence. La loi codifiée, en combinaison avec la jurisprudence, est la base juridique qui donne pouvoir à une juridiction d'écarter ou de suspendre une décision d'attribution de contrat. Pour suspendre ou écarter temporairement l'attribution d'un contrat (décision préjudicielle) les conditions sont : un intérêt bien fondé (point d'intérêt), l'urgence et une violation de la loi. La juridiction écarte l'attribution d'un contrat (temporairement ou autrement) seulement si elle conclut qu'une violation de la loi s'est produite et si elle considère que cette violation doit être réparée en écartant la décision d'attribution. La conclusion du contrat peut être annulée par la juridiction seulement si la violation de la loi est considérée d'ordre public. Dans d'autres circonstances, la cour ordonne à l'entité de marchés publics de résilier le contrat, de ne pas signer le contrat (avec une certain partie ou en général), de ne pas exécuter le contrat, de ne pas commencer une procédure de passation de marchés (une autre), de ne pas admettre une entreprise à la procédure, de ne pas accepter l'offre d'une entreprise comme appropriée, etc. La loi codifiée, en combinaison avec la jurisprudence, est la base juridique pour la détermination des dommages et intérêts. Les dommages et intérêts peuvent être réclamés même si la décision n'est pas écartée. Les conditions sont : le réclamant a enregistré une perte (pécuniaire ou autrement), il y a eu une violation de la loi, il existe un lien de causalité (signifiant que la perte doit être provoquée par la violation de la loi). Dans ce cas, il y a responsabilité (faute). La jurisprudence néerlandaise montre que les dommages et intérêts peuvent aller bien au-delà des coûts de soumission. La loi codifiée et la jurisprudence servent de base aux mesures provisoires. La juridiction ou le jury d'arbitrage prend en considération les conséquences probables des mesures provisoires pour tous les intérêts susceptibles d'être lésés, y compris l'intérêt public, et décide de ne pas attribuer de telles mesures où leurs conséquences négatives seraient supérieures à leurs avantages. La jurisprudence montre que la cour est susceptible de prendre une telle décision seulement si le contrat est entièrement ou presque entièrement exécuté à la date à laquelle les procédures devant la cour sont lancées. Le paiement de pénalités est possible aux Pays-Bas afin de s'assurer que la décision de la Cour est exécutée par l'autorité ou l'entité adjudicatrice. La grande variété de voies de droit disponibles est vue comme force importante du système de recours néerlandais.

\subsection{Procédure}

Le code de procédure civile règle la loi procédurale des tribunaux civils. N'importe qui prétend avoir un intérêt peut lancer des procédures. Ainsi il n'est pas nécessaire qu'une personne ou une compagnie soumette une offre, etc. Des procédures peuvent être lancées sans entrer dans la procédure de marchés publics. Un droit de procédure général variant de $26 €$ à $4563 €$ doit être payé. Le montant précis varie selon l'instance et les intérêts financiers en jeu. Il n'y a aucun droit à payer pour introduire une réclamation auprès de l'entité adjudicatrice elle-même. Les droits sont fixés par loi. Les coûts en plus des droits de procédure comprennent les coûts d'avocats, d'huissiers et d'experts, et ils peuvent varier considérablement. Le résultat des procédures affecte les coûts pour les parties. Si le requérant l'emporte sur tous les moyens, l'entité adjudicatrice doit payer tous les coûts procéduraux, y compris des droits de procédure et les honoraires d'avocats. Si la décision est en faveur de chacune des parties, chacun des deux doit payer plus ou moins la moitié des coûts. La cour décide des demandes concernant les demandes d'expertise faites par les parties et décide quelle partie devra payer les coûts associés. Une action en dommages et intérêts peut être introduite à tout moment dans les cinq ans de la date à laquelle la violation de la loi s'est produite ou a été identifiée. Les procédures «à huis clos» sont une possibilité s'il est nécessaire afin de protéger des affaires confidentielles. En outre, la cour peut interdire les parties de rendre publiques des informations sur les procédures pendant et après le déroulement de la procédure à huis clos (articles 27 et 29 du Wetboek van Burgerlijke Rechtsvordering). Les décisions sont rendues en séance publique. Des jugements sont également distribués aux parties, rendus disponibles sur un site Web (pour autant qu'ils ne contiennent pas d'information confidentielle) et publiés dans diverses revues juridiques (si une question de droit intéressante est soulevée dans la décision). La suspension d'une procédure de passation de marchés doit être spécifiquement demandée comme mesure provisoire devant la juridiction. Il est prononcé sur les procédures provisoires d'injonction en quelques jours. Dans les procédures normales, cela prend plusieurs semaines pour entamer la procédure. La procédure elle-même peut prendre plusieurs mois (selon les 
arguments, la complexité du cas, le nombre ou la complexité des expertises requises et compte tenu du temps pour les parties de demander à la juridiction la production d'un certain argument ou d'une preuve). Après que les procédures elles-mêmes soient finies, la juridiction prend quelques semaines avant de prononcer sa décision. La vitesse des procédures est vue comme force importante du système néerlandais de contrôle de la légalité et de recours. La jurisprudence est d'importance limitée mais d'importance considérable en raison d'un système reposant à la fois sur la codification et la jurisprudence. La cour emploie un formulaire spécial pour commencer les procédures. Ce modèle est le même pour toutes les procédures (des marchés publics ou d'autres sujets). Il y a également un formulaire modèle pour la notification à l'entité de marchés publics que la partie a entamé une procédure. C'est un modèle général pour toutes les procédures (marchés publics ou pas). En principe, toutes les décisions juridictionnelles sont publiques et à la disposition de tous. Les décisions sont prononcées en séance publique. Des jugements sont également distribués aux parties, rendus disponibles sur un site Web et publiés dans divers journaux juridiques. La cour peut faire des exceptions pour des raisons d'intimité et confidentialité. Les versions électroniques de beaucoup de décisions sont disponibles sur www.rechtspraak.nl et www.jol.nl.

\subsection{Culture du recours}

Les juges et les avocats de droit des marchés publics représentant les soumissionnaires ou les entités adjudicatrices dans la cadre de procédure de contrôle acquièrent leur connaissance du droit des marchés publics en particulier, du droit communautaire en général et du fonctionnement concret des marchés publics au cours de leurs études universitaires, de leur formation professionnelle, de l'enseignement continu, dans les cours organisés par le gouvernement, par exemple le ministère de la justice, dans les cours organisés par l'UE ou les organismes internationaux et par la pratique. L'attitude des juges envers l'intérêt public d'une part et les intérêts privés des soumissionnaires d'autre part, est décrite comme juste et équilibrée. Les soumissionnaires qui exercent des recours contre les décisions de marchés publics acquièrent leurs connaissances de l'environnement juridique, financier et administratif présidant aux marchés publics dans la pratique, principalement par l'intermédiaire des avocats et des conseillers. Au cours des dernières années, le nombre de procédure en matière de marché publics a augmenté. Il y a plusieurs raisons possibles pour lesquelles les soumissionnaires peuvent ne pas opter pour un contrôle juridictionnel. Cela signifie normalement que leur dossier n'est pas assez fort (la violation des règles est incertaine ou seulement mineure). Quelques soumissionnaires ont l'intention de faire obstruction à la passation du marché public. La plupart d'entre eux cherchent à réaliser un gain financier par l'utilisation des procédures de contrôle juridictionnel. Certains en sont découragés en raison des coûts (représentation juridique y compris, etc.) ou de la durée de ces procédures. Les publications et les journaux scolaires traitant spécifiquement des questions de marchés publics, y compris du contrôle juridictionnel des marchés publics et des voies de recours, comprennent le «Tijdschrift voor Aanbestedingsrecht », «Tijdschrift voor Bouwrecht», «Tijdschrift voor Europees recht», divers sites Internet, comme (par exemple, www.Ovia.nl), «Nieuwsbrieven IOEA » et «Nieuwsbrieven Kenniscentrum Europa Decentraal». Plusieurs séminaires et conférences sur les marchés publics sont organisés par le secteur privé. En outre, les diverses universités ont des cours traitant des marchés publics. Ces cours sont ouverts à chacun (pas simplement aux étudiants à temps plein). Il y a une association nationale sur la politique et le droit des marchés publics, le voor Aanbestedingsrecht de Nederlandse Vereniging. Les groupes de pression tels que les associations regroupant certaines entités économiques (VNO/NCW, MKB Nederland, Bouwend Nederland, etc.) font du lobbying et conseillent sur les marchés publics. Les organismes consultatifs formels et informels tels que le voor de Nederlandse Vereniging Aanbestedingsrecht, InnovatiePlatform, Regieraad Bouw, etc., existent également dans le domaine. Les décisions de la CJCE ont un impact sur les procédures de contrôle de la légalité parce qu'elles font partie des règles relatives aux marchés publics. Ainsi, Les organes de contrôle font référence à eux.

\section{Pologne}

Les marchés publics en Pologne sont régis par la loi du 29 janvier 2004 modifiée (traduction en anglais : http://www.uzp.gov.pl/english/PPL_29_January_04.doc). Mais les nouvelles directives «marchés publics » de la CE ont été transposées en droit interne par une loi du 7 avril 2006 (entrée en vigueur le 25 mai 2006). Le système polonais de contrôle de la légalité et de recours repose sur un mélange de contrôle administratif, juridictionnel et quasi-juridictionnel. Dans le secteur des services publics, le contrôle des 
décisions de marchés publics est seulement disponible au-dessus des seuils de la CE. L'acteur principal est le bureau de marchés publics (dorénavant : le BMP ; Urząd Zamówień Publicznych, Al Szucha 2/4, 00582 Varsovie ; Téléphone +48 224587777 ; Fax : +48 2245877 00, email : uzp@ uzp.gov.pl, site Web : http://www.uzp.gov.pl), une autorité indépendante établie en 1995 et ayant compétence sur l'élaboration de la politique et la coordination dans le domaine des marchés publics. Le bureau est également responsable de la publication du bulletin national de marchés publics, c.-à-d., l'outil de publicité pour les contrats en dessous des seuils de la $\mathrm{CE}$ et les décisions des autorités adjudicatrices dans les secteurs classiques et les services publics (dans ce dernier cas, seulement au-dessus des seuils de la CE). Le président du BMP est nommé pour un mandat de cinq ans par le premier ministre après qu'une invitation à candidatures. Le BMP comporte un secrétariat du président, un service juridique, un département de contrôle, un département des publications et de la formation, un département pour les études, analyses et la coopération internationale, un bureau des appels et un bureau chargé de l'organisation et du financement. Le contrôle extrajudiciaire est disponible dans le secteur des services publics (mécanisme de conciliation prévu par la directive CE 92/13). Il n'y a aucune entité d'arbitrage chargée d'une mission de règlement alternatif des différends dans le domaine des marchés publics.

\subsection{Contrôle des décisions sur les marchés publics}

En fonction de la valeur prévue du contrat et avant que le contrat ait été signé, le contrôle des décisions liées à une adjudication s'exercent en trois étapes. À la première phase, toute personne ayant un intérêt à obtenir le contrat (soumissionnaire, candidat, participant au concours) qui a été ou est susceptible d'être lésé par un acte ou une omission de l'autorité adjudicatrice qu'elle considère contraire à la loi sur les marchés publics, est autorisée à introduire une protestation par écrit à l'autorité adjudicatrice dans les sept jours de la date à laquelle elle s'est rendu compte de la violation alléguée. Il y a quelques exceptions à cette règle : 1) Les réclamations contre les notices de contrat ou/et le cahier des charges en procédure ouverte doivent être déposées dans les sept jours, dans le cas des contrats en dessous des seuils de la CE, ou 14 jours, dans le cas des contacts au-dessus des seuils de la CEE, à compter de la date la notice du contrat a été publiée dans le bulletin national des marchés publics (pour des contrats en dessous des seuils de la CEE) ou le Journal officiel de l'Union européenne (pour des contrats au-dessus des seuils de la CEE) ou/et le cahier des charges ont été mis à la consultation par le site Web de l'autorité adjudicatrice ; 2) les réclamation contre le cahier des charges dans des procédures autres que la procédure ouverte doivent être déposées dans les sept jours de la date où le soumissionnaire a reçu ledit cahier des charges mais, en tous cas, pas plus tard que a) trois jours avant la date-limite de soumission des offres dans le cas des contrats en dessous des seuils de la CEE et b) six jours avant la date-limite pour la soumission des offres dans le cas des contrats au-dessus des seuils de la CEE. La réclamation doit être déposée avant que le contrat ait été signé. Des réclamations peuvent également être déposées par plusieurs organismes (tels que les chambres de commerce, les organismes de métiers, les ordres de plusieurs professions- entrepreneurs, architectes, ingénieurs civils, planificateurs de ville, les organisations patronales) pas plus tard qu'à la date-limite pour la soumission des offres. La liste de ces organismes peut être modifiée par le président du BMP et doit être publiée dans le bulletin national des marchés publics. Les réclamations sont traitées par le chef de l'autorité adjudicatrice ou un fonctionnaire dûment mandaté par cette autorité. L'autorité adjudicatrice établit une décision motivée sur la réclamation dans les 10 jours de sa réception. L'absence de décision dans ce délai est considérée comme un rejet de la réclamation. La première phase est la procédure de révision applicable unique pour les contrats dont la valeur prévue ne dépasse pas $60000 €$. Concernant des contrats d'une valeur plus élevée que $60000 €$, il y a une seconde étape. Les personnes ayant déposé une réclamation auprès de l'autorité adjudicatrice peuvent porter en appel la décision devant le BMP dans les cinq jours du prononcé de ladite décision ou de l'échéance du délai dans lequel l'autorité adjudicatrice devait prendre une décision. Les personnes ayant déposé une réclamation antérieure ne sont pas recevables à agir devant le BMP. L'examen d'un recours est sujet au paiement antérieur de droits d'inscription. L'appel est traité au siège du bureau, par un groupe de trois arbitres désignés par le président du BMP. Les arbitres sont sélectionnés parmi une liste établie pendant une période de six ans au moyen d'une procédure électronique publique. Les arbitres ne sont pas nécessairement des avocats ou des juristes ; certains sont des experts dans un domaine particulier tels que la construction ou les systèmes informatiques. Un jury d'arbitrage séparé est nommé pour chaque procédure de contrôle. Ceci peut être vu comme une faiblesse du système polonais de contrôle parce que les décisions établies par des jurys d'arbitrage divergent habituellement les unes des autres. Quoique le jury applique les dispositions du code polonais de procédure civile sur 
l'arbitrage et que les arbitres ne soient pas responsables envers le président du BMP, les procédures devant le jury ne constituent pas une méthode de règlement alternatif des différends mais font partie du système formel de contrôle. Le jury ne peut pas se prononcer ultra petita et est tenu d'établir une décision dans les 15 jours de la date à laquelle l'appel a été interjeté auprès du BMP. En 2005, 4094 appels ont été interjetés auprès du BMP, dont 308 ont été retirés, 1714 confirmés, 440 rejetés, 1226 jugés irrecevables, 406 non examinés pour omission de payer les droits d'inscription. En moyenne, les jurys d'arbitrage établissent une décision dans les 13 jours (données 2005). À la troisième étape, la décision définitive du jury d'arbitrage peut être contestée devant un tribunal régional par le réclamant de la première phase ou par l'autorité adjudicatrice elle-même. Les tribunaux régionaux sont les organes de contrôle du dernier ressort dans les affaires de marchés publics. La juridiction territoriale de la cour dépend du siège de l'autorité adjudicatrice. La requête doit être introduite par l'intermédiaire du président du BMP dans les sept jours du prononcé de la décision définitive du jury d'arbitrage aux parties. Le président doit alors fournir à la partie défenderesse une copie de la requête et expédier le dossier de procédure avec la requête, au tribunal compétent dans les sept jours de son introduction. Ensuite après avoir reçu la requête, la juridiction rend une décision en temps voulu mais pas plus tard qu'un mois (sous la loi ancienne sur les marchés publics : trois mois) à compter de sa réception. Le non-respect du délai n'a pas pour effet d'infirmer la décision. En moyenne, les tribunaux régionaux établissent une décision dans les 2,73 mois (données 2005 sous l'empire de la loi ancienne sur les marchés publics). Il y a 45 tribunaux régionaux situés dans plusieurs villes. Les tribunaux régionaux sont des corps permanents, rendant des décisions légalement obligatoires et composés de membres de l'ordre judiciaire dont l'indépendance est garantie par la constitution (articles 173 et 178). En particulier, tout citoyen polonais ayant au moins 29 ans, une expérience démontrée dans le domaine du droit et jouissant de tous ses droits civiques peut être nommé en tant que juge. En 2005, 506 requêtes ont été introduites auprès des tribunaux régionaux. Seulement $12,5 \%$ des jugements établis ont eu comme conséquence l'annulation des décisions prises par les jurys d'arbitrage.

\subsection{Recours}

L'introduction d'une procédure de contrôle exerce un effet suspensif systématique sur l'adjudication actuelle dès la première phase. L'autorité adjudicatrice ne peut pas signer le contrat avant que toutes les voies de recours offertes aient été épuisées, c.-à-d., avant qu'un tribunal régional ait rendu une décision sur une requête faite contre une décision d'appel du jury d'arbitrage. Un contrat signé en violation de l'obligation mentionnée ci-dessus est réputé nul. L'autorité adjudicatrice peut, cependant, signer le contrat si le président du BMP en décidé ainsi sur demande de l'autorité et après avoir pris en considération les conséquences probables de la suspension pour tous les intérêts susceptibles d'être lésés, y compris l'intérêt public. L'autorité adjudicatrice est également autorisée à conclure le contrat si le réclamant ne va pas jusqu'à la deuxième ou la troisième étape. Par sa décision définitive, le jury d'arbitrage peut 1) rejeter l'appel contre la décision du l'autorité adjudicatrice sur la réclamation antérieure ; 2) faire droit à la réclamation et ordonner à l'autorité adjudicatrice d'établir un acte ou d'annuler l'acte allégué ; et 3) écarter (annuler) un acte de l'autorité adjudicatrice. Des circonstances susceptibles d'avoir comme conséquence l'annulation de la décision d'attribution du contrat doivent être examinées d'office par le jury. Le tribunal régional peut 1) écarter la requête si elle est injustifiée ; 2) suspendre la procédure de contrôle pour des raisons de forme ; et 3) faire droit à la requête et annuler la décision du jury d'arbitrage. Dans le troisième scénario, la cour doit examiner l'affaire depuis son commencement et rendre une décision au fond. Avant de rendre sa décision définitive et dans des conditions visées par la loi sur les marchés publics, la juridiction peut sur demande de l'autorité adjudicatrice, permettre à cette dernière de signer le contrat. Il doit avoir été fait droit aux recours mentionnés ci-dessus par les deux organes avant que le contrat ait été signé. L'annulation d'un contrat signé relève de la juridiction des tribunaux régionaux. Des sanctions financières peuvent être appliquées par une décision administrative du président de BMP dans les cas visés à l'article 200 de la loi sur les marchés publics (attribution irrégulière ; défaut de publication d'une notice de contrat ; abandon irrégulier de l'adjudication ; émission de certains actes sans assentiment préalable du président du BMP ; modification irrégulière d'un contrat signé). Des dommages et intérêts peuvent être attribués conformément aux règles générales du code civil.

\subsection{Procédure}

La procédure devant les jurys d'arbitrage est régie par les dispositions du code de procédure civile sur l'arbitrage. La procédure devant les tribunaux régionaux est régie par les dispositions de ce code sur les 
appels. Le dépôt d'une réclamation antérieure auprès de l'autorité adjudicatrice n'est pas sujet au paiement de frais administratifs. En revanche, l'introduction d'une procédure devant un jury d'arbitrage est sujette au paiement de droits d'inscription, dont le montant dépend de la valeur prévue du contrat (en moyenne 3138 PLN en 2005). Avant la loi de 2006, les droits d'inscription ne dépendait pas de la valeur du contrat, c.-àd., leur montant était le même pour les grands et les petits contrats. Sous l'empire de la loi de 2006, les droits d'inscription en cas de contrats au-dessus des seuils de la CEE sont de 20000 PLN pour les contrats d'entretien et de services et de 40000 PLN pour les contrats de travaux. Les droits d'inscription en cas de contrats en dessous des seuils de la CEE sont de 10000 PLN pour des contrats d'entretien et de services et de 20000 PLN pour les contrats de travaux. Selon la loi du 28 juillet 2005, sur les droits de procédure dans des cas civils, l'introduction d'une action devant les tribunaux régionaux est sujette au paiement d'un droit s'élevant à 3000 PLN. La valeur relativement basse des droits applicables est considérée un avantage important du système polonais de contrôle. En effet, les droits d'inscription d'appel étaient bas avant la loi de 2006 et on pourrait se demander s'ils sont encore trop bas-en fait, ils ont été augmentées sensiblement afin de limiter l'abus des recours en vue du contrôle des mesures administratives. Il n'y a pas d'autres coûts obligatoires, mais les parties peuvent souhaiter avoir recours à un avocat. En moyenne, le coût de la représentation juridique devant les jurys d'arbitrage en 2005 était d'environ 694 PLN pour les autorités adjudicatrices et d'environ 1776 PLN pour les soumissionnaires. Par principe, les coûts de procédures devant les deux organes de contrôle doivent être remboursés par la partie perdante. Il n'y a aucun formulaire modèle pour la présentation des appels/des requêtes, mais une liste d'éléments obligatoires (tels que l'indication de la décision contestée, la description des faits, les mesures demandées) qui doivent y figurer. En ce qui concerne les procédures devant des tribunaux régionaux, les dispositions appropriées du code de procédure civile demeurent applicables. Concernant l'expertise utilisée lorsqu'il est nécessaire d'avoir recours à une connaissance spécialisée pour évaluer ou déterminer les faits du cas, les jurys d'arbitrage peuvent nommer un expert parmi une liste disponible au tribunal régional de Varsovie. Les tribunaux régionaux peuvent nommer un expert sur demande d'une partie aux procédures. Dans ce cas, les coûts d'expertise sont payés par la partie perdante. Il n'y a aucune disposition précises pour les procédures au tribunal. Les décisions des jurys d'arbitrage et des tribunaux régionaux doivent être argumentées et prononcées en audience publique. Les décisions de tribunal régional sont notifiées aux parties sur demande dans les sept jours de leur prononcé. Les décisions du jury d'arbitrage sont immédiatement notifiées aux parties. Les décisions les plus importantes sont publiées sur le site Internet du BMP.

\section{$18.4 \quad$ Culture du recours}

Des programmes de formation et d'enseignement à long terme sont organisés par le BMP. En outre, le bureau, seul ou avec d'autres organismes (publics ou privés), tient des conférences périodiques de formation de pour les juges et les arbitres ainsi que pour les autorités adjudicatrices aussi bien et autres entités intéressées. Le bureau tient une conférence internationale importante tous les ans (bien qu'elle ne traite pas toujours des recours). Le BMP a également été responsable de l'application des projets financés par la CE pour les achats publics, comme le projet Phare 2002/2003. Le site Web du BMP est la source d'information première et la meilleure dans le domaine de la politique nationale et européenne de marchés publics. Les soumissionnaires ou les responsables des adjudications peuvent consulter des experts du BMP par l'intermédiaire de son service d'assistance quotidiennement. Les entreprises privées et les conseillers fournissent un large éventail de cours de formation, et les nombreux programmes universitaires de second cycle offrent des cours de droit des marchés publics. L'expérience professionnelle joue un rôle important dans l'attitude des juges et des avocats envers les procédures de contrôle. En général, des juges sont considérés avoir un point de vue équilibré sur les intérêts impliqués dans les affaires de marchés publics. La jurisprudence, cependant, est d'importance limitée due à un système fondé principalement sur l'interprétation de la loi existante. L'attitude des soumissionnaires envers les procédures de contrôle dépend habituellement de la valeur prévue du contrat. Les soumissionnaires pour les contrats de faible valeur sont moins familiarisés avec le droit des marchés publics que ceux qui soumissionnent pour des projets de grande ampleur et qui ont déjà de l'expertise en matière d'achat public. Dans certains cas, ces derniers entament des actions en vue de faire obstruction à la procédure d'adjudication actuelle. Généralement, le travail de familiarisation le droit des marchés publics est principalement assuré par le secteur privé. L'agence polonaise pour le développement des entreprises (PAED) a également préparé des cours Internet que les soumissionnaires peuvent suivre gratuitement. La compétence d'un membre du bureau d'adjudication dans le domaine du droit des marchés publics dépend de la fréquence avec laquelle l'autorité 
adjudicatrice achète des biens et des services. Pour augmenter leur responsabilité et favoriser leur professionnalisation, les membres du bureau suivent des cours fournis par plusieurs institutions, mais il n'y a aucun programme de formation officiel de marchés publics. Les responsables des adjudications doivent respecter la loi sur les marchés publics mais ne semblent pas encourager les procédures de contrôle. Il y a un large éventail de publications officielles sur le droit des marchés publics : commentaire officiel de la loi sur les marchés publics, directives et recommandations pratiques établies par le BMP, etc. La plupart d'entre elles sont disponibles sur la ligne (site Internet du BMP). Il y a les revues juridiques professionnelles également spécialisées, telles que de "Zamówienia Publiczne Doradca ", "Monitor zamówień publicznych» et «Prawo Zamówień Publicznych». Il n'y a aucune association nationale officielle des marchés publics mais les nombreux organismes commerciaux, tels que «Ogólnopolskie Stowarzyszenie Konsultantów Zamówień Publicznych » (l'association nationale polonaise des conseillers sur les marchés publics), ou le «Polski Związek Rzeczoznawców Zamówień Publicznych » (le syndicat polonais des experts des marchés publics), jouent souvent un rôle consultatif à cet égard. La société civile joue un rôle plus actif dans l'évolution des règles de marchés publics, particulièrement par des avis établis par plusieurs corps professionnels tels que «Polska Izba Informatyki i Telekomunikacji » (la chambre polonaise de la technologie et des télécommunications de l'information), «Stowarzyszenie Architektów Polskich» (syndicat des architectes polonais) et «Stowarzyszenie Kosztorysantów Budowlanych» (association des estimateurs de construction). L'impact des actes de la CJCE est considérable, en particulier depuis l'adhésion de la Pologne à l'UE. La Pologne a deux fois soumis des observations écrites dans les procédures devant la CJCE (cas C-220/05, Jean Auroux et C-410/04, ANAV), mais aucun cas n'y a été déféré conformément à l'article 234 du Traité $\mathrm{CE}$ par les juridictions nationales. Cinq cas polonais ont attiré l'attention de la Commission européenne (pour défaut de transposition des directives de «marchés publics » de la CE, pour comportement discriminatoire dans l'achat d'ordinateurs, pour défaut de mise en œuvre de la procédure d'adjudication applicable). Ces cas sont en discussion à niveau formel ; aucune action n'a été portée devant la CJCE conformément à l'article 226 du Traité CE. Le gouvernement polonais considère un certain nombre de propositions d'amendement visant à rationaliser le système de contrôle actuellement en vigueur. En particulier, les modifications les plus importantes comprennent : 1) l'établissement d'un corps professionnel unique d'arbitrage remplaçant les jurys d'arbitrage existants et 2) l'établissement d'une cour spécialisée de contrôle, chargée de la tâche actuellement confiée aux 45 tribunaux régionaux. Le but des amendements suggérés est de parvenir à une meilleure homogénéité jurisprudentielle, parce que sous le système actuel les décisions en vigueur des organes de contrôle divergent habituellement les unes des autres.

\section{Portugal}

Le système de contrôle de la légalité et de recours du Portugal est basé sur un contrôle juridictionnel à deux ressorts auprès de la juridiction administrative. Ceci s'applique aux contrats en dessous et audessus des seuils de la CEE. Il y a un large éventail de voies de recours disponibles. Cependant, la plupart des questions semblent être réglées à une étape préjudicielle. Le Portugal a un système juridique écrit traditionnel qui est considéré un environnement adéquat pour l'accès des soumissionnaires aux voies de recours, complété par un système administratif ouvert et moderne. Les citoyens ont accès aux documents et aux procédures qui les affectent directement, et le système fournit l'opportunité de contester n'importe quelle décision administrative.

\subsection{Réclamations auprès de l'autorité adjudicatrice}

Les soumissionnaires peuvent faire une réclamation directement à l'autorité adjudicatrice ou à ses supérieurs (recurso hierárquico facultativo) à n'importe quelle étape de la procédure jusqu'à l'attribution. Cette procédure de contrôle administratif à deux niveaux est l'instrument principal de contrôle dans la pratique. Cependant, ce n'est pas une condition préalable obligatoire au contrôle juridictionnel décrit cidessous. Les soumissionnaires peuvent faire une réclamation directe et intenter une action en même temps.

\subsection{Contrôle juridictionnel}

Les soumissionnaires peuvent intenter des actions en vue du contrôle juridictionnel des marchés publics situés aussi bien en dessous ou au-dessus des seuils de la CEE devant les tribunaux administratifs ou tribunaux de première instance. Il y a un tribunal administratif dans chaque district du Portugal. Les 
jugements des tribunaux administratifs peuvent faire l'objet d'un appel auprès de la Cour administrative suprême à Lisbonne en deuxième et dernier ressort. Ces juridictions administratives sont indépendantes de l'exécutif, de l'administration ou de n'importe quelle autre partie de l'État, et leurs décisions sont d'une nature juridictionnelle. Toutes les juridictions ont été établies sur la base de la constitution et des lois et remplissent la condition posée par les décisions Dorsch et Salzmann, sauf que la procédure n'est pas contradictoire. Les juges doivent être les juristes expérimentés et reconnus. Ils sont nommés selon une procédure générale. La constitution et d'autres lois garantissent l'indépendance des juges ; ils ne peuvent être démis de leur fonction que dans très des cas particuliers. Les juges de la Cour administrative suprême, ainsi que son président, qui est choisi parmi eux, doivent être des juristes fortement qualifiés. Il y a peu de jurisprudence en matière de contrôle des marchés publics dans la pratique. Une procédure arbitrale conduite par des jurys uniques sélectionnés au cas par cas peut être utilisée, à condition que cette option ait été établie dans les documents de la soumission. Deux juges sont choisis par les parties et un tiers est choisi par les autres juges. La décision du jury lie seulement les parties et est soumise à une procédure de réclamation. Par ailleurs, la décision d'arbitrage n'empêche pas un soumissionnaire d'intenter une action devant le tribunal administratif. Il existe une procédure de conciliation en matière de services publics établie dans un décret-loi $\mathrm{n}^{\circ} 223 / 2001$ du 9 août, mais cette procédure n'exclut pas le droit de lancer une procédure devant les tribunaux administratifs.

\section{$19.3 \quad$ Recours}

Les voies de droit offertes comprennent l'annulation de différentes décisions de marchés publics, l'annulation de la procédure entière de marchés publics, l'ordre de recommencer la procédure et l'octroi de dommages et intérêts. Depuis 2003, il est possible d'annuler les contrats signés. Différentes décisions de marchés publics peuvent être contestées jusqu'à cinq jours après qu'elles ont été prises. La décision d'attribution peut être contestée jusqu'à dix jours après avoir été prise alors que le contrat a été signé. Les actions contre la décision d'attribution auprès du tribunal administratif empêchent la conclusion du contrat. Toutes les voies de droit sont légalement prévues par le droit administratif. Pour qu'une procédure ou un contrat soit annulé, il doit être illégal en raison de violations très sérieuses de la loi, par exemple d'une violation du principe de légalité (quand une entité prend une décision contra legem). Le tribunal administratif peut décider de la suspension de la décision ou de la procédure (loi 15/2002 du 18/02/2003, Código de Processo nos Tribunais Administrativos) sur la base du décret-loi 197/99 du 8/06, du code de procédure administrative et du code de justice administrative. Les conditions sont que la demande du soumissionnaire soit susceptible d'être valable raisonnablement et que la possibilité pour lui de défendre ses intérêts soit sérieusement compromise si la procédure n'est pas suspendue. Dans les cas où l'intérêt public prévaut, le tribunal administratif ne suspend pas la procédure. Le principe de la responsabilité de l'État pour les décisions de droit administratif et de droit civil prises est le fondement juridique de l'octroi des dommages et intérêts. Le soumissionnaire doit prouver des violations sérieuses de la loi. Normalement les coûts de soumission peuvent être remboursés, mais il est difficile de produire la preuve nécessaire pour obtenir réparation au titre d'une perte de bénéfices.

\subsection{Procédure}

La loi procédurale concernée est stipulée dans le code justice administrative (Código de Processo nos Tribunais Administrativos). La cour peut accepter la participation d'experts techniques qui doivent être payés par la partie qui en a fait la demande. Alternativement, la cour peut décider de faire participer des experts et de couvrir leurs coûts d'intervention. N'importe quelle partie à la procédure peut lancer une action mais elle doit prouver sa capacité. Normalement, il est nécessaire d'avoir été un candidat à l'obtention du contrat en question. Les actions doivent être introduites dans le mois suivant la date à laquelle le soumissionnaire a eu connaissance de la décision contestée. La partie perdante couvre les dépenses et les frais exposés par la partie victorieuse. Le Portugal a un système juridique codifié et la jurisprudence est utilisée seulement pour l'interprétation de la loi, sans règle du précédent. Aucun formulaire modèle n'est utilisé. Les parties reçoivent correctement notification des jugements, qui sont également publiés, par la poste.

\subsection{Culture du recours}

Les juges acquièrent leur connaissance du droit des marchés publics dans le cadre de leurs études universitaires (cours de droit constitutionnel et de droit administratif). Les juges suivent la « magistratura 
judicia »', un circuit séparé de la formation juridique spécifiquement conçu pour les juges et séparé du programme d'études pour des avocats. Les juges, les avocats et les soumissionnaires acquièrent leur connaissance du fonctionnement concret des marchés publics dans leurs études universitaires, par formation professionnelle, enseignement et cours continus fournis par le gouvernement, l'UE ou les organismes internationaux et par la pratique. L'attitude des juges envers les différents intérêts impliqués dépend de la situation, du cas et du juge particulier. Il y a les experts très compétents et justes mais également personnes peu sensibles à l'intérêt public en jeu. Certains soumissionnaires ne souhaitent pas lancer des procédures de contrôle parce qu'ils ne souhaitent pas compromettre leur chance d'obtenir le prochain contrat. Certains voient ces procédures comme une issue à utiliser en dernier recours. D'autres l'utilisent pour obstruer la procédure de marchés publics. D'autres cherchent à réaliser un gain financier. Certains sont découragés d'engager une action en raison des droits de procédure élevés, certains sont découragés par ses coûts élevés (représentation juridique y compris, etc.), certains sont découragés par la longueur de ces procédures. Enfin, d'autres soumissionnaires sont ignorants au sujet des possibilités de contrôle juridictionnel ou autre offertes. Certains responsables des adjudications ont acquis leur connaissance des aspects juridiques et autres des marchés publics à l'université ; certains suivent des séminaires internes et externes. Également, l'expérience quotidienne transmise par leurs collègues supérieurs est un outil précieux. Il y a un sens général de respect et de conscience des droits légaux entourant les réclamations et un sens d'équité des procédures envers les soumissionnaires. Il n'y a aucun journal scolaire spécifique, mais le droit des marchés publics est discuté lors des conférences et des séminaires scolaires et professionnels. Il n'y a pas d'association nationale de marchés publics. Les cours se rendent compte de l'importance des arrêts de la CJCE et utilisent cette connaissance dans leurs décisions convenablement.

\section{Roumanie}

Les marchés publics en Roumanie sont régis par l'ordonnance de d'urgence $n^{\circ} 34 / 2006$, qui est entrée en vigueur le 30 juin 2006 (il existe aussi des dispositions complémentaires pour les marchés publics Internet : http://www.e-licitatie.ro). Le système de contrôle et de recours se fonde sur un contrôle juridictionnel et quasi-juridictionnel. Ce système peut être divisé entre voies de recours offertes avant et voies de recours offertes après la signature du contrat. L'octroi de dommages et intérêts est indépendant et peut être cherché avant ou après que le contrat ait été signé. Dans tous les cas, l'existence d'une protection juridictionnelle ne dépend pas de la valeur prévue du contrat. Il n'est pas obligatoire que les soumissionnaires fassent une réclamation formelle directement à l'autorité adjudicatrice comme condition préalable d'un recours. Il y a environ 700 réclamations par an déposées contre des actes des autorités adjudicatrices. Quoique les demandes aient souvent un résultat favorable pour les soumissionnaires lésés, seulement $1 \%$ des actes liés aux marchés publics sont examinés annuellement.

\subsection{Contrôle juridictionnel}

Avant qu'un contrat ait été signé, les soumissionnaires peuvent avoir recours au Conseil National de résolution des conflits juridiques (ci-après le conseil) ou aux juridictions administratives. Les soumissionnaires peuvent contester n'importe quel acte, y compris le défaut d'établissement ou le refus d'établissement d'un acte dans le cadre de la procédure d'adjudication. Le conseil a été établi par l'ordonnance gouvernementale d'urgence $\mathrm{n}^{\circ} 34 / 2006$ (chapitre IX). Il a à la fois une compétence administrative et juridictionnelle. En particulier, le conseil est compétent pour résoudre des conflits juridiques avant qu'un contrat ait été signé, pour émettre des avis sur la légalité et la conformité des procédures d'adjudication lancées par des autorités adjudicatrices (une procédure semblable au mécanisme d'attestation) et enfin, pour établir les avis sur les conflits que des soumissionnaires lésés ont portés devant la juridiction administrative. Les membres du Conseil sont des fonctionnaires avec un statut spécial (indépendance, procédure de la sélection et de nomination, incompatibilités et interdictions, salaires) et ont une expérience dans le droit des marchés publics. Les décisions du conseil lient les parties et peuvent faire l'objet d'un appel auprès de la cour de l'appel compétente dans le lieu de situation de l'autorité adjudicatrice. La cour de l'appel est un corps permanent créée par loi et est indépendante de l'exécutif, de l'administration ou de n'importe quelle autre partie de l'État. Ses décisions sont rendues sur la base des règles juridiques et lient parties. Une chambre spécialisée de la cour de l'appel est responsable de juger des appels contre les décisions du conseil. La chambre examine la légalité et le fond des décisions portées en 
appel. Les arrêts rendus par la chambre ne peuvent pas être portés en appel. Après qu'un contrat ait été signé, les soumissionnaires lésés peuvent faire une demande seulement devant un tribunal conformément à la loi 544/2004 sur les procédures administratives. Les demandes de dommages et intérêts peuvent être introduites devant un tribunal seulement conformément à la loi 544/2004 sur les procédures administratives, indépendamment du point de savoir si le conflit a surgi avant ou après que le contrat ait été signé.

\section{$20.2 \quad$ Recours}

Les recours devant le conseil ont un effet suspensif. Par ailleurs, le conseil a le pouvoir 1) d'annuler totalement ou partiellement l'acte allégué de l'autorité adjudicatrice, 2) d'ordonner à l'autorité adjudicatrice de se conformer à une obligation ou d'établir un acte, 3) de prendre toute autre mesure a considéré nécessaire pour remédier à une violation de la loi sur les marchés publics commise par l'autorité adjudicatrice, 4) d'annuler ou de recommencer la procédure d'adjudication à la lumière des faits d'un cas donné, 5) d'imposer une amende contre des hauts fonctionnaires du l'autorité adjudicatrice afin d'assurer l'exécution des mesures accordées ou de la décision prise et 6) si la demande est rejetée faute de motifs, de faire reprendre la procédure d'adjudication. Les décisions de conseil lient sur les parties et peuvent être exécutées au moyen d'une amende (voir le $\mathrm{n}^{\circ} 5$ ci-dessus). Si l'autorité adjudicatrice néglige la décision et signe le contrat, le contrat est considéré comme nul. Les recours devant les tribunaux administratifs avant que le contrat ait été signé n'ont pas d'effet suspensif. Le requérant peut, cependant, demander la suspension de la procédure d'adjudication. Le conseil ou les juridictions peut prendre en considération les conséquences probables des mesures recherchées pour tous les intérêts susceptibles d'être lésés, y compris l'intérêt public, et décider de ne pas accorder de telles mesures lorsque leurs conséquences négatives seraient supérieures à leurs avantages. Avant ou après la conclusion du contrat, des dommages et intérêts peuvent être attribués par une juridiction administrative dans des conditions suivantes : 1) une disposition juridique relative à l'adjudication a été violée, 2) l'acte allégué est un acte administratif et 3) le requérant a souffert un préjudice matériel ou moral.

\subsection{Procédure}

Généralement, toute personne ayant un intérêt légitime ou considérant que ses droits ont été lésés par un acte de l'autorité adjudicatrice qu'il juge irrégulier est autorisée à requérir contre cet acte devant le conseil ou les juridictions. En cas de demandes de dommages et intérêts, le requérant doit montrer que 1) les dispositions juridiques appropriées ont été violées, 2) qu'il avait une vraie possibilité de remporter le contrat et 3) que l'infraction alléguée l'a privé de la possibilité de remporter le contrat. Des procédures devant le conseil et les cours sont régies, respectivement par l'ordonnance d'urgence $n^{\circ}$. 34/2006 et la loi 544/2004 sur les procédures administratives. Une procédure devant le conseil commence par une demande envoyée par le soumissionnaire intéressé. La demande doit être déposée dans les dix jours de la date à laquelle le soumissionnaire a eu connaissance de l'acte qu'il considère irrégulier. La demande doit mentionner le nom et adresse du requérant, l'objet du conflit, l'objet de l'adjudication ainsi que les motifs et preuves de fait et de droit (le cas échéant). Elle doit être signée et complétée par d'autres documents éventuels. Une copie de la demande et des documents joints doivent être envoyés à l'autorité adjudicatrice. A la date de la notification, la procédure d'adjudication est systématiquement suspendue. L'autorité adjudicatrice doit émettre un avis écrit concernant le conflit. Cet avis est envoyé au conseil et le requérant en est notifié. Le conseil commande alors à l'autorité adjudicatrice d'envoyer le dossier du marché public. Les procédures ont lieu par écrit. Les parties peuvent être entendues si le conseil en décide ainsi. Par ailleurs, le conseil peut administrer la preuve et demander aux parties de fournir des explications sur des questions ainsi que de plus amples informations afin de mieux établir les faits. Il peut également demander à un expert indépendant de donner une opinion sur l'affaire (en particulier sur des aspects techniques et financiers). La durée de l'expertise ne peut dépasser pas le délai dans lequel le conseil doit prendre sa décision. Les coûts de l'expertise sont payés par la partie l'ayant demandée. Les procédures ne peuvent pas dépasser dix jours à compter de la transmission du dossier du marché public au conseil. Dans des cas dûment justifiés, ce délai peut être prolongé pendant encore 20 jours. Les décisions doivent être motivées. Elles sont notifiées aux parties et sont disponibles sur la ligne. Il n'y a aucun droit. Si on le lui demande, le conseil peut ordonner à la partie perdante de payer les dépens de la partie victorieuse. 


\subsection{Culture du recours}

Les juges et les avocats ont pu avoir acquis leur connaissance du droit des marchés publics par l'expérience professionnelle ou des séminaires organisés par des institutions publiques. L'attitude des juges envers des intérêts contradictoires est considérée juste. Les soumissionnaires ont pu également avoir acquis connaissance des marchés publics par l'expérience professionnelle. En plus, ils peuvent être aidés par des avocats et des conseillers ou par l'organisme professionnel approprié. Les soumissionnaires semblent peu disposés, cependant, à lancer des procédures de contrôle parce qu'ils ne souhaitent pas compromettre leurs chances pour d'autres contrats. D'autres intentent des actions simplement afin de bloquer la procédure d'adjudication. Généralement, les procédures de contrôle devant les juridictions sont longues et sont considérés comme un instrument à utiliser en dernier recours. C'est la raison pour laquelle le Conseil National de résolution des conflits juridiques a été créé. Les procédures devant le Conseil sont gratuites et on s'attend à ce qu'elles soient rapides. En raison de sa création récente, cependant, il n'a pas été établi si l'entité respectera effectivement les délais dans lesquels elle est censée prendre une décision. La jurisprudence n'est pas importante. Il y a beaucoup de séminaires tenus par les secteurs publics et privés, et de temps en temps quelques conférences. Il n'y a aucune publication spécialisée ni association nationale sur les marchés publics. La formation des fonctionnaires des marchés publics est assurée par l'institut national d'administration. L'impact des actes de CJUE ne peut pas être évalué pour l'instant.

\section{Slovaquie}

Le système des recours et de contrôle de la légalité des marchés publics de la République slovaque peut être divisés en trois étapes : d'abord, un contrôle par l'autorité adjudicatrice ou entité en question ; en second lieu, un contrôle non-juridictionnel par la division du contrôle du bureau des marchés publics (BMP) ; et enfin, un contrôle juridictionnel par les cours ordinaires. Le système est prévu au titre quatre de la loi slovaque sur les marchés publics (LMP), 25/2006 Coll. www.uvo.gov.sk. Il n'y a aucune disposition spécifique pour les services publics. Il y a généralement des différences purement mineures entre les contrats auxquels les directives communautaires s'appliquent et les contrats auxquels elles ne s'appliquent pas. Selon l'article 140 LMP, les contrats en dessous des seuils s'appellent «en dessous de la limite ». Selon l'article 4, les contrats qui sont en dessous du seuil et les contrats de faible valeur ne rentrent pas dans les dispositions de la LMP sur les procédures de contrôle ; cependant, ils sont sujets à un contrôle interne sans préjudice des pouvoirs de surveillance du BMP.

\subsection{Autorité adjudicatrice}

Selon l'article 136 (1) de la LMP, les procédures de contrôle peuvent être lancées par une communication entre un soumissionnaire ou une personne différente croyant que ses droits ont été ou pourraient avoir été affectés et l'autorité adjudicatrice ou l'entité adjudicatrice, sous forme d'une "demande de réparation » formulée au sujet des faits ou des décisions de cette dernière. Il est obligatoire que les soumissionnaires soumettent formellement une réclamation à l'autorité adjudicatrice ou à l'entité adjudicatrice directement comme condition préalable d'un recours plus poussé : article 138 (1) PPA.

\subsection{Contrôle non-juridictionnel}

Si la demande de réparation faite à l'autorité adjudicatrice ou à l'entité n'a pas été acceptée par cette dernière dans le délai stipulé, le soumissionnaire ou l'autre personne qui croit que ses droits ont été ou pourraient avoir été affectés, peut protester auprès du BMP, requérant le retrait de l'irrégularité dans la mesure limitativement prévue l'article 138 (2) de la LMP. La BMP fait partie du pouvoir exécutif. Ses membres n'ont pas un statut comparable à celui des juges. Il a été établi par la LMP en 2000. En 2005, il y avait 1089 réclamations, y compris 83 de l'étranger et 108 au sujet des contrats au-dessus des seuils de la CEE (en hausse de 50\% en comparaison avec 2004). Le bureau a rendu 500 décisions au fond sur des réclamations faites avant la conclusion des contrats et neuf décisions après conclusion (conformément aux dispositions de la LMP de 2006, les réclamations après la conclusion de contrat ne sont plus recevables). $44 \%$ des décisions étaient en faveur des requérants et $56 \%$ ont été rejetés comme non fondées. Pour 578 réclamations introduites, les procédures ont été interrompues. 18 décisions du BMP sur des réclamations ont été contestées devant les juridictions (voir ci-dessous). La surveillance s'est principalement concentrée sur l'utilisation illégale de la procédure négociée sans notification préalable. Sur un total de 856 procédures portant sur des attributions de contrats, 489 avaient trait à des violations diverses de la loi. Le montant total 
des amendes infligées en 2005 a représenté 25318492 SKK (21 autorités adjudicatrices et une entité adjudicatrice).

\subsection{Contrôle juridictionnel}

Il existe un tribunal ordinaire de dernier ressort examinant les décisions de marchés publics à titre de troisième et dernière étape du processus de contrôle. Les décisions du BMP peuvent être portées en appel au Krajský sud de Bratislava (tribunal régional situé dans la ville de Bratislava) et au súd de Najvyšší (la Cour Suprême de la République slovaque). Un ordre judiciaire indépendant est garanti par la constitution de la République slovaque. Les conditions relatives au président et aux autres membres de ces cours quant à leur nomination sont stipulées dans la législation et les décrets de procédure applicables. Les deux cours remplissent les conditions posées par les décisions Dorsch et Salzmann. Les décisions du BMP par lesquelles la procédure d'attribution du contrat a été suspendue en raison d'une violation de la loi qui pourrait avoir un impact important sur son résultat (par exemple, défaut d'accomplissement au moins d'une condition sur la base de laquelle l'emploi de la procédure non-compétitive d'attribution du contrat peut être justifiée), peuvent être examinées par ces cours. En 2005, il y avait des audiences pour la plupart des affaires débutées en 2004. 30 jugements du tribunal de première instance ont été rendus en faveur du BMP. Dans 25 cas, l'action (accusation) a été rejetée ou il y a été mis fin. Dans trois cas (sur un total de 5) non jugés en faveur du BMP, ce dernier a interjeté appel à la cour de deuxième instance. Dans les cas jugés par le tribunal de première instance en faveur du bureau, 11 appels à la cour de deuxième instance ont été interjetés. Dans dix cas, les décisions ont été rendues en faveur du bureau par la cour de deuxième instance.

\section{$21.4 \quad$ Recours}

Avant la conclusion d'un contrat, l'OPP peut prendre les décisions stipulées à l'article 139 (2) de la LMP. Il peut ordonner l'annulation d'une procédure d'attribution ou de concours sur la base de conditions discriminatoires figurant dans tous les documents de la soumission, notices de contrat, etc., prendre la décision d'exclure ou d'inclure un soumissionnaire, d'exclure la sélection des candidats et ordonner une nouvelle sélection, ordonner l'annulation de l'évaluation des offres et une réévaluation. Après la conclusion du contrat, le BMP peut seulement prononcer l'existence d'une violation de la LMP et, dans les cas énumérés à l'article 149 de la LMP, lancer des procédures administratives ayant pour résultat d'infliger une amende. Les décisions du BMP peuvent être contrôlées par la cour (amendes y compris, infligées à l'autorité adjudicatrice/entité). Selon l'article 148 de la LMP, le contrat signé peut être annulé par la cour à la condition principale qu'il ait été conclut d'une façon contraire à la LMP. Des mesures provisoires sont prises par le bureau en cas de procédure de révision initiée avant la conclusion du contrat conformément à l'article 146 LMP, en combinaison avec l'article 138 LMP. Pour la durée d'une telle mesure, l'autorité adjudicatrice ou l'entité est mis en demeure de s'abstenir d'agir dans toute procédure d'attribution concernée et les délais sont interrompus. Le BMP n'est tenu de prendre des mesures provisoires, bien que dans le cadre des procédures initiées avant la conclusion du contrat, elles soient plutôt habituelles. La base juridique de l'octroi des dommages et intérêts est constituée par les règles générales qui leur sont applicables en vertu de l'article 420 du code civil (qui sera révisé au cours des prochaines années). Pour les décisions illégales prises par l'administration d'État dans l'exercice des pouvoirs exécutifs publics, les dommages et intérêts peuvent être attribués sur la base de la loi $n^{\circ}$ 514/2003 Coll. Une des procédures de contrôle est la surveillance de la procédure d'attribution du contrat. La surveillance peut être lancée avant la conclusion du contrat (sur action du BMP seulement) ou après (dans ce cas, sur action du bureau ou d'une autre personne qui ne pouvait pas/n'était pas éligible pour faire une réclamation ; une telle disposition juridique est justifiée par le fait que ce type de procédure de contrôle ne doit pas appartenir au candidat/au soumissionnaire qui a eu [ou aurait pu] utiliser les opportunités juridiques qui lui étaient ouvertes avant).

\subsection{Procédure}

La loi procédurale appropriée est régie par la LMP. Position : Les soumissionnaires ou toute autre personne qui croit que ses droits ou intérêts protégés par la loi ont été ou pourraient avoir été affectés peuvent lancer des procédures. Une demande d'ouverture d'une procédure de contrôle (surveillance) ne peut être faite que par une personne qui n'a pas participé à la procédure d'attribution du contrat, c.-à-d., ne pourrait pas faire une réclamation. N'est pas recevable à la procédure de surveillance, une personne qui a présenté une demande des documents contractuels mais qui n'a pas par la suite soumissionner. Le BMP 
peut également lancer une procédure de contrôle à sa discrétion. Experts : Le BMP peut inviter des experts du domaine d'activité approprié en cas des décisions portant sur une réclamation ou une contestation des amendes infligées par le bureau. Le BMP couvre les coûts sur la base de la décision du président. Droits : En cas de réclamation, le requérant est tenu de déposer une caution (article 138 (16) LMP). Une demande de surveillance ne donne pas lieu au paiement d'un droit; le bureau exerce une telle activité d'office. N'importe quelle action auprès des juridictions est sujette à un droit (aux termes d'une réglementation séparée). Règle de succès : Le dépôt de garantie pour les procédures devant le BMP est remboursé en cas de succès : Article 138 (17) PPA. Pour les procédures devant les tribunaux, les droits et les coûts (d'avocats) sont remboursés. Délais : Une demande de réparation doit être introduite dans les sept jours (art. 136 (3) à (8) PPA) ou à tout moment avant la conclusion du contrat (art. 136 (3) g) PPA). Le délai pour introduire une réclamation auprès du BMP est également de sept jours (art. 138 (5) PPA). Confidentialité : La supervision est une procédure qui n'est pas ouverte au public; les fonctionnaires sont tenus de maintenir la confidentialité sur tout ce qu'ils apprennent pendant la procédure. Cependant, la décision définitive est accessible au public, bien que les descriptions soient supprimées. Ces principes s'appliquent aussi aux réclamations. Le droit des citoyens au libre accès à l'information est établi dans la loi $n^{\circ}$ 211/2000 Coll., telle que modifiée. Effet suspensif : L'introduction d'une action auprès d'une juridiction n'a l'effet suspensif pas systématique en tant que telle. L'exécution du contrat peut être suspendue seulement par les juridictions dans les cas prescrits. Le délai pour que le BMP se prononce sur les réclamations est de 30 jours : article 139 (5) PPA. Quant aux tribunaux, la période entre l'introduction de l'action et le jugement varie. En première instance (tribunal régional), elle peut être approximativement de 1 an et demi à deux ans et en deuxième instance (Cour Suprême) approximativement de deux à trois ans. La jurisprudence est d'importance limitée due aux interprétations de la législation faites dans les jugements et arrêts. Aucun formulaire-type n'est disponible, mais les conditions de forme et de contenu d'une protestation sont établies par les articles 136 (2) et 138 (6) de la LMP, respectivement. Les décisions d'OPP sont expédiées par courrier recommandé au requérant, à l'autorité adjudicatrice ou à l'entité et, si cela est approprié, à toute personne que la décision concerne. Elles sont également publiées sur le site Web du BMP (certaines parties de la soumission ou d'autres informations et données qui pourraient être confidentielles sont supprimées). Les décisions des tribunaux et cours sont expédiées par courrier recommandé.

\subsection{Culture du recours}

Le droit des marchés publics fait partie des modules universitaires de droit économique et de droit des affaires ainsi que dans quelques agences privées. Le BMP est responsable de la formation des enseignants et la formation (et la formation continue) des autres dans le domaine des marchés publics. A cet égard, elle émet le certificat d'admissibilité aux marchés publics. Les juges, les membres du jury du BMP, les avocats de droit des marchés publics représentant les soumissionnaires ou les autorités adjudicatrices/entités dans des procédures de contrôle, ainsi que les soumissionnaires eux-mêmes acquièrent leur connaissance du fonctionnement concret des marché publics, ainsi que des considérations techniques et financières impliquées dans le cadre de leurs études universitaires et dans les cours organisés sous les auspices du BMP. Quelques soumissionnaires ne souhaitent pas lancer des procédures de révision parce qu'ils ne souhaitent pas compromettre leurs chances pour le prochain contrat (voir la référence ci-dessus aux procédures de contrôle comme voie de dernier recours). Certains utilisent les procédures de révision pour faire obstruction à l'adjudication ou en vue d'un gain financier. Certains peuvent être découragés d'engager une procédure de contrôle en raison des droits de procédure élevés devant la Cour Suprême ou des autres coûts (par exemple, pour la représentation juridique) ; d'autres peuvent être découragés par leur longueur ou peuvent être ignorants des possibilités de recours offertes. D'un autre côté, certains n'hésitent pas à 'entreprendre toute action disponible pour réussir la procédure d'attribution du contrat, même au prix d'une détérioration consécutive possible de leur rapport d'affaires avec l'autorité adjudicatrice impliquée. La connaissance des responsables des adjudications des fondements juridiques et autres des marchés publics est décrite comme assez bonne. Les autorités adjudicatrices et les entités sont tenues de régler les réclamations et de respecter les décisions du BMP. L'association slovaque pour les marchés publics, Transparency International Slovaquie et la chambre des entités d'adjudication s'intéressent aux procédures de contrôle des marchés publics dans leur ensemble. Les arrêts de la CJUE sont entièrement respectés dans la mesure où ils sont connus et disponibles dans la traduction officielle. Jusqu'ici il n'y a eu aucune implication de la CJUE dans le système de contrôle (traité CE, article 234) et aucune procédure en 
manquement initiée par la Commission européenne, y compris à un stade préjudiciel (traité CE, article 226). Les changements les plus importants du système slovaque de contrôle et de recours en matière de marchés publics au cours des 15 dernières années sont la loi numéro 263/1993 Coll. (premier acte juridique compilé sur les marchés publics basés sur l'UNCITRAL), la loi numéro 263/1999 Coll. (premier texte juridique basé sur les directives communautaires), la création du BMP en 2000 sur la base de l'acte mentionné, la loi numéro 523/2003 Coll. (pleine transposition des «vieilles » directives communautaires dans la législation nationale) et la loi numéro 25/2006 Coll. (transposition des «nouvelles » directives de l'UE depuis le 1er février 2006). Une attitude plutôt formaliste résultant de la tradition historique dans le domaine du contrôle est vue comme la faiblesse principale du système, tandis qu'un système fiable de formation en marchés publics qui devraient voir le jour dans le futur et diminuer les erreurs et le nombre d'objections, est vu comme sa force principale. Un des principaux problèmes dans les marchés publics était auparavant l'existence d'objections et de réclamations trop fréquentes, qui ont été souvent utilisées seulement dans le but de retarder, compliquer et faire obstruction à la procédure d'attribution du contrat. Depuis le 1er février 2006, une nouvelle obligation de déposer la caution a été introduite à l'article 138 (16) LMP. Le BMP doit contrôler et évaluer soigneusement les développements pour empêcher le régime d'attribution du contrat d'être perturber par des obstructions intentionnelles et malveillantes de la part de certains soumissionnaires ou candidats infructueux.

\section{Slovénie}

En Slovénie, l'examen des procédures d'adjudication des marchés publics est conduit en deux étapes. Dans la première phase, le soumissionnaire doit faire une réclamation auprès de l'autorité adjudicatrice compétente. À la seconde étape, à défaut de décision satisfaisante de l'autorité adjudicatrice suivant une telle réclamation, le soumissionnaire peut lancer des procédures devant la Commission nationale de contrôle des procédures d'adjudication de marchés publics (CNC). Il n'y a aucune différence entre les contrats faisant partie ou non du champ de l'application des directives communautaires. Le système slovène de contrôle et de recours est considéré rapide et effectif.

\subsection{Réclamations auprès de l'entité adjudicatrice}

L'entité adjudicatrice est compétente pour juger des réclamations des soumissionnaires en première instance. Les soumissionnaires ont l'obligation de faire une réclamation auprès de l'autorité adjudicatrice avant de recourir devant la CNC. Les entités d'adjudication sont énumérées dans le décret des catégories et listes des entités d'adjudication pris en application de la loi sur marchés publics par le gouvernement de la République de la Slovénie (paragraphe 4 de l'article 2.a de la loi sur les marchés publics (RS, 36/04 - texte consolidé officiel).

\subsection{Contrôle juridictionnel}

La CNC (Slovenska 50, 1000 Ljubljana) est une autorité nationale spécialisée, indépendante et autonome examinant les procédures d'adjudication de marchés publics (cf. loi sur le contrôle des procédures de marchés publics). La CNC remplit les conditions posées par les décisions Dorsch et Salzman pour être considérée comme une juridiction. Le président et les membres de la CNC sont nommés par l'Assemblée nationale sur une proposition de la Commission des mandats et des élections, pour cinq ans avec possibilité de réélection. Le président et deux membres doivent avoir un diplôme universitaire de droit et le barreau. Les deux autres membres doivent avoir un diplôme d'université dans les sciences économiques ou l'ingénierie. Le président et les membres doivent également remplir les conditions générales suivantes : être un citoyen de la République de la Slovénie, avoir une bonne maîtrise de la langue slovène, avoir la capacité générale de conclure des contrats, être en bonne santé, avoir au moins 30 ans, ne pas être condamné d'un délit punissable d'emprisonnement et avoir au moins 2 ans d'expérience dans le domaine des marchés publics. Les décisions de la CNC sont envoyées aux parties par la poste. Le public a accès aux décisions par le site Internet de la commission (http://www.gov.si/dkom/).

\subsection{Conciliation}

La procédure de conciliation se conçue seulement pour les procédures pour la passation du marché public dans les secteurs de l'eau, de l'énergie, des transports et des télécommunications. C'est une manière alternative de résoudre les conflits dans les procédures d'adjudication. Elle est entreprise seulement avec la 
l'accord de l'entité adjudicatrice et du soumissionnaire infructueux. La Commission européenne nomme une personne pour mener la procédure (un conciliateur) si l'entité adjudicatrice déclare qu'il est disposé à participer. Les deux parties à la procédure de conciliation doivent déclarer par écrit qu'ils acceptent la personne nommée par la Commission européenne et chacune des parties doit proposer un conciliateur supplémentaire sur une liste, lequel conduit la procédure avec le conciliateur nommé par la Commission européenne. La personne requérant la procédure de conciliation et l'entité adjudicatrice ont le droit de mettre fin à la procédure à tout moment. Si le soumissionnaire infructueux, autre que la personne requérant la procédure de conciliation, a proposé un contrôle de la passation du marché public ou engage une procédure de contrôle juridictionnel après avoir été invité à participer à la procédure de conciliation et n'indique pas dans le délai donné si il accepte de participer à cette procédure, alors les conciliateurs y mettent fin et la procédure de contrôle des marchés publics est exécutée.

\section{$22.4 \quad$ Recours}

Il y a deux types de décisions auxquelles l'organe de recours national peut parvenir. Il peut rejeter une demande de règlement comme non fondée ou l'accueillir et partiellement ou entièrement annuler la procédure. Il y a de diverses raisons de suspendre une attribution du contrat, telle que la discrimination entre les soumissionnaires, la restriction apportée à la libre concurrence, les critères d'attribution et les facteurs discriminatoires non liés au fond du contrat, etc. La conclusion du contrat ne peut pas être annulée par l'autorité adjudicatrice ou l'entité elle-même : seule la CNC peut annuler des décisions des entités adjudicatrices. Le président de la CNC peut retirer des mesures provisoires sur demande d'une partie. Une décision favorable est un préalable pour l'entité adjudicatrice à l'octroi de dommages et intérêts devant les tribunaux civils.

\subsection{Procédure}

Un code spécifique de procédure de contrôle des marchés publics couvrant à la fois les services publics et les entreprises publiques régi les procédures devant la CNC. Les procédures peuvent être lancées seulement après qu'un contrôle ait été effectué en première instance devant du l'autorité adjudicatrice quand le partie lésée ne consent pas (partiellement ou entièrement) à la décision de cette dernière sur sa réclamation ou à défaut de décision de sa part dans le délai imparti (15 jours). Dans la plupart des cas, les soumissionnaires qui ont soumis une offre intentent des actions. Cependant, toute personne ayant ou ayant eu un intérêt à obtenir un contrat particulier et qui a été ou risque d'être lésée par une violation alléguée peut agir. Un partie lésée de fait le droit d'agir quand elle a prouvé son intérêt véritable à l'attribution d'un contrat et l'existence d'une vraie probabilité de perte pour elle. Les parties introduisant une réclamation doivent payer un droit d'environ $420 €$ (contrats de fourniture et services) ou $840 €$ (contrats de travaux). Pour les contrats de valeur élevée, publiés au Journal officiel des Communautés européennes, ces frais sont doublés. Le soumissionnaire doit payer le droit seulement au moment de l'introduction de sa réclamation. Tous les autres coûts peuvent être pris en considération par les tribunaux civils. Il y a un principe prévu par la loi sur les recours: que la partie qui cause les coûts est responsable de leur paiement. Ainsi, un réclamant victorieux obtient remboursement des droits mais pas des autres coûts exposés. La CNC peut, avant sa décision, avoir recours à l'expertise sur des aspects techniques, économiques et juridiques concernant le cas. La CNC doit juger la requête et établir une décision dans les 15 jours de sa réception. Le délai peut être prolongé dans certains cas à un maximum de 20 jours. Il y a des procédures permettant de prendre en considération la nécessité de protéger l'information confidentielle d'affaires comme par exemple, des procédures à huis clos. Cependant, le principe de transparence est primordial, et les possibilités procédurales sont liées à la législation sur l'accès public à l'information. La présentation d'une requête a un effet systématique de suspension de droit devant la CNC. Il n'y a aucun formulaire-type obligatoire ou documents utilisés pour les procédures de contrôle des marchés publics. Les décisions de la CNC sont publiées sur son portail Internet et sont envoyées à l'entité adjudicatrice, au requérant et au ministère des finances.

\subsection{Culture du recours}

La jurisprudence est d'importance limitée mais d'importance considérable en raison d'un système reposant à la fois sur la codification et la jurisprudence. Les juges et les membres du jury sur la CNC, les avocats de droit des marchés publics représentant les soumissionnaires et les entités adjudicatrices dans des procédures de contrôle acquièrent leur connaissance du droit communautaire en général et du droit des 
marchés publics en particulier, ainsi que leur connaissance leur fonctionnement concret - y compris les considérations techniques et financières impliquées — dans le cadre de leur formation continue et dans la pratique. L'attitude des juges et des membres du jury sur la CNC envers l'intérêt public d'une part et les intérêts privés des soumissionnaires d'autre part, est décrite comme juste et équilibrée. Les soumissionnaires requérant l'examen des décisions de marchés publics acquièrent leurs connaissances de l'environnement juridique, financier et administratif présidant à leur fonctionnement concret principalement par la pratique, par les consultations et les avis d'expert donnés par le ministère des finances. Les soumissionnaires sont actifs et enclins à faire une réclamation qu'ils jugent une procédure aisée. La connaissance de responsables des adjudications des fondements juridiques et autre des marchés publics est décrite comme «louable et appréciable». L'attitude des responsables des adjudications et de leurs supérieurs traitant des réclamations faites par les soumissionnaires contre les décisions de marchés publics sont conscients de la possibilité toujours présente d'une protection juridique des parties. Généralement, ils ne tiennent pas rancune à un réclamant mais n'aiment pas néanmoins les procédures de contrôle. Il n'y a aucune publication régulière à l'exception des articles publiés dans quelques périodiques professionnels ; des livres et des manuels sont également distribués. Il y a des séminaires sur la loi et la pratique en matière de marchés publics organisés par le secteur privé, auxquels les fonctionnaires participent également. Il n'y a aucune association nationale sur la loi et la politique de marchés publics. La société civile (groupes d'intérêt national tels que des chambres de commerce, l'association des industries du bâtiment nationales, etc.) est impliquée dans la politique de marchés publics. La société suit attentivement les procédures de marchés publics, particulièrement lorsque des investissements élevés sont en jeu. Le rôle des médias est très prononcé. Il y a une influence considérable des décisions de la CJUE sur les procédures nationales de contrôle des marchés publics.

\section{Suède}

Le système de contrôle des marchés publics et de recours de Suède est basé sur un contrôle juridictionnel indépendant. Le système peut être divisé en voies de droits ouvertes avant et après qu'un contrat ait été signé. Il y a deux circuits séparés de disposant de trois degrés de contrôle juridictionnel pour les contrats au-dessus et au-dessous des seuils de la CEE.

\subsection{Réclamations à l'autorité adjudicatrice}

Il n'est pas obligatoire d'adresser une réclamation à l'autorité ou entité adjudicatrice. Il n'y a aucune règle précise dans le domaine des marchés publics qui régisse les réclamations devant l'autorité adjudicatrice. Cependant, il est possible d'essayer régler les différends de cette façon.

\subsection{Contrôle juridictionnel}

Avant la conclusion du contrat, un tribunal administratif peut suspendre la procédure de passation de marchés et ordonner à l'autorité ou l'entité adjudicatrice de recommencer ou de corriger la procédure dans le cadre d'une première instance. En deuxième instance, un appel peut être interjeté contre les décisions des tribunaux dans une de quatre cours administratives d'appel : la «Kammarrätten » à Stockholm, Göteborg, Sundsvall, ou Jönköping. Enfin, il y a une cour administrative de dernière instance, la « Regeringsrätten » à Stockholm, examinant également les décisions de marchés publics. Toutes ces cours sont indépendantes de l'exécutif, de l'administration ou de n'importe quelle autre branche de l'État et leurs décisions sont d'une nature juridictionnelle. Un contrôle par les tribunaux administratifs est exclu après la conclusion du contrat. Cependant, depuis 2002, l'application de la décision Alcatel assure une période de dix jours entre la notification de l'attribution du contrat aux soumissionnaires et la conclusion du contrat pour agir. Les juridictions administratives sont le forum principal de la révision de marchés publics en Suède. En 2005, 1280 actions ont été lancées- dans la grande majorité devant les juridictions administratives. Très peu d'actions ont été introduites par des soumissionnaires d'autres États-membres, mais la plupart des sociétés internationales ont une filiale suédoise. Moins de $1 \%$ de tous les contrats de marchés publics a donné lieu à des réclamations. Environ $30 \%$ des jugements ont ordonné à l'autorité adjudicatrice ou l'entité de corriger (13\%) ou de recommencer (17\%) la procédure. Beaucoup d'affaires ne finissent pas par un jugement parce que l'autorité ou l'entité a mis fin ou a corrigé à la procédure ou a déjà signé le contrat. La plupart des recours concernent le processus d'évaluation. Normalement, cela prend trois à quatre semaines entre l'introduction d'une requête et la décision définitive. Les coûts du système de 
contrôle et de recours pour le contribuable ne sont pas officiellement estimés. La force du système de contrôle est sa rapidité et son faible coût pour le soumissionnaire et que la décision est prise par une cour locale située dans le ressort de l'autorité adjudicatrice ou de l'entité en question. Après la conclusion du contrat, le fournisseur de services peut demander des dommages et intérêts mais seulement devant le tribunal d'arrondissement (ordinaire ou civil) qui tient lieu de première instance. En deuxième instance, un appel peut être interjeté contre ses décisions devant une cour d'appel. Il y a une juridiction civile de dernière instance, la «Högsta domstolen » à Stockholm, examinant également les décisions d'octroi de dommages et intérêts en matière de marchés publics. Ces juridictions sont indépendantes de l'exécutif, de l'administration ou de toute autre entité de l'État et leurs décisions sont de nature juridictionnelle. Il y a très peu d'affaires concernant les dommages et intérêts. Une faiblesse de ce double système de tribunaux administratifs et de tribunaux civils est son imprévisibilité en raison du trop grand nombre de juridictions et de juges sont impliqués. Par ailleurs, les voies de droit sont insuffisantes contre les attributions illégales faites sans publication. Il est presque impossible d'obtenir des dommages et intérêts en pareil cas. Par conséquent, le risque de contrôle est très inférieur si l'autorité ne suit pas du tout la législation que si les contrats sont publiés et font état de faiblesses procédurales. Comme décrit ci-dessus, il y a deux juridictions de dernière instance à Stockholm traitant des affaires de marchés publics. La juridiction civile de dernière instance, la Högsta domstolen, contrôle les contrats signés et attribue les dommages et intérêts. La juridiction administrative de dernière instance, la Regeringsrätten, examine les décisions de marchés publics. Les deux cours ont été établies sur la base de la constitution et des lois, et remplissent les conditions posées par les décisions Dorsch et Salzmann pour former des juridictions. Les juges, qui doivent être les avocats expérimentés et identifiés, sont nommés selon une procédure générale. La constitution exige que les juges soient indépendants et ils peuvent être évincés que dans très des cas particuliers. Les présidents ou les présidents des cours sont nommés par le gouvernement et ils sont des avocats distingués. Il n'y a eu aucune participation de la CJUE dans le système de contrôle et de recours par le jeu de questions préjudicielles. Il y a quelques affaires de marchés publics soumises à une procédure en manquement initiée par la Commission européenne, y compris une étape purement préjudicielle. Il n'y a aucune cour d'arbitrage. Les soumissionnaires peuvent demander à l'office national des marchés publics («NOU », Vasagatan 44, 11120 Stockholm, www.nou.se) une opinion. Il y a une procédure de conciliation et d'attestation auprès du conseil suédois d'accréditation et d'évaluation de la conformité (SWEDA ; Boîte 2231, 10315 Stockholm ; Téléphone +46 84068300 ; Fax +46 087918929 ; Site Web : www.swedac.se). Cependant, cette procédure n'a été jamais utilisée.

\subsection{Recours}

Les recours peuvent donner lieu à l'annulation de différentes décisions d'attribution, à un ordre de recommencer la procédure d'adjudication, à des mesures provisoires, l'octroi de dommages et intérêts et, pour les services publics, à des astreintes. Le tribunal administratif de première instance peut ordonner que la procédure d'adjudication soit recommencée ou qu'elle ne soit pas conclue jusqu'à ce que la violation ait été réparée. Une action est recevable contre des décisions prises avant la conclusion du contrat, par exemple pour, la sélection d'une procédure d'adjudication particulière, les appels à candidatures ou la présélection. La jurisprudence est peu claire sur le point de savoir si une décision prise après la conclusion du contrat est soumise à la législation sur les marchés publics. La cour peut également adopter des mesures provisoires en attendant la décision définitive, en prenant en considération les conséquences probables des mesures pour tous les intérêts susceptibles d'être lésés, y compris l'intérêt public et décide de ne pas attribuer de telles mesures lorsque leurs conséquences négatives seraient supérieures à leurs avantages. Si l'entité adjudicatrice a violé les dispositions de l'article 4 du chapitre 1 ou toute autre disposition de la LMP et que cette violation a causé un tort actuel ou probable au soumissionnaire, la cour doit ordonner que la procédure d'adjudication soit recommencée ou qu'elle ne soit conclue qu'après rectification de la violation alléguée. Le contrat lui-même ne peut pas être annulé, excepté dans le cas de la fraude ou de circonstances illégales. Quand la procédure d'adjudication est conclue, un fournisseur qui se considère lésé peut réclamer des dommages et intérêts à l'entité adjudicatrice devant un tribunal d'arrondissement (tribunal ordinaire). Il n'est pas nécessaire que la décision contestée soit annulée avant de réclamer des dommages-intérêts. Les dommages et intérêts peuvent dépasser les coûts de soumission et sont habituellement calculés sur la base de la perte nette de bénéfices. Dans les affaires de marchés publics concernant les services publics, la cour peut imposer des astreintes interdisant à l'entité adjudicatrice de poursuivre la procédure d'adjudication jusqu'à ce qu'elle ait rectifié la violation. Selon le chapitre 7, articles 
2 et 6 de la LMP, une entité adjudicatrice qui n'a pas observé les dispositions de la LMP doit indemniser les préjudices qu'elle a pu causer à un soumissionnaire. Un soumissionnaire ou un candidat qui a participé à une procédure d'adjudication comme prévu au chapitre 4 (services publics) a droit à la rémunération des coûts de préparation de l'offre ou de participation à la procédure, si le manquement à respecter les dispositions de la LMP a exercé un effet néfaste sur sa possibilité pour lui d'obtenir le contrat.

\subsection{Procédure}

La loi procédurale concernée est régie par le code de procédure civile, le «Rättegångsbalken », pour les juridictions ordinaires et le code de justice administrative, le «Förvaltningsprocesslagen », pour les juridictions administratives. La juridiction peut décider d'entendre un expert technique ou d'obtenir une déclaration écrite. La juridiction n'a aucune obligation de le faire si l'expertise n'est pas nécessaire pour le jugement. Tout fournisseur qui a un intérêt à se voir attribuer le contrat, même s'il n'a pas soumis d'offre, peut introduire une action. Le NOU n'a aucun droit à agir, bien que cela ait été souvent suggéré. Il n'y a aucun droit à payer devant la juridiction administrative et pas de ministère d'avocats obligatoire. La partie perdante à une action en dommages et intérêts doit payer les frais et dépens de la partie victorieuse. Une requête devant le tribunal administratif doit être introduite dans les dix jours de l'envoi de la décision d'attribution aux soumissionnaires. Une action en dommages et intérêts doit être introduite dans un délai d'un an à compter de la conclusion du contrat. Il est possible que les cours voient des documents sans révéler leur contenu aux parties. Il n'y a aucun effet suspensif systématique de la procédure d'adjudication une fois qu'une requête a été introduite auprès du tribunal administratif. Mais le tribunal peut décider de suspendre la procédure de sorte qu'un contrat ne puisse être signé avant le jugement. Il n'y a aucun formulaire obligatoire pour les procédures de contrôle. Il n'y a aucun délai obligatoire pour que les cours prennent une décision. Cependant, les tribunaux de première instance décident normalement dans un délai de trois à quatre semaines. Les jugements sont envoyés aux parties, et quelques affaires d'intérêt général sont publiées. Il y a une publication des décisions : les rapports annuels de la cour «Regeringsrätten », le « Regeringsrättens årsbok (RÅ)» et de la cour « Högsta domstolen», le « Nytt juridiskt arkiv (NJA)». Un bulletin d'information «NOU-info » publie des informations sur toutes les décisions de dernière instance en matière de marché publics et quelques décisions intéressantes d'autres cours. L'association suédoise des autorités locales et des régions fournit également des informations à ses membres. La jurisprudence est d'importance limitée mais considérable due à un système mixte de codification et de recours à la jurisprudence. Il y a d'importantes interprétations de la loi fournie par les cours. Les seules particularités du système pour les services publics sont la possibilité de prendre les astreintes décrites ci-dessus et un certain nombre de règles spéciales de charge de la preuve dans les actions en dommages et intérêts voisines de la réglementation prévue dans la directive 92/13/CE.

\subsection{Culture du recours}

Les jeunes juges et avocats ont pu avoir étudié le droit des marchés publics et le droit communautaire en tant qu'élément de leurs programmes d'études universitaires. D'autres doivent demander une formation, des cours et des séminaires organisés par des cabinets juridiques ou par des autorités administratives, telles que le NOU ou les organismes internationaux. Ces dernières années, il y a eu une certaine spécialisation volontaire sur les affaires de marchés publics. Le NOU diffuse l'information par téléphone, par ses bulletins d'information, publications, séminaires et conférences afin d'aider l'administration et suivre les développements dans le domaine des marchés publics au sein de l'UE et de l'OMC (davantage d'information sur www.nou.se). Plus de 100 juges traitent des affaires de marchés publics. Leur attitude est normalement juste et équilibrée, mais il peut y avoir des exceptions avec une polarisation vers l'intérêt public. L'administration devrait aider et donner des conseils à tous les parties. Le NOU fournit des informations aux soumissionnaires, de même que fait l'association des administrations et des régions locales et la chambre de commerce. Autrement, les soumissionnaires doivent chercher l'aide des cabinets juridiques et des consultants en la matière. En 2005, 1280 requêtes sur les marchés publics ont été introduites. Quelques soumissionnaires peuvent être ignorants ou s'abstenir de demander le contrôle. Le niveau de connaissance des responsables des adjudications concernant la loi et la pratique en matière des marchés publics s'améliore. La jeune génération est mieux informée au sujet des conditions juridiques et économiques. L'attitude des responsables des adjudications et de leurs supérieurs traitant des réclamations envers les soumissionnaires est normalement juste. Le bulletin d'information $\mathrm{du}$ NOU et le «Anbudsjournalen», un journal sur les marchés publics avec des entrevues, des commentaires, des 
informations sur les jugements et des débats au sujet des problèmes et des succès dans le domaine, diffusent l'information et servent d'un forum de discussion. La loi sur les marchés publics est discutée lors des conférences universitaires et professionnelles et des séminaires, organisés chacun des deux par le public et le privé. Il n'y a aucune association nationale sur les marchés publics en soi, mais il y a des organismes privés et de branche qui s'en occupent. Les chambres de commerce sont actives et ont un rôle de supervision de l'ouverture des offres et des marchés publics par Internet. L'association des industries nationales, ainsi que les associations de la construction, des équipements médicaux, de la santé et d'autres secteurs sont intéressées et ont organisé des séminaires et des réunions. Les O.N.G, telles que la chambre nationale de Transparency International, sur le commerce équitable et l'environnement sont également actives. La presse et la télévision couvrent de temps en temps les procédures de contrôle des marchés publics. Il y a des enseignements universitaires pour des membres du bureau de marchés publics. L'impact des jugements de la CJCE est assez considérable dans les Cours Suprêmes. Les parties font références aux décisions, qui sont connues par les publications du NOU et d'autres organismes.

\section{Le Royaume-Uni}

Les marchés publics au Royaume-Uni sont régis par le règlement de 2006 (règlement 5/2006 transposant les Directives CE 2004/18 et 89/665 http://www.opsi.gov.uk/si/si2006/uksi_20060005_en.pdf) et le règlement de 2006 sur les contrats de délégation de service public (règlement 6/2006 transposant les Directives CE 2004/17 and 92/13 http://www.opsi.gov.uk/si/si2006/uksi_20060006_en.pdf). Les réglementations mentionnées ci-dessus s'appliquent seulement en Angleterre, au Pays de Galles et en Irlande du Nord. En Écosse, l'exécutif écossais a établi deux réglementations semblables (règlements 1/2006 et 2/2006 http://www.opsi.gov.uk/legislation/scotland/ssi2006/ssi 20060001 en.pdf). Le système de contrôle et de recours est fondé sur un contrôle juridictionnel indépendant. Il y a de divers organismes britanniques fournissant des services de règlement alternatif des différends (particulièrement au stade de l'exécution). Les organismes publics et les soumissionnaires peuvent utiliser ces services occasionnellement, mais ils ne sont pas obligé par la loi de le faire. Le mécanisme de conciliation établi par la directive CE 92/13 a été transposé en droit interne par le règlement relatif aux délégations de service public.

\subsection{Contrôle juridictionnel}

Un soumissionnaire qui considère qu'il a ou est susceptible d'enregistrer la perte par suite d'une violation des réglementations sur les marchés publics ou des réglementations sur les délégations de service public, a le droit d'en chercher la réparation par l'intermédiaire du système juridictionnel national. Toute violation des réglementations mentionnées ci-dessus par un l'autorité adjudicatrice/un service public peut être mise en cause devant les juridictions nationales. Ceci comprend la sélection de la procédure d'adjudication, la façon dont le cahier des charges est exposé, l'exclusion à la présélection et l'étape de l'attribution Concernant les contrats quine rentrent pas dans le champ d'application des réglementations (c.-à-d., contrats en dessous des seuils de la CEE), des procédures peuvent être lancées sur la base du droit commun. Une demande, aux termes des réglementations, doit être faite promptement et en tous cas dans les trois mois de la date où les raisons (pratiquement la violation alléguée) pour intenter l'action sont apparu pour la première fois. Dans des cas dûment justifiés, la période de trois mois peut être prolongée par la décision de la juridiction. Avant qu'il ne puisse initier une action, le requérant doit aviser l'autorité adjudicatrice de la violation et de son intention d'intenter à cet égard cette action aux termes des réglementations appropriées. Cependant, le respect de cette obligation n'est pas une condition préalable pour demander le contrôle juridictionnelle. La réclamation est portée devant le bureau des marchés publics de l'autorité adjudicatrice. Les actions sont portées devant le tribunal de grande instance (High Court en Angleterre, au Pays de Galles et en Irlande du Nord, Court of Session or Sheriff Court en Ecossel'Écosse a un système judiciaire et juridique séparé de celui de l'Angleterre, du Pays de Galles et de l'Irlande du Nord). La cour notifie à l'autorité adjudicatrice la requête et l'affaire est alors traitée conformément aux directives prévues pour les tribunaux civils exposées dans la loi sur la procédure civile de 1997. Le tribunal de grande instance est l'organe de contrôle de première instance dans les affaires de marchés publics aux termes des réglementations. Le site central est les Cours de Justice royales à Londres (Londres WC2A 2LL; Téléphone : +44 (0) 207947 6000), mais il y a des tribunaux régionaux dans plus de 20 villes de province. Un juge du tribunal préside la procédure, entendant le dossier fourni par les deux 
parties à l'appui de leur interprétation des événements et prononçant un verdict sur la base des preuves présentées. Si une action intentée par un réclamant est infructueuse et s'il considère la décision n'est pas légale, il peut interjeter appel auprès de la chambre civile de la cour de l'appel (Civil Division of the Court of Appela, Londres WC2A 2LL ; Téléphone : +44 (0) 207947 7882), où leurs arguments seront entendus par trois juges. L'organe de recours de dernière instance est la Chambre des Lords, statuant à titre ordinaire (Lords of Appeal in the Ordinary, Chambre des Lords, palais de Westminster, Londres SW1 ; Site Web : http://www.parliament.uk/judicial work/judicial work.cfm). L'autorisation doit être accordée par la cour de l'appel ou la Chambre des Lords elle-même pour qu'un pourvoi contre une décision d'appel puisse être fait devant eux. Les Lords sont nommés au sein des membres les plus éminents de l'ordre judiciaire du Royaume-Uni par Sa Majesté conformément à l'avis du premier ministre, sur la base de leur expérience et expertise. Ils forment un corps permanent fondé par loi et rendent des décisions légalement obligatoires. Ce corps est indépendant de l'exécutif ou de n'importe quelle autre partie de l'État. Après que l'entrée en vigueur de la réforme constitutionnelle de 2005, les affaires de marchés publics seront entendues en dernière instance par la Cour suprême du Royaume-Uni.

\subsection{Recours}

La base juridique des voies de droit ouvertes en matière de marchés publics est la partie 9 des réglementations. Si la Cour Suprême fait droit à la demande du requérant, elle peut ordonner d'amender la décision appropriée à l'autorité adjudicatrice, ou d'amender un document (tel que le cahier des charges). Si le requérant a enregistré des pertes nées de la transgression de l'autorité adjudicatrice, des dommages et intérêts peuvent également être attribués. Les dommages et intérêts pour pertes (y compris de l'occasion de remporter le contrat) peuvent être attribués si la cour est convaincue qu'il y a eu un manquement à se conformer aux réglementations et que le fournisseur a subi la perte ou des dommages en conséquence de ce manquement. Il n'est pas nécessaire que la décision contestée soit écartée. Les coûts exposés par le candidat victorieux seront probablement payés par l'autorité adjudicatrice. Sauf dans le cas de fraude ou de mauvaise foi, les dommages et intérêts sont la seule voie de réparation une fois que le contrat a été signé. L'introduction d'une requête n'exerce pas d'effet suspensif systématique sur l'adjudication actuelle. Cependant, à n'importe quelle étape des procédures, la cour peut accorder une mesure provisoire sur requête urgente du requérant et prononcer une injonction qui exerce un effet suspensif sur les actions appropriées du l'autorité adjudicatrice. Pour déterminer si la mesure provisoire est appropriée, la cour doit prendre en considération d'une part, la nécessité de fournir un système effectif de protection des règles communautaires relatives aux marchés publics et du requérant et, d'autre part, les intérêts du public dans le progrès des projets publics. Par conséquent, pour obtenir une injonction suspendant l'adjudication ou l'application d'une décision prise à l'égard de l'adjudication, le requérant doit prouver qu'il y a une question sérieuse à juger et que les dommages et intérêts ne sont pas un remède adéquat. La cour n'a pas le pouvoir d'annuler une attribution du contrat une fois que le contrat a été signé. Cependant, et en ce qui concerne les contrats soumis aux réglementations de marchés publics, le R-U a introduit une période d'immobilisation de dix jours entre la notification des résultats de l'adjudication aux soumissionnaires et la conclusion formelle d'un contrat. Cette règle est considérée comme l'évolution récente la plus significative du droit interne des marchés publics. Les soumissionnaires lésés ont ainsi l'opportunité de remettre en cause une décision d'attribution qu'ils considèrent illégales. L'autorité adjudicatrice ne doit pas attribuer un contrat s'elle sait qu'une action judiciaire a été lancée au cours de la période d'immobilisation, jusqu'à ce que le résultat de l'action soit clair. Néanmoins, il est actuellement peu clair si un manquement par l'autorité à respecter la période d'immobilisation de dix jours obligatoire signifierait que la cour peut écarter la décision d'attribution du contrat. Enfin, il n'y a aucune disposition sur les astreintes.

\subsection{Procédure}

Les procédures devant le tribunal de grande instance sont régies par les réglementations sur les marchés publics 2006, les réglementations sur les délégations de service public 2006 et la loi de 1997 sur la procédure civile. La loi sur la procédure civile s'applique également aux procédures devant la chambre civile de la cour de l'appel. Toute personne qui a cherché ou cherche ou aurait souhaité être la personne à qui un contrat est attribué et qui est un ressortissant de ou est établie dans un État approprié, peut intenter une action si elle subit ou risque de subir une perte ou des dommages dus à la violation de la loi par l'autorité adjudicatrice. Ceci pourrait s'étendre au delà de ceux qui ont participé réellement à l'adjudication s'ils croient qu'ils ont été empêchés d'y participer d'une violation des réglementations. Les États appropriés 
comprennent les 25 États-membres de l'UE, le pays de l'EEE, la Bulgarie, la Roumanie et les signataires à la convention gouvernementale sur les marchés publics. Il n'y a aucun formulaire-type pour les affaires de marchés publics mais un formulaire général (disponible en ligne : http://www.hmcourtsservice.gov.uk/HMCSCourtFinder/FormFinder.do). Des experts sont appelés par les parties à la procédure pour appuyer leur dossier et sont interrogés par les avocats représentant les deux côtés. En général, les coûts sont à la charge de la partie perdante. Un requérant peut chercher à obtenir l'accès au dossier de marché public dans le cadre de la procédure normale de communication (disclosure) applicable aux actions en justice en Angleterre et au Pays de Galles. Cependant, une demande de confidentialité peut être faite au tribunal afin que les informations ne soient pas révélées en dehors du cadre de la procédure. La décision est prise par le juge. Sinon, le requérant peut demander des informations en vertu du Freedom of Information Act de 2000 (loi sur la liberté de l'information). L'autorité adjudicatrice peut, cependant, refuser l'accès en application de cette loi lorsque l'information contenue dans le dossier de marchés publics a été reçue sous condition expresse d'en conserver la nature confidentielle de telle sorte que la divulgation des renseignements en question constituerait une violation de la confiance accordée par le soumissionnaire visé que ce dernier pourrait actionner ou qu'elle serait préjudiciable à l'intérêt commercial d'une autre personne. Les droits de procédure sont payables par la partie intentant une action devant le tribunal. Les droits sont réglés suivant l'ordre de la juridiction émanant du Lord Chancellor Ils se situent sur une échelle mobile variant selon la valeur de la demande. Ils sont modifiés par décision de la juridiction en tant que de besoin. Il n'y a aucun droit à payer simplement pour introduire une requête au sujet d'une décision de marchés publics. Une partie intentant une action devant le tribunal de grande instance devra financer l'action sur ses ressources propres en première instance. Ceci comprend les couts de procédure et les honoraires professionnels (avocats et experts). Cependant, la partie perdante devra normalement payer l'intégralité des coûts après la décision définitive. Il n'y a aucun délai obligatoire pour que les cours établissent une décision. Le délai dépend de la complexité des questions étudiées et varie considérablement. Les décisions de la Chambre des Lords sont publiquement prononcées devant les parties et sont alors publiées pour une plus large promulgation. Les décisions sont normalement remises aux représentants des parties devant le tribunal. La plupart des décisions des tribunaux de grande instance sont publiées sur le site Internet de l'Autorité judiciaire (http://www.hmcourts-service.gov.uk) et dans beaucoup de cas, sont également publiées dans la presse juridique.

\subsection{Culture du recours}

Les juges ont pu avoir étudié le droit des marchés publics en tant qu'élément de leurs programmes d'études universitaires et de leur formation professionnelle ou par des séminaires organisés par le gouvernement ou d'autres institutions publiques ou privées. La connaissance pratique du fonctionnement de la politique de marchés publics est principalement assurée par l'information produite par le secteur public et par l'expérience. L'attitude des juges envers les intérêts impliqués dans des affaires de marchés publics est considérée complètement indépendante et impartiale. La jurisprudence des cours de second degré est très importante, car il y a un système de précédent juridique qui lie les tribunaux de degré inférieur à leurs décisions. Les soumissionnaires peuvent se familiariser avec les pratiques d'achat public par l'expérience professionnelle ou par leurs organismes professionnels. Il n'y a aucune donnée empirique concernant l'attitude des soumissionnaires envers les procédures de contrôle mais, généralement, le R-U n'a pas eu traditionnellement une culture de la remise en question des appels d'offres. Par ailleurs, la « Wood Review » (www.ogc.gov.uk//documents/woodreview.pdf)_a trouvé que les soumissionnaires anglais sont en général peu disposés à contester, ceci principalement en raison des conséquences négatives pour leurs relations d'affaires et les difficultés à apporter la preuve des méfaits des autorités adjudicatrices et donc de monter un dossier. Concernant les membres du bureau d'adjudication, ils ont un devoir à agir conformément aux règles régissant les marchés publics et à agir avec équité et conformément aux principes ordinaires du droit public. N'importe quelle réclamation sera traitée conformément à ces règles et principes. Généralement, en termes de procédures de contrôle formelles, un système effectif des recours dépend du degré approprié de transparence des décisions prises par les autorités adjudicatrices publics, un itinéraire clair à suivre pour un soumissionnaire lésé qui souhaite poursuivre un examen formel de la question. Ce système de contrôle doit être visible aux parties intéressées et doit être fondé sur un cadre juridique clair en ce qui concerne l'impact des lois appropriées/des réglementations, etc., et des conséquences d'une transgression des règles en termes de voies de droit ouvertes. À un niveau plus informel, les fonctionnaires impliqués dans les marchés publics doivent être instruits/formés pour apprécier le besoin de dialogue 
effectif et franc avec les fournisseurs si les marchés publics doivent fonctionner de façon aussi efficace que les deux parties le souhaitent. Un élément clé de ce dialogue doit être franchise dans la discussion avec des soumissionnaires quant à la justification des décisions prises et aux réclamations potentielles. Au niveau universitaire, il y a un intérêt croissant pour le droit des marchés depuis l'adoption des directives « recours » de la CEE. Le journal juridique le plus important est « la révision de loi sur les marchés publics (PPLR) » édité par Sweet \& Maxwell. Les conférences universitaires et professionnelles nombreuses ont également régulièrement lieu. Il n'y a pas d'association nationale pour les marchés publics, mais un large éventail d'industries et d'associations commerciales transmettent au gouvernement anglais les intérêts de leurs membres en ce qui concerne les marchés publics. Ces acteurs peuvent fournir des conseils à leurs membres en ce qui concerne des circonstances spécifiques. Parmi les plus influents, sont la confédération de l'industrie britannique et la fédération des petites entreprises. La formation officielle destinée aux bureaux d'adjudication est comprise dans le programme du certificat de compétence en l'achat et fourniture développé par l'école nationale d'administration et l'institut de l'achat et de la fourniture. L'impact des décisions de la CJCE sur les procédures internes est considérable puisqu'elles sont la source fondamentale d'interprétation juridique utilisée par les cours britanniques. S'agissant de l'article $226 \mathrm{du}$ Traité CE, les divergences entre la Commission européenne et le RU en ce qui concerne la transposition des règles relatives aux marchés publics de la CEE ont été arrangées à l'étape préjudicielle (environ 15 cas dans les quatre dernières années). 